Doctorado en Ciencias Sociales

Facultad de Humanidades y Ciencias de la Educación

Universidad Nacional de La Plata

\title{
La institucionalización de las Ciencias Antropológicas en Chile.
}

\section{Una aproximación a las dinámicas socio-organizativas y cognoscitivas en la conformación del espacio científico (1860 y 1954).}

Tesis presentada para optar al Grado de Doctor en Ciencias Sociales

Candidato: Héctor Mora Nawrath

Director: Dr. Juan Ignacio Piovani

Co-dirección: Dra. Noelia Carrasco Henríquez 


\section{Comisión evaluadora}

Jurado externo:

Dra. Hebe Vessuri, Argentina (CENPAT-CONICET).

Dr. Jorge Gibert, Chile (UV).

Jurado interno:

Dra. Susana Ortale, Argentina (FaHCE-UNLP). 
Resumen

Introducción

\section{CAPÍTULO I}

Algunas claves conceptuales. Ciencia, disciplina y estilo en la conformación de la antropología.

1.1 Disciplina y el desborde de fronteras

1.1.1 Los distintos matices en la definición de disciplina

1.1.2 Una visión sobre el concepto de disciplina

1.2 Comunidad y redes sociales en las ciencias

1.3 La vocación interdisciplinaria y pluri-paradigmática de la antropología

1.4 Antropología mundial, antropología periférica, antropología latinoamericana

Estilos disciplinario y antropologías nacionales

\section{CAPITULO II}

Algunos antecedentes sobre la institucionalización de la antropología científica y académica en el espacio internacional

2.1 Institucionalización científica e institucionalización académica

2.2 Aspectos generales de la institucionalización de la antropología en algunos países de Europa y América del Norte

2.3 Notas sobre las primeras experiencias en la institucionalización de la antropología en América Latina

2.3.1 Modelo de ciencia y el proyecto nacional en América Latina. 


\section{Algunas consideraciones generales}

2.3.2 Inicios en México.

2.3.3 Inicios en Colombia.

2.3.4 Inicios en Perú.

2.3.5 Inicios en Brasil.

CAPITULO III

Antesala de la institucionalización científica de las ciencias antropológicas en Chile: Estado, ciencia y formación científica nacional

3.1 Primeros antecedentes acerca de la preocupación por el otro radical en territorio chileno

3.2 Investigación científica, producción intelectual y formación académica

\section{CAPITULO IV}

El modelo de ciencia europeo: museos y sociedades científicas en la conformación del campo antropológico en Chile

4.1 Instituciones en la producción y difusión de las ciencias 101-132 antropológicas en el circuito nacional.

4.1.1 Los museos: entre el patrimonio y la ciencia

107-122

4.1.1.1 El Museo Nacional

108-112

4.1.1.2 El Museo Histórico de Chile 
4.1.2 Las sociedades científicas

122-126

4.1.3 Los congresos en la promoción y difusión del conocimiento de orientación

126-132 antropológica.

CAPITULO V

Dinámicas de campo en los inicios de la antropología científica en Chile

5.1 Los primeros actores en la producción antropológica

140-145

5.2 Dinámicas de campo: algunas manifestaciones

145-154

\section{CAPÍTULO VI}

Las ciencias antropológicas a través de la producción en revistas especializadas de circulación nacional entre 1860 y 1954

6.1 Las revistas científicas de la época $\quad 157-162$

6.2 Tendencias en la investigación en ciencias antropológicas 163-166

6.3 Las áreas temáticas en la investigación en ciencias 167-170 antropológicas

6.4 Los investigadores en ciencias antropológicas

170-178

6.5 El espacio de la producción en ciencias antropológicas en Chile

Conclusiones

188-203

Bibliografía

204-245

Anexo

246-259

Lista de artículos analizados 
Los más sentidos agradecimientos a:

Mis padres.

Mis suegros.

Mis amigos de Alejandro Korn.

Los directores de esta investigación, Juan Ignacio y Noelia.

Colegas del Departamento de Antropología de la Universidad Católica.

Mis profesores de grado Aldo Vidal y Teresa Durán.

La Universidad Nacional de La Plata, los docentes del Programa de Doctorado en Ciencias Sociales.

La Universidad Católica de Temuco, por las facilidades brindadas para cursar los estudios doctorales.

El Consejo Nacional de Ciencia y Tecnología del Ministerio de Educación, que a través del Programa Becas Chile me diera la posibilidad de estudiar en Argentina.

Mi esposa Carolina y a mi hija Amelia, quienes me acompañaron en este viaje. 


\section{RESUMEN}

Esta investigación buscó problematizar el proceso de institucionalización de las ciencia antropológica en Chile entre 1860 y 1954, ello a partir de la caracterización de las dinámicas socio-organizativas y cognoscitivas que van configurando el espacio científico en una etapa previa a su consolidación académico-universitaria, y por consiguiente a su establecimiento como disciplina hacia fines de los años '60. Para el periodo, se delinean algunos aspectos relativos a las trayectorias de instituciones como sociedades científicas y museos en tanto espacios de articulación social -claves en su desarrollo-, así como se profundiza en la producción científica -en artículos publicados en revistas de circulación nacional- dando cuenta de actores, campos de especialización, temáticas, volúmenes y etapas de producción, ello a la luz de ciertos procesos ligados a la política estatal referida a la promoción de esta nueva ciencia.

Más allá de debatir ciertas tesis sostenidas respecto a la conformación y características de la antropología en Chile, esta investigación brinda antecedentes que permiten discutir el supuesto que la antropología fue pensada como una ciencia comprometida con la construcción de la nación, lo que implica un fuerte respaldo estatal. Se evidencia que en su formación prima el impulso de particulares -individuales y colectivos- que se comprometen con levantar las bases de una ciencia moderna conforme a los cánones imperantes de la época, y con ello consolidar una comunidad local vinculada el espacio internacional. La investigación permite concluir que la antropología en Chile está marca por una temprana pero débil institucionalización, que impide su consolidación como disciplina científica en comparación con la situación que experimentan las antropologías en otros países del continente.

\section{Palabras claves}

Ciencias antropológicas, Institucionalización científica, producción antropológica, tendencias temáticas. 


\begin{tabular}{|c|c|}
\hline 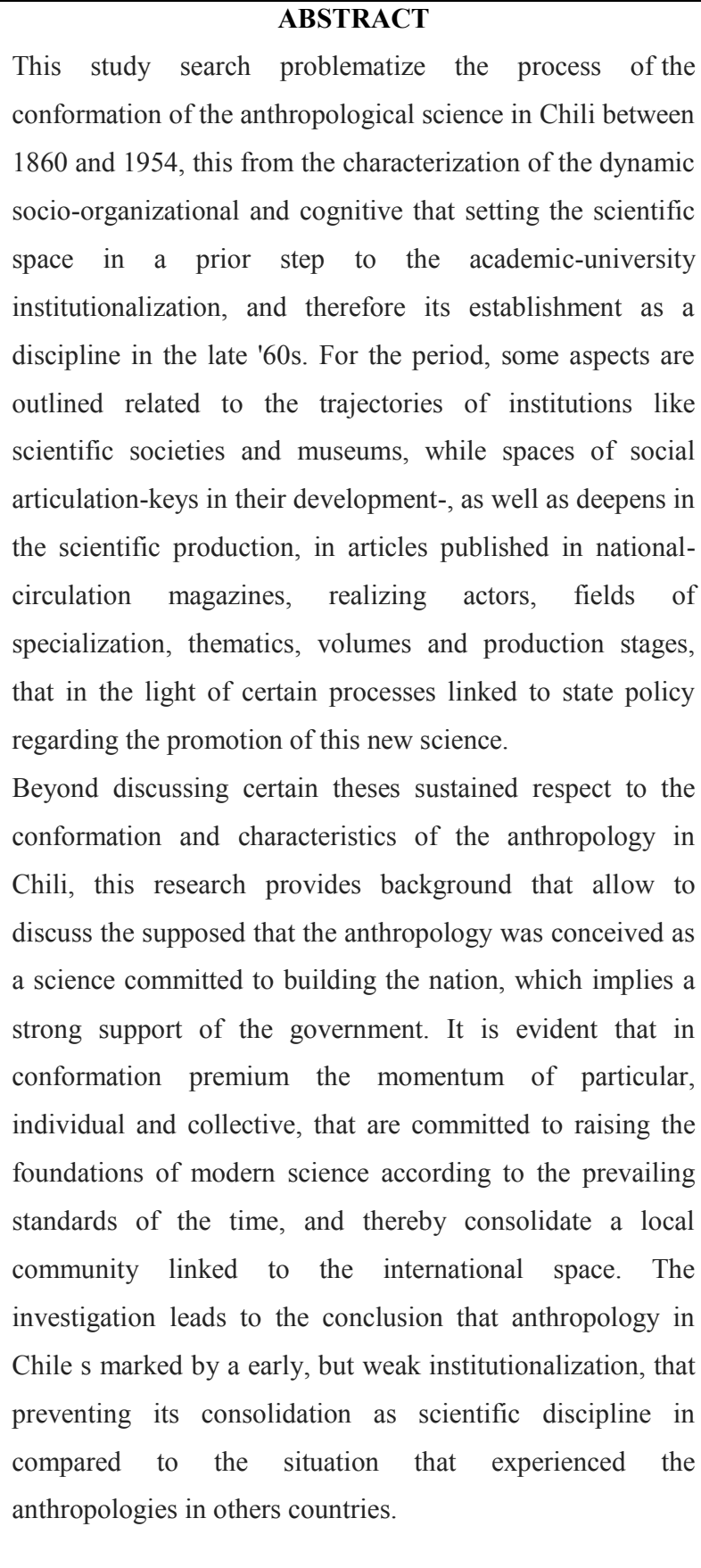 & 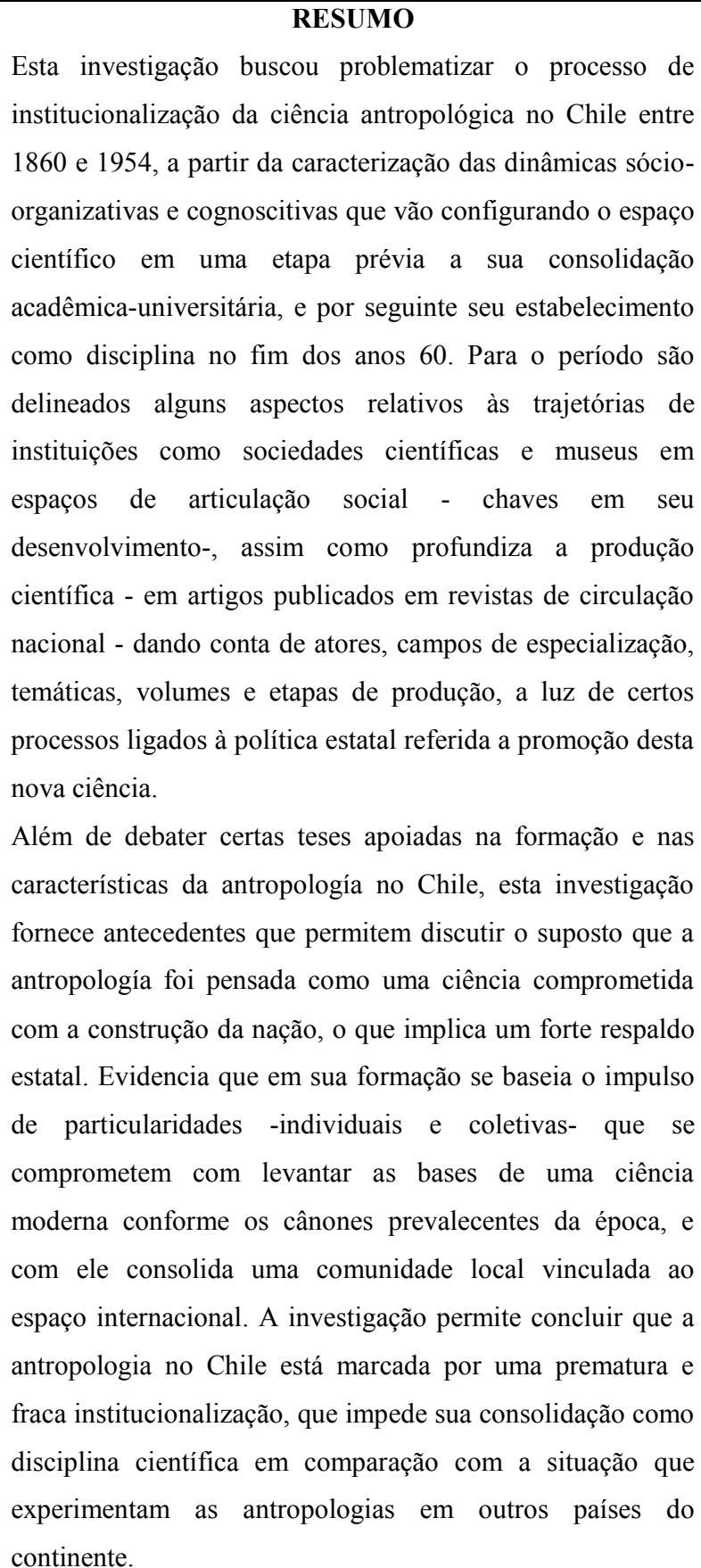 \\
\hline $\begin{array}{l}\text { Keywords } \\
\text { Anthropological Sciene, Scientific Institutionalitation, } \\
\text { Anthropological Production, Thematic Trend }\end{array}$ & $\begin{array}{c}\text { Palavras chaves } \\
\text { Ciência antropológica, institucionalização, produção } \\
\text { antropológica, tendência temática }\end{array}$ \\
\hline
\end{tabular}




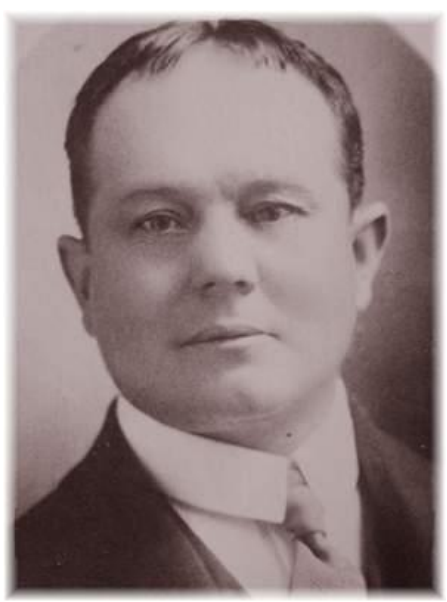

Carlos Emilio Porter Mosso (1847-1942)

Entomólogo y Zoólogo Chileno.

"Ya es tiempo que se reaccione contra esta indiferencia i se tome alguna medida para recoger i clasificar, de una manera científica, todas las informaciones y datos posibles de cada una de estas razas, destinadas en breve a desaparecer ante la marcha del progreso i de la civilización.

Sería mui conveniente que el Supremo Gobierno estimulara el estudio i propaganda de la Antropología, como se ha hecho en todo los países cultos" (Porter 1909:122). 


\section{Introducción}

Esta investigación se sitúa entre los múltiples trabajos que han tenido lugar en América Latina y que han buscado exponer y problematizar las condiciones en las que surgen y se desarrollan las antropologías en el continente, realizando con ello un ejercicio de inscripción de las experiencias y trayectorias obliteradas en las narrativas académicas y disciplinarias en el concierto mundial y/o latinoamericano. En esta dirección, se ha constatado la existencia de "programas" o líneas de investigación, simposios y seminarios que dan cuenta de la preocupación por el estudio sistemático de las antropologías que se desarrollan en Latinoamérica ${ }^{1}$. En el plano más general, se pueden mencionar los estudios sobre los "estilos de antropología" llevados a cabo por Cardoso de Oliveira (1995, 1999) y Vessuri (1993, 1996), los estudios de la antropología de la antropología y el peso contextual en la singularización de la disciplina desarrollados por Peirano (1980, 1990, 1998), el trabajo de Krotz sobre las antropologías del sur (1993, 2006), las reflexiones sobre la vocación crítica de la antropología latinoamericana desarrollas por Jimeno (2000, 2005), o la propuesta de las antropologías mundiales desarrolladas por Restrepo y Escobar (2004, 2005) y Restrepo (2007) entre otros.

Estas propuestas analíticas se ven acompañadas por una serie de investigaciones orientadas a caracterizar y/o problematizar la gestación y desenvolvimiento de la antropología en el marco de contextos nacionales, destacando las realizadas por Warman, Nolasco, Bonfil, Olivera de Vásquez y Valencia (1970), García y Medina (1986), Krotz (1995, 1996), Medina (1995, 1996), Báez (1980), Báez (2005), Bustamante (2005), de la Peña (2008), Kemper (2011) sobre la antropología mexicana; los trabajos de Melatti (1980, 1983), Ribeiro (1988), Corrêa (1993), Peirano (1981, 1998, 1999, 2004, 2008), Grimson, Ribeiro y Séman (2004), Clavia (2005), Ribeiro (2004) y de Araujo (2010) sobre antropología brasileña; las contribuciones de Arenas (1990), Rex González (1992), Stagnaro (1993), Guber (2002, 2007, 2009), Guber y Visacovsky (1997, 1999, 2006), Garbulsky (1993, 2003, 2004), Lazzari (2004), Ratier y

\footnotetext{
${ }^{1}$ A la "I Reunión Técnica de Antropólogos y Arqueólogos en América Latina y el Caribe" -realizada en la Hacienda Cocoyoc, Estado de Morelos, México, en 1979-, se suma la reunión titulada 'Rumbos de la Antropología', organizada por Asociación Brasileira de Antropología (ABA) -llevada a cabo en Rio de Janeiro en 1980-, y la denominada 'La antropología en América Latina' - desarrollada en Brasilia en 1987, y organizada por ABA, el Instituto Panamericano de Geografía e Historia y el Centro Nacional de Desarrollo Científico y Tecnológico (Cardoso de Oliveira 1999).
} 
Guebel (2004); Gil (2006; 2008); Soprano (2006; 2008; 2009), Bartolomé et al. (2007), Podgorny (1995, 2008), Farro (2009), Ratier, H. (2010), Name (2012), Podgorny, Farro, Martínez y Ballestero (2014) sobre la antropología en Argentina; las investigaciones de Jimeno (1990, 2000, 2002, 2007), Correa (2005), Pineda (2004, 2005, 2007), Caviedes (2007), Echeverri (2007) y Jimeno y Arias (2011) acerca de la antropología en Colombia; Montoya (1975), Martínez (1990), Degregori y Sandoval (2007) Salazar (2007) y de la Cadena (2007) para el caso de Perú; Clarac de Briceño (1993) y Pérez para la antropología en Venezuela (2000); las indagaciones de Moreno (1992), Martínez (2007) y García (2011) respecto de la antropología en Ecuador, entre muchas otras.

Sin embargo, aún se puede constatar la persistencia de lo que podemos denominar "producción de las ausencias", que en tanto forma de subalternización se nutre de la narrativa histórica -lo que merece ser contado- para establecer el origen y la supremacía de ciertos enclaves y discursos respecto del ejercicio legítimo y relevante de la antropología. Algunos autores han entrado en esta discusión utilizando como recurso la metáfora centro/sur (Krotz 1996) o centro-periferia (Gerholm y Hannerz 1982; Cardoso de Oliveira 1999), estableciendo una distinción histórica entre los países en los cuales surge y desde donde se expande la disciplina -y la ciencia en general-, respecto de aquellos que la reciben, reproducen, recrean y que al mismo tiempo legitiman. Es decir, identifican la condición periférica o subalterna como propia de regiones que no constituyeron centros hegemónicos de producción antropológica, ocupando posiciones invisibilizadas o marginales respecto de los centros hegemónicos (Cardoso de Oliveira 1999, 2004; Restrepo y Escobar (2004); Restrepo 2006; Krotz 1993, 2006).

Si bien la ciencia tiene su origen en los países de Europa occidental, ello no elude el hecho que a través de la historia han existido trayectorias locales o estilos que han imprimido matices a estos desarrollos (Periano 1981, 1990; Gerholm y Hannerz 1982; Vessuri 1993, 1996; Cardoso de Oliveira 1995; Krotz 1996; Restrepo y Escobar 2004), alterando o problematizando aquello que aparece o se dicta desde la matriz disciplinar o desde modelos de ciencia imperantes. El problema es que estas trayectorias-otras y sus matices no son reconocidos ni en la trama internacional -mundial o latinoamericana- ni en los propios circuitos nacionales; como plantea Krotz (1996), la invisibilización del "sur" se reproduce desde las propias "antropologías del sur”. En este sentido, el carácter hegemónico de las antropologías centrales no se afianza por 
la simple imposición, sino gracias a la reproducción que los mismos antropólogos de los países periféricos realizan, incorporando y transmitiendo de manera a-crítica las formulaciones teórico-metodológicas elaboradas en dichos centros, y que en muchos casos han adquirido de primera mano a través de su formación de postgrado en Europa o América del Norte (Krotz 1993, 2006; Restrepo 2006). Para Krotz (1996). Ello se desprende de la incorporación de un estilo formativo que concibe el desarrollo del pensamiento antropológico como un proceso de difusión unidireccional de ideas -historia de las ideas- que tienen su origen en los países europeos - un único centro de difusión de conocimiento-, en tanto los aportes locales - o de las antropologías del sur- son vistos como un apéndice, una extensión o una versión diluida de la disciplina, con un valor o aporte secundario.

El mismo modelo aplica a escala local; ya sea en los límites del continente latinoamericano o de una nación específica, se producen zonas obscuras de la memoria -siguiendo con la metáfora, podríamos advertir que hay nortes en los sures y sures en los nortes. Al no figurar, las trayectorias nacionales o regionales son reemplazadas por relatos y héroes de la antropología europea, norteamericana o de otras latitudes, y quedan completamente en el olvido o solapados los esfuerzos y desarrollos locales, como si estas antropologías no tuvieran historia, o como si no valiera la pena investigar las huellas que ha dejado a su paso.

Historizar los procesos implicados en la conformación de las antropologías que se desarrollan en América Latina se torna entonces sumamente relevante, puesto que permite conocer y caracterizar las dinámicas y tendencias en tanto expresiones de un quehacer contextualizado en un territorio nacional, en unas instituciones, en unas dinámicas sociohistóricas, etc.- y con ello develar múltiples experiencias y sus particularidades que asume la conformación de la disciplina (Cardoso de Oliveira 1999). Como diría Krotz, hace posible “... reconocer perfiles diversos en el seno de la ciencia especializada en el fenómeno de la diversidad y contribuir, en el sur y desde el sur, a un mejor conocimiento de la antropología como instrumento cognitivo..." (2006:12).

Los antecedentes señalados constituyeron el fundamento de esta investigación; los escasos conocimientos existentes -tanto a nivel nacional como de América Latina- acerca de la conformación de la antropología en Chile $^{2}$, ponen de manifiesto la necesidad de generar

\footnotetext{
${ }^{2}$ Entre los anteriormente citados, Berdichewsky (1980, 2000, 2004) expone antecedentes históricos sobre el desarrollo de la antropología en Chile; el trabajo de Arnold (1990) denominado "Antropología social en Chile.
} 
investigaciones sistemáticas que profundicen en su origen y desarrollo, y de este modo, poner en escena antecedentes que permitan articular una reflexión en torno sus particularidades y proyecciones en tanto campo o saber especializado. Historizar la disciplina, implica poner el foco en procesos relacionales en los cuales intervienen o se conectan objetos, sujetos sociales e instituciones, los cuales a partir de diversas trayectorias, dan lugar a configuraciones concretas -asociaciones, libros, artículos, etc.-, inscribiendo en la historia una pluralidad de narrativas sobre el origen y desarrollo de una disciplina. Es precisamente este ejercicio mirara al pasado desde el presente- el que permite, en un juego entre el historicismo y el presentismo (Stocking 1982), penetrar en la trama en la cual se tejen las fabulas sobre los territorios y tribus académicas -las que actúan como tradición y fundamento para la legitimación de ciertas conceptualizaciones y prácticas en el presente-, y permiten asentar las condiciones para desnudar y/o tensionar los esencialismo y/o naturalización que se transmite y reproduce en las aulas y el quehacer profesional, a punta de forzar los límites y obviar las conexiones y convergencias. Como señaló Gieryn (1983), existe cierto grado de arbitrariedad en la definición de los distintos campos de conocimiento, arbitrariedad que responde las diversas formas que adquieren ciertos procesos a escala local. Estos movimientos permiten registrar en la historia de la ciencia la tensión entre especialización e interacción (Ben-David 1971), lo que tiende a perturbar sistemas rígidos de clasificación y organización del

Producciones y representaciones.”, comprende una investigación que se centra específicamente en la situación profesional y en las tesis de grado de egresados de la Universidad de Chile entre 1977 y 1987. Munizaga y Thomas (1984) investigan la producción antropológica en torno al norte grande y específicamente del área circumpuneñas que toma como base 42 investigaciones realizadas entre 1940 y 1982. Por su parte Richard (2000), establece una reflexión más bien teórica sobre la antropología en Chile que toma como referencia el trabajo de Arnold (1990) y Cancino y Morales (2000); Hernández (2004), con base en su experiencia académica en Chile y Venezuela, se cuestiona respecto a la supuesta identidad de la antropología chilena. Garbulsky (2000), situándose como actor social, reflexiona sobre la emergencia y desenvolvimiento de la carrera de Antropología en la Universidad de Concepción entre el periodo previo al golpe militar (1967-1973); Cancino y Morales (2003) realizan un trabajo que busca caracterizar la antropología que se ha desarrollado en la Escuela de Antropología de Universidad Católica de Temuco, situando ciertos hitos, y analizando de manera general (mediante una clasificación de conceptos en los títulos de los trabajos, la producción de tesis de grado hasta 2001, así como las participaciones en congresos y proyectos del Fondo de Investigación Científica y Tecnológica de alguno de sus docentes; Durán (2005) y Durán, Carrasco y Berho (2005) elaboran un trabajo 'desde a dentro', en el cual reflexionan sobre el curriculum formativo y el tipo de antropología que se imparte y practica en la Escuela de Antropología de la Universidad Católica de Temuco; y Mora (2014) quien realiza una aproximación histórica al proceso de emergencia y desarrollo de la antropología en la Universidad Católica de Temuco entre 1970 y 1978. Por otro lado, trabajos sobre áreas o campos de la antropología en Chile corresponden a los desarrollados por Berdichewsky (1977) y Carrasco e Eyzaguirre (2005) sobre antropología aplicada; Hernández (2003) y Hernández y Pezo (2009) sobre antropología de lo rural; Imilan y Lange (2003) sobre antropología urbana; Maturana (2003) sobre antropología audiovisual; Sadler y Acuña (2003) sobre antropología del género; y Gundermann y González sobre antropología andina y su desarrollo en la zona norte de Chile (2009). 
conocimiento que tiene lugar en universidades e instituciones de investigación. Aquí cobran mucho sentido factores como los enunciados por Gerholm y Hannerz (1982), que nos llevan a pensar las disciplinas como imbricadas en las dinámicas históricas y locales, que configuran diversidades internas como cercanías e interconexiones con otros campos de conocimiento, lo que otorga la posibilidad de conformación de comunidades interdisciplinarias, transepistémicas o redes de cooperación formales e informales (Crane 1972; Granovetter 1973; Mullins 1968; Price 1972 [1963]; Storer 1966: Knorr-Cetina 2005). Las disciplinas son constructos sociales, y como señalamos, se encuentran inscritas en dinámicas sociohistóricas con un origen y unas transformaciones rastreables en el tiempo; arraigan estilos o modos de hacer que se orientan desde modelos diferenciables y coexistentes, conformando un panorama constituido por visiones diversas y/o divergentes (Cardoso de Oliveira 1996).

Pensar en perspectiva histórica, entrega insumos para visualizar las rupturas, las continuidades, las conexiones, las disociaciones, las convergencias y divergencias, permitiendo incorporar una dosis de relativismo para discutir los totalitarismos y generalísimos que acompañan muchas de las reflexiones -una antropología latinoamericana, una antropología chilena, una antropología colonialista-, dando paso a la visibilización de dinámicas particularidades que se inscriben en tendencias globales.

Para esta investigación se adoptó la perspectiva que se sitúa desde los denominados "estudios sociales de la ciencia" (Richard 1987 [1983]; Bowker y Latour 1987; Woolgar 1991 [1988]; Kreimer y Thomas 2004), los cuales combinan orientaciones institucionalistas (Merton 1984 [1970]; 1977 [1973]) con aquellas remitidas al stock de conocimientos (Lamo de Espinosa 1994), otorgando relevancia al marco histórico-social así como al contexto institucional en el cual se desarrolla el trabajo científico, articulando un análisis de orientación relacional que releva las conexiones que se establecen entre distintos actores, sean instituciones y/o sujetos (Bourdieu 2008 [1997]) $)^{3}$. Ello permitió problematizar la institucionalización de las Ciencias Antropológicas en lo que se ha denominado periodo pre-disciplinario (1860-1954), entendiendo dicha institucionalización como un proceso de estructuración de prácticas sociales y de conocimiento en torno a un área del saber que no se ha consolidado ni establecido en

\footnotetext{
${ }^{3}$ Como señala Bourdieu (2008 [1997]), a propósito del campo científico, "Una auténtica ciencia de la ciencia no puede constituirse más que a condición de rechazar radicalmente la oposición abstracta (que se encuentra también en otros lados, por ejemplo en la historia del arte) entre un análisis inmanente o interno, que incumbiría propiamente a la epistemología y que restituiría la lógica según la cual la ciencia engendra sus propios problemas, y un análisis externo, que relaciona sus problemas con sus condiciones sociales de aparición (p. 17).
} 
unidades formales destinadas a la docencia, habilitación profesional y generación de investigación - un instituto o universidad. A partir del trabajo de archivo -revisión de diversas fuentes escritas como actas, informes, cartas, artículos, libros-, se ha podido indagar en algunas dinámicas constitutivas del espacio científico a través de lo que Kreimer y Thomas (2004) denominan dimensiones cognitiva, generacionales y de interacción, lo que ha permitido dar cuenta de aspectos tales como:

a) La identificación de referentes epistemológicos en las delimitación de áreas de conocimiento contenidos en los modelos de ciencia de la época.

b) Las vinculaciones entre la antropología y otras ciencias comprometidas con la producción de conocimiento en el contexto nacional.

c) Los contenidos presentes en la producción académica, como tópicos en el desarrollo de la investigación antropológica, referentes teóricos y metodológicos puestos en juego en la investigación.

d) La relevancia de ciertos investigadores y el surgimiento de actores-productores en el espacio científico.

e) La conformación de grupos de investigación dedicados al abordaje de ciertas temáticas por medio de la colectivización de intereses investigativos.

f) Instancias institucionales -contextos sociopolíticos que hacen o no posible su consolidación-, y de espacios de interlocución y cooperación entre investigadores mecanismos y medios presentes en la difusión del trabajo de investigación.

g) El relevamiento de aspectos generacionales en la configuración de etapas o fases en desarrollo de la antropología, lo que permite identificar tendencias y/o continuidades en la producción científica de los antropólogos.

h) Las especificidades de la antropología en Chile respectos de las antropologías producidas en América Latina, particularmente en lo que respecta a perspectivas que tienden a su homogenización.

Los resultados obtenidos en esta investigación permiten discutir las siguientes afirmaciones previamente establecidas en la literatura especializada:

- Que los estudios iniciales fueron realizados principalmente por extranjeros y bajo el alero institucional de los museos (Palestrini, Ramos y Canales 2010). 
- La consideración de la antropología -los primeros antropólogos- como comprometida con la formación de la Nación y del Estado Chileno (Troncoso, Salazar y Jackson 2008; Castro 2014).

- Desconexión entre los actores que se vinculan a temáticas ligadas a las Ciencias Antropológicas, particularmente por parte de arqueólogos más relacionados con las Ciencias Naturales (Bengoa 2014).

- Que la institucionalización de las ciencias sociales en Chile se produce hacia mediados de 1950, y se inicia en el campo de la sociología (Garretón 2015).

La tesis aquí sostenida, plantea que la antropología en Chile exhibe una institucionalización temprana pero débil ${ }^{4}$, la que descansa y demanda el esfuerzo de sujetos específicos que promueven su desarrollo. En esta dirección, a través de esta investigación se identifican dinámicas propias de lo que podríamos denominar espacio científico, constatando la existencia de especialistas de oficio con volúmenes distintos de producción, siendo en su mayoría especialistas nacionales -hay que reconocer la importancia en la dinámica de la producción realizada por extranjeros, principalmente europeos, lo que se expresa en el volumen de artículos y libros. La institucionalización de la investigación se produce en torno a sociedades científicas y museos, instancias que permiten la generación de conocimiento el cual se socializa por medio de coloquios, correspondencia, congresos y publicaciones en revistas especializadas que estas mismas generan.

La debilidad de la institucionalización se explica por el escaso compromiso exhibido por el Estado en el desarrollo de la ciencia y particularmente de las Ciencias Antropológicas; son apoyos que dependen de ciertos gobiernos y que no se traducen en una política de Estado a diferencia de lo que sucede en otros países de América Latina y el mundo. Por tanto, se discute la tesis de que la antropología desarrollada en Chile haya estado comprometida con la construcción de la Nación, atributo que se suele plantear como una característica común a todas las antropologías en latinoamericanas.

\footnotetext{
4 Más allá de la voluntad y compromiso de sujetos individuales, la consolidación del proceso de institucionalización requiere de recursos colectivos que permitan su estabilidad y proyección en el tiempo. Para la época, y en virtud de lo que acontece en otros países de América Latina, el rol fundamental en el establecimiento y consolidación lo juega el Estado. La institucionalización débil obedece a un proceso en el cual el apoyo estatal es más bien fluctuante, siendo un indicador la intermitencia de ciertas instituciones y la imposibilidad de asentar las bases para la investigación y la formación profesional.
} 
Para la concreción de los objetivos, se trabajó una metodología que incorporó una aproximación de orientación histórica, la cual se sitúa desde la periodización que establece como cortes temporales o hitos: la primera publicación en una revista nacional en temas de orientación antropológica (1860) y la incorporación de la antropología en una institución académica-universitaria abocada al desarrollo de la disciplina en tanto especialidad (Centro de Estudios Antropológicos de la Universidad de Chile, fundado en 1954). La importancia de dicho Centro, es que contribuye a la articulación de la investigación antropológica de la época posibilitando, posibilitando el desarrollo de algunas cátedras y permitiendo, a partir de 1971, a la creación de un programa académico de formación profesional a nivel de pregrado (Licenciatura en Antropología).Tomando en consideración dicho periodo, se desarrolló un trabajo de archivo orientado a la búsqueda y clasificación de fuentes que permitiera identificar políticas de gobierno, instituciones, actores y producción-comunicación que estuviera vinculada de manera directa o indirecta con el cultivo de las ciencias antropológicas, entendida ésta como la ciencia integral del hombre, definición que opera en dicha etapa. De este modo se lograron recopilar distintos documentos que permitieron concretar una interpretación contextualizada de manera de situar la antropología y su desarrollo en el país.

Una segunda aproximación técnico-analítica tuvo como fuente de información las publicaciones en revistas científicas y especializadas, en tanto estas se constituyen en una representativa y en dispositivo central de la producción y comunicación del conocimiento científico, y permiten dar cuenta de las dinámicas que tienen lugar a través de los canales formales que regulan las actividades de investigación (Maltrás 2003) ${ }^{5}$. Se incorporaron procedimientos utilizados por la corriente institucionalista o internalista en los estudios sociales de la ciencia, concretamente algunos de aquellos desarrollados por la cienciometría, particularmente los que buscan conocer los 'marcos cognitivos' de la ciencia -un área o una disciplina-, e indagar en las estructuras formales así como en la determinación de los volúmenes de producción y tendencias intelectuales (Price 1963; Storer 1966; Mullins 1968; Crane 1972; Granovetter 1973; Callon, Courtial y Penan 1993 [1999]). Aun cuando clásica, esta aproximación se ha revelado útil en el estudio de la ciencia y de las disciplinas científicas en lo relativo a los contenidos cognitivos como en la exploración de las relaciones

\footnotetext{
${ }^{5}$ Si bien se reconoce la circulación de información por la vía de canales de comunicación informal a lo que se suma la denominada literatura gris -que son relevante en el proceso de generación de conocimiento científico-, estos acaban siendo publicados en las instancias formales u oficiales (Maltrás 2004).
} 
interpersonales e interinstitucionales, lo que permite rastrear las conexiones entre investigadores y campos diversos, cuestión que además posibilita detectar la inestabilidad de la fronteras disciplinarias (Callon, Courtial y Penan 1999 [1993]; Vanti 2000). En concreto, se desarrolla el levantamiento de una base de datos y la confección de una tabla de datos que incorporó 532 artículos publicados en revistas científicas o especializadas de circulación nacional, las cuales fueron clasificadas en función de variables como: Área temática, autor, origen del autor, profesión del autor, revista en que se publica, año, zona geográfica y población a la que hace referencia el trabajo. Para la clasificación de los artículos se recurrió a la categorización y codificación utilizada para el nivel manifiesto del análisis de contenido, el cual se encuentra entre los denominados indicadores de relación de segunda generación (Callon, Courtial y Penan 1999 [1993]) y criterios de agregación del análisis bibliométrico (Maltrás 2004), y que operan en base a un análisis de palabras asociadas que recogen el contenido de los documentos, y que permite rastrear la aparición conjunta de palabras, identificar la centralidad y densidad de los agregados, identificar la estructuración de un campo (morfología), visualizar actores y su localización, y dar cuenta de transformaciones, ciclos de vida e interacciones entre investigadores y líneas temáticas (Callon, Courtial y Penan 1999 [1993]; Maltrás 2004). Para la realización de una interpretación relacional, se recurrió a la configuración del espacio científico considerando variables/modalidades como fueron área de conocimiento, área profesional del autor y etapa de producción; el análisis utilizó las técnicas multivariadas, específicamente el análisis factorial de correspondencias múltiples (Crivisqui 1999; Lévy y Varela 2003), lo que permito visualizar una estructura de especialización en la conformación del espacio de la producción de conocimiento antropológico.

Respecto al contenido, este informe se organiza en seis capítulos en los cuales se exponen distintos antecedentes que permiten analizar el proceso de institucionalización de la antropología en Chile, y con ello, presentar una interpretación sobre las dinámicas socioorganizativas y las dimensiones cognoscitivas asociadas a la formación del espacio científicoantropológico.

El primer capítulo entrega aportes teóricos orientados a precisar conceptos tales como: disciplina y territorios académicos, comunidad y redes científicas, e interdisciplina y paradigmas. Además, se incluye una reflexión que expone las distintas propuestas teóricas 
dirigidas a caracterizar y situar la especificidad de las antropologías en América Latina -o fuera de las áreas de origen-, incorporando la noción de estilo y antropología nacional.

Un segundo capítulo presenta antecedentes relativos al origen e institucionalización de la antropología a nivel internacional, con un énfasis en la experiencia de México, Colombia, Perú, Brasil y Argentina. Se expone una reflexión sobre la distinción entre institucionalización científica y académica, así como se delinean los componentes fundamentales del modelo de ciencia que se origina en Europa y se implementa a nivel local.

El tercer capítulo caracteriza la política científica y de formación profesional que impulsó el Estado hacia fines del siglo XIX e inicios del XX, y en este marco, se exponen antecedentes relativos a cómo se incorporó la preocupación intelectual por los pueblos originarios que habitaron y habitaban el territorio nacional, aspecto necesario para el establecimiento y consolidación de un campo de estudios antropológico.

El cuarto capítulo sintetiza una reflexión sobre la inserción en el contexto local del modelo de institucionalización de la ciencia europeo, describiendo ciertos procesos ligados a su emergencia, constitución y desarrollo a través del establecimiento de sociedades científicas, museos y congresos.

El quinto capítulo trata sobre el origen de la preocupación científica por la "otredad radical", identificando los primeros actores relevantes y su contribución al desarrollo de la investigación y publicación de artículos de orientación antropológica en diversos temas vinculados a la población nativa del país. Además, aporta un panorama general sobre los primeros debates científicos y su impacto en la sociedad de época, tensión que expresa diferencia entre la representación nacional que promueve la elite, y los enfoques e interpretaciones que producen estos primeros investigadores.

El sexto y último capítulo analiza la producción de orientación antropológica en la época, lo que toma como base las publicaciones realizadas en revistas especializadas de circulación nacional. Se identifican las principales revistas e investigadores en el periodo definido, visualizando las líneas o áreas temáticas, volúmenes y tendencias comprendidas en la producción textual. El análisis se complementa con una aproximación al espacio de la producción antropológica a través del análisis de Correspondencias Múltiples, el cual permite evidenciar la emergencia de algunas áreas de especialización, lo cual se explorara 
considerando la relación entre las modalidades de variables como: área de conocimiento, área profesional y etapas de producción de los investigadores. 


\section{CAPÍTULO I}

\section{Algunas claves conceptuales. Ciencia, Disciplina y Estilo en la conformación de la antropología}

\subsection{Disciplinas y el desborde de fronteras}

Se podría decir que el término disciplina posee un carácter polisémico. Si nos remitimos al acervo de la lengua castellana, la Real Academia Española de la Lengua la define como: a) Doctrina, instrucción de una persona, especialmente en lo moral; b) arte, facultad o ciencia; c) especialmente en la milicia y en los estados eclesiásticos secular y regular, observancia de las leyes y ordenamientos de la profesión o instituto; d) instrumento, hecho ordinariamente de cáñamo, con varios ramales, cuyos extremos o canelones son más gruesos, y que sirve para azotar; e) acción y efecto de disciplinar.

Lo que se constata en el plano de la definición general, también se observa en su tratamiento especializado en el campo científico (Becher 2001 [1989]; Shumway y Messer-Davidow 1991; Wallerstein 2005 [2004]), a lo que se suma el surgimiento de conceptos emparentados como: matriz disciplinar (Kuhn 2007 [1962]; Cardoso de Oliveira 1999), comunidades científicas (Merton 1977 [1973]), campo científico (Bourdieu 2008 [1997], 2006 [1999]), comunidad disciplinar (Becher 2001 [1989]). De hecho, al menos cuatro de sus expresiones vernáculas ( $a, b, c$ y e) son constitutivas de aquellas que se han denotado en el campo científico, siendo sus matices fundamentados desde distintas perspectivas teóricas y epistemológicas presentes en las ciencias en general (González Echevarría 1987).

Por otro lado, si bien se reconoce el lugar de las disciplinas en la organización académica, y se destaca la importancia que poseen en la transmisión del saber -demarcación de un campo formativo-, dicha distinción pierde sentido o se ve en entredicho cuando se analiza el proceder en investigación. Se ha podido constatar que el aumento de las especialidades han tendido a fisurar las disciplinas académicas, esto, dado que en los espacios 'vacios o terrenos inexplorados' que tienen lugar entre disciplinas, puede penetrar la interacción entre especialidades y campos de investigación (Dogan 2003); de allí que varios investigadores enfaticen el cruce de fronteras (Gieryn 1983; Becher 2001 [1989]; Shumway y Messer- 
Davidow 1991; Lattuca 2001; Lamont y Molnár 2002; Wallerstein 2005 [2004]; Dillon 2008), la hibridación (Dogan 2003), el carácter interdisciplinar (Jociles Rubio 1999; Rosaldo 2004) o las condiciones transepistémicas (Knorr-Cetina 2005 [1981], 1992) que caracterizan la organización y desarrollo del trabajo científico.

\subsubsection{Los distintos matices en la definición de disciplina}

Como fue señalado, la revisión de la literatura especializada permite distinguir al menos cinco definiciones de disciplina, cuya diferencias radican en que cada una enfatiza o releva ciertos aspectos o dimensiones como son: cognoscitiva y/o epistemológica, formativa o de enseñanza, organizativa y/o normativa, cultural y/o identitaria, y de poder o disciplinamiento.

Desde una perspectiva cognoscitiva y/o epistemológica, una disciplina estaría constituida por un conjunto de conceptos, métodos y objetivos fundamentales que permiten la problematización de un dominio o ámbito, una tradición de procedimientos y técnicas para abordar problemas teóricos y prácticos. Esto daría lugar a la “... adhesión compartida de los hombres a un conjunto de ideales sobre el que existe suficiente acuerdo [y que] conduce a la elaboración de un repertorio aislable y autodefinido de procedimientos." (Toulmin (1977 [1972]: 363). Conceptos y procedimientos se desarrollan y pueden variar conforme ideales disciplinarios que definen una dirección acordada, y por tanto implica la selección de criterios para aceptar variantes.

Para Boisot (1979) una disciplina "está comprometida con sus objetos, métodos y procedimientos, y finalmente con leyes" (p.109), agregando que conforma una estructura, es decir, “... un sistema en el que se reconoce una organización, y en el cual la suma de las partes no coinciden con el todo.”(p.101). Zabalza (1987) plantea que se caracteriza por “... el tipo de problemas de la realidad que aborda; por los procedimientos conceptuales y operativos que emplea para decodificarlos; por las soluciones que plantea; por los modelos teóricos y conceptualizaciones que genera (p. 140). Para Morin una disciplina "Es una categoría organizadora; instituye en ésta la división y especialización del trabajo y responde a la diversidad de dominios que recubren las ciencias. Por más que esté en un conjunto científico más vasto, una disciplina tiende, naturalmente, a la autonomía, por medio de la delimitación de sus fronteras, por el lenguaje que se da, por las técnicas que tiene que elaborar o utilizar, y eventualmente, por las teorías propias". (2001:115). 
Para la segunda tendencia, que enfatiza su carácter formativo o de enseñanza, una disciplina constituye un "Conjunto específico de conocimientos susceptibles de ser enseñado, y que tiene sus propios antecedentes en cuanto a educación, formación, procedimientos, métodos y áreas de contenidos." (Berger 1979:6). Heckhausen (1979) establece una distinción entre ciencia y disciplina, señalando que la primera corresponde a la actividad de investigación en tanto que la segunda a la actividad de enseñanza. Como actividad, corresponde a “... la búsqueda científica especializada de una materia determinada y homogénea... que consiste en producir conocimientos nuevos que desplazan los antiguos [que]... desemboca en una formulación y reformulación incesante del actual cuerpo de conocimientos sobre una materia."(p.90). Para éste, una disciplina se define según siete criterios: dominio material o serie de objetos, dominio de estudio o fenómenos observables, integración teórica, métodos, instrumentos de análisis, aplicaciones prácticas y contingencias históricas.

En el marco de la definición que realza aspectos organizativos y normativos, Beyer y Lodahl (1976) precisan que una disciplina corresponde a un campo de estudio que provee la estructuración de conocimiento, en la cual los miembros de una facultad son entrenados y socializados; se hacen tareas de enseñanza, se investiga y administra. Para Apostel (1979) “... el conocimiento se organiza en base a las disciplinas académicas, pues tales disciplinas no son sólo un conveniente medio de dividir el conocimiento en sus elementos, sino también la base sobre la cual la universidad se organiza en feudos autónomos que definen las diferentes especialidades de la enseñanza y la investigación. Lo que concierne a las disciplinas concierne, pues, a toda la estructura social de la Universidad." (p. xiii).

Whitley (2000 [1984]) expresa que las disciplinas constituyen agrupamientos sociales organizados, señalando que los campos intelectuales deben tener procedimientos de trabajo distintivos si funcionan como organizaciones reputadas, lo cual actúa como contexto para cohibir y autorregular la existencia de grupos basada en el “... poder para validar la especialización y mediar las carreras de sus miembros..." (p. 20). Pirce (1991) describe las disciplinas como organizaciones sociales que desarrollan normas y criterios que funcionan como autoridad de conocimiento, creando fronteras y excluyendo a los no miembros, en tanto éstas "contribuyen a la legitimación de los cuerpos de conocimiento" (p.26). Dogan (2001) sostiene que disciplina refiere a la organización de unidades en programas de educación y en 
unidades de producción de conocimiento; es “... una rama de instrucción para la transmisión de conocimiento y un mapa conveniente para la administración académica.” (p. 14851).

Stichweh (2001) establece que las disciplinas funcionan como una unidad estructurada en el sistema de la ciencia, en el sistema de educación universitaria, un tema de dominio para profesores y saberes en la escuela, y finalmente como una designación de ocupación o rol profesional. Específica, además, que es primero que todo, una orientación intelectual, “... depende de la decisión concentrada en un campo relativamente pequeño de actividad científica... y necesita un contexto social que la soporte, esto es, otras personas que tomen decisiones.” (p. 13728). Por otro lado, hace hincapié en la “... especialización como diferenciación de roles en el sistema educacional, que es casi siempre un lugar de especialización de roles que pueden ser institucionalizados como roles ocupacionales." (p. 13728). Siler (2005) plantea que las disciplinas “... proporcionan influencias organizacionales que ayudan de manera íntima a las comunidades académicas, derivando profesionales y conocimiento que beneficia la tendencia a la eficiencia y estandarización de la comunicación" (p.23). Éste agrega que las diferentes disciplinas desarrollan profesionales y estructuras sociales con sus fronteras, las cuales son constantemente influidas por un cruce dispar del conocimiento, pudiendo ser vías para “... maximizar el poder de las brechas estructurales, optimizar el nivel de marginalidad y abstracción que aparece en contextos específicos, pero restando conceptos de conocimiento" (p.23).

Desde una óptica cultural y/o identitaria, Clark (1983) resalta los aspectos relativos a la institucionalización y organización ${ }^{6}$, ya que en torno a las tareas intelectuales, “... cada disciplina tiene una tradición de conocimiento - categorías de reflexión- y códigos de conducta propios. Se da con más fuerza en el caso de sistemas avanzados, esto es, en cada campo hay caminos en el que los nuevos miembros son gradualmente introducidos." (p.76). Para éste, resulta clave la socialización que tiene lugar en los campos especializados de conocimiento en los cuales los estudiantes y quienes más tarde trabajarán en ellos, interactúan con sus pares en la disciplina. Además, señala que cada especialidad posee diferentes creencias culturales ligadas a teorías, metodologías, técnicas y problemas- e ídolos que se reflejan en objetos tales

\footnotetext{
${ }^{6}$ En este sentido, Clark (1983) plantea que las disciplinas son la forma de organización académica, estableciendo la división del trabajo profesional y los contenidos definicionales, lo que se refleja en las tareas sustantivas de cada especialidad y en la jerarquización en base a la cual se estructura.
} 
como fotografías, textos, discursos- que se disponen en el espacio físico y social, confiriendo identidad a sus miembros.

Becher (2001 [1989]) plantea que “... las tribus del mundo académico definen su propia identidad y definen su propio territorio intelectual empleando diversos mecanismos orientados a excluir a los inmigrantes ilegales."(p.43). En la definición identitaria cultural resultan clave la lengua y la literatura profesional, agregando que los aspectos de la cultura de una disciplina tienen la función de constituirse en la maquina socializadora, como también en armas que se ponen en juego en las disputas y controversias internas. Es por ello que junto a características estructurales de cada comunidad disciplinaria, los elementos culturales ejercen una fuerza poderosa, integrando “ ... tradiciones, prácticas y costumbres, el conocimiento transmitido, las creencias, los principios morales y normas de conducta, como también sus formas lingüísticas y simbólicas de comunicación y los significados que comparten.” (Becher 2001 [1989]):44). Por su parte, Dillon (2008) la define como “... un cuerpo de conocimientos culturalmente estructurado, que se puede adquirir, practicar y avanzar a través de un acto de creación, y que está culturalmente definido por un sistema de símbolos producidos por otros individuos que se preservan y transmiten a generaciones futuras."(p.256). Complementa señalando que colectivamente, los sujetos que seleccionan y evalúan nuevas ideas, y de este modo controlan e influencian una disciplina, son conocidos en el campo como los porteros de la disciplina.

Por último, es posible de realizar una lectura de propuestas que destacan directa o indirectamente como opera la dimensión de poder en la delimitación de un campo académico, así como en la trasmisión de conocimientos y prácticas por medio de instancias formativas. Desde esta lectura, la demarcación disciplinaria operaría a través de relaciones hegemónicas que se expresan por medio de la coerción, estructuración y la diferenciación interna y externa que se legitiman en el espacio académico o universitario y social, y en cuyo estudio se hace necesario dar cuenta “... del control de la organización y producción de conocimiento por disciplinas académicas y prácticas sociales por las cuales este control es mantenido.”(Greenhalgh 1997:819). Al introducir la dimensión analítica del poder, es posible precisar cómo ella interviene en las dinámicas que se establecen entre los sujetos y colectivos 
sociales, dando lugar a situaciones tales como las referidas en el 'Conflicto de las Facultades' de Kant o en el 'Homo Academicus' de Bourdieu (2008 [1984]) ${ }^{7}$.

Por ello, no es anodino recuperar el sentido de disciplina en Foucault (2002 [1975]), y pensarla como un tipo o forma de poder puesto en práctica que no remite necesariamente a una institución o aparato, sino a una modalidad para ejercerlo “... implicando todo un conjunto de instrumentos, de técnicas, de procedimientos, de niveles de aplicación, de metas; es una "Física" o una "anatomía" del poder, una tecnología". (p.130). En esta dirección, a través de la disciplina se encauzarían “... multitudes móviles, confusas, inútiles de cuerpos y de fuerzas en una multiplicidad de elementos individuales — pequeñas células separadas, autonomías orgánicas, identidades y continuidades genéticas, segmentos combinatorios." (Foucault 2002 [1975]:104). Las disciplinas implicarían mecanismos que son dispuestos a través de sutiles y simples instrumentos como “... la inspección jerárquica, la sanción normalizadora y su combinación en un procedimiento que le es específico: el examen." (Foucault 2002 [1975]:104). Desde esta perspectiva, las disciplinas académicas establecerían mecanismos de diferenciación y legitimación, disciplinando a sus miembros a través de la formación o enseñanza en ciertos principios y perspectivas, controlando el conocimiento que se genera, sancionándolo, y demandando prácticas sociales legítimas que permiten el mantenimiento del control.

Por otro lado, Bourdieu define la disciplina (vista como sub-campo), “... a través de un nomos especial, un principio de visión y de división, un principio de construcción de la realidad objetiva irreductible a la de cualquier otro principio... [y la]... illusio, la fe en el juego, que supone, entre otras cosas, la sumisión sin pretensiones al imperativo del desinterés."(2003 [2001]:95). Representaría un campo relativamente estable, delimitado y fácil de identificar, el

\footnotetext{
${ }^{7}$ Bourdieu muestra que el campo universitario, entendido como ese juego de relaciones objetivas entre varias posiciones y disciplinas en la distribución de estas especies de capital, constituye un lugar de pugnas constantes que se orientan a la transformación de la estructura. El poder académico y el prestigio intelectual son los elementos esgrimidos en la lucha, en tanto que la posición en la estructura define, por selección y condicionamiento específico, las estrategias adoptadas para imponerse como principio de la jerarquización dentro del universo específico. Más allá de las dinámicas propias del campo universitario -en el sentido de campo relativamente autónomo-, Bourdieu desentraña la lógica de su transformación, particularmente de aquellas derivadas de cambios morfológicos. Entre ellos, el que más destaca es el incremento de estudiantes que define el crecimiento desigual de los cuerpos docentes, y por otro lado, la transformación de la relación de fuerzas entre facultades y disciplinas en su interior, que tiene como culminación los eventos de mayo de 1968. Esto le permite establecer una homología entre la posición (en la estructura de la distribución de varias especies de capital en el campo universitario), disposición y las predisposiciones, las que no sólo operan en las prácticas profesionales de diferente tipos de profesores, si no que se orientan explícitamente desde lo político tiñendo opiniones y acciones tomadas durante un periodo de crisis (Mora 2010 b).
} 
que se expresaría en “... un nombre reconocido escolar y socialmente (es decir, está presente de manera clara en las clasificaciones de las bibliotecas, como la sociología en oposición, por ejemplo, a la «mediología»)... inscrita en unas instituciones, unos laboratorios, unos departamentos universitarios, unas revistas, unas organizaciones nacionales e internacionales (congresos), unos procedimientos de certificación de las competencias, unos sistemas de retribución, unos premios.” (2003 [2001]:116). Esta se diferenciaría “... mediante la posesión de un capital colectivo de métodos y de conceptos especializados cuyo dominio constituye el derecho de admisión, tácito o implícito, en el campo" (2003 [2001]:116), expresándose en un habitus disciplinario en tanto esquemas de percepción y apreciación. Recuerda que no sólo se define por unas propiedades intrínsecas (un mínimo de unidad según el autor), sino también por aquellas a las que debe su posición en el espacio jerarquizado de las disciplinas; en este sentido, tanto el campo científico como el campo disciplinario o académico estarían constituidos por relaciones de fuerza, monopolios, luchas y estrategias, intereses y ganancias propias de cualquier campo social (Bourdieu 1984 [2008]; 2001 [2003]:69) ${ }^{8}$, luchas que tendrían como objetivo el monopolio por la distribución del capital específico que se encuentra objetivado en las instituciones y disposiciones, “... y que dirigen las estrategias y las posibilidades objetivas de los diferentes agentes o instituciones en las luchas presentes." (1997 [2008]:27). Establecer diferenciaciones entre disciplinas puede entenderse precisamente como una estrategia para apropiar capital específico en el campo universitario.

\subsubsection{Una visión crítica sobre el concepto de disciplina}

Críticas dirigidas a algunas definiciones de disciplina, guardan relación con que esta se piensa desde la lógica de la diferenciación, dando lugar a visiones autocontenidas y/o que desconectan las disciplinas de sus contextos sociales. De este modo, se tienden a solapar o ignorar los canales de comunicación e interconexión que tienen y han tenido lugar entre las disciplinas al enfatizar los esfuerzos prácticos y declarativos para establecer límites bien

\footnotetext{
${ }^{8}$ Bourdieu muestra que el campo universitario, entendido como ese juego de relaciones objetivas entre varias posiciones y disciplinas en la distribución de estas especies de capital, se constituye en lugar de pugnas constantes que se orientan a la transformación de la estructura. El poder académico y el prestigio intelectual son los elementos esgrimidos en la lucha, en tanto que la posición en la estructura define, por selección y condicionamiento específico, las estrategias adoptadas para imponerse como principio de la jerarquización dentro del universo específico. Más allá de las dinámicas propias del campo universitario -en el sentido de campo relativamente autónomo-, Bourdieu desentraña la lógica de su transformación, particularmente de aquellas derivadas de cambios morfológicos.
} 
definidos a partir de delimitación de campos de conocimiento, objetos, conceptos y métodos reproducidos en instancias académicas en el espacio universitario.

Hay que considerar que las discusiones contemporáneas tienden a relevar que las disciplinas presentan límites más bien difusos, lo que favorece escenarios para la comunicación y el cruce de fronteras disciplinarias. En esta perspectiva, autores como Gibbons (1994) destacan que esta sería una característica de la organización de los sistemas modernos de conocimiento -lo que se expresaría en el modo 2-, en tanto Dogan (2003), lo visualiza como una manifestación de las tendencias a la especialización imperantes en las ciencias, lo que favorece la interacción entre disciplinas en campos de conocimientos cercanos o afines. Sin embargo y como señalan Etzkowitz y Leydesdorff (2000), el formato original de la ciencia, incluso antes de su institucionalización académica, ya funcionaba a través del establecimiento de redes de cooperación, que en muchos casos permitía la conexión entre saberes y campos diversos, cuestión que se ha podido pesquisar en el análisis bibliográfico que remite al origen y desarrollo de la antropología.

De este modo, varios autores incorporan la idea de interconexión y desborde de fronteras, y de este modo complementan o problematizan el concepto de disciplina. En la línea de la complementación, Dressel y Marcus (1982) postulan que la definición de disciplina implica múltiples dimensiones en torno a la organización sistemática de un fenómeno estudiado, entre las cuales se encuentran: componentes sustantivos (acepciones, variables, conceptos y sus relaciones); lingüísticos (simbolismos y elementos que se pueden relacionar y exportar); sintácticos (organización de procesos en torno al desarrollo de la disciplina); valores (cómo y qué se estudia y/o se conoce lo estudiado); conjunciones (relaciones con otras disciplinas). En tanto que King y Brownell (1966), señalan que las disciplinas no son áreas de estudio claramente delimitadas, exhibiendo una variedad de estilos que se aplican a un campo de interés definido. Cada grupo de intelectuales posee "... una herencia y aspira a impulsar el desarrollo de un sector o campo correspondiente a un estado de conocimiento... poseen uno o más modos característicos de conocer - de acotar conocimiento- o participa de modos de investigación comunes con otras disciplinas.” (p.68). Estos autores otorgan importancia a sistemas simbólicos o lenguajes especializados que permite definir la investigación, así como al conjunto de conceptos interconectados y un legado bibliográfico que definen el campo de 
estudio y permite la comunicación entre sus miembros ${ }^{9}$. Para Wallerstein (2005 [2004]) el concepto de disciplina está constituido por tres dimensiones: a) categorías intelectuales que definen un campo de estudio con límites difusos y modalidades de investigación legitimadas; b) estructuración institucional en universidades, departamentos, títulos, cuerpos académicos, bibliotecas (catálogos, anaqueles, etc.), asociaciones académicas, etc.; c) una cultura, en tanto académicos miembros comparten experiencias y contactos en tanto “... han leído los mismos textos $<<$ clásicos $>>$; participan de los mismos debates tradicionales... tienen un mismo estilo y reciben recompensas por ello." (p.141-142). Afirma que las disciplinas son constructos sociales, por ende inscritas en dinámicas sociohistóricas con un origen y unas transformaciones rastreable en el tiempo; como culturas, arraigan modos de presentación y estilos que se expresan en modos de hacer, así como en prejuicios sobre el deber ser de quienes la cultivan.

Estas definiciones permiten relativizar la lógica de compartimentos estancos que lleva a concebir las disciplinas sólo en el marco de la estructuración institucional en universidades, departamentos, títulos, cuerpos académicos, bibliotecas (catálogos, anaqueles, etc.), asociaciones académicas, etc. En tal sentido, las disciplinas deben ser pensadas como imbricadas en las dinámicas históricas y locales (Gerholm y Hannerz 1982), configurando diversidades internas como cercanías e interconexiones con otros campos de conocimiento (Guber 2008; Soprano 2006, 2009; Vessuri 1996; Visacovsky, Guber \& Gurevich 1997), dando la posibilidad de conformación de comunidades interdisciplinarias, académicas o redes de cooperación formales e informales (Price 1963 [1972]; Storer 1966; Mullins 1968; Crane 1972; Granovetter 1973) ${ }^{10}$. En su dimensión cultural, las disciplinas arraigan modos diversos de presentación y estilos que se expresan en el quehacer, así como en prejuicios sobre el deber ser de quienes la cultivan y representaciones respecto de aquellos que se consideran como 'los

\footnotetext{
${ }^{9}$ Además, King y Brownell señalan que “... la comunidad mantiene vínculos, tanto afectivos como cognitivos, con el entusiasmo y el placer de la participación con colegas como características comunes... concede importancia al estilo y a la búsqueda de la verdad... posee una concepción explícita o tácita acerca del hombre. Finalmente, la disciplina es una comunidad instructiva." (1966:68).

${ }^{10}$ En esta dirección, Crane (1972) establece la existencia de estructuras de cooperación informal que denomina 'colegios invisibles', destacando que en ellos la "... participación es voluntaria. La producción es muy alta, las fronteras de investigación son difíciles de definir y el acuerdo entre los cientistas está lejos de ser unánime" (p.335). Con anterioridad Price (1963 [1972]) había señalado que en los 'colegios invisibles' no existen criterios de pertenencia explícitos y únicos (aun cuando da cuenta de relaciones construidas en la formación universitaria, congresos, reuniones científicas, amistad, grupo de trabajo), estando por lo general fundados en la calidad científica de los individuos, siendo sus fronteras difusas y en continua modificación, con estructuraciones inciertas y jerarquías inexistentes, lo que denota su grado de informalidad.
} 
otros', y que sin dudas atienden a variantes vinculadas al acontecer histórico, así como también al anclaje en contexto específico (por ejemplo, nacionales, coloniales, etc.). Como oportunamente señaló Klimovsky “... hay buenas razones para creer que este enfoque disciplinar no es realista ni conveniente. Los objetos de estudio de una disciplina cambian a medida que lo hacen las teorías científicas; ciertos puntos de vista son abandonados o bien, en otro momento de la historia de la ciencia, pueden ser readmitidos... Por ello, en lugar de pensar en disciplinas preferimos pensar en problemas básicos que orientan distintas líneas de investigación (Klimovsky 2005: 23 [1994]).

Por otro lado, enfoques situacionales o contextuales traslucen una crítica a concepciones exclusivas de disciplina, y enfatizan las operaciones que tienen lugar en la práctica cotidiana, siendo fundamental la observación de acciones y toma de decisiones. Al respecto, Woolgar plantea que "La imagen ordenada y pulcra que se filtra a través de las explicaciones idealizadas del proceder científico tiene poco que ver con la esgrima de la práctica cotidiana del laboratorio... Las decisiones sobre el tipo de instrumentos a usar, las clases de experimentos a realizar y los modelos de interpretación más apropiados, dependen en gran medida de condiciones, circunstancias y oportunidades locales.” (1991 [1988]:133). Knorr Cetina (1992) señala que la mayoría de los estudios contemporáneos de la ciencia operan con una noción de comunidad de especialistas en tanto grupo organizado social y cognitivamente, lo cual no problematiza que en muchos casos existe rivalidad entre orientaciones teóricas, metodologías y objetivos. Para la autora

"El trabajo científico parece estar inserto en contextos que, por su naturaleza y necesidad, apuntan más allá de las áreas de especialidad por las cuales los contadores de la vida científica puedan clasificar un trabajo. Paradójicamente, el propio trabajo interno de la ciencia demuestra que el internalismo implicado en nuestra preocupación por la comunidades científicas o por los campos de especialidad necesite, finalmente, ser rechazado." (Knorr Cetina 1992:126).

Por ello, mientras en el plano institucional algunos reivindican la exclusión e independencia que se articula desde una visión clásica de las ciencias sociales (Lamont y Molnár 2002), otros 
fomentan la inclusión e interdependencia; por tanto ambas tendencias debiesen ser reconocidas como propias de las dinámicas científico-académicas.

Pensar desde la lógica de la interconexión nos lleva a advertir las dificultades que existen a la hora de establecer de manera clara los límites o fronteras de algunas disciplinas (Gieryn 1983; Becher 1989 [2001]; Shumway y Messer-Davidow 1991; Lattuca 2001; Lamont y Molnár 2002; Wallerstein 2004 [2005]; Dillon 2008); permite dejar expreso el grado de arbitrariedad que ha operado en la distinción de los distintos campos de conocimiento (Gieryn 1983), así como de movimientos y desplazamientos que han tenido como resultado ciertas imbricaciones y solapamientos. Estos mismos movimientos hacen posible registrar en la historia de la ciencia una tensión entre especialización e interacción (Ben-David 1971), lo que tiende a perturbar sistemas rígidos de clasificación y organización del conocimiento como aquellas formas que operan en universidades e instituciones de investigación. Entonces podríamos plantear si más allá de la defensa de “... sus cotos de caza, que muchos de sus miembros defenderían a muerte de ideas quijotescas..." (Wallerstein 2004 [2005]:147), las distintas disciplinas constituyen algo más que formas de organización, estando lejos de conformar entidades autocontenidas con límites bien definidos y contenidos teóricos y metodológicos-, algo así como islas con pequeños e improvisados puentes que conforman el gran archipiélago de las ciencias.

\subsection{Comunidad y redes sociales en las ciencias}

Desde la emergencia del campo de los estudios sociales de la ciencias, ha existido una preocupación por establecer los factores que median en el desarrollo de la ciencia y producción del conocimiento científico, poniendo énfasis en dimensiones institucionales, cognitivas, prácticas y culturales, otorgando preponderancia a aspectos internos (a la ciencia), externos (sociohistóricos) o combinando ambos ${ }^{11}$.

Dentro de estas preocupaciones, el interés por conocer las formas en que opera la comunicación o conexión entre los científicos y de estos con el mundo social ha sido central.

\footnotetext{
${ }^{11}$ Entre las tendencias contemporáneas destacan el 'Programa Fuerte' o 'Strong Programme' (Bloor 1971 [1998]) el 'programa relativisa' o 'Empirical programme relativism' (Collins 1981) y el 'programa constructivista' (Latour \& Woolgar 1979 [1995]; Woolgar 1982; Knorr-Cetina 1992) ${ }^{11}$, la teoría de los campos aplicada a la ciencia (Bourdieu 1997 [2003]; 1999 [2006]; 2001 [2003]), además de algunas perspectivas metodológicas derivadas de la etnometodología y del análisis del discurso científico (Molina 1999).
} 
Así, desde perspectivas institucionalistas o internalistas, surgen una serie de iniciativas que buscan indagar en las estructuras formales e informales que operan en la organización de ciencia, determinando las conexiones que se establecen entre los científicos en el marco de redes de cooperación intelectual, solidaridad y poder (Price 1963 [1972]; Storer 1966; Mullins 1968; Crane 1972; Granovetter 1973). Esta perspectiva ha sido ampliada para rastrea los nexos que se establecen entre científicos, no científicos, recursos técnicos y política científica, lo que se inscribe en marcos situacionales o socio-históricos, lo que aboga por generar una mirada que inscribe las ciencias en la sociedad (Callon y Law 1982; Callon 1986, (2008 [1992]); Knorr-Cetina 1992, 2005 [1981]; Law 1998; Pinch y Bijker 2008 [1987]; Salomon 2008 [2006]). De este modo, se ha cuestionado la representación del espacio científico como constituido por unidades autónomas o circunscritas a estructuras formales, destacando la importancia que cumplen las redes de cooperación y poder en las comunidades de investigadores.

Un trabajo pionero en esta línea fue el realizado por Price (1963 [1972]), quién empleando el término 'colegios invisibles', conceptualizó las organizaciones científicas como aquellas en las cuales circula información y se establecen relaciones intelectuales ligadas a la revisión de ideas y versiones preliminares de artículos (proyectos de artículos, primeros resultados, comentarios de análisis, etc.). Respecto de las características y función de los 'colegios invisibles', Price (1963 [1972]) señala que no existen criterios de pertenencia explícitos y únicos (aun cuando da cuenta de relaciones construidas en la formación universitaria, congresos, reuniones científicas, amistad, grupo de trabajo), estando por lo general fundados en la calidad científica de los individuos, siendo sus fronteras difusas y en continua modificación, con estructuraciones inciertas y jerarquías inexistentes, lo que denota su grado de informalidad. Según Price (1963 [1972]), estas formaciones tienen una importante incidencia en el sistema de producción científica, editando boletines, poniendo en circulación información, reuniendo a investigadores de diferentes estatus en la jerarquía, y favoreciendo el proceso de socialización de los jóvenes investigadores.

En esta dirección, Crane (1972) reintroduce la noción de 'colegios invisibles', destacando que en ellos la “... participación es voluntaria. La producción es muy alta, las fronteras de investigación son difíciles de definir y el acuerdo entre los cientistas está lejos de ser unánime" (p. 335). Estas configuraciones o círculos sociales conforman, además, grupos 
solidarios que aportan solución a lagunas organizativas presentes en el espacio científico, dando lugar, en ciertas ocasiones, a una red de comunicación. De este modo, tras la estructura aparentemente impersonal del conocimiento científico, hay una vasta red interpersonal -afín con el grupo de pares- que revisa las ideas nuevas en términos de un tema o paradigma central, lo que permite que algunas alcancen difusión relegando a otras. Crane (1972) señala que la comunicación es central en la difusión de ideas a través de variadas uniones que pueden ser operacionalizadas en términos de colaboraciones, citas y la influencia de unos a otros en lo que refiere a la selección de problemas de investigación, métodos y cursos de implementación. Además, Crane plantea que "Una proporción sustancial de conectividad aparece solo cuando todos los lazos entre individuos son considerados simultáneamente... Esto sugiere que la organización en un área de investigación es revelada sólo cuando una variedad de diferentes tipos de relaciones entre miembros de un área de investigación son examinados.” (1972:43).

Por otro lado, Mullins (1968) resume los factores sociales relacionados con la actividad científica en las comunidades de investigación, destacando: la comunicación, las co-autorías o colaboración, redes de citas, compañerismo y aprendizajes. Propone que la distribución de propiedades sociales a través de comunidades de investigación puede ser entendida y direccionada por factores sociales como estatus social y propiedades culturales e institucionales de la investigación, lo cual ordena la estructura de una comunidad. Estas consideraciones pueden ser traducidas en preguntas de investigación que se interroguen acerca de: a) las diferentes categorías sociales que afectan la comunicación y las redes, b) la existencia de límites alrededor de ciertos grupos de investigación o redes que son distintas en términos de comunicaciones e intercambio de información, c) la homogeneidad de los agrupamientos con respecto a las categorías como disciplinas, secciones o instituciones, y organizaciones de la investigación o asociaciones (Mullins 1968).

Mullins (1972) clasifica la estructura de la comunidad de investigación en términos de redes de trabajo profesional y actividades sociales de grupo como: paradigmas de grupo, redes de comunicación, agrupamientos y especialidades. En sus investigaciones sobre la comunidad de biólogos moleculares, observa que una especialidad transita a través de las cuatro fases antes mencionadas; en cada una de ellas ocurren varias actividades sociales y en redes. Estas actividades incluyen: a) comunicación (discusiones acerca de las corrientes de investigación a través de conferencias y medios de comunicación); b) coautoría o publicaciones conjuntas de 
investigación (formas más íntimas de asociación entre dos o más miembros que conjuntamente reportan resultados sobre ciertos tópicos); c) aprendizajes en los que un joven investigador es entrenado y formado por un mentor; d) compañerismo (dos o más miembros trabajan juntos en ciertas áreas problemáticas o dentro de una institución o gran comunidad).

Para Storer (1966), el espacio científico constituye un sistema de intercambio con distintos bienes disponibles - diferentes a los bienes económicos-, a través del cual se busca garantizar la independencia frente a dimensiones políticas, sociales, religiosas y económicas. Lo anterior explica el papel que los científicos intentan desempeñar en la organización y regulación de su profesión, buscando reclutar y formar investigadores, motivar a través de sistemas de recompensas, transmitir y ampliar conocimientos, proposición hacia la sociedad de formación, enseñanza y conocimientos por medio de una asistencia financiera. De este modo, Storer (1966) define a la ciencia como un sistema social de interacción organizada en torno al intercambio de un producto único, y conducido por normas comunes que facilitan su circulación; el producto es el reconocimiento profesional del investigador y su contribución al saber de un campo de conocimiento (citas de trabajos, posiciones editoriales, títulos honoríficos, nominación en puestos prestigiosos).

Hagstrom (1965) produce un nuevo enfoque, distanciándose de las perspectivas normativas de orientación mertoniana. Para éste, los únicos principios de regulación responden al mercado; los científicos generan producciones (resultados de investigación) a cambio de reconocimiento asociados a la notoriedad (diplomas, premios, puestos), donde el intercambio de la producción es clave para adquirir importancia en las instituciones. Por tanto, la comunidad científica funciona en base a la competencia y en la existencia de un sistema de recompensas, siendo condición del comportamiento de sus miembros la necesidad de visibilidad para obtener reconocimiento y conseguir un trabajo satisfactorio. Por otro lado, señala que en base al crecimiento, dispersión geográfica y diferenciación interna, las especialidades han desplazado algunas características formales de las disciplinas conformando asociaciones científicas, estableciendo sus propias conferencias, sus publicaciones periódicas y levantando sus grupos de estudios sobre un problema.

Hagstrom (1965) propone una tipología de investigadores que participan en una comunidad, los cuales son diferenciados según la intensidad o grado de socialización, y cuyas categorías son: a) Líderes comprometidos (responde a aquellos que participan en todos los canales que 
cruzan la comunicación, que tienen gran cantidad de publicaciones, reciben reconocimiento formal, participan activamente en asociaciones, y se contacta y es contactado por otros; b) lideres informales (aquellos que poseen mucha productividad y reconocimiento, pero que poseen mayores contactos informales en la comunidad); c) los estadistas científicos o científicos marginales (miembros de reputación en una comunidad, los que dedican mucho de su tiempo a las relaciones con miembros de otras comunidades científicas o no científicos vinculados al campo de prácticas); d) líder orientador de estudiantes (miembros eminentes por sus contribuciones formales, quienes invierten una gran cantidad de tiempo con estudiantes, y se relacionan con una disciplina o comunidad de investigación a través de sus estudiantes, y su reconocimiento proviene en gran parte del éxito de sus estudiantes); e) científico centrado en el estudiante (miembro menos eminente y relativamente productivo para quien el grupo presente y los estudiantes anteriores son casi el único eslabón con la comunidad científica, siendo nombrado principalmente por el trabajo de sus estudiantes, siendo la mayoría de sus relaciones informales vinculadas a sus estudiantes en lugar de sus colegas de departamento o de otras instituciones); f) científico orientado intra-departamento (quien tiene la necesidad fuerte de aprobación interpersonal, y cuya estima está dada por un número reducido de estudiantes, careciendo del prestigio necesario para acercarse con confianza a especialistas fuera de su propio departamento, teniendo que confiar en sus colegas de departamento); g) productivo aislado (quienes han adquirido una reputación considerable y de mucha productividad, en tanto que se encuentran relativamente aislados de contactos informales con colegas dentro y fuera de la comunidad); h) aislado improductivo (quien rara vez se comunica con otros científicos, casi retirados de la vida científica o comunidad, y por consiguiente giran permanentemente en la enseñanza o administración).

Además, basado en las diferencias individuales en las prácticas comunicativas, Hagstrom (1965) desarrolla un inventario de canales de comunicación científica. Entre los más comunes se encuentran: a) la publicación de artículos y libros presentados en reuniones de asociación, que es el más importante canal de comunicación para los puntos de vista de la comunidad; b) contactos a través de reuniones de asociación; c) contactos informales con otros en la misma especialidad pero en diferentes instituciones; d) contacto con colegas del departamento; e) contacto con formados y estudiantes graduados; f) contacto con miembros de diferentes comunidades o con no científicos. Por último, éste señala que la comunicación y conexión de 
una red en una comunidad científica puede agruparse en: a) participación en actividades de comunicación científica y grupos similares, identificables en roles sociales como miembros en directorio de asociaciones, editor de revistas y asesor en comités académicos; b) comunicación extra-departamental o redes, medibles por contactos informales que un investigador tiene con otros en una comunidad pero en otras secciones, instituciones o asociaciones; c) productividad y rendimientos, medibles en el número de artículos o comunicaciones formales por un miembro en un número dado de años; d) honores y premios; e) comunicación intradepartamental, que puede ser medida por la cantidad de tiempo que invierte en la comunicación con colegas de departamento y el número de colegas con quienes tiene contacto y discute investigaciones; f) número de estudiantes graduados y post-doctorados.

Mulkay (1977) señala que las redes de investigación son agrupaciones sociales amorfas, debido a la migración como a la superposición de miembros en constante flujo, siendo conformadas por diversas redes en distintas etapas: formación, crecimiento y declinación. Además, señala que la comparación de grupos sociales pequeños, especialidades o subcampos son particularmente importantes para la construcción de la capacidad de una comunidad de investigación por razones como: a) la investigación intensiva requiere de un campo significativo mediante el cual las actividades de investigación son altamente especializadas; b) hay un límite de tiempo mediante el cual los investigadores se pueden consagrar a buscar, absorber y producir literatura científica y otra información técnica específica a su propia especialidad; c) los investigadores tienden a establecer, en general, comunicación con quienes persiguen problemas de investigación similares.

Estos factores llevan a la constitución de agrupaciones de comunicación, que conforman varias redes, y estructuran la literatura científica y eventualmente las comunidades de investigación. También ha notado que liderar la temprana exploración de un nuevo campo tiende a ser tomada por aquellos con mejor acceso a recursos como: técnicas, estudiantes graduados, fondos de investigación, acceso a las publicaciones y a la aprobación por parte de científicos eminentes.

Trabajos más contemporáneos como los de March (2004), proponen que comunicación y redes son dos proposiciones cruciales que dirigen a partir del intercambio entre miembros investigadores y el desarrollo de la comunidad. Señala como primer punto una proposición acerca del contacto, en la que plantea que los estudiosos, como ocurre con otros seres 
humanos, prefieren la mayoría del tiempo asociarse con personas similares a ellos, que comparten sus historias, experiencias, lenguajes y visiones de mundo. Estas preferencias generan una estructuración social que se construye en torno a la diferenciación, la coherencia y la unificación de sub-grupos. Como segundo punto, introduce la dimensión intersubjetiva del conocimiento; señala que la tendencia a la diferenciación de los discursos enriquece y otorga valor a la comunidad de investigación. Sin embargo, la tendencia a la asociación entre aquellos con quienes se coincide -y que son en virtud del conocimiento, más familiares y comparten sus creencias-, implica a su vez que se genere un aprendizaje relativamente bajo. Estos dos aspectos dan cuenta de la naturaleza amorfa y la complejidad de la comunicación en la investigación y la conexión de las redes entre los miembros en una comunidad científica, en la cual el ensamble ocurre en concordancia con situaciones, contextos diferentes, y en grados variables.

La discusión contemporánea ha refrescado e introducido nuevas perspectivas de análisis de la comunidad científica. Bourdieu (1997 [2003]) introduce con claridad la dimensión del poder constitutivo de la ciencia y de la vida social- en lo que denominó campo científico; aun cuando no incorpora explícitamente la noción de red, esta puede entenderse como parte de las estrategias posibles de desplegar en el campo. Como señala, el universo puro de la ciencia más pura es un campo social como cualquier otro, en el cual tienen lugar luchas por la dominación, y cuyo objetivo es el monopolio de la autoridad científica legitimada en tanto capacidad técnica y poder social. Este campo se constituye por dominados y dominantes, por estrategias de conservación o de subversión y cuya estructura se define por la distribución desigual del capital (Bourdieu 2001 [2003]); la 'comunidad científica' o los científicos (desde sus habitus) entran en juego en el campo específico de la ciencia, ese mercado, lugar de luchas y competencias en la cual se busca la acumulación de capital simbólico o científico. De éste modo, Bourdieu (2001 [2003]) se manifiesta crítico de los trabajos efectuados por algunas tendencias en sociología y estudios sociales de la ciencia, en tanto operan desde una lógica que desconoce la intencionalidad, el cálculo y el cinismo en la ciencia. Para el autor, la primera propiedad singular del campo científico es la limitación que regula el acceso, y que se desprende del hecho de que todo investigador no tiene más receptores que aquellos más adecuados para entenderlo, para criticarlo, desmentirlo o refutarlo. Una segunda propiedad, que da forma a la censura, refiere a que la lucha científica tiene como objetivo el monopolio 
de la representación científicamente legítima de lo real, y los investigadores, aceptan tácitamente el arbitraje de lo real. Como última referencia, Bourdieu señala que "La lucha científica también debe su especificidad... al hecho de que los competidores por el monopolio de la representación legítima de la realidad objetiva... disponen de un inmenso equipo colectivo de construcción teórica y de verificación o falsificación empírica cuyo dominio se exige a todos los participantes en la competición... Ese equipo no cesa de incrementarse con las nuevas conquistas de la investigación, conquistas en materia de conocimiento del objeto que son inseparables de las conquistas en materia de instrumentos de conocimiento (2001 [2003]: 125-126).

Por su parte, Gibbons (1997) advierte la conformación de un escenario que deriva en una nueva forma de concebir la ciencia y el trabajo científico al que denominó modo 2, que se sostiene en la idea de complejidad, dinamismo y adaptación en el marco de una realidad cambiante. Para Gibbons (1994), lo que caracterizaría esta nueva forma o modelo tendría relación con: a) producción de conocimiento en el contexto de aplicación, que contrastaría con la forma tradicional ligada a intereses exclusivamente académicos, donde el punto de partida serían las posibilidades de aplicación y de generación las cuales no sólo serían definidas por el mercado sino que también implicarían y alcanzarían a la sociedad; b) la incorporación de una perspectiva de abordaje transdisciplinaria, que se distancia de la aproximación disciplinaria de abordaje, y que se caracteriza por sostenerse en una modalidad de consenso que se basa y evoluciona con el contextos de aplicación, en tanto que la solución a problemas involucra necesariamente a un conjunto de actores y de competencias, y en el cual los canales de comunicación se retroalimentan en el proceso acorde a la dinámica que adquiere el proceso de conocimiento; c) la asunción de un punto de vista heterogéneo, donde la universidad no se reconoce como única fuente de conocimiento - se incluyen laboratorios, consultorías, institutos no académicos, centros de investigación y organismos públicos-, los que se incorporan e interactúan a través de redes, integrando la diversidad de puntos de vista en un nueva configuración que hace hincapié en la generación de conocimiento útil y colaborativo en una estructura vertical y altamente jerarquizada d) mayor reflexividad y responsabilidad social, lo que se refleja tanto en la interpretación, difusión de los resultados, como en la definición de problemas y áreas prioritarias de investigación, incorporando desde el principio potenciales impactos y la opinión de grupos de interés en el marco de toma de 
decisiones y definición de las políticas de aplicación; e) un modo más amplio de control de calidad, no sólo considerando la competencia especializada, sino también incorporando una serie de actores y criterios de índole social, política y económica, adquiriendo una visión multidimensional.

También cabe destacar otras propuestas que han tenido eco y aceptación, y se refieren a la vinculación que se establece entre universidad, empresa y Estado, como lo es el modelo de triple hélice, un intento de superación de la propuesta de Gibbons (1994). Este sostiene la alianza o imbricación entre estos actores como impulsores de mayor innovación y competitividad en el ámbito de la generación aplicada de conocimientos, superando modelos lineales como el de 'demandas del mercado' en la transferencia de conocimiento y tecnología (Etzkowitz \& Leydesdorff 2000). Para estos autores, es un modelo destinado a impulsar la innovación de tipo emergente, en el que se concibe cada hélice (universidad-empresasociedad) como en un proceso continuo de redefinición interna, donde la interacción y redes de cooperación son potencial para el conocimiento innovador, los recursos económicos y las posibilidades de mercado, y las normas e incentivos de las políticas públicas de innovación.

Una perspectiva innovadora es introducida por los trabajos de Latour y Callon ligados a la teoría del actor-red, y específicamente a lo que se ha denominado red extendida o simétrica, la que incorpora entidades humanas y no-humanas en el análisis. Para Latour (2005 [2008]), la cuestión no es presuponer un orden, sino “... seguir a los actores mismos... ponerse al día con sus innovaciones a veces alocadas, para aprender de ellas en qué se ha convertido la existencia colectiva en manos de sus actores, qué métodos han elaborado para hacer que todo encaje, qué descripciones podrían definir mejor las nuevas asociaciones que han sido obligados a establecer." (p.28). De lo anterior se desprende la idea de co-construcción de la sociedad y la naturaleza, donde se entiende que sujetos sociales concuerdan sobre una teoría o respecto de determinados resultados de investigación debido a que se produce un proceso simultáneo de construcción social y del hecho científico. Ponen énfasis en cómo se acepta el producto de la ciencia en un espectro mucho más amplio que el laboratorio o el contexto de origen. En esta línea, Callon (1986) propone una sociología de la traducción, donde en el proceso de imbricación entre hechos y actores asociados tienen lugar cuatro momentos: a) problematización, o la intención en que la definición de un problema sea de interés y definición para otros actores, intentando además volverse indispensables; b) participación, en 
el cual se concreta la alianza entre actores y formando una estructuración social que bloquee a asociaciones competidoras; c) enrolamiento, que consiste en la atribución y aceptación de un rol por parte de un actor; y d) movilización, implicando los diferentes actores en asociaciones por medio de voceros, quienes tienden a hablar en representación de otros, reduciendo el número de interlocutores y con ello, homogenizando puntos de vista, intereses y lenguajes.

Para efectos de esta investigación, resulta relevante considerar el trabajo orientado a definir explícitamente lo que entiende Callon (1986) por una red personal de un investigador. En una red personal intervendrían una serie de interlocutores humanos (colegas, investigadores competidores, mundo académico, agencias públicas, servicios administrativos de empresas) y no humanos (las entidades que el investigador examina o analiza). Por otro lado, incorpora una distinción entre redes cortas y redes largas, estas últimas, configuraciones estabilizadas, las que se entienden en lo que denomina colectivos de investigación, a partir de los cuales se daría cuenta de la dinámica de las transformaciones de los conocimientos de innovación. De este modo, se pasa desde la noción de red a la de grupo; "Un colectivo de investigación pone en contacto un conjunto de personas (ingenieros, investigadores, expertos, tanto como usuarios, legos vinculados, etc.) que interactúan con frecuencia entre sí. Dividen los problemas a resolver, ponen en común sus saberes y sus competencias y establecen cooperaciones abiertas. Las relaciones personales basadas en la confianza, los intercambios que favorecen, los proyectos comunes que nutren, explican cómo poco a poco los conocimientos, incorporados o codificados, se diseminan, pero también cómo nuevos individuos pueden reclutarse sean cuales fueran sus afiliaciones institucionales. No es la red la que se extiende, son los colectivos de investigación que crecen asociando nuevos miembros, hibridando competencias y diseminándose de a poco.” (Callon, 2003:709 en Grosetti 2007:96).

\subsection{La vocación interdisciplinaria y pluri-paradigmática de la antropología}

Contraria a la autorreferencialidad percibida por Margaret Mead (1984) ${ }^{12}$, las conexiones de la antropología con otras disciplinas quedan reflejadas tanto en instancias institucionales

\footnotetext{
${ }^{12}$ En el capítulo titulado "La antropología entre las ciencias”, Mead realiza afirmaciones como las siguientes: “... el gran conjunto de mujeres y hombres llamados antropólogos se relaciona muy pobremente con las otras
} 
(Thompson 1961 [1965]; Lévi-Strauss 1968 [1995]; Hannerz 1980 [1986]; Geertz 1995 [1996]; Visacovsky, Guber y Gurevich 1997) como en investigaciones en cuya problematización se incorporan (Tylor 1889; Rivers 1913; Boas 1920 [1997], 1924 [1997); Malinowski 1922 [1975]), Park 1928 [1999]; Kardiner 1939; Linton 1945 [1959]; Mauss 1947 [2006]; Goodenough 1957; Mitchell 1967 [1969], 1966 [1999]; Levi-Strauss 1968 [1995]) o reconocen diversos aportes teóricos y metodológicos generados en otras disciplinas (Harris 1968 [2006]; Leach 1975; Lewis 1975; McEwen 1975; Urry 1984; Auge 1994 [1998]; Vidich \& Lyman 1994; Jociles Rubio 1998; Stocking 2002; Mora 2010, 2011). En tanto, la variabilidad a nivel de objetos, teoría y métodos ha sido abordada desde perspectivas que enfatizan la dimensión internista de la antropología, esto, en el marco de la teoría antropológica (Evans-Pritchard 1962 [1990]; Mercier 1966 [1969]); Cuche 1966 [2002]; Kaplan y Manners 1968; Rossi y O’Higgins 1980 [1981]; Luque 1985 [1990]; Ulin 1984 [1990]; Reynoso 1998) así como desde aquellas que realzan -de manera tenue o en propiedadel contexto social y político en la cual se inserta y desenvuelve (Harris 1968 [2006]; Asad, 1973; Kuper 1973 [1996], 1990 [2001]; Bonte 1974 [1975]; Llobera 1974; Azcona 1987; Vidich y Lyman 1994; Krotz (1994 [2002]; Bovini, Rosato y Arribas 1998; Clifford 1998 [2001]; Ben-Ari 1999; Geertz 2002; Guber y Visacovsky 1999; Guber 2008) ${ }^{13}$.

Respecto de su vocación interdisciplinaria, Stocking releva el carácter de fusión que la antropología posee, siendo "... profundamente interdisciplinaria tanto en su origen como en su constitución.” (2002:14), carácter que también han expresado autores clásicos. Kardiner señalar que "El hecho de que cada una de las disciplinas pueda llevar una existencia independiente indica que tiene una labor propia. En circunstancias constituyen un obstáculo cuando tratan de colaborar en un problema de interés común, por cuanto no pueden incomprenderse mutuamente. Es evidente, por lo tanto, la necesidad de encontrar la forma de que la experiencia de cada una de las disciplinas sea asequible a la otra." (1939 [1945]:27);

ciencias. Dentro de la antropología misma, ellos encuentran en muchos y variados casos cierta repugnancia para cruzar los límites de la disciplina...Uno de los subproductos de tal enfoque ha sido el desarrollo de tres disciplinas paralelas - antropología, sociología y psicología- cada una obstaculizada en su manera peculiar sus relaciones con las otras ciencias y cada una reivindicando para sí, como su contenido gran parte del mismo material de las otras. La originalidad y los reclamos jurisdiccionales de cada ciencia son, desde luego, enérgicamente avasallados de intento por la persistente y mutua ignorancia de la tarea de unas y otras y por el fracaso de las tres en conservar la armónica comunicación con las distintas ciencias de la vida y los esquemas conceptuales y la instrumentación que ellas emplean."

${ }^{13}$ Ya sea en el marco del sistema colonial o de la construcción de la nación y la ciudadanía, en su vinculación con categorías teóricas y/o perspectivas epistemológicas. 
Firth, plantea que "Cuanto más se aproxime el antropólogo al examen de la civilización contemporánea, tanto más deberá tener en cuenta el aporte de las otras ciencias sociales para la solución de los problemas." (1951 [1971]:33); Beattie, para quien "Los antropólogos sociales, más que otros científicos sociales, necesitan tener por lo menos un leve conocimiento de algunos de los conceptos y métodos de muchas otras disciplinas... [lo que se debe a que] en las sociedades más simples y pequeñas que generalmente estudian, muchas de las relaciones y valores sociales institucionalizados en que están interesados pertenecen a campos estudiados por otras disciplinas especializadas en culturas más complejas.” (1964 [1986]:51); Gluckman y Eggan, quienes sostienen que "A medida que se independizaban entre sí las diferentes antropologías, los respectivos especialistas recurrían a otras ciencias cuyas técnicas y métodos de análisis se adecuaban más a sus problemas que los de sus antiguos colegas... [agregando que]... Aparentemente, el rasgo común de la antropología social, cultural y psicológica era su carácter comparativo y multidisciplinario...” (1966 [1999]:13-14) ${ }^{14}$. En cierto modo, éste carácter también es reconocido por Harris y Lévi-Strauss. Para el primero, “... la correcta comprensión de las opiniones del período que precedió inmediatamente a la cristalización formal de las especialidades científico sociales, resulta absolutamente necesaria una cierta dosis de calculada indiferencia ante los límites disciplinares existentes. Sin duda sería útil mantener esa indiferencia y la consecuente ampliación del campo de visión hasta el momento actual, dado que la teoría antropológica contemporánea comparte muchos de sus rasgos con las disciplinas adyacentes.” (1968 [2006]:6). Para el segundo, la antropología era aún una ciencia en desarrollo la cual se encuentra asociada a otras disciplinas, por tanto “... lejos de aparecer en el escenario del desarrollo científico como un cuerpo autónomo que reivindica su lugar entre otras disciplinas, cobra forma un poco a la manera de una nebulosa, incorporando progresivamente una materia hasta entonces difusa o repartida de otro modo, y determinando, por efecto de esta misma concentración, una redistribución general de los temas de investigación entre todas las ciencias humanas y sociales.” (1968[1995]:360).

Por otro lado, la antropología aparece caracterizada -y problematizada- desde sus orígenes por: su amplitud y variedad de métodos (Kluckhohn 1949 [1957]); el desarrollo de escuelas, “...

\footnotetext{
${ }^{14} \mathrm{Al}$ respecto, Gluckman y Eggan agregan que "Los antropólogos físicos se apoyaban más en las ciencias biológicas; los antropólogos psicológicos (que estudiaban la interacción entre cultura y personalidad) en la psicología, especialmente en la psicología profunda y en la psiquiatría, y los antropólogos sociales en la sociología, la historia, las ciencias políticas, el derecho y la economía (1966 [1999]:13).
} 
sectas que dependen de un lenguaje esotérico, hostilidad a otras escuelas, lemas, vocabulario idiosincrásico y controversias que impiden efectivamente el contacto con los miembros de otras sectas dentro de la antropología y con miembros de otras ciencias" (Mead 1984); el desarrollo de estilos nacionales de antropología en tanto particularidades que perfilan especializaciones y marcos cognitivos ligadas a los sistemas educativos y aspectos de la vida intelectual y circunstancial de cada contexto nacional (Thompson 1961 [1965]; Gluckman y Eggan 1966 [1999]; Gerholm y Hannerz 1982; Cardoso de Oliveira 1990; Vessuri 1996).

Esto habría llevado a la continua separación en sub-campos de la antropología, donde se releva que la especialización no permite hablar de un discurso y un conjunto compartido de términos entre sus practicantes (Wolf 1984), destacando la imposibilidad de ser pensada como un paradigma común o único (Ortner 1984) ${ }^{15}$ dando lugar a tantas perspectivas como antropólogos existen (Peacock 1989). Algunos sostienen que la antropología habría sido tomada por místicos, fanáticos religiosos y culturalistas californianos, y que las reuniones en la Asociación Americana de Antropología eran dominadas por chamanismo, brujería, estudios anormales, y que las ponencias científicas sobre investigaciones empíricas habían sido excluidas premeditadamente (Harris 1978 en Ortner 1984), en tanto que otros expresan la tendencia a exhibir “... una imagen borrosa de sí misma... amplia, general y de grandes aspiraciones $(<<$ el estudio del hombre $>>)$, y al mismo tiempo particular, miscelánea y obsesionada con cosas raras...". (Geertz 1995 [1996]:101). Así, mientras que algunos argumentan la imposibilidad de pensarla como disciplina más allá de los esfuerzos de disciplinamiento y confesiones de fe (Geertz 1995 [1996]), e incluso algunos plantean su muerte (Reynoso 1992) o disolución en las especialidades (Needham 1970, en Llobera 1974), otros identifican ciertos aspectos que brindan un grado de identidad, articulación o continuidad en algunas etapas de su desarrollo histórico, ya sea en base a un enfoque y aparatos teóricos y prácticos (Levi-Strauss 1968 [1995]), a la concepción de praxis (Ortner 1984), una metodología (Yates 1985 en Becher 1989 [2001]); una matriz disciplinaria (Cardoso de Oliveira 1999, 2004), un contexto de institucionalización y profesionalización, así como problemas y aproximaciones teórico-metodológicas (Menéndez 1991).

\footnotetext{
${ }^{15}$ Ortner (1984) plantea que a pesar de las diferentes perspectivas que han tenido lugar en antropología, y que pueden ofrecer un panorama caótico, está surgiendo una nueva estructuración teniendo como núcleo el concepto de praxis.
} 
Por tanto, habría que concluir que la antropología no constituye una "empresa estable", uniforme u homogénea; como señala Geertz "Otros campos también cambian, por supuesto, algunos más rápida o fundamentalmente incluso, pero pocos lo hacen de una forma tan poco metódica como la antropología. Ella se altera como una moda, una actitud o un clima de opinión" (1995 [1996]:103) $)^{16}$.

Pero esta imagen dinámica y heterogénea que caracteriza a la antropología, que para Geertz sería una constante, parece ser compartida -en mayor o menor medida- por otras disciplinas de las ciencias sociales. Así, frente al consenso que se articula en torno a la 'naturaleza' multiparadigmática (Ortner 1984; Cardoso de Oliveira 1993 [2004], 1996) o en "equilibrio poliparadigmático" de la antropología (Stocking en Cardoso de Oliveira 1996), la sociología exhibe una condición similar, marcada por periodos de pluralismo teórico, así como de integración y desintegración (Johnston 1998), y por “... el vago y cambiante carácter de gran parte de su conocimiento, sus tendencias a las modas teóricas pasajeras y lo trillado de algunas de sus leyes." (Jones 1976 en Becher 1989 [2001]:63). Esto también es resaltado por Sztompka (2009), para quien la sociología siempre ha sido una disciplina pluralista y multiparadigmática respecto de sus teorías y métodos, cuestión que esta cruzada por los paradigmas vigentes y por los contextos sociopolíticos e ideológicos. Esto sería una constatación de la diversidad de objetos de investigación -y por ende teorías y métodos- que han sido construidos o dinamizados por ambas disciplinas desde sus inicios, situación que puede dejar en evidencia las conexiones y 'cruces de fronteras' 17 .

\footnotetext{
${ }^{16}$ Este punto es abordado con mayor profundidad en Geertz (2002), en el apartado que denomina "una explosión de paradigmas". Allí señala que en antropología se hace patente "El sentimiento de un campo que está quebrado en más pequeños y pequeños fragmentos inconmensurables, la unidad primordial se fue perdiendo en un enjambre de novedades y modas, creció produciendo lamentos, enfadado, desesperación... Tipos y variedades de antropología, concebidas y organizadas separadamente aparecieron, una sobre la próxima: antropología médica, antropología psicológica, antropología feminista, antropología económica, antropología simbólica, antropología visual, antropología del trabajo, de la educación, de la ley, de la conciencia; etnohistoria, etnofilosofía, etnolingüística, etnomusicología."(p.10).

${ }^{17}$ Entre muchos ejemplos de investigaciones interdisciplinarias, se puede referir la 'Expedición Cambridge' encabezada por Alfred Haddon y William Rivers-, una de las primeras empresas de investigación vinculada a la antropología. Por otro lado, entre los años ' 40 y '70 es posible identificar varias iniciativas interdisciplinarias producidas en Norteamérica, entre las que Thompson (1961 [1965]) destaca: la conducida por Whiting entre los Kwoma de Nueva Guinea; el experimento Hawthorne llevado por la Escuela de Administración de Negocios de Harvard y la Compañía Western Electric, con la colaboración Abram Kardiner y Ralph Linton; el estudio sobre el pueblo Alor llevado por Cora DuBois; y el proyecto de Educación, Personalidad y Administración Indígena encargado por el Servicio Indigenista de los E.E.U.U. al Comité de Investigaciones Educativas de los Indios de la Universidad de Chicago - encabezado por W. Lloyd Warner-, entre otros. Otras instancia a destacar corresponden a: la creación del 'Departamento de Relaciones Sociales de la Universidad de Harvard' presidido por Talcott
} 
Respecto a los factores que han gatillado dichas dinámicas, encontramos énfasis en aquellos referidos al contexto social, político y académico-institucional, desencadenando lo que se ha denominado 'la vuelta a casa de la antropología' (Burgess 1984; Peirano 1998; Stocking 2002) y todo un movimiento crítico que denuncia las bases colonialistas, cientificistas y de alianza con la política de Estado (Asad 1973; Llobera 1974; Ben Ari 1999; L’Estoile, Neiburg, Sigaud $2002)^{18}$, planteándose la posibilidad de una redefinición en tanto proyecto político de liberación y transformación social (Harrison 1991); esto llevaría a una paulatina revisión y 'reinvención' que atraviesa planos ideológicos, éticos, teóricos-metodológicos y epistemológicos. Sobre este punto, Stocking señala que "En el mismo periodo en que empieza a ser percibida una $<<$ antropología mundial $>>$, había fuerzas históricas en funcionamiento que, en el último tercio del siglo, habían de problematizar y redefinir las cambiantes fronteras de la antropología."(2002:25), mencionando como aquellas fuerzas: el final del colonialismo independencia y conformación de nuevas naciones a partir de los '60-, las "intrigas ultramarinas" de los Estados Unidos en la guerra fría contra el comunismo internacional y su incursión en el sudeste asiático, y la contracultura y resistencia política entre la juventud en países capitalistas avanzados. Estos movimientos, que redefinen las fronteras de la antropología, se vinculan a aproximaciones y temáticas que emergen o son recuperadas desde

Parson -animado por la 'teoría de la acción social'- el cual integró sociología, antropología, psicología clínica y psicología social (Kuper 1999 [2001]; Geertz 2002); el Centro de investigaciones Rusas de la Universidad de Harvard -Centro de estudios y formación interdisciplinario-, cuyo primer director -en 1950- fue Clyde Kluckhohn; el 'Laboratorio de Relaciones Sociales de Harvard', conducido por el sociólogo y estadístico Samuel Stouffer (Geertz 2002); el 'Instituto de Ciencias Sociales de la Universidad de Princeton', fundado por Geertz en los años '70 (Geertz 1995 [1996]); el Centro de Investigaciones Superiores INHA en México -hoy CIESAS. Por otro lado, y como resalta Hannerz (1980 [1986]), cabe destacar el fructífero intercambio, posibilitado por la atmósfera intelectual reinante en esta época, entre sociología y antropología en la Universidad de Chicago -la división entre el departamento de antropología y sociología se produce sino hasta 1929, situación que se constata en otras Universidades. Así lo señala Lévi-Strauss, quien afirma que excepto en Gran Bretaña, en otro países es casi imposible identificar antropología como disciplina autónoma ya que en “... muchos departamentos universitarios, sobre todo en los Estados Unidos, se denominan «de antropología y sociología», de "antropología y ciencias sociales» y otros títulos equivalentes". (1968 [1995]:359). Esta situación también es posible de visualizar en Latinoamérica, quedando expresa en la particular estructura de los programas de formación universitaria brasileña, lo que hace posible la especialización e investigación en varios campos; o ciertas tendencias a la vinculación entre sociología y antropología promovida por Gino Germani expresadas en la incorporación del antropólogo Ralph Beals en la carrera de Sociología de la Universidad de Buenos Aires en la década de los '60, así como las conexiones entre disciplinas en el origen y desarrollo de la Carrera de Antropología de la Universidad de Buenos Aires (Visacovsky, Guber \& Gurevich 1997). Se podrían señalar muchos otros ejemplos.

${ }^{18}$ L'Estoile, Neiburg, Sigaud (2002) señalan que frente a la denuncia de una antropología al servicio del colonialismo y expansión del capitalismo, se denuncia también una antropología militante o al servicio de las minorías, cuya politización “... se constituye en obstáculo para el entendimiento de procesos sociales implicados en la producción de conocimiento y de sus efectos sobre el mundo social.”(p.10). 
fines de los '60, y que guardan relación con: el pensamiento marxista y temáticas referidas al poder y la dominación, el interés que despiertan los movimientos sociales de resistencia, las dimensiones sociales y culturales ligadas a la crisis ecológica, la emergencia de las temáticas de género - y denuncias de androcentrismo-, acercamiento a las humanidades y la recuperación de la tradición hermenéutica y fenomenológica, y la revisión crítica de la antropología y al proceso etnográfico desde las implicancias ideológicas y éticas, y que dio origen a lo que se denominó la "crisis de la representación" y el desarrollo de etnografías experimentales (Marcus y Cushman 1982 [1992]; Ortner 1984; Harrison 1991; Cardoso de Oliveira 1996; Goddard, Llobera \& Shore1996; Geertz 2002; Stocking 2002).

\subsection{Antropologías mundiales, antropología periférica, antropología latinoamericana}

Por otro lado, y como manifestación de los procesos autocríticos que se fueron desarrollando en antropología desde finales de los '60, surge lo que se ha tendido a llamar una 'antropología de la antropología' (Gerholm y Hannerz 1982; Peirano 1991, 1998; Krotz 1993, 2006) ${ }^{19}$, y cuya problematización ha dado lugar a la conformación de una serie de 'programas de investigación' afincados en redes de comunicación científica que se expresan en reuniones, congresos, publicaciones e investigaciones ${ }^{20}$. Estos han derivado en discusiones que apelan a diferenciaciones a nivel de determinados modelos de ciencia y formas de concebir la antropología - para algunos, la manifestación de una crisis-, en la priorización de ciertas temáticas y perspectivas analíticas, así como la necesidad de distanciamiento y develación del

\footnotetext{
${ }^{19}$ Restrepo y Escobar (2004) señalan que 'Reinventing Anthropology' editado por Hymes en 1969, representa el primer llamado hacia la realización de una antropología de la antropología. Aun cuando circunscrito a la antropología angloamericana, trabajos como los de Hymes, Scholte y Diamond, señalan la necesidad de hacer de la antropología un objeto de reflexión, de modo de analizar los fundamentos epistemológicos, institucionales y políticos de esta.

${ }^{20}$ Algunas referencias a las primeras instancias son las siguientes: la 'I Reunión para la integración de la Enseñanza con las Investigaciones Antropológicas', realizado en Burg Wartenstein, Viena, en 1967; la 'II Reunión para la integración de la Enseñanza con las Investigaciones Antropológicas', realizada en Ciudad de México en 1968; la reunión llevada a cabo en Burg Wartenstein, Viena, en 1978, con el título 'Indigenous Anthropology in Non-Western Countries'; la 'I Reunión Técnica de Antropólogos y Arqueólogos de América Latina y el Caribe', desarrollada en la Hacienda Cocoyoc, Morelos, México, en 1979; la reunión 'Rumos da Antropologia', realizada en Río de Janeiro, Brasil, en 1980; 'The zapping of National Anthropologies, que da origen a la publicación homónima realizada por la revista Ethnos; la reunión 'A Antropologia na América Latina', llevada a cabo en Brasilia, en 1987 (Cardoso de Oliveira 1999).
} 
dominio que establecen los centros hegemónicos de producción antropológica. Estas reflexiones representan una búsqueda de especificidad que se expresa en las denominadas: antropologías nacionales (Gerholm y Hannerz 1982), de la construcción del imperio y construcción de la nación (Stocking 1982); nativas (Jones 1970 [1988]; Narayan 1993; Kuwayama 2003); indígenas o no occidentales (Fahim y Helmer 1980), periféricas (Cardoso de Oliveira 1999, 2004; Grimson y Semán 2004), subalternizadas o no hegemónicas (Restrepo y Escobar 2004; Restrepo 2006), del sur (Krotz 1993, 2006; Vázquez 1993), o latinoamericanas (Jimeno 2005).

Gerholm y Hannerz (1982) hacen mención a una serie de aspectos o dimensiones relevantes a considerar en el análisis de las antropologías nacionales; estas adquirirían sus particularidades frente a la antropología internacional -que sería la suma de los puntos de vista nacionales- a partir de “... la influencia en la situación nacional, el estilo de pensamiento o clima de opinión; las particularidades de la estructura académica en los diferentes países; las características del bagaje y entrenamiento de los antropólogos; los grados de diversidad entre la disciplina en el país; tendencia a largo plazo ..." (p. 5-6). Lo interesante de la reflexión de estos autores, es que reconocen la insuficiencia de abordar una caracterización de estilos nacionales como estilos cognitivos o teóricos al margen del contexto nacional, y sobre todo, de una caracterización del sistema educacional nacional, de la vida intelectual del país y la constelación de eventos y circunstancias que parezcan dar lugar a sensibilidades especiales, a la experiencia de una generación particular. Por otro lado, frente a la distinción nacional/internacional introduce otra: centro/periferia. Esta distinción representaría relaciones estructuradas asimétricamente tanto en el plano internacional -entre las diferentes antropologías nacionales- como nacional -entre diferentes instituciones como universidades o colleges- (p.21), mencionando entre aquellos mecanismos de consolidación de las asimetrías: la posición desigual en la industria editorial, la producción en un lenguaje que predomina sobre otro, los recursos gubernamentales y privados, la formación que los estudiantes reciben en las antropologías de las metrópolis, así como las misiones de antropólogos de las metrópolis, que extienden la legitimación de estas en la periferia y en las antropologías nacionales (p.9). Discusiones contemporáneas han recuperado análisis basados en las relaciones centro-periferia, la dependencia y asimetría construidas en relación a ciertas potencias económico-sociales respecto de países o regiones periféricas representadas por 
América Latina, África, Asia y Europa oriental, y el tipo y posibilidades de la producción científico social y del desarrollo de disciplinas particulares. Desde una lectura internacional y que trasciende a la antropología, destaca el trabajo de Patel (2009), al cual se suman aquellos que reflexionan en el contexto Latinoamericano desde una nueva lectura de la teoría de la dependencia (Beigel 2006, 2010, 2011; Falero 2006), desde la geopolítica de conocimiento y la colonialidad del saber (Lander 2000; López 2000; Mignolo 2000, 2002; Quijano 2000; Castro-Gómez, Schiwy, Walsh 2002; Walsh 2002), o desde la necesidad de endogenizar la ciencia y la tecnología, en post de una desoccidentalización y/o deseuropeización de su puesta en práctica en realidades particulares de América Latina. (Vessuri 2007).

Por otro lado, Stocking (1982) introduce la distinción 'antropologías de la construcción del imperio' -característica de algunos países anglosajones y europeos como Inglaterra, Francia, Alemania- y 'antropologías de la construcción nacional' -representado por Estados Unidos-, diferenciación que no sólo refiere al ámbito geográfico -más allá de la frontera nacional, o al interior de la nación-, sino que también se vincula con una determinada política y con el perfilamiento-tradición del objeto de estudio y de perspectivas teóricas en los centros. Además, distingue en el plano de la antropología internacional -que en un momento fue eminentemente euro-americano- como ella se dinamiza a la luz de procesos sociopolíticos y disciplinarios, siendo características las relaciones centro-periferia, donde se perfilan tradiciones nacionales hegemónicas representadas por países dominantes en la historia de la ciencia moderna (p.178) que ejercen influencia en la periferia. Al mismo tiempo destaca la diversidad presente en las antropologías metropolitanas y periféricas, lo que matiza la tendencia a homogenizar ambos polos. Identifica tradiciones hegemónicas como la británica, francesa, alemana, norteamericana y soviética, en tanto diferencia otras tradiciones como: la 'metropolitana secundaria' representada por Suecia y Polonia; la de 'asentamientos blancos' representada por Canadá anglófona, Quebec y Brasil; y las ex-colonias representadas por India y Sudán.

Otra categoría que emerge es la de 'antropología nativa' y 'antropología indígena'. Jones (1970 [1988]) la define como “... un conjunto de teorías basadas en preceptos y asunciones no occidentales en el mismo sentido que la antropología moderna se basa y sustenta en las creencias y valores occidentales...” (p. 30-31). Para Jones (1970 [1988]), el antropólogo nativo mira los fenómenos sociales desde un punto de vista diferente del antropólogo 
tradicional, el cual tiende a estar en favor del propio grupo; sin embargo, la formación o entrenamiento que los antropólogos reciben en las universidades obscurece lo que pudo emerger como un punto de vista nativo distinto -a nivel de las teorías y métodos-, cuestión que ha ido cambiando a través de la formación en las bases y juicios presentes en las ciencias sociales, no limitados por los valores de objetividad y neutralidad. Señala que la emergencia de una antropología nativa “... es parte de una descolonización esencial del conocimiento antropológico y requiere cambios drásticos en el reclutamiento y entrenamiento de antropólogos."(p.39).

Por otro lado, la dicotomía nativo-no nativo ha sido problematizada por autores como Narayan (1993) y Kuwayama (2003). Narayan (1993), quienes exponen la complejidad de asignar el estatus de nativo a quienes tienen múltiples experiencias culturales y trabajan entre comunidades que ellos consideran su casa. Al respecto, discute la asignación de una frontera fija entre nativos y no nativos, y señala que en el contexto actual, se debe reflexionar profundamente en las múltiples y cambiantes identificaciones más allá de los inmanentismos nacionales o culturales, y profundizar en cómo estas están cruzadas por la educación, el género, la orientación sexual, la clase, la raza. Al respecto, habría que agregar que el mundo social se compone por una pluralidad de sentidos que pone en entredicho la idea de univocidad de la realidad; la dimensión subjetiva emerge como una posibilidad de interpretación que se encuentra ligada a la posición y el locus de socialización del sujeto, lo que lleva a relativizar dicotomías totalizantes que buscan establecer la dicotomía nativo-no nativo afincada en la ubicación geográfica o nacionalidad del antropólogo. Realidades altamente desintegradas o jerarquizadas hacen pensar en la natividad como una cuestión más compleja tal como advierte Narayan (1993); el foco de atención debe estar puesta en la calidad de las relaciones que establecemos con las personas que nosotros buscamos representar en nuestros textos, viendo si sólo están al servicio de nuestros intereses profesionales con miras a la generalización acerca del otro, o si son considerados como sujetos con sus voces, puntos de vista y dilemas personales garantizando lazos recíprocos e inclusive críticos de nuestra empresa profesional (p.672).

Kuwayama (2003) da cuenta de dos concepciones de nativo en antropología: como objeto de representación, excluidos como agentes activos en la lectura y escritura etnográfica, y rara vez reconocidos como co-autores; como esfuerzo de superación del eurocentrismo o la hegemonía 
de la academia occidental en un contexto post colonial, donde la antropología nativa disuelve las fronteras entre colonizar-ver-describir-conocer y colonizando-viendo-describiendoconociendo (p.8). El nativo sería parte del proceso de construcción antropológica y disminuyendo la brecha de poder tejida entre investigador e investigado. Define al antropólogo nativo como aquel que pertenece a la comunidad investigada, no pudiendo ser considerados como nativos en un sentido estricto, pues en muchos casos viven fuera de las comunidades y trabajan en instituciones educativas en las ciudades (p.9) -no compartiendo todas las esferas de la vida social-, aun cuando en términos amplios comparten intereses con las comunidades estudiadas. Para Kuwayama (2003), la diferencia se sitúa en el distanciamiento que pueden mantener los no nativos, que pueden escribir desde puntos de vista alejados en nombre de la ciencia. Entre los elementos que distinguen a un nativo de un no nativo se encuentran: la cultura como punto de referencia de la observación etnográfica, la audiencia asumida que leerá la investigación, la lengua en la que el antropólogo nativo escribe los resultados y el grado de implicación que tenga éste en la representación cultural de un grupo. Desde su concepción, supone cercanía al colectivo estudiado -pertenencia cultural, ciudadanía o implicación emocional-, lo que permite establecer un tipo de representación del colectivo comprometida, bienintencionada y auténtica, en tanto que la lejanía llevaría una comprensión tergiversada (eurocéntrica) dirigida al sometimiento y dominio del otro. Señala que no hay una defensa exclusiva en pos de una antropología nativa, advirtiendo que "Es verdad que las capas más profundas de una cultura no son fácilmente accesibles a los forasteros, pero hay muchas cosas que escapan a la atención de personas que están dentro... algunas cosas pueden analizarse mejor desde el exterior que del interior." (p.13). El problema radica cuando los residentes “... asumen la superioridad de sus habilidades de la investigación y excelencia de sus interpretaciones mientras desatienden las reacciones nativas... [Objetando]... cuando los investigadores extranjeros se elevan al estado de último juez en su cultura." (p.13). Señala que la clave es si en la disciplina somos o no capaces de aceptar al nativo como compañero en el diálogo.

También se encuentran referencias a otras especificidades como son las antropologías indígenas o no occidentales (Fahim y Helmer 1980); como señalan Fahim y Helmer (1980), “... la antropología nativa es solo una faceta de la antropología indígena, que da cabida a varias relaciones que pueden existir entre el investigador local y las personas estudiadas, y se 
centra en las consecuencias epistemológicas y operacionales de estas relaciones.” (p.645). Para Fahim y Helmer (1980), antropología indígena indicaría la práctica de los antropólogos en su país, sociedad o grupo étnico (p.644), lo que implica, además, una identificación particular con esos contextos que repercute en la aproximación teórica, metodológica y compromiso social de estos, más allá de la sensibilidad e interés que pueden demostrar algunos antropólogos occidentales; “...implica un cambio cualitativo en el proceso y resultados de la investigación atribuible a la afiliación del investigador con un nación-estado particular, cultura, o grupo étnico.” (p.645). Para estos autores, por tanto, un cambio en el actor conlleva un cambio en el papel y perspectiva que asume, lo que cuestiona la premisa que sostiene que la antropología debiese ser la misma sin importar la identidad o locus de la investigación. Estos autores dan cuenta, además, del fenómeno de 'profesionalización' o descentración académica que sufre la antropología, lo que refleja un cambio en el locus del antropólogo indígena o no occidental; ya no operan tanto en el espacio académico, sino que se dirigen a desarrollar labores en programas de gobierno a nivel local, orientados a la resolución de problemas concretos o en la discusión y evaluación de políticas públicas. Para los autores, la dicotomía indígena/forastero -la que precisan de mejor manera como foráneos/locales- releva la distinción de problemas éticos y de investigación que enfrentan los antropólogos en su quehacer, esto, sin desconocer los variados posicionamientos que asumen respecto de las agrupaciones sociales.

Sumado a lo anterior, desde América Latina se plantea una interesante discusión respecto de las particularidades que asume la antropología, la que se articula en torno a los conceptos de antropologías periféricas (Cardoso de Oliveira 1999, 2004), antropologías hegemónicas y subalternas (Restrepo y Escobar 2004; Restrepo 2006; Ribeiro y Escobar 2006 [2008]), del sur (Krotz 1993, 2006), o latinoamericanas (Jimeno 2005).

Cardoso de Oliveira (1999, 2004), advierte que por lo general se piensa a la antropología en América Latina en términos nacionales, cuando mucho en términos regionales, y de manera excepcional en términos universales. Señala que los conceptos de antropología periférica y matriz disciplinar permiten aprehender la singularidad de la antropología sin perder de vista su pretendida universalidad. Estas antropologías “... pueden existir en cualquiera de los mundos, hasta incluso en el mundo europeo, siempre que sean identificadas en países que no hayan registrado la emergencia de la disciplina en su territorio y, de esa manera, no haya ocupado una posición hegemónica en el desarrollo de nuevos paradigmas."(2004:37). Agrega, no 
obstante, que en la pretendida universalidad de la antropología como disciplina científica, es posible encontrar particularidades o diferencias en el conjunto de paradigmas articulados en la matriz disciplinar, esto, cuando es ejercida fuera de las metrópolis, adquiriendo ciertos rasgos estilísticos como resultado de encontrarse volcadas casi exclusivamente a objetos en su propio contexto sociocultural (Cardoso de Oliveira 1999, 2004).

Restrepo y Escobar (2004) se posicionan desde lo que se ha denominado 'antropologías del mundo', lo que constituye un proyecto de comunidad de discusión que se sitúa de manera crítica frente a la producción de la antropología hegemónica. Afirman la necesidad de apertura hacia las prácticas no-disciplinarias y no-académicas de modo de desmantelar estas polaridades, para sostener una crítica radical a los cánones de autoría/autoridad/autorización que hacen posible el establecimiento de las antropologías hegemónicas. Por medio de esta propuesta, se busca el reconocimiento de una pluralización de visiones existentes en “... una coyuntura en que prevalecen discursos hegemónicos, centrales y nortatlánticos sobre la diferencia." (Ribeiro y Escobar 2006 [2008]:18). Estos autores entienden a las antropologías hegemónicas como “... el conjunto de formaciones discursivas y prácticas institucionales asociadas con la normalización de la antropología académica llevada a cabo principalmente en Estados Unidos, el Reino Unido y Francia.” (p.19), lo que se expresa en la configuración y naturalización de "cánones disciplinarios y las subjetividades que interpelan a los antropólogos no sólo en los establecimientos centrales, sino también en los periféricos (Restrepo 2006:16). En tanto, las antropologías subalternizadas corresponderían a aquellas que se ubican en los márgenes e intersticios de los establecimientos antropológicos periféricos y centrales, y que por diversos motivos no encajan en las articulaciones hegemónicas en determinado momento. Restrepo y Escobar (2004), reconocen que las antropologías hegemónicas han emergido debido a una serie de modalidades de producción y regulación de discursos y de prácticas institucionales, localizándose en una relación de poder con respecto a las subalternizadas, lo que se ha sedimentado a partir de procedimientos formativos, investigación, escritura, publicación y contratación, las que “...opturan el empoderamiento de las prácticas y conocimientos antropológicos producidos en múltiples locaciones en el mundo."(p.114), e invisibilizan o consideran como derivadas otras modalidades de antropología. Para Restrepo y Escobar (2004), aun cuando las antropologías hegemónicas tienden a ser visualizadas como paradigmas y en posiciones epistemológicas privilegiadas, 
constituyendo "... aparatos de borramiento de la diferencia en nombre del establecimiento y cánones antropológicos."(p. 114), los cánones que establecen no son homogéneos -incluso en los propios centros-, en tanto que sus condiciones de existencia deben entenderse como "... equilibrio inestable de luchas permanentes en y en contra de lo que aparece como los 'centros' del establecimiento antropológico en un momento determinado."(p.114).

Krotz (1993, 2006) introduce el concepto de 'antropologías del sur' o 'antropologías periféricas', a partir del cual espera fijar criterios para diferenciar el quehacer de aquellas antropologías metropolitanas. Para este autor, en el sur, que ha sido el hábitat principal de los objetos de estudio de la antropología, la antropología se arraigó cobrando vida propia estableciéndose en instituciones académicas, programas de estudio de pre y postgrado, congresos, museos, revistas, asociaciones profesionales y proyectos editoriales-, lo que ha llevado a que “... practicantes de la antropología formados y provenientes de las culturas del Norte se encuentren en sus lugares de estudio no sólo con informantes, sino con estudiantes y colegas nativos" (p.6). Esto ha llevado a generar posicionamientos desde los cuales se advierte la necesidad de generar lecturas propias respecto de los fenómenos socioculturales que se desarrollan en estos contextos, considerando que los investigadores forman parte de lo estudiado. Krotz (1993) advierte la inexistencia o falta de consideración del conocimiento generado en el sur tanto en su contexto de origen como en los países del norte, lo que se funda en la dependencia generada desde estos (Krotz 1993, 2006). Sin embargo, plantea que las antropologías del sur son “... tanto o más polifacéticas como las diferentes 'escuelas' o 'corrientes' que se conocen de la antropología del norte.”(p.10).

Miriam Jimeno (2005) se pregunta lo siguiente: ¿es pertinente discutir sobre la diferencia o relación que existe entre los antropólogos de países desarrollados y no desarrollados?, ¿existen en Latinoamérica realmente comunidades científicas o prima el trabajo voluble e incidental?, y ¿hasta qué punto es relevante considerar lo nacional respecto del quehacer disciplinario? Jimeno (2005) argumenta que existe en Latinoamérica una relación entre producción teórica y compromiso con las sociedades estudiadas, el que otorga un carácter específico a la antropología producida en este contexto; los antropólogos se preocupan de las consecuencias sociales de los estudios, y asumen una posición crítica que se grafica en las propuestas teóricas y conceptos que elaboran, los que buscan comprender a los pueblos estudiados en el marco del problema de construcción de la nación y ciudadanía. 


\subsection{Estilos disciplinarios y antropologías nacionales}

Como se ha planteado en la fundamentación de esta investigación, la antropología conforma una disciplina multiparadigmática y con una clara tendencia o vocación interdisciplinaria. Sin embargo, no es antojadizo preguntarse respecto de cómo estos rasgos o características, bien descritos en la literatura, son posibles de observar en antropologías que han sido denominadas como "no hegemónicas" o "periféricas". En este sentido, forman parte de las inquietudes de esta investigación interrogantes como las planteadas por Peirano (1981) respecto de la posible identidad de la antropología brasileña, a decir: ciertos problemas que se vuelven gravitantes en una época determinada, ciertas temáticas que se recogen de la discusión internacional, así como el impacto -mayor o menor- de ciertas tradiciones antropológicas a nivel local. En acuerdo a lo anterior, se sostiene la tesis de que más que una antropología nacional con una identidad bien definida, la antropología practicada en Chile (se evita hablar de antropología chilena dado el cosmopolitanismo que la cruza) exhibe una diversidad que ofrece distintos matices a la luz de algunas tendencias antropológicas europeas y norteamericanas que se han trasformado, en el circuito local (de origen) como mundial, en hegemónica y/o cosmopolitas.

$\mathrm{Al}$ respecto, el concepto de estilos de antropología resulta analíticamente relevante en tanto se abre a la posibilidad de la variabilidad o diversidad interna a nivel local, como también entrega oportunidades analíticas que hacen posible identificar elementos constitutivos y distintivos en las expresiones pesquisadas. Sin embargo, la revisión bibliográfica registra distintas perspectivas teóricas en lo que refiere a la caracterización de las antropologías, ya sean denominadas periféricas, nacionales o subalternas, en función de las cuales la noción de estilos se complementa (Cardoso de Oliveira 1999, 2000, 2004) o se levanta como alternativa (Vessuri 1993, 1996).

Una primera discusión se enmarca en la postulada relación centro-periferia que cruza la conformación y dinámica de las ciencias en general; correspondería a un modelo que caracterizaría la dependencia y asimetría que tendría lugar entre metrópolis y satélites en la producción y circulación de conocimiento $-\mathrm{y}$ todo lo que ello involucra; prestigio, recursos, etc. En este esquema, el centro corresponde, para el caso de la antropología, a tradiciones vinculadas a ciertas escuelas de antropología en Inglaterra, E.E.U.U., Francia, Alemania, frente a aquellas periféricas localizadas en América Latina, África, Asia, etc. 
Este modelo ha vuelto a la escena, siendo recuperado como marco para interpretar las dinámicas de relaciones desiguales que acontecen en el campo de las ciencias sociales, y ha sido trabajado o referido por diversos autores que analizan la situación latinoamericana (Beigel 2006, 2010, 2011; Falero 2006) y en particular el caso de la antropología (Cardoso de Oliveira 1999, 2000, 2004; Restrepo 2006). A esta se han sumado perspectivas como sistemamundo (Wallerstein 2005 [2004]), la colonialidad del poder y la geopolítica del conocimiento (Lander 2000; López 2000; Mignolo 2000, 2002; Quijano 2000; Castro-Gómez, Schiwy, Walsh 2002; Walsh 2002), y aquellas que destacan relaciones de hegemonía y sub-alternidad (Restrepo y Escobar 2004, 2005; Ribeiro y Escobar 2006 [2008]; Restrepo 2006), todas ellas poniendo como punto central de análisis la dimensión del poder como mediadora de relaciones e intercambios.

Al respecto, Gerholm y Hannerz (1982) han manifestado un acuerdo parcial con este abordaje. Concuerdan en que es posible observar la estructuración de relaciones asimétricas en la antropología internacional y nacional ligado esto a la posición desigual en la industria y circulación editorial, la producción académica en un lengua que se torna predominante, en los recursos gubernamentales y privados, la formación que los estudiantes reciben en las antropologías de las metrópolis, así como en las misiones de investigación que antropólogos de las metrópolis emprenden en la periferia -lo que resulta en la extensión de la legitimación por sobre las antropologías nacionales. Sin embargo, advierten que la relación centro-periferia puede ser vista en términos de una red, poniendo el foco de análisis en las formas y canales de interconexión que establecen los antropólogos fuera de las fronteras nacionales, y que en muchos casos se reproduce por relaciones de dependencia mutua, donde las mismas antropologías sindicadas como periféricas han contribuido al rol dominante de aquellas situadas como centrales, y donde estas últimas han necesitado de las periféricas para su consolidación. Esto es posible por medio de múltiples, no localizadas y pequeñas redes que se establecen en base a habilidades, experiencias particulares y contactos personales, por medio de los cuales las antropologías metropolitanas pueden reclutar a individuos particulares en las antropologías periféricas, situándose estos últimos en posiciones más igualitarias y generando nuevos eslabones de comunicación (p.12). Esta cuestión ha sido bien referida por Bourdieu (2008 [1997]) a propósito del campo científico, y lo que se define como estrategia en la lucha por la apropiación de capital científico y simbólico. 
Por otro lado, Roberto Cardoso de Oliveira (1993 [2004]; 2000) desarrolló un programa de investigación centrado en la conformación y singularidad que adquiere la antropología en los espacios periféricos. Como el mismo autor reconoce, la idea de periferia y de antropología periférica ha sido bastante discutida a la luz de conceptualizaciones como antropología indígena, nativa, no-occidental, nacional. No obstante lo anterior, Cardoso de Oliveira sitúa el carácter periférico como condición contextual que excluye a aquellas antropologías hegemónicas en la producción teórica, y respecto de las cuales se desarrollan dinámicas en el marco de una matriz disciplinar de orden cosmopolita con pretensiones de universalidad. La particularidad del abordaje de Cardoso de Oliveira (1993 [2004]; 1999; 2000), es que plantea que la antropología periférica puede existir en cualquiera de los mundos -incluso en Europaen tanto no hayan registrado la emergencia o más bien el origen de la antropología en su territorio -la ontogénesis disciplinaria-, y con ello, ocupado una posición hegemónica en el desarrollo de nuevos paradigmas. Además, sostiene que la 'matriz disciplinar', originada en países centrales en el desarrollo de la antropología, ha sufrido adecuaciones y trasformaciones en las 'nuevas realidades' en el movimiento desde el centro a la periferia, en el cual estas últimas han realizado aportes y retroalimentaciones que le otorgan un carácter 'estilístico'. En palabras de Cardoso de Oliveira (1993 [2004) “... no obstante la pretendida universalidad de la antropología como disciplina científica manifestada... en el conjunto de paradigmas articulados en su matriz disciplinar, persisten diferencias o particularidades significativas cuando es ejercitada fuera de los centros metropolitanos donde, al parecer, no se observaría la misma pretensión de universalidad." (p.37). Para este autor, 'matriz disciplinar' estaría ligada a los países centrales en tanto los estilos o variedades estilísticas estarían ligados a los países no hegemónicos o periféricos.

La matriz disciplinar sería una adecuación de la noción de paradigma en la versión kuhniana, en tanto la define como “... constituida por un conjunto de paradigmas articulados en un campo de tensión epistémica de forma que ni uno de los paradigmas consiga superar o anular al otro..." (1999:24), los cuales corresponderían al estructuralismo Levi-straussiano, el estructural-funcionalismo británico, el culturalismo norteamericano, el interpretativismo Geertziano o posmoderno, y en menor medida el marxismo (Cardoso de Oliveira 1996, 1999, 2000). Para el autor, los cambios producidos en la matriz, en la visión universalista de la disciplina, afectarían mayormente su dinámica interna (cambios en la matriz) que su estructura 
(cambios de la matriz), lo que implica que no se efectúa un cambio substancial o profundo. Estilo tendría que ver con la 'gramaticidad' de la disciplina en la periferia, vinculándose operativamente a la noción de redundancia en tanto expresa un estado de cosas, donde información anexa no contribuiría a la ampliación de la capacidad explicativa, lo cual configuraría u otorgaría esa forma particular y prolongada de expresar un hacer.

Cardoso de Oliveira (1999) propone seis indicadores para el 'diagnóstico' de las antropologías en contextos periféricos: a) la concentración de las investigaciones en el marco del territorio nacional; b) debilidades institucionales, reflejadas en carencias de infraestructura, salariales y financieras; c) dependencia formativa del exterior de académicos y profesionales; d) mercado de trabajo inferior a la demanda; e) ausencia de periódicos de circulación internacional; f) el problema metateórico de la antropología en nuestros países, relativo al dominio de paradigmas fundadores de la disciplina, hasta actualizaciones de la matriz disciplinar.

Por otro lado, Hebe Vessuri (1993) se muestra crítica frente a la idea de antropología periférica pensada como relación asimétrica y flujo unidireccional de ideas y prácticas. Introduce la noción de interdependencia y congruencia relativa que tiene que ver con la interlocución necesaria que puede ser establecida entre la antropología metropolitana y una periférica. Esta última no necesariamente se asume como tal, y articula el discurso metropolitano dentro de una matriz propia, donde puede existir clara complicidad entre el intelectual dependiente y el dominante. Por ello, Vessuri considera más fructífera la idea de estilo, a decir "esos rasgos peculiares de una práctica científica realizada en contextos socioinstitucionales particulares, que comparten con otros contextos la creencia, como apropiada y natural, en la estabilidad y universalidad de las formas de pensamiento y práctica disciplinaria." (1993:727). Un estilo se entendería en la consistencia, selectividad e integración, así como en las combinaciones diversas que en determinados contextos y momentos tiene lugar, esto en tanto singularidad o tipicidad del trabajo antropológico. Plantea que la noción de estilo permite identificar 'configuraciones sociocognitivas' comparables entre sí al interior de configuraciones disciplinarias más amplias, en el entendido que una disciplina no es homogénea y consensual y por ende, su desarrollo en un contexto nacional tampoco adquiere necesariamente esta característica.

Para Vessuri (1996), el estilo antropológico puede reflejar la situación de una escuela de investigación o de un país, que se desprenden de su impronta poliparadigmática, donde tienen 
lugar variadas combinaciones resultantes de adaptaciones entre la matriz disciplinar, los paradigmas dominantes, los contextos socioinstitucionales particulares y relaciones con otras disciplinas o campos de estudio. El argumento de la autora se funda en que la antropología recibió en contextos específicos formas y relaciones que se cristalizaron en una tradición particular, donde orientaciones y oportunidades diferentes configuraron las carreras de antropólogos que se desempeñaban en distintos departamentos universitarios, así como el funcionamiento y forma de los propios departamentos. Así, la conexión entre contextos institucionales y estilos disciplinarios puede verse mejor analizada en los departamentos universitarios y con ello, la forma como se definen las cátedras, se organizan los departamentos y los programas de estudio. Para ello, Vessuri (1993, 1996) aplica un modelo de análisis que resulta de los aportes de Jamison para el abordaje de la dimensión nacional de la institución científica (1982 en Vessuri 1993, 1996) a la antropología venezolana. En este modelo destacan cuatro niveles: a) sesgo metafísico, relativo a tradiciones filosóficas nacionales que condicionan como se piensan los problemas o resultados de investigación; b) el interés científico nacional, que se relaciona con la necesidad de desarrollar determinados aspectos o problemas relativos a imperativos de carácter nacional; c) estructuras institucionales, ligada a la dinámica que adquieren las instituciones científicas en lo relativo a procesos de institucionalización, roles científicos, funciones de los intelectuales en el ejercicio en la hegemonía de clase, ubicación social de los investigadores, el cómo se define una ciencia y cómo se organiza; d) la congruencia entre tradiciones nacionales, que remite a la convergencia entre el estilo nacional y aquel que se manifiesta como dominante a nivel internacional, siendo a su vez relevante apreciar las rivalidades nacionales en tanto oposición en los intereses científicos respecto de objetivos económicos, búsqueda de prestigio o condiciones ideológicas.

Para efectos de esta investigación, un estilo antropológico no se limita a una realidad periférica (Cardoso de Oliveira 1993 [2004], 1999), ni a los marcos más generales de un país en el cual se perfila una característica particularizante a nivel cognitivo o institucional (Vessuri 1993, 1996) a la manera de una antropología nacional (Gerholm y Hannerz 1982). Se postula que la diversidad es posible de encontrar internamente -al interior de los distintos países-, incluso en los países denominados centrales; la supuesta homogeneidad nacional estilística o de una matriz disciplinar que se levanta como hegemónica en su contexto de 
origen y se expande por la orbe, no permite observar procesos sociopolíticos así como debates teórico-metodológicos que ocurren en realidades y contextos específicos de los países 'centrales', lo que denota un juego de posiciones y de recursos, una lucha por el capital social, simbólico y académico, como diría Bourdieu. Estas tensiones quedan claramente expresadas, por ejemplo, en opiniones como las efectuadas por Marvin Harris respecto a que la antropología habría sido tomada por místicos, fanáticos religiosos y culturalistas californianos, y que las reuniones en la Asociación Americana de Antropología eran dominadas por chamanismo, brujería, estudios anormales, y que las ponencias científicas sobre investigaciones empíricas habían sido excluidas premeditadamente (Harris 1978 en Ortner 1984).

En este sentido, Gutiérrez (1996) también ha referido a la 'extrema dureza' de la matriz disciplinar presentada por Cardoso de Oliveira (1993 [2004], 1999), lo que puede ser complementado señalando incluso que tradiciones, paradigmas o componentes de la matriz, pueden ser internamente diversos y por ende, presentar ciertos matices o lecturas en los mismos contextos de origen (no es lo mismo la hermenéutica en Schleiermacher, Dilthey, Heidegger, Gadamer o Ricoeur). Restrepo (2006) plantea la no homogeneidad de los 'establecimientos periféricos'; hay relaciones internas de poder, posicionamientos frente a modelos antropológicos dominantes y articulaciones. La misma relación de desigualdad que opera en el concierto internacional (la relación centro-periferia se constituye en un esquema de amplia operatoria) puede operar al interior de una país. Estas reflexiones también permiten plantear el problema de la existencia de una antropología latinoamericana, frente a la posibilidad de múltiples estilos. Ribeiro (1996) da cuenta de la tendencia a reificar América Latina como una entidad, aun cuando es posible encontrar diversidad de antropologías en esta parte del continente. Por ello, más que hablar de una antropología chilena, se habla de la antropología en Chile, partiendo del supuesto de la heterogeneidad interna y de la posibilidad de evidenciar tendencias y estilos de antropología en el periodo propuesto; lo que se buscó investigar específicamente, fueron los contenidos de estos estilos, es decir, componentes cognoscitivos o teóricos metodológicos y su vinculación a ciertos contextos institucionales, actores-antropólogos y redes de comunicación. 


\section{CAPÍTULO II}

\section{Algunos antecedentes sobre la institucionalización de la antropología científica y académica en el campo internacional ${ }^{21}$}

\subsection{Institucionalización científica e institucionalización académica}

Según Shils (1970), la institucionalización corresponde al proceso de estructuración que organiza y jerarquiza la interacción en torno a una actividad intelectual, la que tiene como base cierto acuerdo en las normas de actuación, membrecías, comunicación y proyecciones de dicha actividad. Respecto a esta definición, se hace posible introducir una distinción con el objeto de diferenciar dos dimensiones que forman parte de este proceso en una disciplina: institucionalización de la investigación científica e institucionalización académico-profesional. La institucionalización de la investigación científica puede ser entendida como aquella que alcanza su consolidación con la formación de comunidades o asociaciones de investigadores que definen un área de conocimiento específico, desarrollando indagaciones o estudios de manera sistemática en torno a un "objeto", y regulando su actividad a partir de un conjunto de normas mediante las cuales se definen adscripciones y posiciones. En esta etapa entran en escena dispositivos cognoscitivos, procedimentales y escriturales que permiten conferir autoridad y legitimación a las construcciones discursivas realizadas, conforme a ideales normativos de ciencia ${ }^{22}$. Para el caso de la antropología, los discursos se orientan a representar la "otredad radical" (Peirano 2007), conforme a exigencias de estar allí -realizando descripciones concretas, sistemáticas y prolongadas entre los grupos nativos-, y formas de

21 Este capítulo tiene como objetivo presentar un panorama general respecto de la institucionalización de la antropología académica en el campo internacional, la que incluye países donde se origina la antropología científica y aquellos latinoamericanos de temprana institucionalización, fijando algunos hitos asociados a la consolidación e inicios de la formación profesional. Se habla de panorama general, ya que a pesar que la mayoría de nuestros países han experimentado fenómenos comunes -fruto de movimientos políticos y económicos de carácter internacional-, resulta imposible entrar en la densidad implicada en la trama histórica y social local que marca o delinea el desarrollo de la antropología en cada país.

${ }^{22}$ Como ha señalado insistentemente Bourdieu, los principios de autoridad en ciencias sociales siempre están en disputa con aquellos argumentos que emergen de la sociología o antropología espontanea. En palabras de Clifford (1992 [1988]), los adversarios en el campo, representados por los administradores, disputan sentido y legitimidad con aquellos cultores de unas incipientes ciencias antropológicas. Ello lleva a la necesidad de regulaciones metodológicas y exigencias formativas que actúan como credenciales para entrar en la comunidad de especialistas. A ello se suma, la necesidad de incorporar requisitos de cientificidad, que tenían como referente aquellos desarrollados en el marco de las ciencias de la naturaleza. 
representación que textualizan requisitos metodológicos, con el objetivo de establecer comunicación con una audiencia de especialistas -para quienes se escribe- a través de la denominada retórica etnográfica (Geertz 1989 [1988]; Clifford 1992 [1988]; Marcus \& Fisher 2000 [1986]). En los inicios de la institucionalización de la antropología -fines del siglo XIX y principios del siglo $\mathrm{XX}$-, eran indicativos el carácter altamente concreto, descriptivo y factual de la textualización, la que buscaba reproducir una narrativa despersonalizada y/o neutral, que a través de un efecto objetivista e inocuo, intentaba demostrar que se entró con profundidad en la vida de los otros (Geertz 1989 [1988]; Trinchero 2007).

De hecho, y contario a lo que se reproduce desde las corrientes anglosajonas, las primeras prescripciones metodológicas se formulan en el marco de la Sociedad de Observadores del Hombre de Paris ${ }^{23}$, institución creada en 1799 por un conjunto de médicos y naturalistas. Esta sociedad establece como programa la realización de estudios sobre la historia natural del hombre, siendo su objetivo dar un propósito y direccionar las descripciones realizada sobre sociedades no europeas por parte de viajeros (De Gérando 1800; Broca 1870). Entre los cuestionamientos de orientación epistemológica y metodológica que realiza esta sociedad hacia la producción de la época, encontramos que a su juicio las observaciones:

1) Son bastante incompletas.

2) No siempre son muy ciertas y muy auténtica.

3) Están hechas sin orden.

4) Juzgan las costumbres de los salvajes por analogías tomadas de nuestras propias costumbres.

5) Utilizan un lenguaje vago e inadecuado.

6) Muestran falta de imparcialidad.

7) Expresan falta de interés por la lengua de los salvajes.

8) Dan cuenta del desconocimiento de su forma de pensar.

\footnotetext{
${ }^{23}$ Esta sociedad fue creada en Paris en diciembre de 1799, y se inspiraba en los supuestos establecidos por Buffon, siendo el objetivo de dicha sociedad la instrucción de viajeros para recoger la mayor cantidad de datos que permitieran desarrollar un trabajo de anatomía comparada para caracterizar las variedades de la especie humana. Estuvo constituida por 13 historiadores, 11 médicos, 7 lingüistas, 5 publicistas, 4 filósofos, 3 naturalistas, 2 eclesiásticos y 2 helenistas. Su primer presidente fue Maymieux y su secretario perpetuo el naturalistas Louis Francois Jauffret (Bouza 1988).
} 
Por otro lado, la institucionalización académica-profesional resulta de la consolidación de prácticas de investigación con base en la delimitación de un campo u objeto, y de ciertos enfoques o perspectivas teórico-metodológicas relativamente consensuadas. Desde esta consolidación se proyecta la formación sistemática de "capital humano", que da paso a la especialización y formación profesional, lo que se desarrolla en el marco de centros de investigación y/o al alero de instituciones universitarias. En esta instancia cobra pleno sentido la noción de disciplina; el espacio universitario o formativo no sólo posibilita la organización de especialidades - es decir la delimitación de campos o disciplinas-, sino también establecer tradiciones intelectuales locales, dar lugar a la socialización de nuevos miembros, a la construcción de una identidad, y la definición de un territorio académico (Clark 1983; Becher 2001 [1989]).

Investigación sistemática y formación profesional permiten la delimitación de un campo de estudio, aspecto fundamental en la constitución de una disciplina, a lo que se suman factores ligados al financiamiento, administración de recursos, demandas de objetos y prácticas intelectuales y modelos de práctica intelectual (Pereyra 2010). Además, estas facetas de la institucionalización disciplinaria deben ser entendidas a la luz de condiciones sociohistóricas particulares que definen las dinámicas y características que adquieren estos proceso a escala nacional -que pueden ser propios del contexto local u obedecer a fenómenos de alcance global- (Gerhlom y Hannerz 1982), lo que repercute en la emergencia -temprana o tardía y continua o discontinua- y en las particularidades que adquiere el desarrollo y formación en antropología (Lévi-Strauss 1995 [1968]; Urry 1984; Peirano 1980, 1990).

\subsection{Aspectos generales de la institucionalización de la antropología en algunos países de Europa y América del Norte}

La antropología se desarrolla desde mediados del siglo XIX en Francia, Alemania, Inglaterra y Estados Unidos, países que más tarde se constituirían en centros hegemónicos en la producción científica y antropológica (Stocking 1982; Restrepo y Escobar 2005). Logrando hacia 1840 el reconocimiento como campo autónomo (Urry 1984), se institucionaliza en museos y asociaciones, las que promueven la investigación y publicaciones en revistas 
especializadas, dando paso, en las primeras décadas del siglo XX, a la formación profesional en instituciones académicas universitarias (Mitra 1933; Urry 1984; Beleé 2009; Barth, Parkin, Silverman y Gingrich 2012 [2005]).

En este contexto tienen lugar los primeros debates sobre los estándares científicos de la investigación en concordancia con los criterios de época. Es en las instituciones especializadas donde se discuten, perfeccionan y distribuyen cuestionarios a nivel mundial (Urry 1984), siendo el objetivo instruir a administradores coloniales, gubernamentales y misioneros en la obtención de datos (Malinowski 1929; Hogbin 1974 [1957]; Stocking 1992; Mauss 2006 [2002]). En esta primera etapa, operó de manera más o menos generalizada la lógica de la antropología arm-chair, en la cual teoría y método -recolección- se encontraban disociados (Stocking 1992), siendo la etnografía pensada como técnica de recolección de datos que permitía dar paso a la teorización. Se realizan prescripciones para la aplicación de técnicas, así como recomendaciones referidas al acercamiento y consideración de las poblaciones nativas, alcanzando ello consenso internacional hacia 1930 (Clifford 1992 [1988]).

En esta dirección, ya a inicios del siglo XIX y en tanto participe de la Société des Observateurs de l'Homme (1799), Joseph Marie De Gérando publica el libro Les Considérations sur les diverses méthodes à suivre dans l'observation des peuples sauvages (1800), en el cual se establecen una serie de apreciaciones sobre la vida de los "salvajes" y se establecen ciertas recomendaciones para la observación y descripción empírica de sus costumbres. A fines del siglo XIX, Edward B. Tylor realiza las primeras observaciones respecto a la necesidad de un método científico para la antropología (Tylor 1889), preocupación que también manifiestan Alfred C. Haddon y Williams H. Rivers (Stocking 1992; Barth 2012 [2005] $)^{24}$. En América del Norte, Franz Boas publica The limitations of the Comparative Method (1896), y en 1920, The Method of Ethnology (Boas 1896, 1920); en Alemania, Fritz Graebner ${ }^{25}$ publica en 1911 Methode der Ethnologie y en Francia, Marcel Mauss, entre 1926 y 1939, imparte cursos de "Instrucción de etnografía descriptiva" en el

\footnotetext{
${ }^{24}$ Una política institucional al respecto resulta la creación, por parte del Royal Institute of Anthropology, de Notes and Queries on Anthropology, for the Use of Travellers and residents in Uncivilized Lands (1874), y que en 1912 se extiende hacia prescripciones sobre metodología intensiva y concreta de campo y del método genealógico, esto, a propósito del trabajo de Rivers sobre los Todas (Stocking 1992; Barth 2012 [2005]).

${ }^{25}$ Traducido al castellano por la Universidad Nacional de La Plata, y que a 2010 algunos de sus ejemplares aún circulaban por tiendas de libros usados de esta ciudad. Graebner, F. (1940). Manual de etnografía. La Plata: Ediciones de la Universidad Nacional de La Plata.
} 
Instituto de Etnología de la Universidad de Paris, los que dieron origen al Manuel d'ethnographie editado en 1947 por Denise Paulme (Mercier 1969 [1966]; Mauss 2006 $[2002])^{26}$. A ellos se suman las figuras de Bronislaw K. Malinowski y Alfred R. RadcliffeBrown, quienes además de iniciar un ataque al amateurismo en el trabajo de campo, consolidan lineamientos metodológicos que se institucionalizan a nivel global bajo la exigencia del trabajo de campo sistemático y prolongado (Marcier 1969 [1966]; Urry 1984; Clifford 1992 [1988]); Barth 2012 [2005]).

Esta discusión se hace posible tras la constitución de una serie de instituciones que buscan desarrollar un trabajo antropológico de carácter científico. En Francia: la Société des Observateurs de l'Homme (1799), la Société Ethnologique de París (1839), Société d'Ethnographie Americaine et Orientale (1859), Société Anthropologique de Paris (1859), Trocadero Musee d'Ethnographie (1878), la Société Asiatique y la Société Géographique (ambas en 1922) y, en 1925, el Instituto de Etnología ${ }^{27}$ (Parkin 2012 [2005]). En Inglaterra, la Ethnological Society de Londres se fundó en 1843, y en 1869, Royal Institute of Anthropology de Gran Bretaña e Irlanda -en 1884 la Asociación Británica para el Progreso de la Ciencia identifica a la antropología como campo independiente de la biología (Stocking 2002; Palerm 2004). En Alemania se funda en 1867 la Sociedad de Antropología, Etnología y Prehistoria de Berlín junto al periódico Zeitschrift für Ethnologie, que preceden a la instalación del Königliches Museum Für Volkerkunde, en Berlín (1873). En Estados Unidos, surge en 1842 la American Ethnological Society fundada en Nueva York, el Smithsonian Institute (1846), el Bureau of American Ethnology (1879) y la American Anthropology Asociation (1902) aun cuando una parte importante de la investigación antropológica norteamericana se realizó al alero de los museos -varios ligados a instituciones universitarias-, los cuales comienzan a proliferar hacia fines del siglo XIX (Mitra 1933; Stocking 1992; Beleé 2009).

Como se planteó, las primeras cátedras de antropología son pensadas como cursos generalistas -que den a conocer esta nueva ciencia- o como capacitación-preparación de administradores y funcionarios coloniales o gubernamentales. Las más tempranas referencias a cursos de formación en antropología se encuentran en Francia; la primera cátedra de antropología -física

\footnotetext{
${ }^{26}$ Según Mercier (1969[1966]), este era el único manual de etnografía publicado hasta la fecha en lengua francesa.

${ }^{27}$ En 1799 se funda la Société de Observateurs de l'Homme, y que promovió la emisión de cuestionarios etnológicos para viajeros, y que se disuelve en 1804, debido a que la mayoría de sus miembros se unen a la Société de Philantropie (Parkin 2012 [2005]).
} 
o biológica- fue instituida en 1855 en el Musée d'Historie Naturelle (Mercier 1969 [1966]; Parkin 2012 [2005]), en tanto a partir de 1875, se realizó en la Facultad de Medicina de París. Ambas actividades fueron respaldadas por la École Anthropologique (Parkin 2012 [2005]). En 1876, y desde la Sociedad de Antropología de París fundada por Paul Broca (1859), se abre Ecole d'Antropologie con cinco profesores, impartiendo la formación en antropología con un énfasis en antropología biológica y raciología que se abre paulatinamente -hacia fines del siglo XIX- a temáticas vinculadas a la etnología, etnografía, lingüística y religión entre otras (Documento L'École Anthropolgie de Paris 1907; Broca 1907; Mitra 1933) ${ }^{28}$.

Sin embargo, sería James G. Frazer, en 1908, el primero en obtener el título de profesor de antropología, dictando - por un breve periodo- la cátedra honoraria denominada "antropología social" en la Universidad de Liverpool (Radcliffe-Brown 1974). Por otro lado, se pueden mencionar los cursos que dictó Mauss en la École des Hautes Études acerca de la "Historia de las religiones de los pueblos no civilizados" (1901) y las "Instrucciones en etnografía" en el Instituto de Etnología de la Universidad de París (1926-1939) (Paulme 2006 [2002]), orientada precisamente a "administradores, a los colonos desprovistos de formación profesional." (Mauss 2006 [2002]: 30). En Gran Bretaña, los primeros cursos de formación se inician en 1896, cursos generales en antropología dictados en la Universidad de Oxford por Edward B. Tylor, y continuados por Robert R. Marett a partir de 1908 (Barth 2012[2005]) ${ }^{29}$, a lo que se suma los cursos dictados bajo la dirección de Haddon en Cambridge y Turner en Edinburgh. En tanto en Alemania, Alfred Bastian -Director del Königliches Museum für Volkerkunde o Museo Real de Etnología-, fue el primero en obtener habilitación de docencia para Völkerkunde en 1869 (Gingrich 2012[2005]).

Si bien es en Europa, particularmente en Francia, donde la antropología sitúa sus orígenes hacia inicios del siglo XIX- las actividades de investigación y formación se desarrollan en instituciones no universitarias. Es en Norteamérica donde por primera vez la antropología se

\footnotetext{
${ }^{28}$ El primer año se establecen 6 cátedras: antropología anatómica, antropología biológica, etnología -entendida como estudio de las razas-, antropología prehistórica, antropología lingüística, y geografía demográfica y médica. Hacia 1906 ya se impartía antropología prehistórica, antropología y embriología, etnología, antropología zoológica, antropología psicológica, técnicas etnográficas, sociología, antropología geográfica y etnografía (Documento L'École anthropolgie de Paris 1907).

${ }^{29}$ En 1884, Tylor comenzó un ciclo de conferencias en el museo de la Universidad de Oxford, con el objetivo de divulgar la antropología en Inglaterra, siendo creada en dicha universidad un Readership en antropología ese mismo año (Palerm 2004).
} 
inserta como especialidad formativa en el espacio universitario ${ }^{30}$, lo que es posible debido al fuerte respaldo recibido desde el gobierno (Urry 1984). Los primeros programas que siguen el modelo de graduación doctoral, se sitúan en la Universidad de Pennsylvania (1886), Harvard (1887), Clark (1889), Chicago (1892), Columbia (1896) California (1901), Arizona (1915), Utah (1926), entre otros. El primer doctor en antropología fue Alexander Chamberlain, quien se graduó en $1891^{31}$ con la disertación doctoral "The Language of the Mississagas Indians of the Skukog. A Contribution to the Linguistics of the Algonquian Tribes of Canada", presentada en la Universidad de Clark bajo la dirección de Franz Boas (Bernstein 2002) ${ }^{32}$. Por otro lado, las primeras discusiones sobre la enseñanza de la antropología en E.E.U.U. se llevan a cabo a partir de 1916, en el marco de una reunión que tiene lugar en la Universidad de Columbia, Ciudad de New York. En dicha reunión se discutió sobre el objetivo y los métodos de enseñanza de la antropología a nivel de College y Universidades (Boas 1919) ${ }^{33}$.

Aun cuando en Europa la investigación antropológica es más temprana que en Norteamérica, la formación profesional universitaria - con programas de estudios especializados en la materia-, no se inicia sino hasta 1902, primero en París (Francia), y luego en Munich, Berlin, Marbourg (Alemania), Oxford, Cambridge y Edinburgh (Gran Bretaña) (Mitra 1933:142). Como ya se señaló, para el caso Francés la formación comienza de manera más temprana, pero al margen del espacio universitario.

\footnotetext{
${ }^{30}$ De hecho, varios museos se encontraban asociados a instituciones universitarias.

${ }^{31}$ La primera mujer doctorada en antropología fue Miriam Van Waters, quien obtuvo su doctorado en la Universidad de Clark en 1913, con la disertación "The Adolecents Girls among Primitive Peoples". Van Waters fue Trabajadora Social, y se desempeñó como superintendente del reformatorio femenino de Framinhgan, Massachusetts (Bernstein 2002) y como oficial del libertad condicional en la Sociedad de Asistencia Infantil de Boston.

${ }^{32}$ Chamberlaine, de origen británico pero radicado desde su infancia en E.E.U.U., se desempeñó como profesor de antropología en la Universidad de Clark y editor de Journal of American Folklore. Antes de estudiar antropología, se graduó en lenguas modernas en la Universidad de Toronto, Canadá.

${ }^{33}$ En 1917, en la Reunión Anual de la Asociación celebrada en Philadelphia, se funda el comité permanente de enseñanza de la antropología, con la participación de Franz Boas (chairman), R. B. Dixon, P. E. Goddard, E. A. Hooton, A. L. Kroeber, George Grant MacCurdy, F. G. Speck, A. M. Tozzer (Boas 1919).
} 


\subsection{Notas sobre las primeras experiencias en la institucionalización de la antropología en América Latina}

La institucionalización de la antropología en América Latina se produce a comienzos de los años '30 e inicio de los '40 en países como México, Colombia, Perú y Brasil. Resultan gravitantes para su desarrollo, los aportes intelectuales y económicos de instituciones y antropólogos norteamericanos y europeos, quienes tejen una red político-académica que vincula a intelectuales y especialistas locales, realizando trabajo de campo y contribuyendo a la formación profesional (de la Cadena 2008). El interés académico no sólo se centra en el registro de tradiciones pasadas, sino también en investigar in situ los procesos de cambio cultural y/o aculturación, cuestión que es fundamental a la hora de definir una política de investigación y financiamiento (de la cadena 2008).

A pesar de compartir como ideal el modelo de ciencia europeo, una ideología que se orienta hacia el progreso social y económico de las naciones, y el interés geopolítico y científico por parte de distintos gobiernos no latinoamericanos, factores locales de raigambre social y política imprimen cierta especificidad a cada experiencia. La emergencia y desarrollo de la antropología se diferencia a razón del rol que juega en la agenda estatal la disciplina y la profesión, ello con miras en la consolidación del proyecto de conformación de la nación (Reyna 2004), a lo que se suma la importancia que se presta a los pueblos originarios -ya sea como problema o como acervo cultural de tradiciones que desaparecen-, y las dinámicas sociopolíticas locales.

Cuadro $\mathrm{N}^{\circ}$ 1: Inicios de la formación profesional de antropólogos de grado o postgrado en algunos países de América Latina.

\begin{tabular}{|l|c|l|}
\hline \multicolumn{1}{|c|}{ País } & Año & \multicolumn{1}{c|}{ Institución } \\
\hline México & 1937 & Escuela de Ciencias Biológicas, Instituto Politécnico Nacional. \\
\hline Colombia & 1942 & Instituto Etnológico Profesional, Escuela Normal Superior. \\
\hline Perú & 1942 & $\begin{array}{l}\text { Sección Arqueología y Antropología, Facultad de Letras, Universidad } \\
\text { Nacional San Antonio Abad del Cusco. }\end{array}$ \\
\hline Brasil & 1945 & Facultad de Filosofía, Ciencias y Letras, Universidad de Sao Paulo. \\
\hline Venezuela & 1954 & $\begin{array}{l}\text { Escuela de Antropología y Sociología, Facultad de Economía, Universidad } \\
\text { Central de Venezuela. }\end{array}$ \\
\hline Argentina & 1958 & $\begin{array}{l}\text { Facultad de Ciencias Naturales y Museo, Universidad Nacional de La } \\
\text { Plata. }\end{array}$ \\
\hline Chile & 1966 & Centro de Antropología y Arqueología, Universidad de Concepción. \\
\hline Ecuador & 1971 & Departamento de Antropología, Universidad del Ecuador. \\
\hline
\end{tabular}




\subsubsection{Modelo de ciencia $y$ el proyecto nacional en América Latina. Algunas consideraciones generales}

En América Latina, la antropología y la ciencia en general comparten la reproducción del modelo de ciencia europea, modelo hegemónico en la producción del discurso científico del siglo XIX (Stocking 1982). Se inspira en los ideales de la ilustración y pensamiento positivista, lo que armoniza con los principios republicanos dispuestos en pos de consolidar las nuevas naciones en América (Vessuri 2007). El modelo mantiene su base en la fundación de museos y sociedades de especialistas, tal y como ocurrió en los países centrales (Barth, Parkin, Silverman y Gingrich 2012 [2005]).

En esta dirección, los museos son pensados como espacios de investigación e ilustración ciudadana, los que permitían albergar el conocimiento y material recolectado en el marco de la caracterización de la historia natural de las nuevas naciones -un área de interés para los científicos europeos. Como señala Vessuri (2007), estas instituciones son 'ad hoc' a las exigencias cognoscitivas de la ciencia de la época, y en tal sentido, reunir colecciones y realizar inventarios tenía como objetivo “... movilizar al mundo clasificándolo y ordenándolo en espacios institucionales especialmente concebidos." (p.155). Al respecto, Arias (2007) señala que los modelos taxonómicos incorporados en la lógica científica del siglo XIX, se orientaron hacia la clasificación de lo que aparecía variado, disperso e irregular frente a la élite nacional, ejercicio que fundamenta el pensamiento racialista y se conjuga con la necesidad del conocimiento y clasificación de las riquezas poblacionales y naturales. De este modo, surgen las taxonomías poblacionales, donde la diferenciación hace posible el establecimiento de jerarquías naturalizadas por medio de una relación incuestionable entre la constitución socialmoral, la constitución física individual y del "medio físico". Esto permitió estructurar el poder del Estado en el marco de la nación, articulando las relaciones desiguales entre los pueblos y territorios incorporados, donde la colonización física y simbólica hace posible su inserción en la economía mundo capitalista.

El conocimiento albergado en estas instituciones, constituyó un referente importante para la definición de la identidad nacional, permitiendo acopiar evidencia acerca de los recursos, el ambiente y la población nativa, ello, en el marco de la proyección del potencial económico presente en los distintos territorios (Vessuri 2007). En tal sentido, los museos no sólo son 
espacios patrimoniales; se inscriben en una política cultural de integración nacional, donde, en el marco de una ideología ilustrada y en post del ejercicio soberano, “... las elites y los nacientes estados se dieron a la tarea de construir una nación de ciudadanos, vale decir, una nación cuyos miembros debían estar unidos por una sola cultura y por un conjunto de creencias, valores y tradiciones compartidas" (Rodríguez 1983 en Alegría 2004:60).

En este proceso también resulta gravitante la participación de eruditos, profesionales y científicos europeos o norteamericanos que emigran hacia América Latina o son contratados por los diversos gobiernos con el objetivo de reunir antecedentes sobre los territorios nacionales, con ello, contribuyendo a impulsar la profesionalización y expandir los principios de la ciencia. En este marco comienza el desarrollo e institucionalización de la antropología en América Latina, teniendo como denominador común que fue profesada por especialistas de oficio, muchos de ellos migrantes de otros campos -naturalistas, médicos, abogados, historiadores, filólogos, matemáticos, etc.-, o con formación en antropología-etnología recibida en Europa y América del Norte.

El proceso antes descrito puede ser significado bajo el rótulo de lo que Peirano (1981) y más tarde Stocking (1982) denominaron nation-building; la ciencia se concibe en el marco ideológico del proyecto político nacional, modelo bajo el cual también ha sido pensada la emergencia de la antropología Norteamericana. En este escenario, la antropología define su objeto de estudio considerando lo que, evocando a Peirano (2008), podríamos denominar "alteridad radical interna". El trabajo antropológico se articula en torno a grupos nativos o pueblos originarios que quedaron cautivos o situados en los límites de los nuevos territorios nacionales. En este marco, la antropología se vincula directa o indirectamente con una política estatal orientada a la construcción y consolidación del proyecto nacional, cuestión que se articula en torno al imaginario que se nutre del exotismo, la necesidad de integración, preservar para generaciones futuras vestigios de las culturas que desparecen frente al progreso y el interés por conocer los orígenes y costumbres de las poblaciones nativas. Sin embargo, esta situación no se expresa de igual modo en América Latina y específicamente en Chile quizá sea más distintivo de México-; como se argumentará en los capítulos posteriores, el papel de la antropología en la construcción de la nación chilena es más bien marginal, rol que si cumplen otras de la ciencias como la geología, economía, geografía, botánica, mineralogía, etc., áreas que son explícitamente demandas por el Estado. 
Tal como plantea Trinchero (2007), y aun cuando no es generalizable, muchas de las antropologías clásicas evadían el hecho de que el trabajo antropológico se implicaba en una política neo-colonial, lo cual se encontraba ligado a la expropiación territorial en el marco de la consolidación de la economía nacional en un modelo de reproducción del capital. Sin embargo, una vez delineadas las bases de la antropología académica en países como México, Colombia, Argentina y Perú, intelectuales y especialistas ligados a la vertiente indigenista asumen un posicionamiento crítico en pro de los derechos indígenas y los problemas sociales, lo que en muchos casos lleva a redefinir los principios de la antropología científica en el marco del compromiso político con los pueblos originarios (Uribe 1980; Pineda 2004, Degregori 2008). Este proceso, que se perfila hacia fines de los años '60, marca un vuelco en la concepción de la antropología así como en los requerimientos éticos demandados al trabajo antropológico, dando lugar a un estilo que pugna por la hegemonía en el campo frente al indigenismo de estado y la antropología denominada cientificista.

\subsubsection{Inicios en México}

Uno de los primeros países en desarrollar e institucionalizar la antropología en América Latina fue México. De hecho, y a diferencia de lo que ocurrió en otras latitudes, la antropología cuenta entre las disciplinas que principiaron las ciencias sociales en este país. Lo anterior tiene su origen en el rol que asume en el marco del Estado revolucionario (de la Peña 2008), el impulso de una política indigenista, así como en el interés que suscitó la riqueza arquitectónica de las civilizaciones prehispánicas (Reyna 2004). A esto se agrega que la gran presencia y diversidad de pueblos originarios, características que motivan la presencia e inversión de instituciones e intelectuales norteamericanos y europeos (Kemper 2011). En este contexto, la antropología surge como fuente auxiliar para la "solución del problema indígena" y la incorporación de estas poblaciones a la sociedad nacional, jugando un rol importante en instituciones oficiales en apoyo, diseño y ejecución de políticas específicas de integración (Báez-Jorge 1980, Medina 1995; de la Peña 2008) ${ }^{34}$.

\footnotetext{
${ }^{34}$ A modo de ejemplo, señalar que en 1917 se crea la Dirección de Antropología, dependiente de la Secretaría de Agricultura y Fomento (Medina 1996).
} 
A pesar que las actividades de investigación y su incursión en la política estatal son tempranas, a lo que se suma la existencia de cursos generales de formación en el Museo Nacional ya en 1877 (Medina 1989), el campo antropológico -problemas y definiciones- se constituye en propiedad a partir de 1940. Los principales hitos en la institucionalización corresponden a la fundación del Museo Nacional, decretada en 1831, la implementación de una sección de antropología y etnografía en 1895, y la celebración del IX Congreso Internacional de Americanistas (Bustamante 2005).

Los primeros cursos en antropología son promovidos a partir de 1903 por Nicolás León, esto al alero del Museo Nacional, destacando además la creación (1906), en el mismo museo, de cátedras de Antropología Física, Etnología y Arqueología por parte de Justo Sierra -entonces, Secretario de Educación Pública- y Ezequiel Chávez -subsecretario (Gamio 1942).

En septiembre de 1910, dicho museo se convierte en sede de la Escuela Internacional de Arqueología y Etnología Americana ${ }^{35}$, contando con la participación de connotados antropólogos como Franz Boas, Ales Hrdlicka, Eduard Seler (Bustamante 2005) ${ }^{36}$. En esta escuela, con una línea de formación arqueológica y etnológica, y en el marco de los estudios descriptivos de orientación folklórica y de rescate, comienzan su formación figuras como Manuel Gamio ${ }^{37}$. Los cursos de antropología se mantienen hasta 1916, año en que son incorporados al curriculum de la Escuela Nacional de Altos Estudios (Bustamante 2005). En 1918, Gamio funda la Dirección de Antropología, institución gubernamental dedicada a la investigación, diagnóstico y transformación de las poblaciones, en una simbiosis en la que se conjugaba lo indígena como fundamento de la mexicanidad en la idea del mestizaje cultural (de la Peña 2008). El rol fundamental de la antropología de la época fue su carácter aplicado, cuestión que también sostiene Moisés Sáenz, uno de los creadores del Departamento de Asuntos Indígenas (1938-1946) -posteriormente absorbida por la Secretaría de Educación

\footnotetext{
35 El proyecto se concretó bajo los auspicios de los gobiernos de México, Alemania y Francia, y de las universidades de Columbia, Harvard y Pennsylvania (Bustamante 2005).

${ }^{36}$ Según Gamio (1942), Franz Boas concibe la idea de crear la Escuela Internacional, la que secundaron Ezequiel Chávez y Eduard Seler (Universidad de Berlin), su primer director. También dirigieron dicha escuela, Franz Boas, Alfred Trozzer y el geólogo George Engerrand.

${ }^{37}$ En 1922, Manuel Gamio alcanzó el grado de PhD en la Universidad de Columbia. Bajo la dirección de Franz Boas, Gamio presentó la síntesis y conclusiones de su trabajo "La población del valle de Teotihuacan" (Bernstein 2002). Cabe destacar que Gamio figura como el primer latinoamericano en obtener su PhD en antropología en una universidad norteamericana, siendo uno de los cuarenta y cuatro PhD hasta 1922.
} 
Pública- , siendo la antropología la promotora de la integración social desde abajo (de la Peña 2008).

La institucionalización disciplinaria se consolida en 1937, a partir de la creación de un Departamento de Antropología y la puesta en marcha del programa de formación profesional en la Escuela de Ciencias Biológicas del Instituto Politécnico Nacional (Medina 1996; Ramírez 2011) ${ }^{38}$, y posteriormente en el Instituto Nacional de Antropología e Historia en 1939 (Kemper 2011). La consolidación de la antropología y su alianza con la política nacional indigenista se genera en el Congreso Indigenista Interamericano de Pátzcuaro (1940), donde el presidente Lázaro Cárdenas; se delinea el carácter mexicano, y la antropología es llamada a promover el proceso de mexicanización (AAVV 1986). En octubre de 1940, se dicta un decreto presidencial en el cual el presidente Cárdenas reconoce el carácter profesional de la carrera de antropólogo (Kemper 2011).

Ese mismo año se firma un plan de cooperación para la enseñanza de la antropología entre el Departamento de Antropología del Instituto Politécnico Nacional (IPN) y el Instituto Nacional de Antropología e Historia (INAH), el cual posteriormente incluye la Sección de Antropología de la Facultad de Filosofía y Letras de la Universidad Nacional Autónoma de México (Kemper 2011).

A partir de 1942 se produce la fusión entre el INP y el INAH, transformándose en Escuela Nacional de Antropología e Historia a partir de 1946 (Kemper 2011; Ramírez 2011). En esta época tiene lugar la denominada "edad de oro" de la antropología en México, con una fuerte presencia y aporte de universidades y fundaciones Norteamericanas como la Rockefeller Foundation, Division of the Humanities, Viking Fund, Inc. -que cambia su nombre a Wenner Gren para la Investigación Antropológica-, Guggenheim Foundation y Smithsonian Institution of Washington (AAVV 1986; Kemper 2011). Dicha escuela desarrolló un programa interdisciplinario con base en el modelo germano-estadounidense (de la Peña 2008), ofreciendo los dos primeros años una serie de cursos de formación básica como: fundamentos de la Arqueología, Antropogeografía, Geografía General, Antropología Física, Etnohistoria, Etnología, Prehistoria, Lenguas Modernas y Lingüística. Los tres últimos años eran en una línea disciplinaria considerando una de las cuatro especialidades ofrecidas: Arqueología,

\footnotetext{
${ }^{38}$ El programa de formación contempló la formación en dos ramas, la biológica y la cultural, esta última con especialización en etnología, arqueología y lingüística (Ramírez 2011).
} 
Etnología, Etnohistoria, Lingüística; ello se complementaba con la obligación de cursar tres prácticas de campo, cada una de 45 días (Ramírez 2011) 39 $^{39}$ La orientación marcadamente historicista y arqueológica del programa, cambia a mediados de los '50, con la necesidad explícita de formación en antropología aplicada. Por iniciativa del Instituto Nacional Indigenista, en 1951 se forma una comisión para fundar un Departamento en Antropología Aplicada en la ENAH, bajo la idea de contribuir al cambio social; esta línea fue iniciada por Fernando Cámara a partir de 1954, y se levantó en función de la distinción entre antropología social -estudio de las relaciones y los problemas ligados al desarrollo y la persistencia de las sociedades indígenas- y etnología - pueblos del pasado y sus manifestaciones presentes (Ramírez 2011).

Cuadro $\mathrm{N}^{\circ}$ 2: Año de institucionalización de formación de grado y postgrado en Antropología en México.

\begin{tabular}{|c|l|}
\hline Año & \multicolumn{1}{c|}{ Institución } \\
\hline 1936 & Escuela Nacional de Antropología e Historia. \\
\hline 1952 & Universidad Veracruzana. \\
\hline 1965 & Universidad Nacional Autónoma de México. \\
\hline 1968 & Universidad Iberoamericana. \\
\hline 1970 & Universidad de Yucatán. \\
\hline 1974 & Centro Investigaciones Sociales-INAH/CIESAS \\
\hline 1975 & Universidad Autónoma Metropolitana-Iztapalapa. \\
\hline 1978 & Colegio de Graduados de Chapingo. \\
\hline 1979 & Colegio de Michoacán. \\
\hline 1982 & Universidad de Querétaro. \\
\hline
\end{tabular}

\subsubsection{Inicios en Colombia}

Para el caso colombiano, la antropología científica logra su institucionalización hacia fines los ‘30, lo que representa la culminación de un periodo de trabajos de investigación antropológica y de formación general que se extiende desde fines del siglo XIX (Uribe 1980; Pineda 2004). Resultan claves la Revista Anales de Instrucción Pública (1880), la creación de la Comisión Permanente (1881) y la Obra de Jorge Isaacs, "Estudios sobre las tribus indígenas de Santa Marta”, ello, en el marco de un movimiento de raíces románticas que buscó resaltar lo

\footnotetext{
${ }^{39}$ En sus inicios el programa contaba con 21 profesores y con una Junta de Consejo compuesta por: Alfonso Caso, Pedro Sánchez, Alfred Kroeber y Paul Rivet; Ralph Beals y Alfonso Villa Rojas figuraban como profesores honorarios. Para 1946, el programa contaba con 12 antropólogos físicos, 11 arqueólogos, 16 historiadores, 13 lingüistas, 10 etnólogos, además de 10 profesores invitados, en su mayoría norteamericanos (Kemper 2011).
} 
americano y sus características frente al otro europeo, siendo una expresión de ello la conformación del denominado Movimiento Bauché (Uribe 1980). Un hito importante se produce en 1937, cuando Gustavo Santos junto a Gregorio Hernández de $\mathrm{Alba}^{40}$ fundan el Servicio Arqueológico Nacional, dependiente del Ministerio de Educación Nacional (Uribe 1980; Perry 2006). Los vínculos que Hernández Alba sostiene con Paul Rivet, y la llegada de especialistas extranjeros que migraron a comienzos de los ' 40 por causa de la guerra y las dictaduras desde Europa hacia Colombia -con el apoyo del presidente Santos-, permiten contar con un cuerpo de profesores que hace posible pensar la formación sistemática en antropología (Uribe 1980; Pineda 2004; Perry 2006). Entre ellos destacan Justus Schottelius, Ernesto Guhl, Gerardo Reichel-Dolmatoff, José de Recasens, Pablo Vila y Paul Rivet (Uribe 1980).

De este modo, se inicia la docencia en la Escuela Normal Superior, la que busca introducir a profesores de educación secundaria en los conocimientos antropológicos. El 2 de julio 1941, bajo la promoción del gobierno de Eduardo Santos, se funda, como una división de la Escuela Normal Superior, el Instituto Etnológico Nacional ${ }^{41}$. Este instituto se orienta a la investigación y formación profesional, y tuvo como base el modelo francés seguido en el Museo del Hombre de Paris, siendo su primer director Paul Rivet (Uribe 1980; Pineda 2004; Perry 2006). El programa se organizó en dos ciclos. En el primero se dictaba Antropología General, Bioantropología, Etnografía General, Sociología, Geología del Cuaternario, Prehistoria, Lingüística General y Fonética; en el segundo, Antropología Americana, Bioantropología Americana, Etnografía y Sociolingüística Americana, Museo y tecnología, Técnicas de Excavación y Origen del hombre americano. La formación, además, estaba acompañada por una intensa formación de campo (Pineda 2004).

Además, se crea en 1942 el Instituto Indigenista Colombiano bajo la gestión de Gregorio Hernández de Alba y Antonio García (Pineda 2004), el cual según Uribe (1980), sigue una orientación indigenista de carácter sociológica, que desde un posicionamiento más político no meramente académico- buscó la transformación de la estructura agraria y política de Colombia. El instituto se aboca exclusivamente a desarrollar investigación, de modo de

\footnotetext{
${ }^{40}$ A partir de 1939, Hernández Alba recibió formación antropológica en Francia a través de una beca de dos años en Museo del Hombre, la cual fue gestionada por Paul Rivet, y cursó bajo la dirección de Marcel Mauss.

${ }^{41}$ Entre los docentes con los que contaba el instituto, se encontraban: Paul Rivet (Director), Francisco Socorrás (Psiquiatra), Gregorio Hernández de Alba, Justus Schottelius (arqueólogo Alemán), Manuel José Casas Manrique (Lingüista), José Castilla Acosta (Geólogo), Luis Sánchez (Museógrafo) (Pineda 2004).
} 
abordar científicamente la situación del indio, plantear el problema de su liberación e integración a la política nacional a través de la investigación de campo y una línea de estudio crítico del material histórico, y con una orientación que contrasta con la visión academicista y conservadora del Instituto Etnológico Nacional (Uribe 1980).

A partir de 1945 entró en funcionamiento el Servicio Etnológico en la Universidad de Antioquía -bajo la gestión de Garciliano Arcilia-, y en 1946 se funda la Sociedad Etnológica de Antioquía. En paralelo, tiene lugar la conformación de Institutos Etnológicos regionales bajo los auspicios del Ministerio de Educación; en 1946 se crea el Instituto Etnológico del Cauca (bajo de gestión de Hernández de Alba) y el de Magdalena (por parte de Gerardo y Alicia Reichel Dolmatoff) -filiales del Instituto Etnológico Nacional-, y en 1947 el Instituto Etnológico de la Universidad del Atlántico en Barranquillas (Uribe 1980; Pineda 2004).

De los institutos antes mencionados, el Etnológico de la Universidad del Cauca fue el único que entregó formación en etnología (Pineda 2004), el cual fue encabezado por Gregorio Hernández de Alba y Alberto Ceballos. Según informe de Hernández de Alba (1947), el instituto tuvo como objetivo la investigación y enseñanza de la etnología o antropología social, centrándose en América, Colombia y Popayán, teniendo también a su cargo el museo arqueológico y etnográfico de la universidad. Además, consideró una sección indigenista destinada a estudiar y dar solución a los problemas sociales de la población indígena del país, en coordinación con el Gobierno del Departamento, el Instituto Indigenista de Colombia e instituciones afines. El curriculum consideraba una serie de materias troncales en primer y segundo año (antropología Física, Arqueología, Etnología, Lingüística, Colonización española, Museografía, Investigación bibliográfica), trabajo de terreno -tres temporadas de tres semanas cada una y una de tres meses al año-, contando con campo de experimentación y trabajos prácticos en el Museo (Hernández Alba 1947). Dicho instituto contó con investigadores como Hernández de Alba, John Rowe -enviado del Smithsonian-, Alberto Ceballos -del Instituto Etnológico Nacional- Juan Fried, Henri Lehman, Raymond Cristi y George Foster (Hernández de Alba 1947; Pineda 2004).

En 1952, el Instituto Etnológico pasa a ser denominado Instituto Colombiano de Antropología, y se amplía hacia la problematización ligada a todo grupo humano -no sólo indígenas (Uribe 1980), incorporando la perspectiva integral de la antropología norteamericana, en tanto en 1953, el Servicio de Etnología de Antioquía pasa a denominarse Instituto de Antropología de 
la Universidad de Antioquía (Pineda 2004). A inicios de los '60 tiene lugar la creación, en distintas universidades, de cuatro Departamentos de Antropología: Universidad de los Andes (1963), Universidad Nacional y Universidad de Antioquía (1966), y Universidad del Cauca (1970).

Cuadro N³: Año de institucionalización de formación de grado y postgrado en Antropología en Colombia.

\begin{tabular}{|l|l|}
\hline Año & \multicolumn{1}{|c|}{ Institución } \\
\hline 1941 & Instituto Etnológico Nacional. \\
\hline 1946 & Instituto Etnológico del Cauca. \\
\hline 1952 & Instituto Colombiano de Antropología. \\
\hline 1963 & Universidad de los Andes \\
\hline 1966 & Universidad Nacional \\
\hline 1966 & Universidad de Antioquía \\
\hline 1970 & Universidad del Cauca \\
\hline
\end{tabular}

\subsubsection{Inicios en Perú}

Como señalan Valderrama y Escalante (2008), ya a inicios de 1900 se registran trabajos de carácter etnográfico y antropo-físicos en Perú, destacando el realizado por Fortunato Herrera, "Ensayo etnográfico acerca de una rama de la raza quechua", y el de Manuel Bueno, "Etnografía de los indígenas de Qolqepata". Estos primeros trabajos están fuertemente influenciados por los estudios del folklore y el relevamiento de las tradiciones indígenas en el marco de una ideología romántica, y cuyo giro hacia la investigación de corte etnográfico se aprecia en el trabajo de Hilderbando Castro Pozo "Nuestra comunidad indígena" (1924), monografía sobre las comunidades del Valle del Mantaro (Álvarez 2008). Sin embargo, la maduración de una antropología institucionalizada se hace posible sólo después de los años '40, debido a procesos políticos de tinte conservador y al movimiento hispanista que desplaza la preocupación por el indígena y su papel en la conformación de la nación ${ }^{42}$. En este contexto, la antropología se repliega a espacios como la Escuela de Bellas Artes o el Museo de la Cultura Peruana (Degregori 2008).

\footnotetext{
${ }^{42}$ Valcárcel (1981) plantea que las actividades etnológicas se inician en Perú en 1937 con la llegada de Bernard Mishkin, un etnólogo de origen ruso, pero nacionalizado Norte Americano, y con asiento institucional en la Universidad de Columbia. Realizó trabajo de campo en Perú entre 1937-1939 y entre 1941-1942, publicando en 1953 el trabajo The Contemporany Quechua. Además, se vinculó al Museo Nacional contribuyendo con sus investigaciones así como a través de conferencias y formación de investigadores locales, como también apoyando el plan de desarrollo del Museo e Instituto Etnológico.
} 
Los primeros antecedentes de la institucionalización en la formación antropológica en Perú, se remontan a la fundación, en 1942, de la Sección Arqueología y Antropología en la Facultad de Letras de la Universidad Nacional San Antonio Abad del Cusco, la que a partir de 1962 se convierte en Departamento de Antropología (Valderrama y Escalante 2008) ${ }^{43}$. Destaca la creación, en 1943, de la cátedra de Folklore y Lenguas Indígenas bajo la dirección de Víctor Navarro del Águila, desde la cual se promueve el estudio de la cultura popular andina, y se instruye a los estudiantes respecto del trabajo de campo, recopilación y análisis. Además, se edita la revista Tradición, el Boletín de la Sociedad Peruana de Folklore, los Archivos de Folklore y la revista del Instituto Americano de Arte (Valderrama y Escalante 2008) ${ }^{44}$.

Sin embargo, la consolidación de la formación en antropología tiene lugar bajo el gobierno democrático de José Luis Bustamante y Rivero (1945-1948), siendo fundamental la figura de Luis Valcárcel. Valcárcel, abogado de profesión, recibió formación en Ciencias Sociales y Humanas, manifestando interés por la cultura de los pueblos indígenas del Perú, lo que canalizó a través de la promoción de trabajos de corte arqueológico y antropológico. Sus estadías en Estados Unidos y Europa le permiten conocer el desarrollo de la antropología en aquellas regiones, establecer contactos con destacados antropólogos -como Franz Boas, Ralph Beals, George Kubler, Ruth Bunzel, Ruth Benedict, Ralph Linton, Bronislaw Malinowski, Alfred Kroeber- y gestionar cooperación a través de proyectos de investigación y donación de medios tecnológicos ${ }^{45}$. Además, conocer la cultura material de los pueblos indígenas del Perú albergado en los museos norteamericanos y europeos, lo motiva a profesionalizar la antropología en el país (Valcárcel 1981) ${ }^{46}$.

Un vez nombrado Ministro de Educación, promueve la gestación de programas de formación antropológica, como es el caso del Instituto de Etnología de la Universidad de San Marcos en

\footnotetext{
${ }^{43}$ González (1982) señala que la formación en Antropología se inicia en la Universidad Nacional de San Marcos, en tanto Degregori (2008) indica que ambas universidades comienzan a impartir la formación en 1946.

${ }^{44}$ Valderrama y Escalante (2008) señalan que la primera promoción de antropólogos estuvo formada por: Oscar Nuñez del Prado, Luisa Béjar, Gabriel Escobar, Guillermo Fuentes Díaz, Darío Alencastre. El primer graduado fue Nuñez del Prado, quien obtiene el grado de Doctor en Historia y Antropología.

${ }^{45}$ Por ejemplo, becas de estudio de fundaciones como Guggenheim, Carnegie o Rockefeller, además de tecnología gestionada por Franz Boas.

${ }^{46} \mathrm{Al}$ respecto, Valcárcel señala: "El entusiasmo que me provocó esa visita a Estados Unidos está resumido en el informe que presenté a mi regreso. Para mí la etnología era la ciencia antropológica que estudia al hombre vivo, mientras la arqueología lo estudia muerto. Era, pues, una disciplina que urgía implantar en el Perú, donde el indígena era una fuente valiosísima para relacionar las supervivencias de las extinguidas culturas con los restos arqueológicos. El proceso de aculturación de estos pueblos, las comunidades de indios o las tribus selváticas, constituía el objeto de la investigación etnológica” (1981:319).
} 
1946 (Degregori 2008), y San Antonio Abad del Cusco y Huamanga (González 1982). Ello es posible en el contexto de la nueva Ley Universitaria (1946), lo que permite la creación de varios institutos en San Marcos, como son: el de Arqueología a cargo de Julio Tello, el de Historia a cargo de José M. Valega; el de Filosofía a cargo de Julio Chiriboga, el de Filología a cargo de Fernando Tola, el de Literatura Peruana y Folklore a cargo de José Gálvez, el de Geografía a cargo de Javier Pulgar Vidal, y el de Etnología a cargo Luis Valcárcel (Valcárcel 1981) ${ }^{47}$. En la consolidación del Instituto de Etnología destaca el aporte de antropólogos norteamericanos y franceses, quienes además ponen en marcha proyectos de investigación en los cuales participan algunos estudiantes. En este sentido, son fundamentales los aportes del Smithsonian Institution, la Comisión Fulbright, la Fundación Wenner Gren y de universidades como Cornell, Yale, California y Columbia, y del Instituto Francés de Estudios Andinos (Valcárcel 1981; Robles 2008).

Por otro lado, en 1959, con la reapertura de la Universidad de Huamanga (Ayacucho), se crea el Instituto de Antropología en la Facultad de Ciencias Sociales, en cuya organización participan Luis Valcárcel y José María Arguedas (González 1981), y además, la creación de la Carrera de Antropología en la Universidad Nacional del Centro del Perú, siendo gravitantes las figuras de Ramiro Matos Mendieta, Waldemar Espinoza Soriano y Manuel Baquerizo (Álvarez 2008).

Cuadro Nº4: Año de institucionalización de formación de grado y postgrado en Antropología en Perú.

\begin{tabular}{|l|l|}
\hline Año & \multicolumn{1}{c|}{ Institución } \\
\hline 1942 & Universidad Nacional San Antonio Abad del Cusco. \\
\hline 1946 & Universidad de San Marcos. \\
\hline 1959 & Universidad de Huamanga. \\
\hline 1959 & Universidad Nacional del Centro. \\
\hline 1967 & Pontificia Universidad Católica del Perú. \\
\hline 1982 & Universidad de Arequipa. \\
\hline
\end{tabular}

\footnotetext{
${ }^{47}$ La formación del etnólogo contemplaba cursos iniciales de Etnología -dictado por Valcárcel- y Geografía del Perú -dictado por Javier Pulgar Videla- en el Colegio Universitario. Estos se complementaban con cursos avanzados y de investigación en Historia del Perú (Incas) e Historia de la Cultura Peruana - a cargo de Valcárcel; Etnología General e Investigaciones Etnológicas en el Perú -a cargo de Jorge C. Muelle-; y Sociología -a cargo de Roberto Mac Lean- e Historia de la Cultura - a cargo de Teodosio Cabada. La formación se completaba con cursos a cargo de profesores invitados, siendo estos: etnología sudamericana y norteamericana, grupos étnicos y transculturación, análisis de elementos culturales peruanos, psicología social, religión y magia, y población indígena en el Perú bajo la dominación española (Valcárcel 1981).
} 


\subsubsection{Inicios en Brasil}

Tanto la sociología como la antropología se institucionalizaron como ciencias sociales en Brasil en la década del '30, bajo la influencia del modelo de ciencia francés y de los estudios de comunidad de la Escuela de Chicago (Peirano 1980; Trindade 2007). En específico, la presencia de antropólogos y de cursos de formación general se hace posible con la creación de la Escuela Libre de Sociología y Política, en 1933, y la Facultad de Filosofía, Ciencias y Letras en la Universidad de Sao Paulo, en 1934 (Melatti 1980; Peirano 1980). Sin embargo, y hasta los '60, la sociología se establece como la ciencia social dominante siendo la antropología más bien dependiente o subsidiaria (Melatti 1980; Peirano 1980, 2000).

Ello tiene lugar en una época de reforma en la cual la educación ocupa un lugar central en el discurso modernizador, orientándose a la formación de las elites políticas locales de modo de impulsar cambios sociales y económicos (Peirano 1980). Las Ciencias Sociales fueron concebidas como motor de dicha modernización, aspirando alcanzar el nivel teórico que estas mantenían en Europa, y definiendo transformaciones efectivas disminuyendo potenciales tensiones y conflictos sociales (Trindade 2007).

En esta época quienes tenían interés en una formación en ciencias sociales cursaban en instituciones extranjeras -Eduardo Galvao en la Universidad de Columbia, Ruy Coelho y Otavio de Costa Eduardo en Northwestern, Antonio Rubbo Muller en Oxford- y los impulsores de las cátedras y cursos de formación, a falta de especialistas locales, fueron profesores norteamericanos o europeos interesados por iniciar investigaciones en Brasil (Mellati 1983). A partir de este interés, se establecen convenios con instituciones universitarias, centros de investigación y con la UNESCO, lo que permite configurar una red de cooperación internacional que hace posible la llegada de varios investigadores que impulsan los programas de la Universidad de Sao Paulo, del Instituto Libre de Sociología y del Museo Nacional. A la Facultad de Filosofía, Ciencias y Letras, y dadas sus conexiones con centros europeos, llegan investigadores como: Alfred Metraux, Claude Levi-Strauss, Donald Pierson, Herbert Baldus, Roger Bastides, Charles Wagley, Paul Abrousse-Bastide, Jean Maugué (Peirano 1980). Los primeros catedráticos fueron Abrousse-Bastide y Levi-Strauss, y tras el alejamiento de este último -en 1937-, se incorpora Roger Bastide. En 1941 se crea la cátedra de Antropología, la que estuvo a cargo de Emilio Willem hasta 1949, siendo sucedido 
por Egon Schaden y posteriormente por Joao Baptista Borges Pereira en 1967 (Jackson 2010). Trindade (2007) señala que el hibridismo entre las ciencias sociales se mantiene en la permanencia de Roger Bastide hasta la llegada de Egon Schaden (1949), quien sucede a Emilio Willem, y da una orientación más disciplinaria. En tanto, la Escuela Libre, con apoyo del Smithsonian Institute, recibe investigadores norteamericanos o formados en este país, como fueron Donald Pierson -su primer director- Emilio Willem, Herbert Baldus, y la visita, por un breve periodo, de Alfred Radcliffe-Brown (Correa 1993). Por otro lado, el convenio suscrito entre el Museo Nacional y la Universidad de Columbia, permite las estadías de: Franz Boas, Ruth Benedict, Jules Henry, Buel Quine, Ruth Landes y Williams Lipking (Trindade 2007). Otro de los primeros centros de formación antropológica surge en 1935 en la Universidad del Distrito Federal. Allí se crea la primera cátedra de antropología social, la cual fue conducida por Gilberto Freyre, y posteriormente asumida por Arthur Ramos y Darcy Ribeiro (Trindade 2007).

Melatti (1980) señala que la primera especialización de postgraduación doctoral en antropología tiene lugar a partir de 1945 en la Facultad de Filosofía, Ciencias y Letras, Universidad de Sao Paulo. Otra experiencia relevante resulta la instalación, en 1955, del curso de perfeccionamiento en antropología cultural en el Museo del Indio, órgano del Servicio de Protección del Indio. En esta iniciativa destaca Darcy Ribeiro, quien además gestiona en 1957 un curso de formación de investigadores sociales en el Centro de Investigaciones educacionales. En 1960, por impulso de Roberto Cardoso de Oliveira y financiamiento de la Universidad Federal de Rio de Janeiro, se instala en el Museo Nacional el curso Teoría e Investigación en Antropología Social, con la colaboración de Luiz de Castro Faria (Melatti 1983).

Sin embargo, Melatti (1980) agrega que sólo a partir de 1966 se establece un programa formal de postgraduación en antropología como es la Maestría en Antropología de la Universidad de Sao Paulo, la cual es sucedida por un programa de las mismas características en el Museo Nacional en 1968 bajo la dirección de Roberto Cardoso de Oliveira. Desde inicios de los 70 se comienzan a abrir una serie de programas de doctorado y maestría en distintas universidades: en la Universidad Estadual de Campinas (1971) y en la Universidad de Brasilia. En 1976 se crea un curso de especialización en la Universidad Federal de Santa Catarina, y se abren en 1977 tres programas de doctorado y una maestría: Pontificia Universidad Católica de Sao 
Paulo, Museo Nacional, Universidad de Brasilia y Universidad Federal de Pernanbuco (Melatti 1980).

Habría que agregar que toda la formación antropológica hasta fines de los '70 se remitía al postgrado - maestría o doctorado- o de cursos de especialización en el marco de departamentos de sociología u otros, en tanto la graduación es de carácter generalista -en ciencias sociales- o en disciplinas como Historia, Geografía, Estudios Sociales y Servicio Social, en las que se incluye algún curso de antropología o algún antropólogo (Melatti 1980).

Cuadro ${ }^{\circ}$ 4: Año de institucionalización de formación de grado y postgrado en Antropología en Brasil $^{48}$.

\begin{tabular}{|l|l|}
\hline Año & \\
\hline 1945 & Universidad de Sao Paulo. \\
\hline 1968 & Universidad Federal de Rio de Janeiro. \\
\hline 1971 & Universidad de Campinas. \\
\hline 1972 & Universidad de Brasilia. \\
\hline 1976 & Universidad Federal de Santa Catarina. \\
\hline 1977 & Universidad Federal de Pernanbuco. \\
\hline 1977 & Pontificia Universidad Católica de Sao Paulo. \\
\hline
\end{tabular}

Fuente: elaborado en base a Melatti (1980: 236).

\subsubsection{Inicios en Argentina}

Con anterioridad a la institucionalización de las carreras de grado en antropología a fines de los '50, la actividad antropológica se encontraba localizada en museos e institutos universitarios como: el Museo Nacional de Ciencias Naturales "Bernardino Rivadavia" (1823), la Facultad de Filosofía y Letras de la Universidad de Buenos Aires (1896), el Museo Etnográfico de la Universidad de Buenos Aires (1904), el Museo de Ciencias Naturales de La Plata (1884), el Instituto de Etnología de la Universidad de Tucumán (1928) ${ }^{49}$, el Instituto de Etnografía Americana de la Universidad Nacional de Cuyo (1940), el Instituto de Arqueología, Lingüística y Folklore de la Universidad Nacional de Córdoba (1941), el Museo del Departamento de Estudios Etnográficos y Coloniales (1943), el Instituto de Antropología de la Facultad de Filosofía y Letras de la Universidad de Buenos Aires (1947), y el Instituto de Antropología de la Universidad del Litoral, fundado en 1951(Soprano 2006).

\footnotetext{
${ }^{48}$ El cuadro incluye el primer programa de maestría o doctorado abierto en la institución.

${ }^{49}$ Destaca el aporte de Alfred Metraux, recomendado por Paul Rivet para ocuparse del proyecto de formación del Museo de etnográfico y del Instituto de Etnología.
} 
La instrucción general en antropología y disciplinas adyacentes -Arqueología, Folklore, Lingüística, Etnología- se desarrolló en varias de las instituciones antes mencionadas, aun cuando el énfasis estuvo puesto en la investigación. Además, cabe mencionar que la antropología mantuvo presencia como materia de especialización en varias carreras universitarias a nivel de grado y postgrado tanto en Buenos Aires, La Plata y Rosario (Bartolomé 1980; Garbulsky 1993; Ratier 2010). Desde 1904 -inauguración del Museo Etnológico-, y por iniciativa de Juan Bautista Ambrosetti, se dictaron cursos de antropología y arqueología en la "Carrera de Profesor de Enseñanza Secundaria, Normal y Especial en Historia”, esto, en el Museo Etnográfico de Buenos Aires (Guber 2007). En la misma universidad, y específicamente en la carrera de Historia, existió una orientación antropológica en la que se especializa la base del plantel docente que funda la carrera de Ciencias Antropológicas en 1958 (Bartolomé 1980). También cabe hacer mención a la especialización que surge en la Universidad del Litoral Sede Rosario, y que se gesta en el contexto de la fundación del Instituto de Antropología en dicha universidad (1952) bajo la dirección de Antonio Serrano y Alberto Rex González. A partir de la reforma curricular que experimentó la carrera de Historia -Facultad de Filosofía y Letras-, se comenzó a dictar, a partir de 1959, la orientación en antropología, siendo su promotor Alberto Rex González (Garbulsky 2004).

A pesar de estas experiencias, la formación profesional se inicia a partir de 1958 con la apertura del programa de Licenciatura en Antropología en el Museo de Ciencias Naturales de la Universidad Nacional de La Plata, el cual es sucedido por el programa Licenciatura en Ciencias Antropológicas, en la Facultad de Filosofía y Letras de Universidad de Buenos Aires, esto, hacia 1959 (Guber y Visacovsky 1999; Guber 2002; Ratier 2010). Sin embargo, la primera cátedra de antropología social -en el sentido actual-, se crea a inicios de los 60 en la carrera de Sociología de la Universidad de Buenos Aires - por gestión de Gino Germani-, siendo su primer docente el norteamericano Ralph Beals; a partir de 1965 dicha cátedra se incluye en el curriculum de antropología (Garbulsky 1993).

Respecto al primer programa de formación profesional, la Licenciatura en Antropología del Museo de La Plata expresa cierta particularidad, la que está dada por la marcada orientación naturalista del curriculum. Ello obedece a la tradición intelectual que desarrolla el Museo de 
Ciencias Naturales desde su instalación en 1884 y apertura en 1888 (Soprano 2009) ${ }^{50}$, tradición que se consolida en el marco de la formación doctoral que el mismo Museo ofrece desde 1937 en el área de las Ciencias Naturales, y cuyo sello queda establecido en el momento mismo de creación del Museo y su anexión a la Universidad Nacional de La Plata: “... un espacio académico destinado al desarrollo de la investigación, la extensión universitaria y la formación profesional en Ciencias Naturales." (Soprano 2008:118). El Museo ${ }^{51}$, adscrito a la Facultad de Ciencias Naturales y Museo, fue impulsado por su gestor y primer director, Francisco Pascasio Moreno y por Florentino Ameghino, y se desempeñaron allí, en calidad de investigadores visitantes y académicos, connotadas figura de la primera etapa de antropología Argentina e internacional: Samuel Lafone, Roberto Lehmann-Nitsche, Fernando Márquez Miranda, Alberto Rex González, Oswald Menghin, Marcelo Bórmida, Armando Vivante, entre otros (Soprano 2006). La orientación naturalista predomina en el perfil formativo hasta 1966, cuando se produce una reforma que decanta en la definición de tres orientaciones: arqueología, antropología biológica y etnografía. Reflejo de ello, es la creación en 1965 de la cátedra en Antropología Social, a cargo de José Cruz, y posteriormente de Mario Margulis (Ratier 2010).

En la ciudad de Buenos Aires, la conformación de la carrera de Licenciatura en Ciencias Antropológicas es la culminación de varias iniciativas. La creación del ya mencionado Museo Etnográfico en la Universidad de Buenos Aires (1904), que además de desarrollar investigaciones en antropología, arqueología y etnografía, incluía la cátedra de Arqueología Americana -dictada por Samuel Lafón- y de Antropología Física, la cual dictaba Roberto Lehmann Nitsche. También destaca la fundación del Instituto de Ciencias Antropológicas en la Facultad de Filosofía y Letras, la graduación, a partir de 1952, en Filosofía, Letras e Historia con la posibilidad de optar a la especialización en Antropología -básicamente Arqueología y Antropología Física, y la Licenciatura en Folklore en 1954 (Visacovsky, Guber, Guverich 1997). La fundación de la licenciatura (1958) es atribuida a la gestión del epistemólogo Mario Bunge, a los antropólogos José Imbelloni, Ralph Beals, Fernando Márquez Miranda -primer director- y a un grupo de estudiantes de la carrera de Historia. Entre

\footnotetext{
${ }^{50}$ En 1906, y por gestión de Joaquín V. González, el Museo pasó a formar parte de la Universidad Nacional de La Plata (Soprano 2009).

${ }^{51}$ Según plamtea Farro (2009), este museo se nutrió de la colección que reunión y exhibió Moreno en el espacio familiar (1867-1877), y de aquellas trasladadas desde el Museo Arqueológico y Antropológico de Buenos Aires (1877-1884).
} 
los primeros docentes, contaban Fernando Márquez Miranda -historiador-, Oswald Menghin filósofo y prehistoriador- y Ciro René Lafón -Historiador-; el etnógrafo Enrique Palavicino; los especialistas en Folklore Augusto Cortazar - graduado en Literatura- y Armando Vivante Geógrafo-; el arqueólogo-etnólogo Marcelo Bormida -Historiador, con estudios en Ciencias Naturales (Visacovsky, Guber, Guverich 1997). El plan curricular, con una perspectiva muy ligada a la historia, con un marcado predominio del enfoque histórico-cultural (Bartolomé 1980; Ratier 2010), estuvo compuesto por un primer ciclo con las materias de: Historia, Filosofía, Sociología y Ciencias Antropológicas, y que permitía al estudiante contacto con otras carreras de la Facultad de Filosofía y Letras; en un segundo ciclo, doce materias pertenecían al Departamento de Ciencias Antropológicas, de las cuales cuatro eran de etnología, tres de arqueología y prehistoria, tres de Folklore, y una de Antropología Física. Otras materias obligatorias eran dictadas por sociología -Introducción a la Sociología, Sociología Sistemática y Antropología Social-, Geografía -Introducción a la Geografía y Geografía Humana- y Letras -Lingüística. El diseño del plan curricular hacía posible que los estudiantes eligieran entre tres menciones: Etnología, Arqueología o Folklore.

Ya en la década de los '70 se crean nuevas licenciaturas y postgrados; destacan la apertura de la Licenciatura en Antropología en la Universidad de Mar del Plata $(1971)^{52}$ y de una especialización en antropología Social en la Universidad de Salta (1971) -ambas cerradas en las intervenciones militares de 1974-, y la fundación de la carrera en la Universidad de Misiones a partir de 1975 (Bartolomé et al 2007; Gil 2006). Por otro lado, en 1974 Esther Hermitte crea en el Instituto de Desarrollo Económico y Social, el Centro de Antropología Social, dictando cursos y seminarios de especialización en materias antropológicas; esta última, junto a Leopoldo Bartolomé y Carlos Herrán levanta una propuesta de incorporar materias de antropología social a la Maestría de FLACSO.

\footnotetext{
52 Gil (2008) afirma que el programa organizado en la Universidad Nacional Mar del Plata -en la época, universidad provincial- por Eduardo Menéndez, Mirtha Lischetti y María Rosa Neufeld, fue la primera experiencia orientada hacia la Antropología Social en Argentina.
} 
Cuadro No5: Año de institucionalización de formación de grado y postgrado en Antropología en Argentina $^{53}$.

\begin{tabular}{|c|l|}
\hline Año & \multicolumn{1}{c|}{ Institución } \\
\hline 1957 & Museo de Ciencias Naturales, Universidad Nacional de La Plata. \\
\hline 1958 & Facultad de Filosofía y Letras, Universidad de Buenos Aires. \\
\hline 1967 & Facultad de Filosofía y Letras, Universidad Nacional del Litoral. \\
\hline 1969 & Facultad de Humanidades, Universidad Nacional de Mar del Plata. \\
\hline 1971 & Universidad Nacional de Salta. \\
\hline 1975 & Universidad Nacional de Misiones. \\
\hline 1984 & Universidad Nacional de Jujuy \\
\hline
\end{tabular}

Fuente: Bartolomé et al (2007).

53 El cuadro incluye el primer programa especialización, licenciatura, maestría o doctorado abierto en la institución. 


\section{CAPÍTULO III}

\section{Antesala de la institucionalización científica de las ciencias antropológicas en Chile: Estado, ciencia y formación científica nacional}

Como ya se mencionó, el desarrollo de la antropología -y de las ciencias en general- forma parte de un proceso en el cual intervienen factores socio-históricos y culturales de orden global y local, los que generan configuraciones particulares en la disciplina o campo de conocimiento antropológico (Vessuri 1993a). Dichos factores pueden dar origen a lo que diferentes autores han denominado un estilo nacional (Gerhlom y Hannerz 1982; Vessuri 1993b, 1996), el cual se expresa tanto en el contenido cognoscitivo -predominio de ciertas orientaciones de tipo epistemológicas, teórico-metodológicas e incluso éticas- como en la especificidad que adquiere el proceso de institucionalización y organización de la disciplina a escala local -por ejemplo, un país, una región o área dentro de los límites de un país. Sin embargo, más allá de las particularidades nacionales o regionales que pueda exhibir una disciplina, hay que reconocer que ella tiene lugar en un campo de pretensión universal y cosmopolita denominado ciencia, desde la cual se definen -en términos generales- contenidos, alcances y formas de organización social según los criterios de época (Glaser 1963; Vessuri 1991). Por ello, la ciencia debe ser entendida en la tensión entre dicha pretensión universal y su correspondiente vocación internacional, y la concreción local y/o expresión particular, esta última, adquirida según procesos sociales concretos.

Lo anterior se explica debido a que la ciencia, en tanto producto histórico-cultural, se expande en el marco de las dinámicas colonialista e imperialista originadas en Europa a partir del siglo $\mathrm{XV}$, transmitiendo un modelo de sociedad y de hombre que se difunde y encarna en América Latina y el mundo, y que se torna en el sistema de generación de conocimiento hegemónico. Institucionalizar dicho modelo en América Latina, implicó un largo proceso a través del cual se produjo la incorporación de estructuras formalizadas que paulatinamente estandarizaron las operaciones intelectuales y organizativas en conformidad con el canon del quehacer científico, definiendo modelos prescriptivos-normativos y demarcatorios que se impulsan a partir del siglo XVII y consolidan durante el siglo XIX (Ben-David \& Sullivan 1975). La adquisición o reproducción de este modelo permitió legitimar el proceder conforme al ideal de ciencia 
moderno -definir lo que es científico-, consignando como requisito fundamental un objeto de orden cognoscitivo, un cuerpo teórico y un método, lo que se reproduce a través de la formación especializada y su institucionalización en el espacio público (Salomon 2008 $[2006])^{54}$. Ello queda patente en la breve referencia a la institucionalización de la antropología presentada en el capítulo anterior.

Por ello, pensar cualquier iniciativa vinculada al temprano cultivo e institucionalización de una ciencia, implica reconocer que en su primer impulso estuvieron fuertemente imbricados tanto los intereses políticos y económicos de las elites gobernantes como aquellos desplegados por intelectuales y profesionales que se ponen al servicio de empresas gubernamentales, ello con fines técnico-científicos - generación de conocimiento y búsqueda de la verdad- que se entremezclan con el afán de reconocimiento y autoridad en el campo científico local y/o global (Bourdieu 2008).

El proceso de conformación de los estados-nacionales latinoamericanos -en el transcurso del siglo XIX-, se ve acompañado por esfuerzos gubernamentales e individuales dirigidos a la incorporación de la ciencia, ya sea con fines político administrativo y/o de conocimiento. En este sentido, en el imaginario de época la ciencia moderna juega un rol fundamental en la articulación de la doctrina social y política, y la sitúa como central en la consolidación de los emergentes estados nacionales en tanto motor e indicador de progreso y desarrollo económicosocial (Vessuri 1994).

Dicho lo anterior, habría que consignar que la antropología en tanto campo científico o disciplina, surge en la tensión global/local y política/ciencia. En este escenario, la clásica idea de que esta emerge como la ciencia que problematiza la alteridad y se interroga ante la otredad cultural o radical (Krotz 2002; Peirano 2008) ${ }^{55}$, lo que incluso se alza como consigna éticovalórica, puede ser discutida o relativizada. Si reconocemos como objeto formal de la antropología el conocimiento integral -todas las formas o expresiones de vida- de la población aborigen o no occidental, dicho objeto fue más bien una cuestión colateral para los intelectuales y científicos que inician las primeras descripciones de estas poblaciones. Si nos

\footnotetext{
${ }^{54}$ Institucionalizar una actividad, hace necesario contar con condiciones materiales-económicas y humanas para su reproducción y proyección en el tiempo.

${ }^{55}$ Con alteridad radical u otredad cultural, se quiere destacar que la antropología, en su origen, se preocupó por comprender la diversidad cultural -en lo que refiere a organización social, creencias, base material y fenotipocuya expresión fueron pueblos con tradiciones diferentes a la europea, específicamente definidas como indígenas o poblaciones de ultramar (Peirano 2008).
} 
remitimos a la orientación o propósito de los trabajos que en muchos países latinoamericanos son sindicados como pioneros en la disciplina -desde mediados del siglo XIX y principios del $\mathrm{XX}$-, estos tienen lugar en el marco de empresas que se generan por medio de contratos con el Estado y cuyos propósitos iniciales poco tienen que ver con el conocimiento profundo del "otro indígena". Las investigaciones que llevan a la exploración del territorio nacional responden al interés geopolítico de los gobiernos -establecer los límites de la nación y conocer los recursos disponibles para impulsar el desarrollo-, donde las formas de vida y cultura material indígena se aparecen a la experiencia del investigador, quien deja registro de ellas -en algunos casos breves referencias- bajo el entendido que son resabios de un pasado remoto o expresiones arcaicas que desaparecerán frente al progreso. Si bien valiosos, mucho del conocimiento generado a lo largo del siglo XIX y XX contribuye a exotizar y esencializar los rasgos del "otro indígena" fundamentando la reproducción de la diferencia, no necesariamente contribuyendo a una comprensión de los procesos sociales e históricos y las dinámicas en las cuales estos se encontraban insertos (Briones 1998).

Como ocurre en la mayoría de los países latinoamericanos, los precursores y cultores de las ciencias antropológicas fueron especialistas en áreas de conocimiento como la botánica, medicina, ingeniería, geografía, derecho, geología, educación entre otras, quienes de forma paralela a sus labores profesionales -investigaciones o docentes en liceos, institutos o universidades-, realizaban actividades de corte antropológico. Sin embargo, actividades que para algunos analistas representen un hobby o pasatiempo para estos primeros cultores, no dimensiona la pasión y exhaustividad que estos ponían en dichos trabajos, y que deja de manifiesto expresiones constitutivas de lo que Bourdieu ha denominado habitus científico (Bourdieu 2003). Dicha dedicación llevó a muchos de estos precursores de la antropología a abandonar sus oficios iniciales, para dedicarse por completo al desarrollo de esta nueva ciencia.

\subsection{Primeros antecedentes acerca de la preocupación por el otro radical en territorio chileno}

En Chile, la antropología científico-académica se consolida -con relativa estabilidad- hacia mediados del siglo XX, ello, con la fundación de las primeras instituciones de investigación y 
formación que permiten proyectar el quehacer antropológico (Mora 2014). Lo anterior no excluye que la pregunta antropológica y/o preocupación por la descripción de las costumbres y vida material de la población nativa haya surgido con anterioridad, e incluso al margen de lo que denominamos antropología científica. Cómo señala Krotz (2002), la situación de contacto y co-presencia que hace posible el encuentro de diversos grupos a través de los viajes de exploración comercial $\mathrm{y} / \mathrm{o}$ en el marco de la expansión imperial, permite constatar $\mathrm{y}$ experimentar la existencia de un otro, y con ello la emergencia de interrogantes sobre su origen y formas de vida. Dicha interrogante, que se articula en la reflexión acerca de la igualdad en la diversidad (motivada por el extrañamiento), puede adquirir un carácter antropológico al reconocer que tal diferencia es atribuible a una tradición histórica y cultural que posee una racionalidad particular que merece ser conocida y relevada. Algunas de estas consideraciones ya formaban parte del círculo intelectual cercano a la Sociedad de Observadores del Hombre de Paris, quienes sin una total influencia de la ideología de la ilustración, realizan una serie de comentarios y críticas a la forma en cómo se considera o describe a las culturas no europeas; en esta dirección De Gérando señala que:

"A menudo, los viajeros se basan en hipótesis o hechos defectuosos, o por lo menos dudosos... Nada es más común a ellos, por ejemplo, que juzgar las costumbres de los salvajes por analogías extraídas de nuestras propias costumbres, que sin embargo tiene muy poca relación con ellos. Así, según ciertas acciones; atribuyen ciertas opiniones, ciertas necesidades, desde el punto de vista de nuestras necesidades u opiniones. Ellos razonan acerca del salvaje, aun cuando el salvaje no les explique el mismo sus razonamientos. Así, a menudo han señalado sobre una nación frases excesivamente duras, acusándolas de crueldad, robo, libertinaje y ateísmo. Hubiera sido más prudente obtener un gran número de datos antes de tratar de explicar y admitir supuestos, sólo después de agotar todas las luces de la experiencia" (1800:9).

Para efectos de esta investigación la antropología, en tanto práctica institucionalizada, se diferencia de aquella inquietud o curiosidad intelectual que se proyecta desde la esfera privada a través de esfuerzos y capitales personales, o de aquel registro que se objetiva en crónicas e 
informes de viajeros y militares con propósito de notificar a autoridades regionales, administradores o gobernantes. Si bien, el conocimiento generado en los marcos anteriormente descritos es sin duda relevante, dicha relevancia no necesariamente la permite inscribir en lo que se define formalmente como antropología. La antropología emerge cuando se destinan recursos financieros, infraestructura, medios técnicos y profesionales que permiten la emergencia de una comunidad-identidad -que se diferencia de otras ciencias o campos de conocimiento- que adquiere consciencia de campo y que está dispuesta a jugar el juego, proyectándose en el tiempo (Becher 2001 [1989]; Bourdieu 2003 [2001]). Es decir, se delimita un área de conocimiento y se aborda sistemáticamente, generando investigación que se comunica y formación de capital humano desde el cual se busca influir en el espacio intelectual y/o científico-académico a través de publicaciones de alcance nacional e internacional.

Al margen de aquello, hay que reconocer que la preocupación por la población indígena en Chile es temprana; en 1909 y 1910 Carlos Porter publica dos trabajos en los cuales identifica una serie de obras -en distintos formatos- que refieren a dicha población, las que se ubican entre 1843 y 1906. Sin embargo, y como es de pleno conocimiento, la descripción de la población nativa a través de mecanismos de registro escrito es anterior, y se sitúa en el denominado periodo de conquista y colonia española, teniendo lugar entre los siglos XVI y XVII. Podemos mencionar una serie de documentos, entre otros, aquellos producidos por: Gerónimo de Vivar (Relación copiosa y verdadera del Reyno de Chile, 1558), Alonso Góngora Marmolejo (Historia de Chile, 1535-1576), Pedro Mariño de Lobera (Crónica del Reyno de Chile, 1598); se suman los trabajos de Alonso de Ovalle, Felipe Gómez de Vidaurre, Juan Ignacio Molina, Miguel de Olivares, Diego de Rosales, Alonso González de Nájera, Francisco Núñez de Pineda y Bascuñán, Vicente de Carvallo y Goyeneche y José Antonio Pérez García (estos dos últimos, para el siglo XVII).

En su mayoría, estos informes fueron escritos con propósitos militares o evangelizadores por parte de soldados y sacerdotes que participaron en las campañas de conquista y exploración del territorio, quedando dicho registro objetivado en el género denominado relaciones y crónicas de conquista y colonización (Mignolo 1982). Este se enmarca en el tipo de comunicaciones de carácter oficial, y sigue la forma de un cuestionario o interrogatorio extenso sobre una materia, por lo general vinculada a actividades administrativas o religiosas. 
Como aclara Mignolo (1982), el objetivo central de estos documentos fue brindar información para el establecimiento de sistemas gubernamentales, siendo fundamental la distinción entre tradiciones indígenas compatibles con el orden social de la corona versus aquellas que se deben erradicar. En tal sentido, una crónica supone la narración de verdades por parte de un hombre sabio o letrado y de integralidad moral -criterio de validez y confiabilidad-, la cual está determinada por la estructuración temporal que organiza una serie de fechas y acontecimientos; puede llegar a conformar un relato incorporando una elaboración discursiva y figuras retóricas. Sin embargo, si se parte de la consideración de la crónica como una construcción discursiva y no como una adscripción objetiva, y se sopesa con precaución los antecedentes que brinda, veremos que permite no sólo conocer ciertos antecedentes de la población nativa, sino también el imaginario europeo que se materializa en la forma de representación del otro que se adopta en el texto.

Otra fuente de información que entrega referencias indirectas sobre la población nativa de nuestro país, se enmarca en las primeras expediciones con fines científicos-naturalistas y militares, las que tienen lugar en el periodo de la colonia -siglo XVIII. Al hablar de referencia indirecta, se destaca la idea que esta población no conforma el "objeto" central o exclusivo de conocimiento de dichas empresas ${ }^{56}$. Lo anterior se entiende en el impulso que da la Corona española al desarrollo de la ciencia y la cultura conforme la política que ya se estaba implementando en varios países de Europa occidental, y que denotaba una particular preocupación por el hombre americano, el cual había sido olvidado a partir del siglo XVII (González 1992). En este contexto, los objetivos militares, geopolíticos y mercantiles ${ }^{57}$ en muchos casos se mezclaban con el interés o curiosidad científica de algunos especialistas que integran estas expediciones -naturalistas y cartógrafos- ${ }^{58}$, y que motivan la exploración de los territorios sur-australes de la Corona Española -que también despiertan el interés de la Corona

\footnotetext{
${ }^{56}$ Objeto, se refiere a la definición clásica de objeto de estudio sobre el cual se levanta la antropología: las culturas primitivas, salvajes, no occidentales, indígenas; es lo que más tarde se sintetizó como problematización de la otredad cultural u otredad radical, poniendo acento no en la población concreta, sino en la definición del contenido relacional, de los marcos de comprensión de dicha realidad, y de las formas de autodefinición y/o interpretación puestos en juego por dichos sujetos.

${ }^{57}$ De hecho, Alessandro Malaspina declara que su expedición corresponde a un viaje político-científico alrededor del mundo, dejando expreso que sus objetivos fueron “... la construcción de cartas hidrográficas para las regiones más remotas de América, y de derroteros que puedan guiar con acierto la poco experta navegación infantil; y la otra la investigación del estado político de América, así relativamente a España como a las otras naciones extranjeras." (en De Novo y Colson 1885).

${ }^{58}$ En este contexto surge la figura del "soldado científico" (Vessuri 2007:71).
} 
Francesa y el Imperio Prusiano-Alemán. De este modo, se buscó expandir los conocimientos sobre las especies naturales, la geografía y población nativa en un intento por recuperar la historia original natural del hombre de estas tierras (González 1992) en el marco de lo que Basalla (1967) ha definido como la fase de exploración como recurso para la ciencia europea, primera de tres etapas de su modelo de difusión ${ }^{59}$.

En esta dirección, una de las primeras iniciativas es la encabezada por el ingeniero militar francés Amadée François Frezier, quien en 1716 publica la monografía "Relación del viaje por el mar del sur a las costas de Chile y Perú". En ella Frezier resume el trabajo de observación efectuado en Chile entre 1712 y 1713, y que hace posible la exploración del Estrecho de Magallanes, Cabo de Hornos, Tierra del Fuego, las fortificaciones de Valdivia, Concepción y Valparaíso, realizando informes de la vida social, política y comercial asociada a estos puertos. Además, recorre Santiago y lleva a cabo estudios mineralógicos en Til-Til, Limache, Quillota, dirigiéndose posteriormente a Coquimbo, La Serena y Arica (Frezier 1902) ${ }^{60}$, e incorpora algunas notas e ilustraciones sobre las costumbres mapuche en el capítulo titulado "Los indios de Chile". También caben destacar los aportes al conocimiento de la región por parte del fraile francés -botánico y Astrónomo- Louis Feuillée, quien plasma en publicaciones entre 1714 y 1725 descripciones de la flora, fauna, situación geográfica y astronómica de la zona de Concepción y la bahía de Valparaíso, esto, fruto del viaje realizado en 1709.

Algunos años más tarde tiene lugar la expedición encabezada por el ingeniero y alférez de fragata José de la Moraleda i Montero, quien recorre las costas de Perú y Chile realizando registros de orientación geográfica e hidrográfica en Chile entre noviembre de 1772 y abril de 1773, desarrollando además expediciones en la zona de Chiloé, Maullín, Calbuco y Palena, de las cuales levanta una detallada cartografía (Barros Arana 1888). A esta se suma la expedición española encabezada por el botánico Hipólito Ruiz y el farmacéutico José Pavón, quienes entre 1777 y 1788 recorren el territorio realizando un catastro de flora y fauna de las costas de

\footnotetext{
${ }^{59}$ Basalla (1967) propuso un modelo difusionista de tres estadios que permitirían describir el proceso de introducción de la ciencia en las naciones no europeas, y que identifica las siguientes fases: exploración científica, ciencia colonial y formación de una tradición científica independiente. Si bien dicho modelo ha sido ampliamente criticado, por su carácter lineal, homogenizante y eurocéntrico, ha suscitado una serie de respuesta que han permitido su complementación así como propuestas alternativas (MacLeod 1982; Krishna 1992; Raina 1999).

${ }^{60}$ Si bien esta expedición se realiza bajo los auspicios del Rey de Francia Luis XIV, y su objetivo posee una orientación geopolítico-militar dirigida a evaluar la defensa militar de las costas del sur de manera de hacer frente a la invasión Holandesa e Inglesa, contiene información relevante para el trabajo de naturalistas e historiadores del siglo XIX (Peña 1902).
} 
Chile y Perú. La expedición permanece en Chile por 22 meses, llegando al puerto de Talcahuano en enero de 1782 y comenzando el trabajo de registro de la Flora en las inmediaciones de Concepción ${ }^{61}$, dirigiéndose posteriormente a Santiago de Chile y Valparaíso (Rodríguez y González 2007).

La expedición que más destaca para el periodo colonial español -por sus pretensiones-, es la dirigida por el Brigadier Italiano Alessandro Malespina y el marino José Bustamante y Guerra. Comisionada por la Corona Española, tuvo como objetivo la exploración y descripción del medio natural y físico comprendido en el territorio bajo dominio de la Corona Española. Malespina contó con los servicios del naturalista nacido en Bohemia -hoy República ChecaThadeus Haenke, quién tras la llegada a Chile -en abril de 1780-, realiza un trabajo de caracterización del entorno natural y mineral de las zonas de Valparaíso, Santiago de Chile y Archipiélago de Juan Fernández; además integró información de la vida social, agricultura y comercio de estas áreas, realizando comentarios generales sobre la población indígena al sur de Santiago (Haenke 1942). Esta exploración permite a Haenke escribir entre 1789 y 1794 la obra "Descripción del Reyno de Chile".

Si bien en la época no es posible encontrar abundantes trabajos de orientación científicanaturalista realizados por criollos chilenos, es notable la obra producida por el Abate Juan Ignacio Molina, sindicado como el primer científico nacional. El trabajo de Molina es reconocido por su calidad en Europa - es aceptado en la Docta Academia de Ciencias del Instituto de Bolonia-, donde desarrolló gran parte de su actividad científica debido al exilio que sufrió la orden jesuita en 1767. Sus obras más destacadas fueron "Ensayos sobre historia natural de Chile", "Ensayos sobre la historia civil del Reyno de Chile" y "Memorias de historia natural", la primera publicada en 1782, la segunda en 1787 y la última en 1829 (Hanisch 1974; Jaramillo 1986). Molina incorpora en su "Historia Civil" algunas reflexiones acerca de la población indígena de Chile, en particular de su desarrollo evolutivo y su civilidad, estableciendo comparaciones con la sociedad europea.

\footnotetext{
${ }^{61}$ Ruiz tiene oportunidad de presenciar un desfile y ceremonia con Indígenas, la que tiene lugar en el fuerte Arauco en febrero de 1783, realizando algunos comentarios respecto a su aspecto físico y forma de vida (Rodríguez y González 2007).
} 


\subsection{Investigación científica, producción intelectual y formación académica.}

\subsubsection{Investigación científica}

La ciencia nacional, como proyecto de la elite gobernante, comienza su desarrollo con el inicio de un ciclo de expansión que experimentó el país entre 1830 y 1878 (Cariola y Sunkel 1982) ${ }^{62}$. En este periodo, no exento de episodios de inestabilidad social, política y económica de alcance nacional e internacional (Cariola y Sunkel 1982; Fernández 2008), el Estado de Chile buscó establecer soberanía efectiva dentro de sus límites geográficos, y con ello dar inicio a la construcción de la nación con base en: a) una política autoritaria, b) una economía orientada a hacia mercados internacionales, y c) la puesta en escena de estrategias dirigidas a la construcción de referentes identitarios que permitieran el levantamiento de un proyecto común (Pinto 2000; Larraín 2001).

Destacan el esfuerzo en la reorganización y consolidación de un Estado fuerte a través de la creación de diversos cuerpos legales, lo que permitió el control social de la población a través de un sistema de gobierno centralizado que subordina a cualquier gobierno provincial (Pinto 2000). Para logar la consolidación política y económica, el Estado impulsa medidas proteccionistas continuadoras de la tradición mercantilista conservadora, las que estimularon la economía nacional manufacturera y mercante, ello, por medio de una política altamente jerarquizada, centralizada y autoritaria que hizo posible el sostenimiento de un modelo económico exportador (Cariola y Sunkel 1982; Pinto 2000; Larraín 2001). A través de esta política se buscó garantizar la inserción de la economía chilena a nivel internacional, profundizando la conexión con mercados tradicionales como Perú, y estableciendo nuevas relaciones comerciales con California, Australia e Inglaterra a través de la exportación minera -oro y principalmente plata y cobre- y agrícola, fundamentalmente triguera (Cariola y Sunkel 1982; Pinto 2000; Larraín 2001).

Al mismo tiempo, fue una etapa marcada por la dinamización de la economía nacional a nivel interno, la que tuvo lugar en el marco del descubrimiento de nuevos yacimientos y la incorporación de tecnologías para la explotación minera y de manufactura. A ello se suma la reactivación de la producción agrícola en el sur del país a la luz de la demanda nacional que

${ }^{62}$ El primer ciclo se define entre 1830 y 1878, en tanto el segundo, entre 1880 y 1930. 
provenía de la zona norte -efecto de la expansión territorial y aumento de población-, lo que se asocia al auge de la industria de la minería en dicha zona, así como al crecimiento y emergencia de varios centros urbanos a lo largo del país (Cariola y Sunkel 1982).

La consolidación del Estado hace necesario fijar los límites del territorio nacional ${ }^{63}$, de modo de establecer soberanía y proyectar la política económica para impulsar el desarrollo. Ello implica adquirir conocimiento cabal de los recursos naturales y poblaciones comprendidas en dichos límites, de modo de detectar áreas de expansión de fronteras e inventariar los recursos existentes, lo que descansa en el convencimiento -por parte de la clase política-, que las riquezas naturales presentes en el territorio permitirían un rápido desarrollo del país, con independencia de cualquier proyecto panamericano (Pinto 2000).

Por ello, la constatación científica de riquezas naturales presentes en el territorio fundamentó la estrategia expansiva del Estado, y además, sienta las bases para impulsar la ciencia nacional y la formación de especialistas. Ello ocurre en una época en la cual el conocimiento científico va adquiriendo gran valoración en el marco de la tradición ilustrada europea. Destaca la emergencia de una nueva perspectiva inspirada por la filosofía positiva, la que es adoptada y promovida por la élite intelectual latinoamericana, y cuya expresión política se materializa en el liberalismo. El imaginario de la modernidad sitúa a la ciencia y el conocimiento científico como medio objetivo y orientación fundamental para trazar la proyección del país.

A modo de ejemplo, bajo la Dirección Suprema de Ramón Freire se decreta, en junio de 1823, la realización de un viaje científico por todo el territorio nacional, tendencia que será parte de la política de varios gobiernos durante el siglo XIX y principios del XX. En dicho decreto, Freire plantea que el objetivo de esta expedición sería:

“... examinar la jeolojia del país, sus minerales i demás pertenecientes a la historia natural: todos los datos que puedan contribuir a formar una exacta estadística de Chile, señalando los puntos en que sean navegables los ríos i los lugares a propósito para el establecimiento de fábricas, los puertos, canales $\mathrm{i}$ caminos que puedan abrirse para facilitar la comunicación i comercio, designando

\footnotetext{
${ }^{63}$ Es así como la constitución de 1822 establece jurídicamente los límites territoriales -subsumiendo aquellos ocupados por la población indígena-, lo que es ratificado en las constituciones de 1828 y 1833, reconociendo como límites: norte a sur desde el desierto de Atacama hasta el Cabo de Hornos, y de oriente a occidente, desde la cordillera de los Andes al océano Pacífico, incluyendo la isla de Chiloé y el archipiélago de Juan Fernández (Fernández 2008).
} 
los medios de fomentar la agricultura, i los territorios a propósito para el cultivo de las primeras materias e industrias, i proponiendo por fin último los arbitrios más adaptables para conseguir estos fines" (Barros Arana 1876:3).

Por ello, es posible afirmar que la ciencia en general fue pensada como funcional a la consolidación de la nación, lo que permite precisar que la categoría nation building que Peirano (1980) y Stocking (1982) utilizan para caracterizar el surgimiento de ciertas antropologías, puede ser extendida hacia otros campos de conocimiento que se estructuran desde fines del siglo XIX. Habría que agregar que la ciencia es impulsada desde la elite gobernante en tanto fundamento para concretar el ideal de nación moderna, recurriendo para ello al modelo hegemónico de ciencia -la ciencia europea- y especialistas extranjeros con el objetivo de legitimar dicho proceso gracias a la formación especializada y conocimiento adquirido. Es decir, la ciencia transita entre un ideal de ciencia nacional, que tiene que ver con generar un conocimiento del territorio y formar a con-nacionales a través de un impulso difusor por medio de la radicación de científicos y expertos extranjeros, y la reproducción del canon de época para la ciencia moderna. Estos expertos europeos exploran el territorio e informan en detalle acerca de los recursos naturales a través de trabajos de corte monográfico; así también instruyen a los gobiernos en la gestión de los recursos catastrados en el marco del plan de explotación de las materias primas, y en líneas formativas ligadas a la educación primaria, secundaria y universitaria (Cariola y Sunkel 1982; Pinto 2000; Fernández 2008). Dicho reclutamiento forma parte de una política de Estado, la que queda manifiesta en 1818, cuando Bernardo O’Higgins y Joaquín Echeverría envían al diplomático José Irisarri a la Corte de Londres, con el fin de promover la migración de científicos y especialistas al país, declarando que:

"No hay un ramo de la industria y la agricultura del Reino de Chile que no requiera del auxilio de los conocimientos europeos... Pero sobre todo, será infatigable en incitar a hombres científicos en mineralogía, maquinaria, química, economía política, matemática, historia, geografía y demás ciencias útiles, llamando a Chile la mayor porción de hombres capaces de formar un plantel de instrucción común y elegante.” (González 1984 en Gutiérrez 2011). 
Requerimientos similares son entregados en 1824 a Mariano Egaña, Ministro Plenipotenciario en Londres, a quién se le encomienda atraer hombres instruidos, y especialmente profesores para los institutos científicos, rama industrial y museos, incentivo que queda reflejado en la constitución de 1823, en la cual se concede la nacionalidad por gracia a cualquier extranjero experto que ha enseñado o traído al país alguna invención (Gutiérrez 2011). Consignar que la actividad inicial en investigación se ve impulsada con la creación, por decreto del gobierno promulgado el 10 de diciembre de 1823, de una Academia Chilena destinada al cultivo y fomento de las ciencias y las artes, encargada de divulgar sus descubrimientos, establecer vínculos con otras sociedades científicas, e iniciar los trabajos de investigación que se le encomendaran (Barros Arana 1876). Por motivos económicos y políticos -conflictos y luchas internas-, dicha academia nunca se concretó.

Conjugando intereses científicos y políticos en la naciente República, bajo Gobierno de Ramón Freire y la supervisión de Mariano Egaña, se comisiona a Juan José Dauxion Lavaysse -militar francés y naturalista-, la exploración científica del territorio (Barros Arana 1876). En diciembre del mismo año, se encomienda a los franceses Coronel de Ingenieros Alberto d'Albe e Ingeniero Carlos Ambrosio Lozier la elaboración de estadísticas, cartografías y topografías con fines militares y para el desarrollo de la industria (Barros Arana 1876). Más tarde, en 1830 y bajo el mandato de Tomás Ovalle, el Gobierno Chileno contrató por un plazo de tres años y medio a Claudio Gay (1800-1873 $)^{64}$, esto, con el objetivo que llevase a cabo la exploración del territorio de la República. En dicho contrato, difundido a través del periódico El Araucano, se consignaba que el objetivo de dicha empresa era:

“... estudiar la historia natural de Chile, su geografía, jeología, estadística i cuanto contribuya a dar a conocer las producciones naturales del país, su industria,

\footnotetext{
${ }^{64}$ Gay fue sin duda uno de los primeros naturalista que realiza un trabajo sistemático en Chile, con una experiencia previa en los Alpes, las canteras de Carrara en Italia, y como colector del Museo de Historia Natural de París, recorriendo Grecia y algunas islas del oriente de Asia Menor. Además, recibió formación en Medicina y Farmacia, Botánica, Entomología, Física, Química, Anatomía comparada, los que siguió en París, primero en la Universidad de la Sorbonne y posteriormente en el Museo Histórico Natural (Barros Arana 1876). Llegó en 1828 a Chile a raíz del contacto que establece en París con el aventurero francés Pedro Chapuis, quien reclutaba a profesores con el objeto de abrir un colegio en Santiago de Chile. Si bien el proyecto de Chapuis fracasa, siendo desplazado de la dirección del proyecto, Gay es contactado por el Presbítero Juan Meneses para asumir como profesor de Física e Historia Natural en el recién creado Colegio de Santiago, el cual tuvo como segundo director a Andrés Bello. Después de dos años de funcionamiento, el colegio es absorbido con la creación del Instituto Nacional (Barros Arana 1876).
} 
comercio i administración i presentar al gobierno en el término de cuatro años, por medio de una comisión que inspeccione sus trabajos..." (Barros Arana 1876:35).

El trabajo de Gay da lugar a la publicación "Historia Física y Política de Chile", la que consta de 29 volúmenes cuyo último tomo publica en 1871. Además, realizó diversos viajes a Francia con el objetivo de difundir los resultados de investigación en la comunidad científica internacional, lo que le valió reconocimiento al ser aceptado como miembro de la Sociedad Científica de París. Destacaron en Gay el espíritu científico que imprimió a su trabajo como naturalista e historiador sistemático y basado en un método que se remite a datos recolectados ya sea como evidencia natural o proveniente de fuentes archivísticas (Sagredo 2007). El mismo contrato firmado por Gay estipulaba que éste debía constituir un Gabinete de Historia Natural -que dará lugar al Museo de Historia Natural hacia 1837-, y cuyo objetivo fue alojar y dar a conocer los materiales recolectados en las empresas científicas. El trabajo encomendado a Gay marca un precedente para la ciencia nacional, en tanto la conformación del Gabinete materializa la proyección del quehacer científico, siendo el primer hito en la institucionalización de la ciencia en el país.

Con el mismo objetivo de investigación, el Gobierno de Manuel Bulnes contrata en 1848 al geógrafo y geólogo francés Pierre Joseph Noel Aimé Pissis Marín (1812-1889) ${ }^{65}$, ello, como complemento a la labor que se encontraba desarrollando Claudio Gay en el marco del contrato con la administración de José Joaquín Prieto, y que al momento no había expuesto resultados (González y Andrade 2011). Dicho contrato, firmado por el Ministro del Interior Manuel Camilo Vial, establece que Pissis deberá realizar estudios geológicos, topográficos y mineralógicos por un máximo de tres años, además de levantar cartas y mapeo mineralógico del territorio nacional. Su actividad de campo y gabinete fue realizada entre 1848 y 1868 , y consideró la exploración del territorio comprendido entre el desierto de Atacama y la región de La Araucanía. La publicación de los resultados de su trabajo se vertió en la revista Anales de la Universidad de Chile, donde publica: "La descripción geológica de la República de Chile e Informe y nuevo examen y análisis sobre el carbón fósil del Estrecho de Magallanes"

\footnotetext{
${ }^{65}$ Pissis había estudiado en la Escuela Politécnica de París, la Escuela de Minas y el Museo de Historia Natural. Además, formó parte de la Sociedad Geológica de Francia y de la Academia de Clermont Ferrand. Con anterioridad a su llegada al país, prestó servicios como investigador en Brasil y Bolivia (González y Andrade 2011).
} 
(1850); "Descripción de la Provincia de Valparaíso" (1852), "Plano topográfico y Geológico de la Provincia de Aconcagua" (1859). En 1873 publica en París el Plano topográfico y geológico de la República de Chile, y en 1875 "Geografía Física de la República de Chile” (González y Andrade 2011).

\subsubsection{La formación profesional}

Si bien algunos extranjeros que llegan a Chile son reclutados por el Gobierno para cumplir directamente funciones de investigación -incorporándose posteriormente a la formación ${ }^{-66}$, varios de los que contribuyen de manera notable al desarrollo de la ciencia nacional son contactados para asumir labores formativas a nivel secundario y universitario, estableciendo contratos con el propio gobierno o con empresas particulares. En esta línea destaca Claudio Gay, quién llega a Chile para cumplir tareas docentes en el marco de un proyecto de origen privado, siendo posteriormente contratado en su calidad de científico. A él se suma Ignacio Domeyko (1802-1889), contactado por Carlos Lambert -ingeniero en minas de origen francés y avecindado en Chile-, para ocupar la plaza de profesor de química y mineralogía en el Liceo San Bartolomé de La Serena ${ }^{67}$. Domeyko arriba a Chile procedente de París en 1838, dedicándose en los primeros años a la enseñanza, la que complementó con viajes de exploración en las inmediaciones de La Serena y Coquimbo, además de recorrer la zona sur del país, entre la ciudad de Concepción y Valdivia (Pinto 2010). Su trabajo fue publicado en los Anales de Minas de París, y su calidad de profesor y científico fue reconocida por las autoridades de la época, quienes revisaron con atención los informes de investigación que Domeyko difundía. Además, tomaron conocimiento de diversas propuestas que éste había elaborado: la necesidad de una reforma en la educación pública en el país, y un plan que incorporaba recomendaciones para la explotación minera (Pinto 2010). Ello le valió la designación como profesor del Instituto Nacional (1847) y como Académico del Claustro de la Universidad de Chile, casa de estudios en la cual llega a ocupar el cargo de rector.

\footnotetext{
${ }^{66}$ A modo de ejemplo, el mismo Pissis desempeñó tareas académicas en la Facultad de Ciencias Físicas y Matemáticas de la Universidad de Chile, lo cual se hace posible gracias a su labor cómo investigador contratado por el Gobierno de Chile.

${ }^{67}$ Domeyko tenía formación universitaria en la Universidad de Vilna -Lituania-, los que posteriormente completó en París, asistiendo a la Universidad de la Sorbona y el Colegio de Francia, graduándose en la Escuela en Minas de París.
} 
Otro destacado hombre de ciencias fue Rodulfo Amando Philippi (1808-1904), naturalista nacido en Alemania y titulado como médico en la Universidad de Berlín (1830), quién desarrolla una importante labor en el campo de la zoología y botánica -trabajos que comienza a desarrollar a partir de 1830 en la zona de Nápoles y Sicilia-, publicando su primera obra científica en 1836 -sobre el tema de los moluscos (Barros Arana 1904; Orellana 1996). Tras su llegada a Chile en $1851^{68}$, asume como Rector, por gestión de Vicente Pérez Rosales, del Colegio de Valdivia hasta el año 1853; el 10 de octubre de ese año -y con el apoyo de Andrés Bello- recibe el ofrecimiento para impartir docencia en las cátedras de Zoología y Botánica en la Universidad de Chile, y el 20 de octubre, se le solicita ocupar la plaza de Director del Museo Nacional de Historia Natural (Barros Arana 1904). El 9 de noviembre del mismo año, el Gobierno le comisiona para realizar la exploración y reconocimiento del desierto de Atacama, con el objetivo de describir la geología y caracterizar las especies minerales, así como obtener datos geográficos de esta región, antecedentes que publica en una serie de revistas europeas (Barros Arana 1904). Entre las actividades docentes desarrolladas por Philippi, destaca su nombramiento como profesor del Instituto Nacional, dictando su primera cátedra referida a la Historia Natural en 1866 a la que se suma más tarde la de Geografía Física. Además, y producto de su labor en el Museo, Philippi realiza la descripción y catalogación de material arqueológico y de historia natural que se encontraba almacenado, así como de trabajos de orientación etnológica (Barros Arana 1904; Orellana 1996). En los diversos viajes de Philippi, se manifiesta el interés por describir a las poblaciones indígenas que habitan las regiones visitadas, particularmente a Changos y Atacameños, además de detallar antiguos asentamientos, ruinas y recolectar material arqueológico para la colección del Museo Nacional (Orellana 1996). Philippi publica en 1869 un estudio descriptivo de la población mapuche de la provincia de Valdivia en la revista alemana "Das Ausland".

A estas figuras que aportan significativamente a la ciencia en Chile a través de la investigación y docencia, se suman: Ludwig Darapsky (1857-1916), naturalista nacido en Alemania, Dr. en Química (Universidad de Wuzburg) y Geografía (Universidad de Liepzig), realiza su trabajo en mineralogía y escribe sobre lengua araucana, siendo profesor de la

\footnotetext{
${ }^{68}$ Philippi llega a Chile motivado por su hermano Bernardo, quien había sido comisionado por el Gobierno de Chile para cumplir la función de agente promotor de la colonización europea en el sur del país, estableciéndose en un primer momento en San Juan de Bellavista, hacienda propiedad de su hermano en las cercanías de la ciudad de la Unión.
} 
Universidad de Chile y miembro de la Sociedad Científica Alemana y ayudante en el Museo de Historia Natural; Francisco Fonk (1830-1912), médico nacido en Renania, y que realiza en el país estudios en geografía y arqueología; Rodolfo Lenz (1863-1938), nacido en Sajonia Prusia-, llega a Chile en 1890 para ejercer como profesor de idiomas en el Instituto Pedagógico, realizando investigaciones y publicaciones en el área de la lingüística y particularmente el maрисеzиgu -lengua del pueblo mapuche; Ricardo E. Latcham (18691943), nacido en Inglaterra y de profesión ingeniero, contratado para la preparación de los asentamientos e infraestructura vial para la colonización del sur, y se desempeñó como profesor y Decano de la Facultad de Bellas Artes de la Universidad de Chile, siendo director del Museo Nacional y uno de los fundadores de la Sociedad Chilena de Historia y Geografía. Otras figuras destacadas fueron Martín Gusinde, sacerdote Alemán que llega a Chile como profesor de Ciencias Naturales del Liceo Alemán en 1912 y que posteriormente desarrolla un carrera como etnólogo, y Max Uhle, arqueólogo alemán que había trabajado en Bolivia y Perú, y que fue contratado como encargado de la sección de Prehistoria del Museo Nacional y posteriormente funda el Museo de Etnología y Antropología, permaneciendo en Chile entre 1912 y 1919 (Hamp 1998). Uhle puede ser sindicado como el primer arqueólogo de profesión -es decir, con formación universitaria- que llega a Chile, y en tal sentido, el primero en colaborar en la creación de una institución de orientación antropológica como fue el Museo de Etnología y Antropología. Estos últimos investigadores serán referidos en el siguiente capítulo.

La emigración de estos intelectuales y profesionales extranjeros se entiende debido a que la naciente "comunidad científica internacional" busca expandir los conocimientos sobre áreas más bien desconocidas, lo cual actúa como motivación para radicarse en regiones distantes de Europa $^{69}$. La posibilidad de descubrir la existencia de nuevas especies constituye un incentivo para la ampliación de conocimientos del medio físico y natural, así como para la obtención de reconocimiento en la comunidad internacional (Saldivia 2004). Por otro lado, la mayoría de la producción científica generada en la empresa de conocimiento estatal, es destinada -por parte

\footnotetext{
${ }^{69}$ Además, cabe señalar que en la mayoría de los casos, los científicos que se radican en Chile tenían al momento de emigrar posiciones más bien marginales, e incluso totalmente desvinculadas del campo científico europeo. $\mathrm{Su}$ establecimiento en la región les permite situarse no sólo en el circuito nacional, sino también Latinoamericano e incluso europeo.
} 
de los especialistas- a circular en el campo científico nacional, latinoamericano y europeo por medio de la publicación de libros o artículos.

La revisión de estos antecedentes permite afirmar que desde el Estado se privilegia el desarrollo de ciertos campos de conocimiento por una necesidad práctica ligada a impulsar el crecimiento económico, y con ello responder al modelo de sociedad moderna y evolucionada que resultaba el canon de la época. Con esta lógica se promueve una política educativa que buscaba elevar el nivel intelectual de la población y desarrollar la formación de capital humano que contribuyera al país (Larraín 2001). La nación se concibe como unitaria, y el indígena se ve como un obstáculo al desarrollo, siendo necesario integrarle; en base a estas ideas se fundamenta la ocupación y colonización de los territorios indígenas al norte y sur del país. Cómo señala Fernández (2008), la élite nacional articula la "metáfora del desierto", la que pone en juego una retórica que justifica la empresa civilizatoria en tanto deber moral del Estado, y que se plasmó en un discurso que expresaba la necesidad de liberar al indígena de "estado de barbarie" al mismo tiempo que garantizaba la ocupación "racional" del territorio en aras del progreso económico, social y cultural que debía operar en el mundo moderno.

Por otro lado, la intención de transformar a Chile en una nación moderna, descansa en la profunda admiración por el estilo europeo, estilo que busca ser reproducido por parte de los grupos dirigentes (Pinto 2000). El diagnóstico de la época concluye que la riqueza natural del país contrasta con la escasa y limitada preparación de sus habitantes, lo que hace imposible pensar en el progreso nacional en tanto no se cuente con una población educada y con profesionales y científicos que contribuyan al desarrollo de éste (Pinto 2000). Dicho diagnóstico se basa en la noción de cultura-civilización promovida por la elite francesa, y que junto al evolucionismo se constituyen en referentes intelectuales para Latinoamérica del siglo XIX. Mientras cultura se entiende como estado del cultivo de la mente por medio de la instrucción o estado del individuo que tiene cultura -individual-, civilización pasa a ser concebida como el logro cultural de un pueblo que ha alcanzado el progreso y con ello el estado de civilización -colectivo (Cuche 2002). Desde la equivalencia entre cultura y civilización se establece la distinción entre un estado "natural o bárbaro" y otro "cultural y civilizado". Ello constituye precisamente el motor que inspira las reformas educativas y culturales del Estado, las que buscaban la preparación moral del pueblo, imponiendo el dominio de la razón y formando nuevos ciudadanos disciplinados, obedientes y leales a la 
patria (Pinto 2000). La educación se convierte en la clave que legitima la política de intervención sobre grupos sociales subalternos; desde un orden moral, se piensa la cultura y civilización como un derecho y una condición necesaria para la humanidad, que se logra a través de la instrucción formal.

En este marco, se vuelve a pensar en la contribución de intelectuales y profesionales extranjeros contratados como especialistas en diversas materias (Cariola y Sunkel 1982), la mayoría de ellos con graduación universitaria en sus países de origen. Su función también se liga a la promoción y fortalecimiento de una política en educación superior moderna, y con ello, brindar un fuerte impulso al desarrollo de la ciencia nacional, proyectando la profesionalización de la actividad científica y académica a través de la formación de especialistas nacionales (Serrano 1994; Saldivia 2004). Ello es posible en un periodo de auge económico, que a partir de 1830 permite una fuerte inversión para el fomento a la educación ${ }^{70}$, tecnología, ciencias y el conocimiento de los recursos del país, la que será continuada por la mayoría de los gobiernos (Cariola y Sunkel 1982; Fernández 2008).

En este contexto, tiene lugar un primer esfuerzo dirigido a la creación de instancias de educación primaria y profesional universitaria, incorporando el canon transmitido desde el sistema de educación y ciencia europea. El impulso científico se ve acompañado por la fundación de la Universidad de Chile, lo que se complementa con diversas iniciativas como son: sociedades científicas, la edición de revistas especializadas, la celebración de congresos y reuniones -aspectos que serán profundizados en el siguiente apartado.

En esta dirección, mediante decreto del Presidente Manuel Bulnes, el 19 de noviembre de 1842 se funda la Universidad de Chile, siendo la elaboración de la Ley Orgánica que establece y regula su funcionamiento encomendada a Andrés Bello ${ }^{71}$ por el entonces Ministro de Educación Don Manuel Montt. Esta institución, designada como superintendencia de educación del país, incorpora una visión moderna de corte académico que promueve la investigación y formación de científicos conforme los cánones de ciencia de la época ${ }^{72}$.

\footnotetext{
${ }^{70}$ Intelectuales como Sarmiento -elegido Director de la Escuela Normal de Preceptores fundada en 1842 contribuyen a la promoción de la educación primaria -vista como motor del progreso intelectual del hombre (Cariola y Sunkel 1982).

${ }^{71}$ Bello asumió el cargo de Rector entre los años 1842 y 1865. Además, y desde ideales liberales, definen una orientación que se corporiza en la elaboración de varios tratados y cuerpos normativos que delinea el derecho nacional.

${ }^{72}$ Por otro lado, la Academia de San Luis puede ser considerada la primera experiencia educacional de corte ilustrado. Fundada en 1799 por Manuel de Salas -con autorización de la Corona española y aportes económicos
} 
El concepto de universidad moderna que incorporó Bello, desplaza a la universidad docente y el sistema de educación escolástica que caracterizaba a las instituciones creadas durante la administración colonial, modelo de formación seguido por las universidades conventuales y/o universidades menores ${ }^{73}$-jesuitas y domínicas que funcionaban en Santiago y Concepción-, y por la Real Universidad de San Felipe (Mellafe et al. 1992; Serrano 1994). Con la creación de la Universidad de Chile, la Real Universidad de San Felipe cesa sus actividades ${ }^{74}$, y el Instituto Nacional (fundado en 1819) ${ }^{75}$ adquiere mayor protagonismo en la formación profesional, sobre todo en la primera etapa de funcionamiento de la Universidad de Chile, ello, hasta la reforma de 1852 que reinstituye el concepto de universidad docente y profesionalizante promovida por Ignacio Domeyko (Serrano 1994).

La Universidad de Chile contó en sus primeros años con una composición de académicos extranjeros -de los 281 académicos nombrados entre 1843 y 1879 , un $15 \%$ era extranjero(Serrano 1994), muchos de los cuales realizaron contribuciones científicas para la gestión de distintos gobiernos. En tanto el Instituto Nacional enfatiza la formación en economía (Jaksic 2013), la universidad organizó el espacio académico en cinco Facultades: Teología, Leyes y Ciencias Políticas, Matemáticas y Física, Medicina, y Filosofía y Humanidades (Montt 1844). Más tarde la Pontificia Universidad Católica de Chile (1888), implementa su proyecto de formación universitaria en torno a las carreras de Derecho, Matemáticas, Arquitectura, y a partir de 1930 crea las facultades de Tecnología, Teología, Comercio, Filosofía, Ciencias de la Educación y Medicina. A estas instituciones se suman otras tres universidades que se

del Tribunal del Consulado, del Cabildo y el Tribunal de Minería-, mostró apertura al pensamiento científico en tanto posibilidad transformadora de la realidad. La formación que brindó la Academia, fue pensada como un apronte para el desarrollo de especialidades asociadas al comercio, la industria y la agricultura, y en tal sentido consideró la enseñanza de geometría, aritmética y dibujo (Serrano 1994).

${ }^{73}$ Las universidades conventuales o menores otorgaban grados a partir de 1622 en Artes, que habilitaban al estudiante para continuar con estudios en facultades mayores. En Chile, sólo era posible cursar Teología, y para adquirir formación universitaria en otras materias, el estudiante debía continuar estudios en Lima (Mellafe et. al. 1992).

${ }^{74}$ Esta universidad, a partir de 1756, comienza a impartir formación en filosofía, teología, leyes, medicina, matemáticas, aun cuando el foco fue la instrucción de teólogos y juristas, ello, siguiendo el método de enseñanza escolástico y con una orientación exclusivamente docente (Mellafe et. al. 1992; Serrano 1994). Aun cuando esta universidad se funda en 1738, comenzando su actividad entre 1751 y 1758; reemplaza a las denominadas menores que existían en el marco del trabajo misional de la congregación de los Domínicos y Jesuitas, los cuales entregaban formación en Artes y Teología.

${ }^{75}$ El Instituto Nacional se había constituido en un centro de convergencia para académico e investigadores, alcanzando conocimiento incluso en Europa, y que reunía a especialistas, algunos de ellos extranjero que habían sido contratados por el gobierno (Saldivia 2005). 
establecen en el circuito regional en la primera mitad del siglo XX: Universidad de Concepción (1919), Pontificia Universidad Católica de Valparaíso (1928), Universidad Federico Santa María (1929). La Universidad de Concepción comenzó impartiendo dentística -odontología-, Farmacia, Química Industrial y Pedagogía en Inglés; la Universidad de Valparaíso con la Facultad de Industrias y Ciencias Aplicadas y Comercio y Ciencias Económicas; y la Universidad Federico Santa María con Escuelas de Matemática, Comercio y Economía, Ciencias Físicas y Químicas y Ciencias Biológicas.

Sin embargo, el desarrollo académico y científico de las primeras universidades no visualiza la apertura de instancias académicas de investigación y formación en el campo de las Ciencias Sociales y de la antropología, siendo la Filosofía y la Historia las ciencias humanas que alcanzan mayor realce hacia inicios del siglo XX en el contexto universitario nacional (Jaksic 2013). Lo anterior es tardío en comparación con lo que acontece a nivel internacional; si bien la formación universitaria o especialización en Antropología y ciencias afines tiene lugar hacia 1860 en Europa, 1886 en Norte América y 1937 en América Latina, en Chile sólo se concreta a partir de 1966, con la Carrera de Antropología fundada en la Universidad de Concepción, la cual se suma al Centro de Investigaciones Antropológicas creado en 1954 en la Universidad de Chile, centrado principalmente en la investigación (Mora 2014). 


\section{CAPÍTULO IV}

\section{El modelo de ciencia europeo: museos y sociedades científicas en la conformación del campo antropológico en Chile}

\subsection{Instituciones en la producción y difusión de las ciencias antropológicas en el circuito nacional}

Como se planteó, las primeras iniciativas abocadas a la descripción de las formas de vida y cultura material en Chile, fueron promovidas en su mayoría por especialistas y/o eruditos extranjeros, quienes imbuidos por el interés que las poblaciones nativas despiertan en Europa -ya sea como otro exótico o como vestigios del pasado que desaparecen debido al inevitable progreso-, incorporan prácticas investigativas de orientación antropológica. Estas cumplen en muchos casos un papel secundario y/o complementario al trabajo de investigación y formación que desarrollan en campos profesionales o áreas como la botánica, medicina, química, derecho, educación, historia, geología, geografía, entre otras. Cabe agregar que las actividades de orientación antropológica se llevan a cabo casi en su totalidad al margen de las instituciones universitarias, y mayoritariamente bajo al alero de entidades cuyo objetivo principal no es el cultivo de estas ciencias.

Es el trabajo de estos primeros eruditos, filántropos, naturalistas, viajeros y profesionales nacionales y extranjeros (Porter 1909; Porter 1910; Brand 1941; Orellana 1996), lo que permite dar un lento impulso a la generación de espacios para el desarrollo de las ciencias antropológicas en Chile, lo que se expresa en la preocupación inicial por la prehistoria, arqueología, paleontología, antropología física, etnología, folklore y la etnografía.

La organización institucional en el país tiene como trasfondo la definición conceptual de la antropología de raigambre francesa, cuyos referentes se encuentran en Broca y Buffon (Broca 1871; Bouza 1988), y que la caracterizan como una ciencia integral en el marco de lo que se denomina "historia natural del hombre" -que distingue al hombre físico y moral. De hecho, Broca (1871) define la antropología como la ciencia que se centra en el estudio del grupo humano como un todo, en sus detalles y relación con el resto de la naturaleza. Es una ciencia 
cuyo método distintivo proviene de la observación que se nutre de la descripción y la estadística. Señala que la antropología se ramifica en tres grandes áreas que la estructuran:

1) Un estudio comparativo que sitúa a un grupo humano entre la serie de otros grupos y de los seres de la naturaleza, lo que compete a la antropología zoológica.

2) Un estudio de los grupos humanos en cuanto especie, dando cuenta de la descripción de dichas características o de sus múltiples variaciones a nivel anatómico, fisiológico, intelectual, moral y social, cuestión que compete a la denominada etnología en tanto ciencia de las razas humanas.

3) Un estudio integral del hombre, en todas sus dimensiones, conformando lo que se denomina antropología general, la cual se nutre de ciencias auxiliares.

Figura Nº1: Modelo de antropología de $\mathrm{Broca}^{76}$

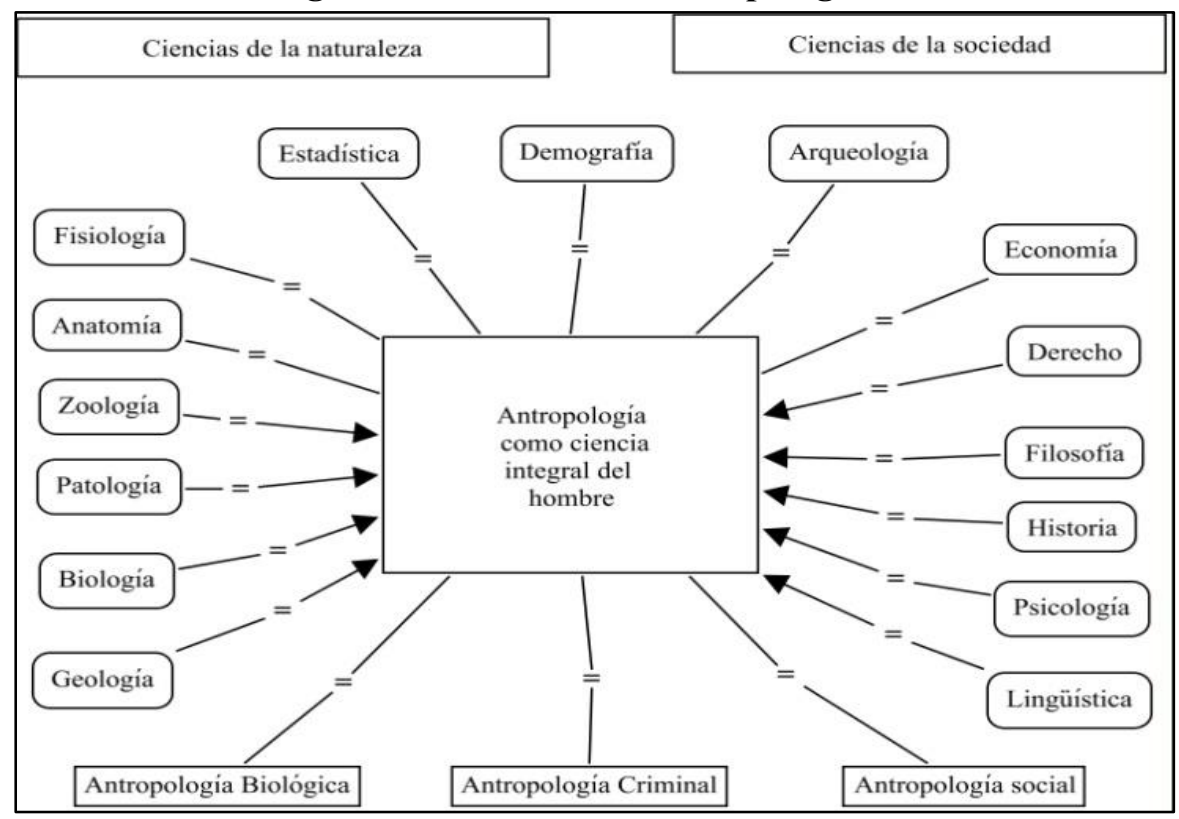

Como señala Bouza (1988), este modelo de institucionalización se expandió por todo el mundo a través de los Bulletines y la Revue d'Anthropologie. Además, ello se acompañaba de reuniones y congresos internacionales a través de los cuales se propagaba la nueva ciencia, y se impartían cursos de formación para dar especialización a los sujetos preocupados por estas materias.

\footnotetext{
${ }^{76}$ Elaborado en base a Broca (1871) y Bouza (1988).
} 
Los aspectos centrales del modelo que se expande o difunde mantienen las siguientes características (Bouza 1988:39):

1. La antropología se encuadra metodológicamente en las ciencias naturales.

2. La importancia que adquiere la antropología física, siendo el núcleo la preocupación científica positiva que articula las distintas ramas.

3. Tendencia hacia el desarrollo de la prehistoria en tanto suministra datos objetivos por sobre la etnología.

4. Institucionalización iniciada y desarrollada por médicos en el marco del positivismo.

5. Iniciativas que se sustentan en aportes económicos de privados.

6. Articulación en torno a una sociedad científica, desde donde se promueve la fundación de museos.

El impulso inicial para el desarrollo de la ciencia en Chile sigue algunas de las orientaciones propuestas por el modelo francés de organización institucional, lo cual se expresa en la conformación de museos y sociedades científicas. La diferencia fundamental radica en que en el país las primeras instituciones -sociedades y museos- se definen como generalistas, en el entendido que en ellas confluyen varias ramas del saber, imprimiéndoles un carácter que actualmente podríamos denominar multidisciplinario. De hecho, la única sociedad científica relacionada con el campo antropológico fue la Sociedad Arqueológica de Santiago, la cual se fundó en julio de 1878 y que desaparece hacia 1880. Igual situación ocurrió con los Museos; el Museo Etnológico y Antropológico fundado en 1912 y que abre sus puertas en 1917, constituye la única iniciativa de carácter antropológico que se levantó hasta finales de los '30, siendo cerrado y anexado al Museo Histórico Nacional a partir de 1926 (Hamp 1998).

Esta adaptación del modelo francés o europeo se encuentra atravesada por cuestiones de tipo económico y de infraestructura -no es la falta de colecciones, ya que como comentan sus directores, las bodegas no daban abasto-, a lo que se suma el compromiso más bien fluctúate de los distintos gobiernos nacionales. La mayoría de las iniciativas refieren o se nutren de impulsos privados o particulares -donación de colecciones, bibliotecas y recursos económicos-, donde individuos y grupos reducidos pujan por inscribir esta nueva ciencia entre los campos de saber más antiguos y consagrados a nivel nacional. En esta dirección, se constata que las ciencias antropológicas no tuvieron cabida en el espacio académico- 
universitario sino hasta 1954, lo que impidió iniciar la formación de profesionales e investigadores; sin embargo, ciertas áreas que parecen haber sido prioritarias, se consolidan tempranamente en el espacio académico universitario como son: la educación, el derecho, la medicina, la economía, entre otras. Ello supone la falta de interés por parte del Estado en la promoción y consolidación de una política ligada al conocimiento, relación y relevamiento de los pueblos indígenas que habitaban el territorio.

Lo anterior lleva a que abiertamente quienes promueven y desarrollan la investigación antropológica interpelen al gobierno, insistiendo en la necesidad de difundir y contribuir a la consolidación de estas ciencias. Ya en 1909 Carlos Porter señala:

"Ya es tiempo que se reaccione contra esta indiferencia i se tome alguna medida para recoger i clasificar, de una manera científica, todas las informaciones y datos posibles de cada una de estas razas, destinadas en breve a desaparecer ante la marcha del progreso i de la civilización. Sería mui conveniente que el Supremo Gobierno estimulara el estudio i propaganda de la Antropología, como se ha hecho en todo los países cultos" (p. 122).

Seis años más tarde Leotardo Matus, Jefe de la Sección de Antropología y Etnología del Museo Nacional de Historia Natural agrega:

"En Chile no contamos todavía con la cátedra de antropología en ninguna de las secciones Universitarias; i aunque tenemos un buen laboratorio para el estudio de la Psicología Esperimental, no hemos hecho nada por conocer el estado de desarrollo físico que es el pedestal en que se basan todos los otros estudios humanos (1915:22).

La necesidad de impulsar la antropología, como bien deja de manifiesto la intervención de Porter (1909), se inspira en un imaginario que se nutre del ideal europeo en tanto expresión de civilización y cultura. La antropología goza de cierto prestigio en tanto la preocupación del hombre por el hombre da muestra de un avance intelectual, indicador del progreso. En Europa ya existían instancias de formación profesional universitaria para la época, a lo que se suma 
la temprana formación que se realiza al alero de las denominadas escuelas. Además, en varios países de Europa y América se contaba con el apoyo estatal para la generación y mantención de ciertas instancias especializadas como museos, institutos, y sociedades.

El acoplamiento de la antropología en las Ciencias Naturales, que resulta de la adaptación del modelo europeo francés a la realidad nacional, se vio favorecida por la concepción de ciencia integral del hombre como entidad natural, la que también se difunde y replica tempranamente en otros países de Europa y América (Broca 1870). Carlos Porter (1909), miembro de la Sociedad Científica de Chile -conformada mayoritariamente por migrantes franceses-, Director del Museo de Historia Natural de Valparaíso -entre varias otras sociedades y museos en los que colaboró- y promotor de la antropología, define a las Ciencias Antropológicas como "historia natural del hombre" (p. 110), en el entendido que constituye un ciencia integral en la línea que ya había planteado De Gerándo (1800) y Broca (1870). En tal dirección, señala que las ramas constitutivas de la antropología son: la Antropografía - descripción anatómica, física y patológica-, Etnografía -descripción de tribus o naciones aisladas-, Etnología, Lingüística, Arqueología y Prehistoria (Porter 1909: 110-111).

Ello estableció condiciones para que la antropología se desarrollara al alero de instituciones que mayoritariamente declaran su campo de especialización en lo que podríamos denominar Ciencias Naturales. Estas mismas instituciones contribuyen y/o hacen posible la difusión de esta nueva ciencia, publicando a través de las distintas revistas más de 500 trabajos relacionados con distintas ramas de la antropología (ver Capítulo VI). Esta práctica se explica debido a la inexistencia -que se prolonga hasta mediados del siglo XX- de instituciones académicas o de investigación y difusión estrictamente antropológicas ${ }^{77}$. Ello permite que, parafraseando a Becher (2001 [1989]), no opere la demarcación de territorios académicos y la conformación de tribus - lo que se reproduce en instancias académicas de formación- que reivindique sus derechos sobre un área de conocimiento, permitiendo el desarrollo de una práctica o quehacer transfronterizo y multidisciplinario.

Por otro lado, hacer mención que esta concepción de antropología se sostiene en una epistemología naturalista, la que define un vasto campo fenoménico que incorpora al hombre como especie y lo inscribe en la historia natural, otorgándole cabida legítima en el conjunto de

\footnotetext{
${ }^{77}$ Esta situación cambia a partir de 1954, con la Fundación del Centro de Estudios Antropológicos de la Universidad de Chile.
} 
las Ciencias Naturales; como señala De Gérando “... la ciencia del hombre es en sí misma una ciencia natural, una ciencia de la observación, la más noble de todas." (1800:2). A lo anterior, habría que agregar que la práctica científica estuvo representada por la figura del científico integral, quién canaliza sus inquietudes intelectuales tanto en áreas de especialización formal habilitaciones profesionales- como informal -autodidactas o prácticas de oficio- ${ }^{78}$, teniendo como referente a la ciencia como un todo. Estos aspectos permiten dar sentido a la estructura y programática organizativa y temática sobre la cual se levantan tanto museos como sociedades científicas.

Resulta oportuno señalar que hasta las primeras décadas del siglo XX, sociedades científicas y museos generaban casi la totalidad de la actividad científica y antropológica de circulación nacional, ello, prácticamente al margen del espacio académico universitario, constituyendo además los escenarios de sociabilidad, lo cual hace recordar la función que Crane (1972) atribuye a los colegios invisibles. En ellos tenía lugar la lectura y discusión de trabajos elaborados por sus miembros o adquiridos en otros países -vía canje o compra directa-, así como la promoción y publicaciones de trabajos en revistas especializadas gestadas al alero de estas instancias. Allí fue posible afianzar los lazos entre sus participantes constituyendo un espacio de reflexión científica e incluso de formación -a la manera de colegios invisibles- en materias de índole folclórica, arqueológica, lingüística y antropológica y/o etnológica, lo que queda patente en las actas de reuniones e informes que son incluidos en las mismas revistas.

Es relevante agregar que para dicho periodo existen sólo tres instancias con vinculación a la orgánica universitaria en las cuales se difunde el trabajo antropológico: Anales de la Universidad de Chile (fundada en 1843), revista que publica sobre una amplia gama de temas y perspectivas disciplinarias, cuyos primeros trabajos de orientación etnológica se registran a partir de 1860 -179 trabajos; la Academia Chilena de Ciencias Naturales, la cual se crea desde la institucionalidad de la Universidad Católica, y que publica sus anales en la Revista Universitaria -si bien no se trata de una revista de especialidad en antropología, allí figuran alrededor de 41 trabajos en distintas áreas de la antropología, los que aparecen entre 1926 y 1958; La Sociedad Biológica de Concepción, que nace y se desarrolla al alero de la

\footnotetext{
${ }^{78}$ Informal, quiere decir que no cuentan con habilitación o certificación de formación académica en un área o disciplina.
} 
Universidad de Concepción, y que publica el Boletín de la Sociedad Biológica a partir de 1927, con 15 trabajo hasta 1954.

\subsubsection{Los museos: entre el patrimonio y la ciencia.}

Como se planteó en el capítulo anterior, los museos son pensados en una lógica que va más allá de la recolección y acumulación de vestigios del pasado indígena, colonial o criollo. Se inscriben en la matriz cultural de una porción de elite gobernante, desde la cual resulta central el desarrollo de la ciencia, la formación de la identidad nacional y la instrucción de la población, ello con referencia al modelo europeo occidental (Vessuri 2007; Schell 2009).

En este sentido, es ilustrativo que el primer impulso para la creación de un museo en Chile se inicia inmediatamente después de la independencia del país. En el periódico El Araucano se publica que:

"La Junta Ejecutiva del Senado, reunida en la sala de Gobierno, acordó el establecimiento de un Museo Nacional en la Universidad de San Felipe. En la ciudad de Santiago á 27 del mes de julio de 1813. Hallándose el Supremo Gobierno del Estado de acuerdo constitucional con el M. I. Senado" (Philippi 1908:4).

Tras este primer intento fallido ${ }^{79}$, en 1822 Bernardo O’Higgins -Director Supremo- promueve la formación de un Museo Nacional comisionando dicha tarea a Juan José Dauxion Lavaysse en su rol de director, el cual fue finalmente concretado por el naturalista Claudio Gay (Barros Arana 1876). Esta primera iniciativa marca el inicio de una política destinada a la apertura de museos estatales -en los cuales se expresan los vaivenes de la economía nacional y el fluctuante apoyo de los gobiernos-, lo que se intensifica hacia la segunda mitad del siglo XX y se complementa con iniciativa de índole privado. Los museos no sólo constituyen espacios para la exhibición de colecciones; marcan el inicio de las actividades de investigación de algunas ciencias a nivel nacional. Ello permite afirmar que la institucionalización científica de

79 Según Philippi (1908), la concreción del museo no se pudo materializar, dado que la atención de las autoridades de la nueva república se centraron en otras materias. 
las ciencias sociales en Chile -particularmente de la antropología- se inicia mucho antes de lo que sostienen autores como Garretón (2015), para quien esta tiene lugar a partir de la década de los '50.

\subsubsection{El Museo Nacional}

El Museo Nacional representa la concreción de un viejo anhelo de la elite gobernante, y que renace luego de la infructífera labor científica y organizativa de quien había sido inicialmente encomendado para dicha tarea, a decir el francés Juan José Dauxion Lavaysse ${ }^{80}$. Es así como el 14 de septiembre de 1830, el gobierno gestiona la contratación de Claudio Gay, quien debe cumplir, entre otros requerimientos, con la conformación de:

“... un gabinete de historia natural que contenga las principales producciones vejetales i minerales del territorio, i un catálogo en que se denominen por sus nombres vulgares i científicos; $\mathrm{i}$ en que se demuestren los usos i utilidades de dichos objetos i los lugares donde se encuentren" (Barros Arana 1876:35).

Si bien la intención del Gobierno fue generar un museo para que el pueblo de Chile pudiera conocer su país, Gay le imagina como un espacio desde el cual “... investigar y conocer, a través de la investigación científica, la realidad de un país joven y sobrio" (Mostny 1983:5). La tarea de Gay consistió en organizar el museo a través de colecciones que él mismo reunió en sus viajes, y otras que obtuvo a través de contacto con científicos y coleccionistas, incorporando además una sala con objetos de fabricación indígena destinada a formar una sección de antigüedades chilenas (Philippi 1908).

A partir de 1842 el museo queda vinculado a la Universidad de Chile, siendo sus directores hasta 1853 el Decano de la Facultad de Ciencias Físicas y Matemáticas Francisco García Huidobro, sucedido por Andrés Antonio Gorbea -profesor de Matemática y Decano de la misma Facultad- y posteriormente por Francisco Borja Solar, todos ellos ajenos al campo de las ciencias naturales. Durante este periodo, el museo quedó en un casi total abandono,

\footnotetext{
${ }^{80}$ Barros Arana atribuye este fracaso a la falta de competencia de Juan José Dauxion Lavaysse, a quien se refiere en duros términos en las páginas 14 y 15 de la biografía de Claudio Gay (Barros Arana 1876).
} 
sufriendo un profundo deterioro, lo que fue agudizado debido al casi inexistente presupuesto destinado a su mantención (Philippi 1908).

\section{Fotografía $\mathrm{N}^{\circ} 1$ : Museo Nacional hacia 1890 (Santiago, Quinta Normal)}

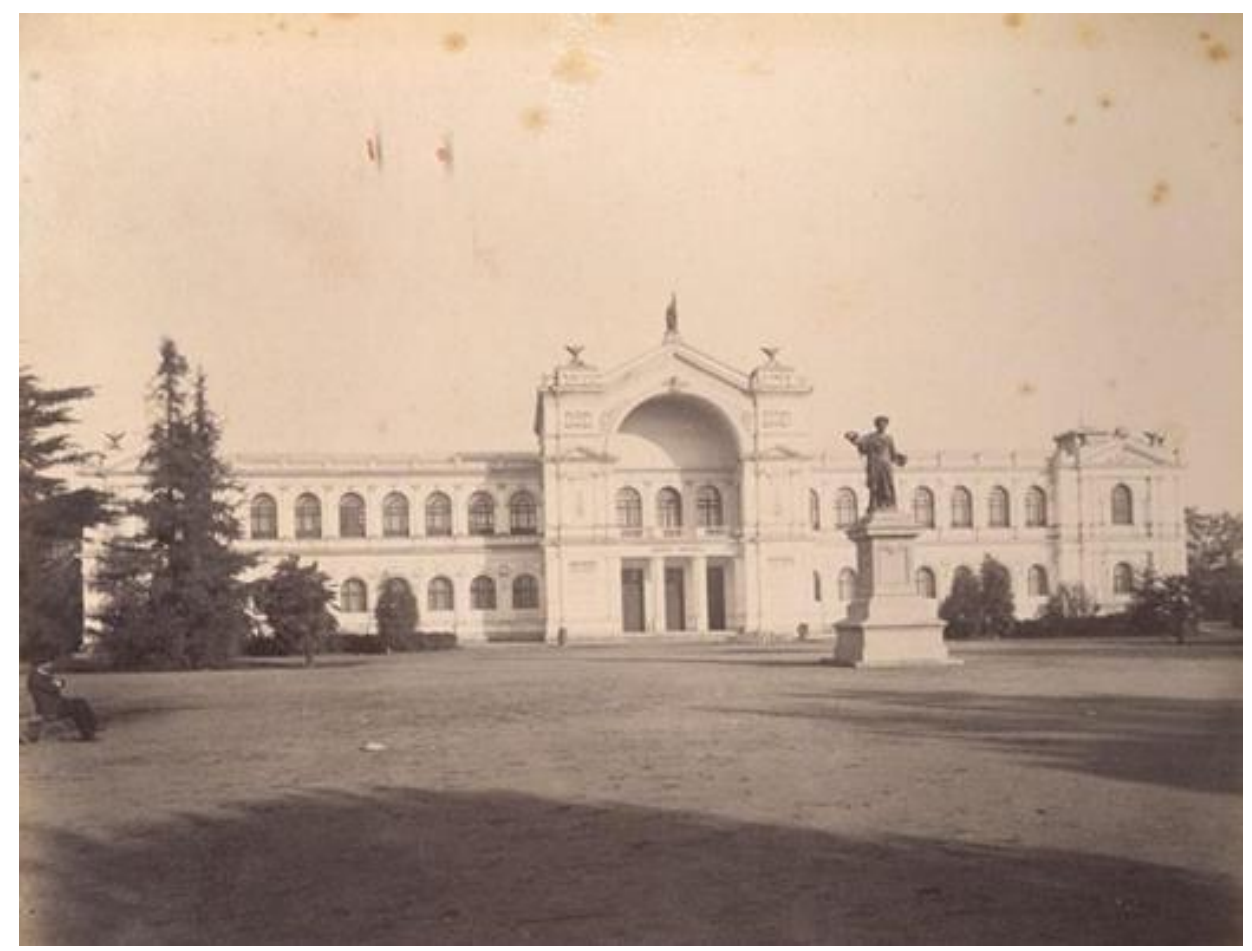

Fuente: http://www.memoriachilena.cl/602/articles-67604_thumbnail.jpg

A partir del 20 de octubre de 1853 asume su dirección Rodulfo Amando Philippi ${ }^{81}$, quien además impulsa la creación de la revista Anales del Museo Nacional -desde 1891-, revista que a partir de 1908, bajo la gestión de su hijo Federico, pasa a ser denominada Boletín del Museo Nacional de Historia Natural. La dirección de Philippi mantiene la orientación científica promovida por Gay, lo cual se evidencia en el esfuerzo que este realiza al establecer vínculos a nivel internacional, contratando además a colaboradores franceses y alemanes para contribuir en el desarrollo de sus distintas secciones (Mostny 1983) ${ }^{82}$. Como señala Schell (2009), bajo la gestión de Philippi las colecciones aumentan significativamente en cantidad, sobrepasando la

\footnotetext{
${ }^{81}$ Ese mismo año, con fecha 7 de octubre de 1853, se había nombrado a Philippi como profesor de Zoología y Botánica de la Universidad de Chile y encargado la formación e inspección de un Jardín Botánico (Philippi 1908).

${ }^{82}$ Fueron también directores Ricardo E. Latcham C. (1928-1943) y Enrique E. Gigoux V. (1943-1948), quienes promueven y realizan investigaciones en el campo de la antropología.
} 
capacidad espacial del museo, estableciendo además una red de colaboración e intercambio con instituciones internacionales como: El Smithsonian Museum, el Museo de La Plata en Argentina, The Royal Botanic Gardens of Kew en Inglaterra, el Museo Británico, The Boston Society of Natural History, entre otras.

Tras la administración de Philippi, el museo quedó compuesto por las secciones de botánica, zoología, geología, mineralogía y paleontología, a lo cual se agregaba una colección de objetos etnográficos y arqueológicos. La colección etnográfica contaba con un total de 1.086 piezas que ocupaban 43 estantes y dos nichos -armas, vestimentas, cerámicas, momias, etc.-, resaltando una selección de objetos de la Isla de Pascua. La colección de arqueología contenía 1.301 objetos de Chile y 2.386 extranjeros -dos momias egipcias y antigüedades peruanasque ocupaban la galería del salón central del museo (Philippi 1908); ambas colecciones habían sido obtenidas en su mayoría a través de la donación de 215 benefactores (Matus 1916).

A pesar de la existencia de dichos objetos, la sección especializada en materias de antropología -y una línea de investigación en tal dirección-, no había sido creada. En un informe redactado por Eduardo Moore -quien asume como director del Museo tras la muerte de Federico Philippi-, se consigna que para 1910 no existe un encargado de la sección de antropología, arqueología y etnología que desarrolle un trabajo sistemático, pese a la importancia que se le atribuye a estas ciencias en otros países del continente y Europa, y al gran número de piezas que se poseen -1.086 objetos etnográficos y 3.687 objetos arqueológicos. El mismo Moore deja expreso que la dirección trabaja en la apertura de esta sección, solicitando fondos al gobierno para cubrir el salario de éste (Moore 1910:4), y además toma como modelo el Museo de La Plata con el objetivo de orientar programas académicos de modo de sentar las bases de una Escuela de Ciencias Naturales, siendo la preparación requerida en materias como: botánica, zoología, geología y antropología.

Bajo la dirección de Moore, y en consideración de las riquísimas colecciones con las que cuenta el museo, en el Boletín de 1914 se anuncia la creación de la sección de Arqueología y Etnología, la cual recaerá en Leotardo Matus Zapata -Antropólogo y profesor de Educación Física con estudios en Museos de Francia, Alemania y Bélgica- primero como encargado de sección (1915) y ya como jefe de sección a partir de 1917 -y hasta 1927. A partir de 1928, asume la jefatura ad honorem de la sección de Antropología Gualterio Looser, ello tras la jubilación de Matus y del levantamiento de la suspensión del cargo por problemas de 
asignación de recursos económicos por parte del Gobierno (Latcham 1929). Bajo la dirección de Latcham (1928-1943), las redes nacionales e internacionales permiten incrementar ostensiblemente las colecciones del museo, frente a lo cual se genera un problema de espacio y de fondos para proveerlos. A modo de ejemplo, cabe destacar la gran cantidad de piezas recibidas a través de intercambio y donaciones, entre las que destaca una colección de 35 objetos -máscaras y figuras de madera- procedente de las colonias africanas de Francia obsequiadas por el Museo Etnográfico de Paris; esta fue una retribución al apoyo que recibió la expedición Franco-Belga que visitó Isla de Pascua (Latcham 1936). Además, en 1935 el museo recibe por la vía de donaciones e intercambios un total de 9.976 piezas, de las cuales 389 corresponden a piezas arqueológicas, etnológicas y antropológicas (Latcham 1936). Desde el punto de vista de la investigación y bajo la gestión de Latcham, el museo organiza una serie de expediciones o trabajos de campos, las que dan lugar a la indagación y recopilación de objetos con la intención de incrementar la colección; varios de estos trabajos se publican en el Boletín. El trabajo en el campo de la arqueología se ve reforzado con la incorporación de la Dra. Grete Mostny como ayudanta y luego Jefa de la Sección -Latcham ocupaba hasta la fecha tanto el cargo de Director como encargado de la Sección de Arqueología- a partir de 1940.

Pese al prestigio científico que alcanzó el museo, el problema de recursos es una cuestión que aparece de manera reiterada en las comunicaciones e informes de gestión emitidos por las diversas direcciones del museo, lo que afectó principalmente a la sección de prehistoria, posteriormente denominada de antropología y arqueología. Se puede mencionar que en varios periodos el cargo de Jefe de Sección de Antropología y Arqueología -así como el de otras secciones- fue ad honorem, y además, debido a reiterados apremios económicos, dicho cargo fue suprimido en más de una oportunidad (Latcham 1935); los mismos problemas afectan al ítem destinado a publicaciones, suspendiendo el Boletín entre 1919 y 1929, y entre 1930 y 1935. Al respecto, en comunicación dirigida a Ricardo Latcham, Director del Museo, Humberto Fuenzalida señala lo siguiente:

"Como la situación económica del museo no ha variado durante los últimos años, las necesidades son las mismas que hemos reiterado en tanta ocasiones. Pueden resumirse en la necesidad de terminar el edificio para poder exhibir las 
importantes colecciones ahora guardadas; en la falta de personal y en el aumento de los fondos disponibles para el fomento del museo" (1936:196).

En el caso del financiamiento para el trabajo de campo, los escasos recursos asignados a través del presupuesto estatal son complementados por los aportes de los propios investigadores o benefactores. Destaca el nombre de Guillermo Macqueen Sutherland, sindicado como gran amigo y benefactor del Museo Nacional, quien donó importantes sumas para la adquisición de colecciones y viajes de estudio del personal (Latcham 1936). Además, financió la denominada Expedición Aysén o Expedición Macqueen -luego que esta no fuera costeada por el gobierno por problemas económicos-, la que se lleva a cabo en 1934 por un tiempo de dos meses, y estuvo compuesta por un equipo multidisciplinario del cual Macqueen formó parte (Latcham $1935)^{83}$.

Tras la muerte de Latcham en 1943, asume la Dirección del Museo el Botánico Enrique Ernesto Gigoux (1943-1948), sucedido por Geólogo Humberto Fuenzalida, continuando como Jefa de la Sección de Arqueología Grete Mostny hasta asumir como Directora en 1964.

\subsubsection{El Museo Histórico de Chile.}

El Museo Histórico tiene como antecedente la Exposición del Coloniaje, la cual fue inaugurada el 17 de septiembre de $1873^{84}$, y contó con el patrocinio de Benjamín Vicuña Mackenna, siendo su objetivo central generar conciencia histórica e instruir a la población sobre su pasado (Schell 2009). Esta misma exposición motivó la necesidad de inaugurar un Museo, lo cual se concreta con la apertura, en 1874, del Museo Histórico e Indígena del Santa Lucía, el cual se emplazó en la Fortaleza Hidalgo. Dicho museo albergó una serie de cuadros y objetos del pasado colonial e historia más reciente de la república, exhibiendo además "algunos utensilios indíjenas de notable mérito que se guardan en cuatro estantes del departamento de la derecha." (Vicuña Mackenna 1874:87).

\footnotetext{
${ }^{83}$ En dicha expedición murió ahogado en el Río Blanco el botánico Francisco Fuentes Maturana.

${ }^{84}$ Para revisar el contenido de la exposición, se puede consultar el catálogo disponible en http://www.memoriachilena.cl/archivos2/pdfs/MC0058269.pdf
} 
Fotografía N²: Museo Histórico e Indígena Palacio Hidalgo 1874 (Santiago, Cerro Santa Lucía)

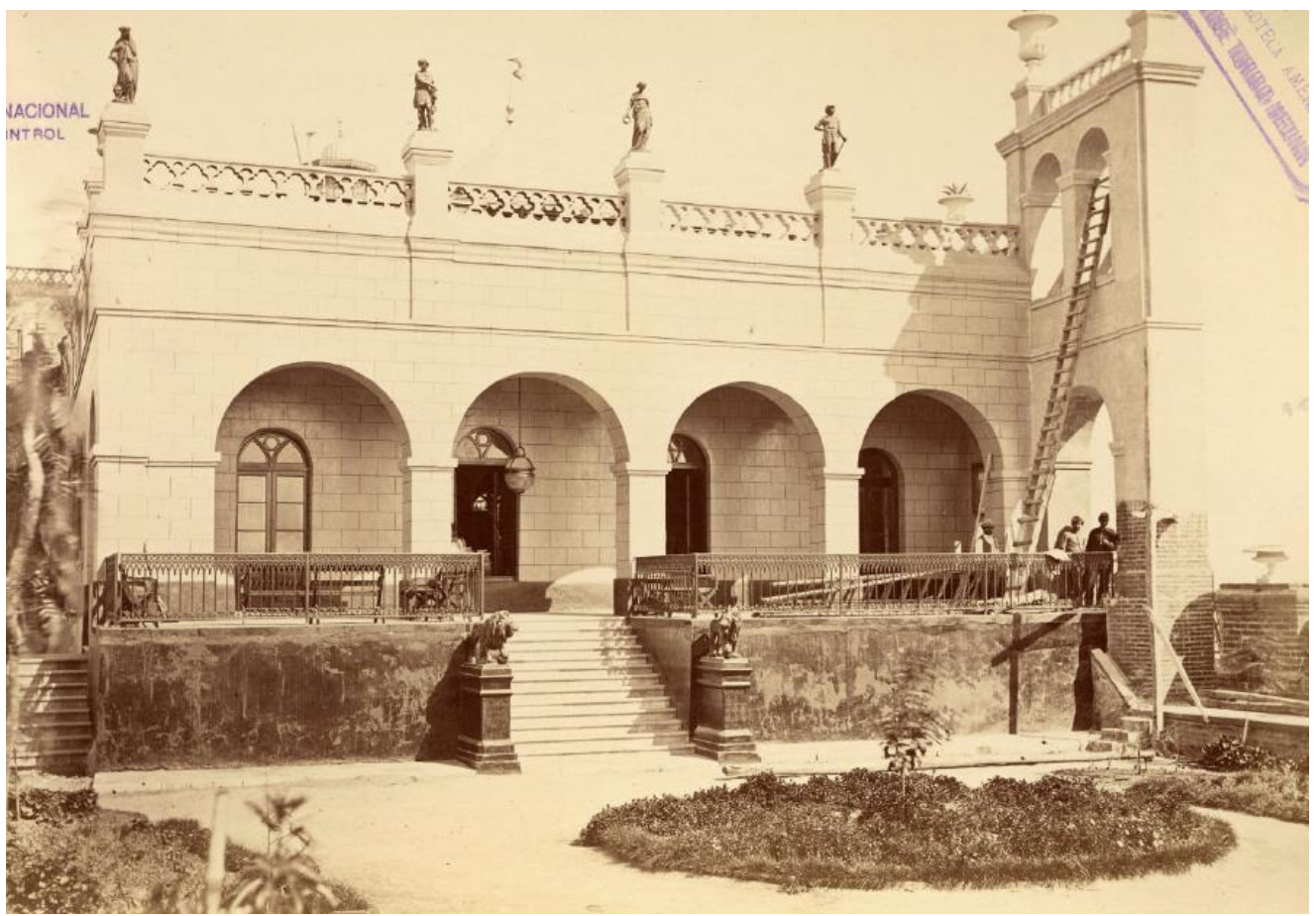

Fuente: http://www.memoriachilena.cl/602/w3-article-8035.html

Después de la muerte de Mackenna, en 1886, en Museo Histórico e Indígena del Santa Lucía cerró, y la colección se dispersó, quedando almacenada en las bodegas del Museo Nacional o siendo facilitada a otras instituciones (Schell 2009).

Otro antecedente que influye en la fundación del Museo Histórico de Chile lo constituye la Exposición Histórica del Centenario, la cual busca exhibir objetos que permitan representar la historia expresando la continuidad y cambio del país en el marco de un gran festejo nacional. La coordinación de dicha exposición fue encomendada a Joaquín Figueroa Larraín en el rol de director y a Nicanor Molinare como secretario (Alegría 2007).

De éste modo, y con el objetivo de dar continuidad a la exhibición de colecciones históricas que no encajaban en los lineamientos y contenidos que había definido el Museo de Historia Natural, es que por decreto supremo del 3 de mayo de 1911 se crea el Museo Histórico en un sector del Palacio de Bellas Artes. Ello ocurre bajo el gobierno de Ramón Barros Luco, quien nombra como su primer director al senador Figueroa Larraín (Alegría 2007). Como señala Gusinde (1916), el propósito del museo era abarcar “... desde nuestros antepasados más remotos de la edad de piedra hasta los aborígenes que encontraron los españoles en el 
descubrimiento, y además, la Conquista, la Colonia, la Independencia y la República hasta el presente..." (p.30).

Fotografía N³: Edificio Museo Histórico hacia 1880 (Plaza de Armas de Santiago)

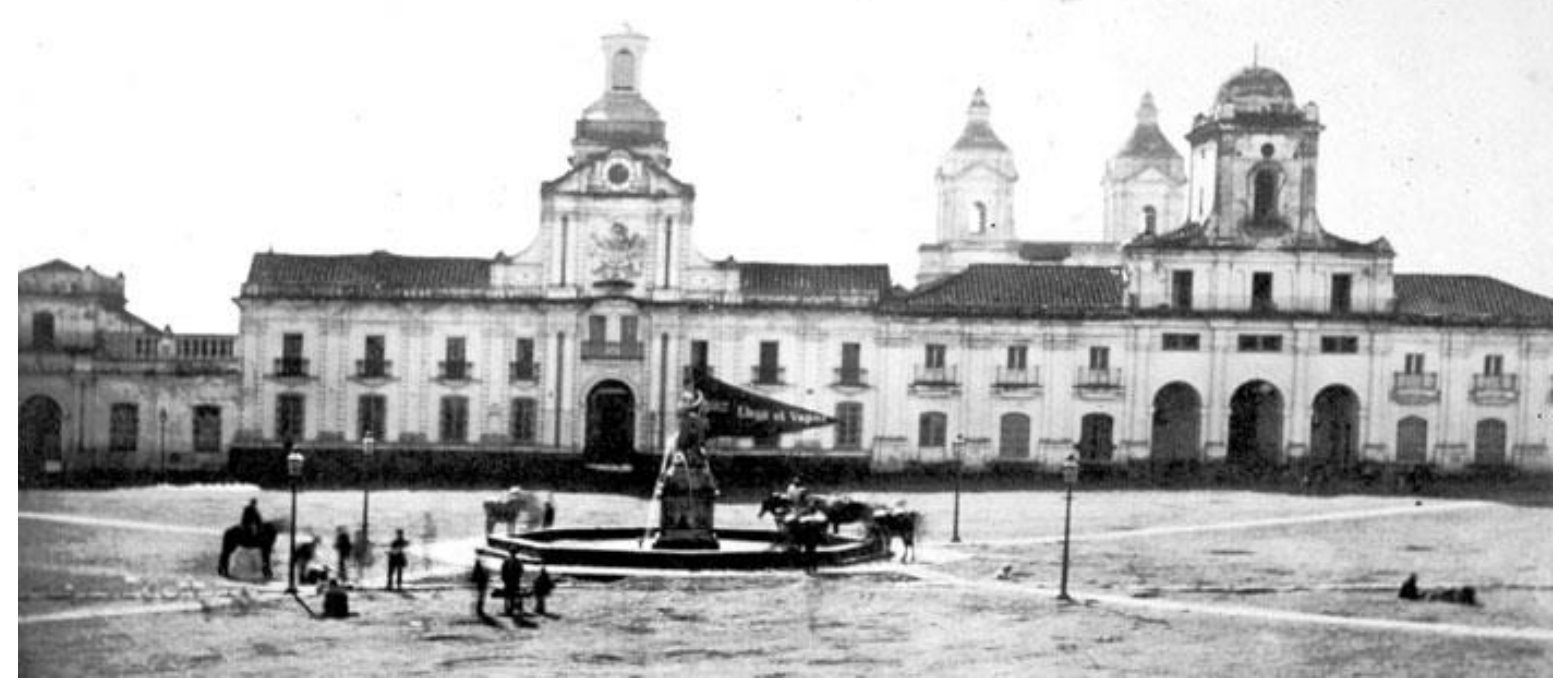

Fuente: http://www.museohistoriconacional.cl/

Según Gusinde (1916), el Museo se nutre de una parte de las colecciones exhibidas para el Centenario en el Palacio Hurmeneta y por la colección de prehistoria formada por Rodulfo y Federico Philippi, la cual se almacenaba en el Museo Nacional. La gran cantidad de piezas adquiridas bajo la gestión de Figueroa, a las que se suman las obtenidas por Max Uhle, en su calidad de encargado de la sección de Prehistoria de dicho museo, hace imposible trasladar la totalidad de las colecciones desde el Museo Nacional. Tal situación, más el interés del gobierno de la época por promover el desarrollo de la etnología y antropología, decantan en la fundación del Museo de Etnología y Antropología.

Considerando los antecedentes que se han podido recabar, el Museo Histórico, a diferencia del Museo Nacional, no habría incorporado actividades de investigación y con ellas el desarrollo o cultivo de la antropología. En tal sentido, no se ha registrado un boletín o revista de divulgación en dicha dirección, lo cual permite afirmar que este cumplió más bien un rol de almacenamiento y difusión del patrimonio histórico de la nación. 


\subsubsection{El Museo Etnológico y Antropológico}

Por otro lado, una de las primeras iniciativas nacionales en el campo de la antropología referida a la realidad presente y pasada de los pueblos indígenas, la constituyó el Museo Etnológico y Antropológico. Su creación guarda relación con el interés explícito por parte de algunos investigadores e intelectuales extranjeros y nacionales, de hacer eco de la tendencia y auge que venían cobrando las ciencias del hombre y los museos de carácter etnológico y arqueológico a nivel mundial y específicamente Latinoamericano ${ }^{85}$.

Su nacimiento se gesta en la sección de Prehistoria del Museo Histórico ${ }^{86}$, adquiriendo estatus de museo a partir de 1912, fruto del trabajo que había realizado en dicha sección el arqueólogo Max Uhle como parte del contrato que sostuvo con el Gobierno de Chile desde fines de 1911 (Gusinde 1916). Es así como el Museo Etnológico y Antropológico es fundado por Uhle en mayo de 1912, y cobra sentido en consideración de la amplia colección especializada que se encontraba en el Museo Histórico Nacional, la cual había sido reunida gracias a la gestión de Rodulfo y Federico Philippi - guardada en las bodegas del Museo Nacional. Dicha colección fue complementada con cerca de 3.800 objetos, 400 cráneos indígenas y 50 momias, fruto de la recopilación y las excavaciones que Uhle llevó a cabo en la zona norte desde su llegada al país (Gusinde 1916). Como informa Gusinde (1916), las colecciones anteriormente referidas serían trasladadas a su local definitivo - desde el Museo Nacional de Quinta Normal al Museo Etnológico y Antropológico- una vez se contara con el espacio adecuado, lo cual da origen al decreto que instruye el cambio de nombre de Museo Nacional a Museo de Historia Natural, en el cual sólo quedarán las colecciones de zoología, botánica y geología (Gusinde 1916).

85 A modo de ejemplo, señalar que en Argentina se había creado en 1878 el Museo Arqueológico y Antropológico de Buenos Aires, y en 1884 -abierto al público en 1888- el Museo Nacional de La Plata, con una componente fuerte en el campo de la antropología física y arqueología sobre la base de colecciones que reunió Francisco P. Moreno (Farro 2009). A este se suma, en 1904, la creación del Museo Etnográfico Juan B. Ambrosetti (Pegoraro y Spolinasky 2013).

${ }^{86}$ Sin embargo, y como señala Orellana (1979), los antecedentes de este museo se encuentran en la conmemoración de los 100 años de independencia (1910), donde Aureliano Oyarzún Navarro fue encargado de llevar a cabo la retrospectiva histórica en la Exposición Histórica del Centenario, dedicando una de las 15 sección de la exposición a la prehistoria de Chile. Como ya fue señalado, en esta exposición, además, se sitúa el origen del Museo Histórico de Chile. 


\section{Fotografía $\mathbf{N}^{\circ} 4$ : Museo Etnológico y Antropológico $1916^{87}$}

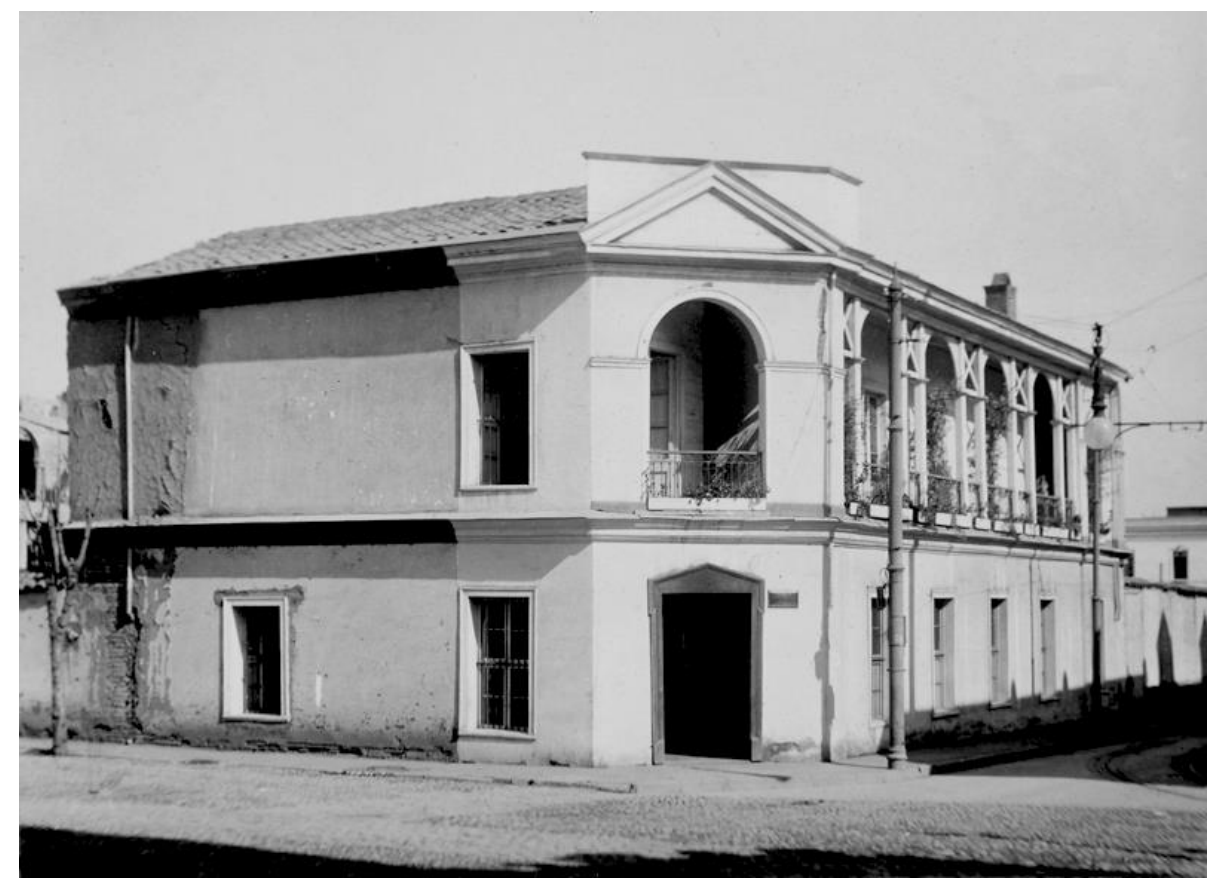

Fuente: $\underline{\text { http://www.museohistoriconacional.cl/ }}$

Como señala Gusinde (1916), "los museos públicos ofrecen un campo de educación para el pueblo y otro de investigación para el sabio.” (p.37), y en tal dirección es pensado el Museo Etnológico; junto con reunir y exhibir colecciones, financia actividades de investigación que desarrollan tanto Max Uhle -en su primera etapa- como posteriormente Aureliano Oyarzún ${ }^{88}$ y Martín Gusinde -entre otros trabajos, el realizado en Tierra del Fuego. El espíritu y orientación que persigue el museo se puede sinterizar en la siguiente cita de Gusinde (1916):

“... para que el pueblo se comprenda a sí mismo, debe empezar por estudiar su propia cultura, los elementos fundamentales de su índole nacional y después analizar los diferentes elementos que entraron en el desarrollo de su civilización." (p.38)

\footnotetext{
${ }^{87}$ El Museo se ubicaba en la esquina de la calle Miraflores con Moneda, en la ciudad de Santiago de Chile. En la actualidad, se encuentran en dicho lugar las dependencias del Archivo Nacional.

${ }^{88}$ Oyarzún, siendo médico de profesión y desempeñándose en distintos cargos y funciones profesionales y docentes en el área médica entre 1880 y 1920, ya en 1910 publica trabajos en el campo de la arqueología año en que además participa en comisionado por el Gobierno de Chile -junto a Medina, Guevara, Lenz y Echeverría- en el XVII Congreso Americanista celebrado en Buenos Aires (Orellana 1979). Realizó dos estancias en Alemania (entre 1887-1891 y entre 1911 y 1913), donde cursa estudios primero en el campo médico, y luego antropológico, donde tiene oportunidad de conocer la organización del Museo Etológico y Antropológico de Berlín.
} 
"Por consiguiente, los museos etnológicos y antropológicos constituyen un vigoroso centro de cultura, un verdadero hogar científico, que abre sus puertas al sabio y al hombre del pueblo, para dejar pasar ante su vista las sucesivas etapas por las cuales ha evolucionado el hombre desde los comienzos más primitivos hasta la altura de nuestra civilización actual” (p.40).

Sin embargo, debido a los problemas económicos y la consiguiente reducción de presupuesto, el Museo de Etnología y Antropología no logra su consolidación. Al problema de infraestructura que implica que las colecciones se encuentren dispersas e incluso almacenadas en bodegas, se suma el finiquito del contrato de Max Uhle (1916), lo cual es referido de la siguiente forma por Gusinde: “... guiado por el espíritu de economía de los gastos de la nación consideró oportuno poner término a su contrato." (1916:33). Es así como a partir del mismo año, Aureliano Oyarzún pasa a ocupar el cargo de Director del Museo en calidad ad honorem (Gusinde 1916), en tanto Martín Gusinde permanece como colaborador de museo, rol que venía cumpliendo desde la administración de Max Uhle, a quienes se suma el historiador Ernesto de la Cruz (Feliú 1970).

La tensión sobre el lugar de las colecciones emerge tras la partida de Uhle, ello, a raíz del reclamo que el Director del Museo Nacional -más tarde Museo Nacional de Historia Natural-, el Sr. Eduardo Moore, realiza al Gobierno respecto de los materiales recopilados por el Dr. Uhle y sus colaboradores. Dicha solicitud es replicada por Oyarzún, en el entendido que ello significa la supresión del Museo de Etnología y Antropología, agregando que: a) no existe espacio para almacenar y exhibir las colecciones en el Museo de Historia Natural; b) no existe espacio en el Museo Histórico, lugar donde, en su defecto, corresponderían ser exhibidos; c) porqué su ubicación actual es la apropiada; d) porque en el Museo de Historia Natural no existe ni ha existido una sección de Etnología y Antropología con carácter oficial; e) que se contará con un edificio definitivo para el Museo Histórico en la Plaza Vicuña Mackenna, junto a la Biblioteca Nacional, constituyendo este un espacio digno (Gusinde 1916).

Aureliano Oyarzún, sucesor de Max Uhle, da continuidad a la tradición de museo de investigación, promoviendo el enfoque teórico y metodológico propuesto por la Escuela Alemana Histórico-Cultural, y realizando trabajo de campo en la zona norte del país yacimiento arqueológico de Tal-Tal- como en la zona sur -el trabajo llevado a cabo por 
Gusinde en Tierra del Fuego y la Araucanía-, a lo cual se suma la edición de la denominada Revista del Museo de Etnología y Antropología de Chile que publica cerca de 2000 páginas (entre 1916-1927). A través de esta se comunican los resultados de investigaciones empíricas, así como las reflexiones de aquellos que se abocan al desarrollo de temáticas de corte antropológico en el país. En dicha revista publica trabajos de Uhle, Oyarzún, Gusinde y Latcham, entre otros.

A partir de 1917, el museo abre sus puertas al público, siendo en 1927 trasladado de manera transitoria al subsuelo del edificio de la Biblioteca Nacional. Sin embargo en 1926, bajo el gobierno del Militar Carlos Ibañez del Campo, y con el objeto de reducir gastos en el presupuesto de la nación, el Ministerio de Instrucción Pública suprime el cargo de Jefe de Sección que ocupaba Gusinde -quien regresa a Europa-, lo que forma parte de las medidas económicas y políticas que continuamente afectaban, y sin mayor argumento, los servicios culturales (Feliú 1970). En esta lógica, y pese a la contribución que el museo estaba realizando en materias etnológicas y antropológicas, en 1928 el Gobierno acuerda suprimir los Museos de Historia y de Etnología y Antropología, para ser reorganizados en 1929 con el nombre de Museo Histórico Nacional (Latcham 1929:149), lo cual consta en los artículos 20 y 21 del D.F.L. N`5.200 dictados el 18 de noviembre de 1929:

Artículo 20. El Museo Nacional de Historia Natural reunirá todos los materiales de Botánica, Zoología, Geología, Mineralogía, Paleontología, Antropología, Etnología y Arqueología universales. Incluirá en sus colecciones antropológicas, etnológicas y arqueológicas al hombre de Chile; pero la colección de base y preferencia relativa a la prehistoria chilena formará la sección de prehistoria del Museo Histórico Nacional.

Artículo 21. El Museo Histórico Nacional reunirá todos los objetos relacionados con la historia patria, tanto civil como militar, y con el ambiente y las costumbres de Chile en sus diversas épocas. En su sección de prehistoria, se limitará al aborigen chileno, con lo cual, en conformidad al artículo anterior, constituirá la colección de base y preferencia en el ramo, dentro del país. 
De este modo, Aureliano Oyarzún pasa a ser nombrado jefe de la sección de Prehistoria del Museo Histórico Nacional y el mismo año -hacia el mes de junio- Director del establecimiento. Luego de ser cesado en 1931, retoma la dirección del Museo Histórico en 1936 y hasta 1946, año en que renuncia por problemas de salud (Orellana 1979).

\subsubsection{Otras iniciativas regionales}

Además de los museos establecidos en Santiago, a nivel regional tiene lugar una serie de iniciativas de origen estatal y privado que nuclean la actividad arqueológica y antropológica. Estos museos regionales canalizan el interés que despiertan estas materias entre actores locales, y particularmente en la exhibición de colecciones adquiridas por particulares a través de la recolección y excavaciones; además, se constituyen en espacios en los cuales se comienza a desarrollar investigación. De hecho, la fundación de museos regionales forma parte de una política gubernamental que buscó replicar a escala local los objetivos ligados a la construcción de la identidad nacional y educación de la población fuera de la metrópoli santiaguina, lo cual se consigna en el artículo 25 de D.F.L. $N^{\circ} 5.200$, en el cual se indica que:

"Los diversos museos de la República formarán colecciones duplicadas de su región, con el objeto de canjearlas entre sí y contribuir al progreso del servicio en general", agregando que "Podrán formar igualmente colecciones destinadas al canje con establecimientos similares del extranjero".

\subsection{Zona Sur}

El Museo de Concepción fue fundado por Decreto Supremo N4427 del Ministerio de Instrucción Pública en $1902^{89}$, destacando en su creación la gestión realizada por el naturalista británico Edwyn Reed Brookman (ex-director y fundador del Museo de Historia Natural de Valparaíso y director y fundador del Museo de Concepción entre 1902 y 1910). Este museo exhibió inicialmente las colecciones que el mismo Reed aportó, las cuales hacia 1909 fueron dispuestas en tres secciones: Museo general en la Antigua Capilla del Liceo y, el Museo

\footnotetext{
${ }^{89}$ Etcheverry (1990) advierte que ya en 1823 se había manifestado la intención de abrir un museo, lo que se consigna en el Decreto del 20 de junio de 1823, promulgado durante el gobierno del Director Ramón Freire. En dicho decreto contaba la apertura de un museo para la práctica de la ciencia.
} 
regional y Museo escolar, en una casona arrendada, propiedad de la familia Reed. Dicha tarea se llevó a cabo con la colaboración de Carlos Reed -hijo de Edwyn- y del taxidermista Gabriel Castillo (Yáñez 1950). Tras la muerte de Reed, y la dirección poco eficiente de Néstor Muñoz Ramos, el museo fue suprimido, y las colecciones pasan al Liceo de Concepción (Yañez 1950). Yáñez (1950) señala que por iniciativa del Intendente Tomás Sanhueza, el Museo reabre nuevamente hacia 1916, designando como Director Honorario a Alcibíades Santa Cruz, con apoyo de Carlos Oliver Schneider. Ya hacia 1918 el museo se reorganiza, designando personal científico compuesto por un director honorario y encargado de la sección de etnografía, el Sr. Alcibíades Santa Cruz ${ }^{90}$, y un conservador y encargado de la sección de Historia Natural, el Sr. Carlos Oliver Schneider (Etcheverry 1990). Se destaca la Figura de Oliver Schneider $^{91}$, conservador ad honorem del museo, quien contribuye al progreso de esta institución por medio del aumento de las colecciones, asumiendo como Director entre 19251949. Además, es indicado como uno de los gestores de la primera publicación del museo, denominada Comunicaciones del Museo de Concepción, y cuyo número inicial se publica en 1936. Según consigna Etcheverry (1990), el Museo pasa por varios problemas de infraestructura hasta alcanzar su ubicación definitiva, a lo que se suman los problemas económicos que obligaron a la suspensión de sus actividades en varias ocasiones.

El Museo Araucano de Temuco -hoy Museo Regional de la Araucanía- fue fundado el 12 de marzo de 1940 mediante el Decreto N735 del Ministerio de Educación Pública, y su organización encomendada por el gobierno a Domingo Amunátegui a Carlos Oliver Schneider, siendo su primer director Hugo Gunckel Lüer (1940-1952), Farmacéutico y Botánico graduado en la Universidad de Concepción (Pino 1969). El museo se orientó hacia la antropología, arqueología y etnología Araucana, así como a la historia de la conquista y pacificación de la región, y a través del estudio e investigación sistemática, buscó exhibir y difundir esta modalidad de vida y ambiente geográfico (Oliver Schneider 1970:19, en Sánchez 1984:8).

\footnotetext{
${ }^{90}$ Fue trasladado a Concepción como cirujano jefe de esta División del Ejército, y tuvo un rol importante en la apertura de la universidad.

${ }^{91}$ Carlos Oliver se matriculó en la Escuela de Ingeniería Química de la Universidad de Concepción, siendo discípulo y ayudante de Edmundo Larenas en la cátedra de Geología. Tras abandonar sus estudios, se traslada a estudiar geología y paleontología a la Universidad Nacional de La Plata, y regresa para ocupar un cargo de profesor en la Universidad de Concepción y Director del Museo (Yañez 1950).
} 


\subsection{Zona Norte}

El Museo Arqueológico de Serena fue fundado en 1943. Este museo partió como iniciativa privada con patrocinio municipal, y su gestión fue encabezada por Francisco Cornely Bachman $^{92}$, nacido en Alemania y radicado en Chile, con estudios de litografía en Chile y Alemania (Orellana 1996). El museo exhibió la recopilación de material de la cultura Diaguita del Valle de Elqui reunida por Cornely. Este museo es transferido a la Dirección de Bibliotecas, Archivos y Museos a partir de 1948. A partir de 1944 se publica el Boletín del Museo Arqueológico de la Serena, en el cual se publican los resultados de diferentes investigaciones.

El Museo Regional de Arqueología de Arica. Fue creado en junio de 1959 con el patrocinio de la Sociedad de Instrucción Popular y por gestión de Percy Dauelsberg, autodidacta que se aboca a la enseñanza de la arqueología a nivel universitario en las universidades de Chile, de Chile sede Arica, del Norte y de Tarapacá a partir de los años '60 (Orellana 1996). En el Noticiario Mensual del Museo de Historia Nacional se señala que “... reúne en sus salas un riquísimo material extraído de cementerios y sitios habitados por los indígenas de la zona." (1959:1). En el mismo año, y bajo la dirección de Sergio Chacón, aparece el primer número del Boletín del Museo regional de Arica, el cual reúne los resultados de las investigaciones realizadas por Dauelsberg (Orellana 1996).

El Museo Arqueológico de San Pedro de Atacama - en la actualidad Museo Arqueológico R. P. Gustavo Le Paige- fue fundado en 1957 por iniciativa del Padre Jesuita Gustavo Le Paige, quien se interesó por la cultura material referida al pasado atacameño, reuniendo una gran cantidad de objetos que formarán parte de la colecciones.

\subsection{Zona Centro}

El Museo de Historia Natural de Valparaíso fue creado en 1878 por el educador Eduardo de la Barra, siendo implementado en dos salas del Liceo de Hombres de Valparaíso. Destacan entre sus directores dos reconocidos científicos de la época: Edwyn Redd Brokman (1878-1879) y

\footnotetext{
${ }^{92}$ Cornely estuvo vinculado al Museo Nacional de Historia Natural, siendo influido por Ricardo Latcham. Fue naturalista adhonorem de dicho museo y en 1942 sumió en la misma condición como ayudante y colector del Museo de Concepción, el cual financiaba trabajos arqueológicos que realizaba en la III y IV región (Orellana 1996).
} 
Carlos Porter Muso (1897-1910). Bajo la dirección de Carlos Porter se edita el Boletín Estadístico y de Canjes del Museo de Historia Natural de Valparaíso, el cual se mantiene vigente entre 1897 y 1910 (Etcheverry 1988) ${ }^{93}$. En dicho boletín, financiado a través de insertos comerciales, se informaban las actividades del museo, adquisiciones, obsequios, canjes, visitas recibidas y correspondencia intercambiada. Además, entre 1897 y 1941, y con una subvención del gobierno, Carlos Porter crea, edita y dirige la Revista Chilena de Historia Natural, órgano oficial de comunicación científica del Museo. Posterior al fallecimiento de Porter, la revista pasa de ser publicada por la Sociedad Chilena de Historia Natural, a una publicación dependiente, a partir de 1981, de la Sociedad Biológica de Chile (Bahamonde 1983).

Asimismo, se registra la creación del Museo de Arqueología e Historia de Viña del Mar -hoy Museo Francisco Fonck-, fundado en 1937 por Dr. el Fonck en el marco de la conformación de la Sociedad de Arqueología de Viña del Mar.

\subsubsection{Las sociedades científicas}

Los extranjeros que se radican en el país promueven la creación de sociedades científicas que aglutinan a connacionales de origen Alemán, Francés, entre otros, participando además de manera simultánea en varias sociedades.

En relación a las instancias científicas creadas desde fines del siglo XIX, cabe destacar la Sociedad Arqueológica de Santiago, una de las primeras sociedades, la cual fue fundada el 28 de julio de 1878. En sus estatutos declara como objetivo en el artículo 1:

"Estudiar al etnografía americana en todos sus períodos; Estudiar las lenguas americanas como elemento etnográfico i arqueolójico; estudiar las antigüedades americanas en sus diversas faces i ramos; Procurar la publicación de obras que se relacionen con los objetos anteriores; Publicar una revista de sus trabajos; Hacer adquisiciones i canjes de objetos i de obras que se relacionen con su institución para formar un museo y una biblioteca."

\footnotetext{
${ }^{93}$ A partir de 1968 se comienzan a editar los Anales del Museo de Historia Natural de Valparaíso.
} 
Lo anterior da cuenta de una concepción más bien amplia del quehacer arqueológico, incorporando tanto la etnografía como la lingüística, que se materializa posteriormente en la idea clásica de la antropología como ciencia integral. Además, se piensa en la sociedad científica como un órgano promotor de la ciencia, impulsando publicaciones y la conformación de instituciones especializadas. La Sociedad estuvo presidida por Rodulfo Philippi, siendo vicepresidentes Wenceslao Díaz y Francisco Astaburuaga, y secretario Luis Montt $^{94}$. Convocó a intelectuales y eruditos destacados en la época -nacionales y extranjeros-, algunos de ellos vinculados a la Universidad de Chile como autoridades o catedráticos, formados en las ramas del Derecho, Medicina, Ingeniería, Letras, Astronomía, así como vinculados a la Armada o la función pública (Orellana 1996). La situación económica y política que atravesaba el país -crisis de 1875 y la Guerra del Pacífico- no fue un escenario que contribuyera a que esta sociedad continuara en el tiempo, logrando editar en 1880 el primer y único número de la Revista de la Sociedad Arqueológica.

Por otro lado, destaca la Sociedad Científica Alemana, la cual se funda en junio de 1885; congrega a intelectuales de origen alemán que realizan investigación científica en los campos de la Zoología, Botánica, Mineralogía, educación y etnografía -asociado a la lengua y folklore-, entre otras. En su inicio, la sociedad estuvo bajo la dirección de Rodulfo Philippi (Presidente), Johannes Bruner (vicepresidente) y Ludwig Darapsky (secretario y tesorero). Esta sociedad comienza a publicar en idioma alemán a partir de 1885 la Revista "Verhandlungen des Deutschen Wissenschaftlichen Vereins zu Santiago de Chile" (Transacciones de la Sociedad Científica Alemana de Santiago de Chile), la cual continúa vigente hasta 1936 (Etcheverry y Peña 1997). En dicha revista se registran 7 trabajos vinculados a temas de orientación paleontología, lingüística, etnología, arqueológica y folklore.

Por otro lado, asociada inicialmente a intelectuales y profesionales franceses residentes en Chile, se crea en abril de 1891 la Société Scientifique du Chili (Sociedad Científica de Chile). El primer directorio estuvo compuesto por tres profesores de la Universidad de Chile: Huber Albert Obretch (Presidente; Director del Observatorio Astronómico), Alphonse Nogués (Vicepresidente; Ingeniero Civil en Minas) y Fernand Lataste (Secretario; Subdirector del

\footnotetext{
${ }^{94}$ Además, estuvieron presentes en la primera reunión, entre otros: Demetrio Lastarria, Rafael Garrido, Marcos Maturana, José Toribio Medina, Augusto Orrego Luco, Federico Philppi y Augusto Villanueva.
} 
Museo Nacional del Historia Natural). En 1891, la sociedad aparece constituida por 80 socios fundadores y 108 titulares, todos ellos considerados miembros de la intelectualidad de la época (Etcheverry 1989), contando catedráticos y autoridades universitarias, autoridades de gobierno, comerciantes y empresarios con interés en la ciencias. La sociedad comienza a publicar en el mismo año de su fundación las “Actes de la Société Scientifique du Chili”, las que se compilan en 45 tomos, siendo su último número publicado en 1938 (Etcheverry 1989). En julio de 1909 se funda la Sociedad del Folklore Chileno, la cual es promovida por Rodolfo Lenz, Ramón Laval y Julio Vicuña, estos últimos, reconocidos folkloristas, y con la participación de socios como: Domingo Amunátegui, Agustín Cannobio, Ricardo Latcham, Eliodoro Flores, Enrique Blanhard-Chessi, Antonio Orrego, Maximiano Flores y Francisco Zapata. La sociedad sitúa como líneas de interés en la literatura, Música y Coreografía, Costumbres y Creencias, y Lenguaje Vulgar. Su objetivo fue promover el estudio del folklore chileno y la publicación de trabajos referentes a esta ciencia (Lenz 1909), generando la publicación de la denominada Revista de Folklore Chileno. Algunos de los trabajos producidos por la sociedad también fueron publicados en Anales de la Universidad de Chile y en la Revista Chilena de Historia y Geografía (Pereira 1945). Esta sociedad se fusiona dos años más tarde con la Sociedad Chilena de Historia y Geografía, pasando a integrar la sección de Folklore de dicha sociedad, manteniéndose activa hasta 1921 (Dannemann 2010).

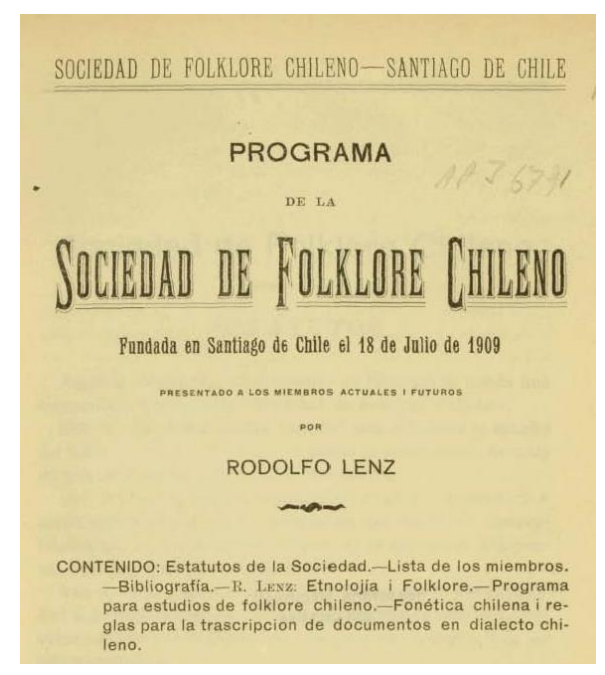

La Sociedad de Folklore Chileno, y particularmente el estilo y calidad de las investigaciones de sus miembros, lograron alcance internacional. Entre sus miembros y asociados figuran los 
socios corresponsales: Franz Boas (Universidad de Columbia), Alexander Chamberlain (Universidad de Clark), Juan Ambrosetti (Director del Museo Etnológico de Buenos Aires), Robert Lehmann-Nitsche (Museo de Ciencias Naturales de La Plata), Samuel Lafon (Museo de Ciencias Naturales de La Plata), Luis Torres (Director del Museo Mitre), Aurelio Espinosa (Universidad de Stanford), entre otros de países como Alemania, Suecia, Brasil, Portugal y Austria (Labarías y Hernando 1998).

También destaca en la época la Sociedad Chilena de Historia y Geografía, creada en septiembre de 1911 tras una convocatoria que reúne 72 personas, la cual fue presidida por Tomás Guevara, y cuya junta administrativa consideró inicialmente a 16 miembros. Entre los miembros de la junta figuraron Domingo Amunátegui, Gonzalo Bulnes, Enrique BlanhardChessi, Ramón Laval, Enrique Matta Vial, entre otros, más cinco presidentes honorarios Ramón Barros Luco, Crecente Errázuriz, José Toribio Medina, Gonzalo Bulnes y Francisco Fonk. En 1912, la Revista Chilena de Historia y Geografía -creada en 1911 por Enrique Matta Vial- es cedida a la sociedad, y dirigida a partir de esta fecha por Ramón Laval, en su calidad de secretario (Martínez 1986).

En mayo de 1926 se crea la Revista Universitaria, que incorporará trabajos derivados de la Academia Chilena de Ciencias Naturales bajo el título Anales de la Academia Chilena de Ciencias Naturales. La creación de la academia fue iniciativa del Rector de la Universidad Católica, Monseñor Carlos Casanueva, con la finalidad de generar una instancia que contribuyera al desarrollo de estas ciencias en Chile, nombrando como director vitalicio a Carlos Porter, quien es secundado por un Consejo Académico (Etcheverry 1988). La revista, bajo el alero de la Universidad Católica de Chile, se comienza a editar en 1926 y hasta 1968, cuando se incorpora en la revista los anales de diversas Facultades y Academias (Etcheverry 1988).

También cabe destacar a la Sociedad Biológica de Concepción, creada en abril de 1927 en dicha ciudad al alero de la Universidad de Concepción ${ }^{95}$. Entre los impulsores de esta iniciativa estuvieron Salvador Gálvez, Guillermo Grant, Alejandro Lipschütz, Ernesto Mahusier, Carlos Oliver Schneider, Ottmar Wilhelm y Alcibíades Santa Cruz. La sociedad comienza a publicar entre 1927 y 1958 un Boletín a través del cual se dan a conocer las

\footnotetext{
${ }^{95}$ Esta universidad contaba a la fecha con las Escuelas de Química Industrial, Farmacia, Odontología y los dos primeros años de Medicina.
} 
comunicaciones realizadas en las reuniones de la sociedad, así como otras producciones en el campo de la biología (Etcheverry 1989). La mayoría de las publicaciones vinculadas al campo antropológico refieren a antropología física o biológica y arqueología.

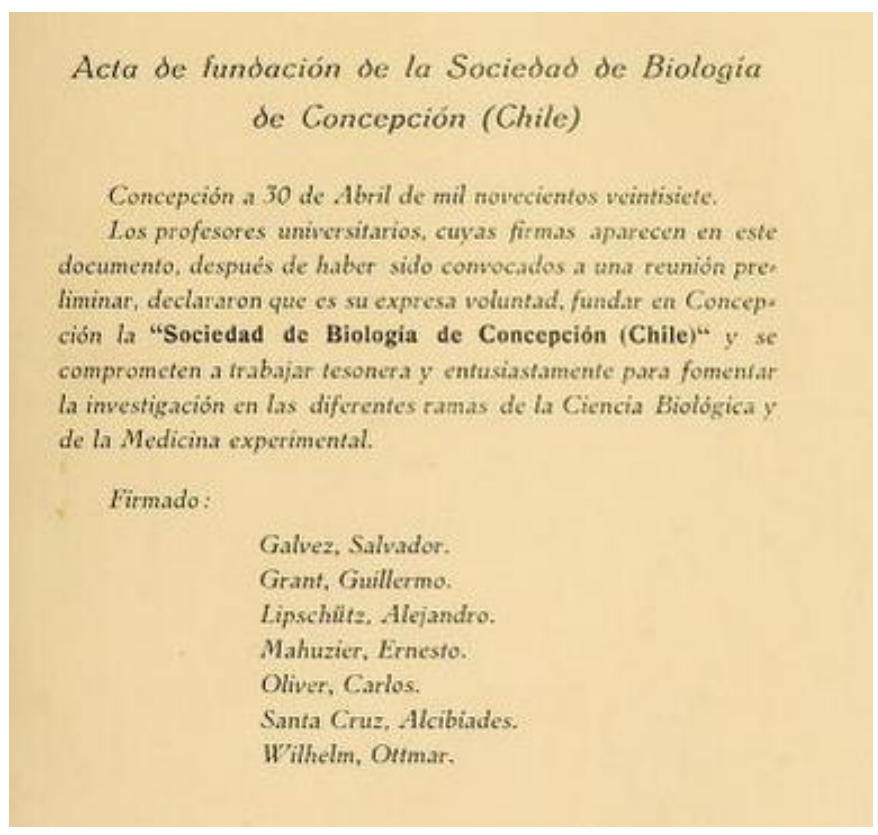

Fuente: Boletín de la Sociedad Biológica de Concepción, Tomo I, número 1 y 2, 1927.

Otras sociedades científicas identificadas son la Sociedad de Arqueología e Historia Francisco Fonck de Viña del Mar, fundada en 1937 -que da vida al Museo del mismo nombre- y la Sociedad Arqueológica de La Serena, fundada en la ciudad de La Serena en 1944, siendo su presidente Eliseo Peña, y contando en su directorio con Jorge Iribarren Charlin y Francisco Cornely. El objetivo de esta sociedad fue difundir la arqueología y ciencias afines.

\subsubsection{Los Congresos en la promoción y difusión del conocimiento de orientación antropológica}

Desde fines del siglo XIX, las dinámicas en las que se juega la comunicación científica se encuentran vinculadas a las sociedades, museo y revistas o boletines. En sociedades científicas y museos tienen lugar la presentación y discusión de trabajos de investigación realizados a nivel nacional, así como el debate en torno a los textos más recientes publicados en América Latina y Europa. Este es el núcleo central de las reuniones periódicas de estas instituciones, 
que además de asociados y "funcionarios", convoca a personalidades e intelectuales de la época.

Sin embargo, y conforme a las orientaciones del modelo de ciencia europeo, se piensa tempranamente en la orgánica de los congresos científicos ${ }^{96}$, instancia de presentación y debate de resultados de investigación que ya estaban teniendo lugar en América Latina.

El primer congreso científico identificado en nuestro país, denominado Congreso Científico Chileno, data de fines del siglo XIX (1893), y en la idea de ciencia integral incluye las temáticas etnológicas, antropológicas y arqueológicas en la sección de Historia, Filología, Etnología, Psicología y Pedagogía, formando parte de otras cuatro secciones que estructuran el congreso: Matemáticas puras y aplicadas, Física y Química; Medicina, Farmacia y Biología; Sociología, Derecho y Economía Política y Agricultura; Ciencias Naturales, Zoología y Botánica.

\section{Fotografía N`5: Cuarto Congreso Científico Chileno, realizado en Talca en 1897.}

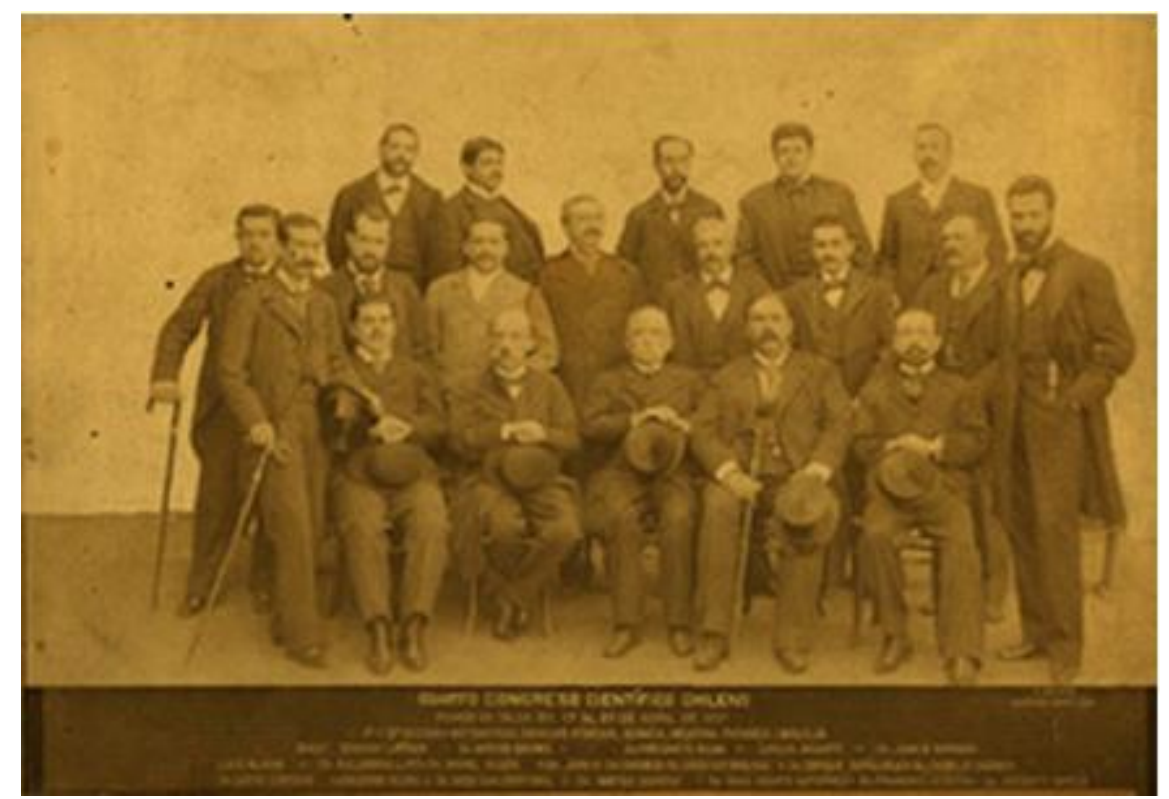

Fuente: http://www.museomedicina.cl/home/index.php/noticiasmnm/224-prueba-after-erish.html

\footnotetext{
${ }^{96}$ El primer congreso realizado en Chile, fue el Congreso Libre de Agricultura (1875), seguido del Congreso Industrial Agrícola (1889), el Congreso Médico Chileno (1889) y el Congreso Nacional Pedagógico (1889). Todos ellos giran entono a temáticas o campos específicos que resultan de interés para el desarrollo nacional: agricultura, salud y educación. Todos estos congresos fueron realizados en Santiago de Chile.
} 
El Congreso Científico Chileno, que se realizó en diez oportunidades entre 1893 y 1944, tuvo su origen en la Sociedad Científica de Chile, tal y como figura en las actas de la sesión del 15 de agosto de 1892. Esta sociedad, de raigambre francesa -y que en las cuatro primeras versiones del congreso incluyó trabajos en castellano y francés-, establece la necesidad de realizar un congreso chileno con una frecuencia de entre uno a tres años. El objetivo de dicho congreso es hacer converger a la intelectualidad científica esparcida por el territorio y divulgar la ciencia nacional a través de comunicaciones técnicas, conferencias, excursiones científicas, vistas industriales, entre otras actividades (Etcheverry 1991). Por ello, la intención inicial, que se mantuvo hasta su última versión, fue que las sedes se establecieran fuera de la ciudad de Santiago.

Cuadro N6: Congreso Científico General Chileno.

\begin{tabular}{|l|l|l|l|l|}
\hline \multicolumn{1}{|c|}{ Congreso } & \multicolumn{1}{|c|}{ Ciudad } & \multicolumn{1}{c|}{ Año } & \multicolumn{1}{c|}{ Presidente } & N $^{\circ}$ Participantes \\
\hline Primer & Valparaíso & 1893 & Alphons Nogués & S/Ref. \\
\hline Segundo & Santiago & 1894 & Pablo Lemétayer & 100 \\
\hline Tercer & Concepción & 1895 & Máximo Cienfuegos & 200 \\
\hline Cuarto & Talca & 1897 & Federico Puga Borne & 250 \\
\hline Quinto & Chillán & 1898 & Adolfo Murillo & 388 \\
\hline Sexto & La Serena & 1900 & Máximo Cienfuegos & S/Ref. \\
\hline Séptimo & Valdivia & 1903 & Máximo Cienfuegos & 275 \\
\hline Octavo & Temuco & 1913 & Ascanio Bascuñan & 800 \\
\hline Noveno & Valparaíso & 1936 & Valentín Brandau & S/Ref. \\
\hline Décimo & Santiago & 1944 & Jorge Zlatar Franulic & S/Ref. \\
\hline
\end{tabular}

Fuente: Elaboración propia en base a Etcheverry (1991).

En base al catastro realizado por Etcheverry $(1991)^{97}$, en los congresos generales se han podido identificar 26 trabajos de orientación antropológica, los que se detallan a continuación:

Cuadro N7: Clasificación de los trabajos presentados en los Congresos Científicos Generales Chilenos, sección de Historia, Filología, Etnología, Psicología y Pedagogía

\begin{tabular}{|l|c|}
\hline \multicolumn{1}{|c|}{ Área } & Número de trabajos \\
\hline Antropología Física & 5 \\
\hline Arqueología & 8 \\
\hline
\end{tabular}

${ }^{97}$ El autor señala que logró recopilar sólo parte del material expuesto y publicado en las actas de estos congresos. 128 


\begin{tabular}{|l|c|}
\hline Etnología y etnografía & 5 \\
\hline Lingüística & 3 \\
\hline Folklore & 1 \\
\hline Antropología Criminal & 2 \\
\hline Prehistoria & 2 \\
\hline Total & 26 \\
\hline
\end{tabular}

Fuente: Elaboración propia en base a Etcheverry (1991).

Set fotografía $\mathrm{N}^{\circ} 6$ : Octavo Congreso Científico Chileno, realizado en Temuco en 1913.

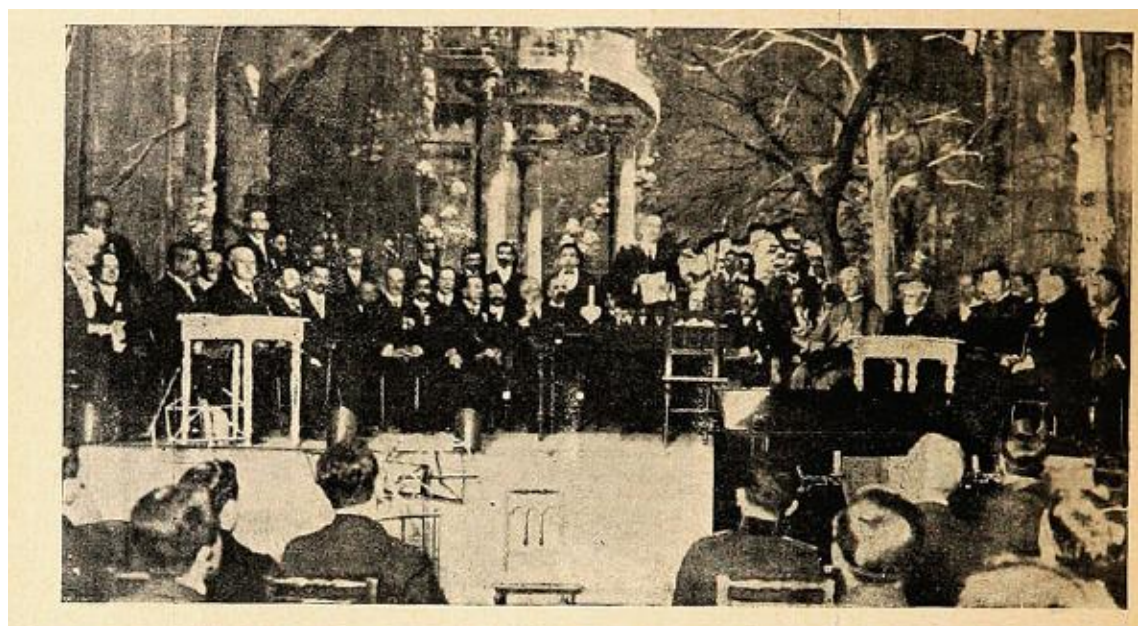

LA MESA DIRECTIVA DE ESTE CONGRESO XN LA SESIÓN DE APERTURA, DURANTE EL DISCURSO DEL INTENDENTI DE LA PROVINCIA, SR, BARRIGA, EN EL THATRO TEPPER,

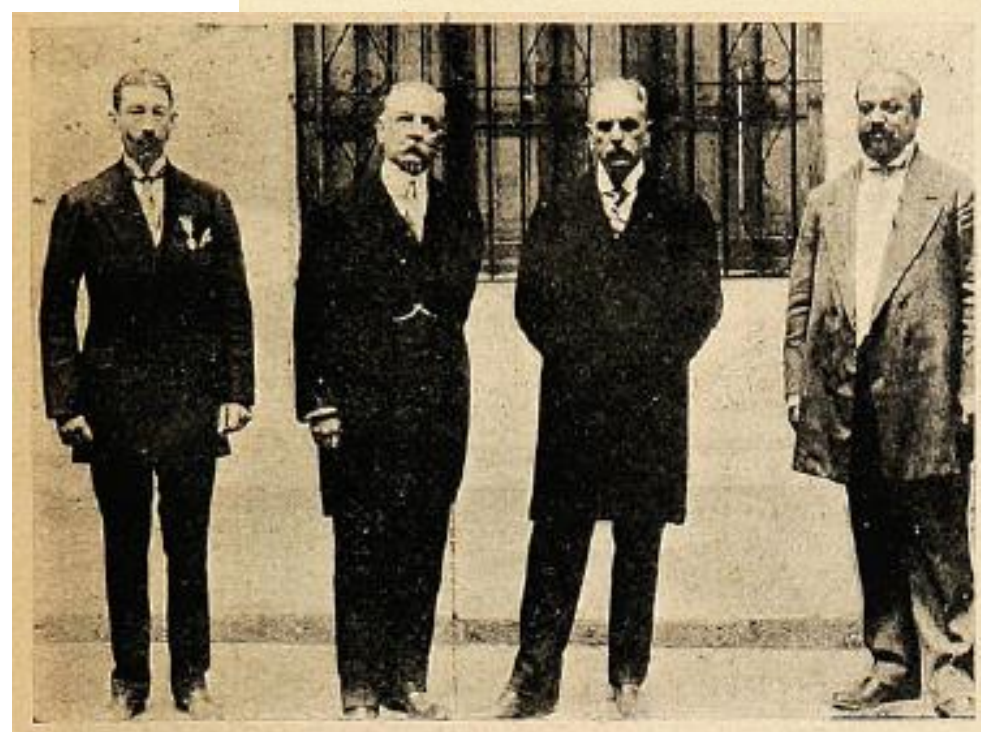

Stes. Carjos Calderón Vergara, José M. Barriga, Tomás Guevara y Victor Hernández que formabin el Comité local de Temuco.

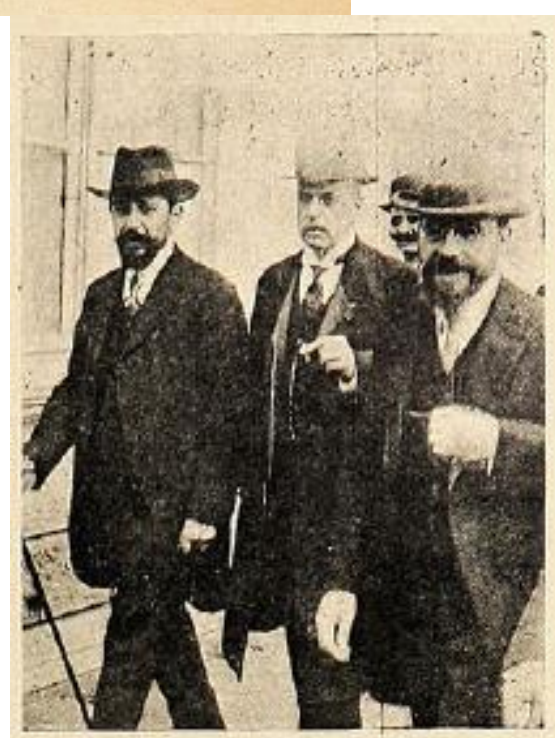

Sres. Samuel Lillo, Tomás Guevara, y Armando Quezada, llegando a teatro Tepper. 


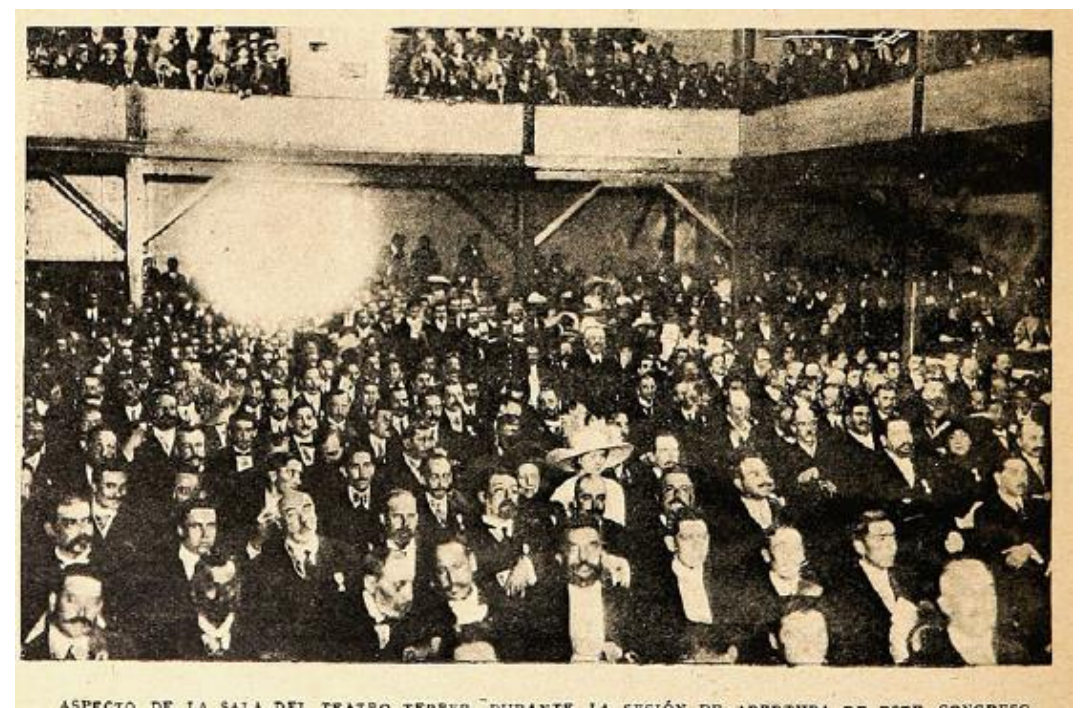

Fuente: Revista Sucesos N546. Febrero de 1913.

Entre los expositores que forman parte del circuito de los estudios de orientación antropológica de la época, destacan: el Médico Luis Vergara Flores (1893-94-97-1900), el Ingeniero Daniel Barros Grez (1893), el Filólogo Rodolfo Lenz (1893-94), el Médico Karl Henckel (1936), el Agrónomo Dillman Bullock (1936-44), y Francisco Cornely (1944), con estudios en Artes Gráficas. Además, para 1944 figuran expositores norteamericanos con formación antropológica o arqueológica: el arqueólogo Junius Bird presenta el trabajo "Problemas de la arqueología en Chile", el antropólogo John Cooper "Aborígenes de Sudamérica", el antropólogo Donlad Brand "El presente de la población india de las Américas”, y el arqueólogo Hebert Joseph Spinder “Civilización Arcaica en Sudamérica”.

Por otro lado, para el primer decenio del siglo XX destaca la realización en Chile del "Primer Congreso Científico Panamericano y Cuarto Congreso Científico Latinoamericano"98, el que se realiza entre el 25 de diciembre y el 5 de enero de 1909 en Santiago. Los países representados en dicho congreso fueron: Argentina, Bolivia, Brasil, Colombia, Costa Rica, Chile, Ecuador, El Salvador, Estados Unidos, Guatemala, Honduras, México, Nicaragua, Panamá, Paraguay, Perú, República Dominicana, Uruguay y Venezuela (Sagasti y Pavéz 1989; Calvo 2011).

\footnotetext{
${ }^{98}$ El Tercer Congreso Latinoamericano se había realizado en 1905 en Rio de Janeiro; el segundo había sido celebrado en Montevideo en 1901 y el primero en Buenos Aires en 1898.
} 
Entre las doce diferentes secciones ${ }^{99}$ y 742 trabajos presentados, podemos destacar la sección de Ciencias Naturales, antropológicas y etnológicas, que contempló la presentación de 81 trabajos -de los cuales 40 fueron publicados, siendo 12 de autores chilenos. El presidente de esta sección fue Vicente Izquierdo y la secretaría asumida por Carlos Porter. Entre los vocales de esta sección se encuentran: David Benavente, Otto Bürger, Alejandro Cañas Pinochet, Federico Yohow, Washington Lastarria, Ricardo Latcham, Rodolfo Lenz, Miguel Machado, José Toribio Medina, Luis Montt, Federico Philippi, Carlos Reiche, Julio Schneider, R. Schuller, Lorenzo Sundt, Maúlen Tirapegui e Isaac Ugarte. (Sagasti y Pavéz 1989). Para la sub-sección de Antropología y Etnología de las razas americanas, el Boletín del Congreso da cuenta de 10 temas generales y 18 temas especiales (28 trabajos en total). Los temas especiales estuvieron referidos a Chile, de los cuales 17 recogieron diversas temáticas asociadas a la población indígena y uno se abocó a la revisión bibliográfica sobre la producción antropológica.

Cuadro N8: Clasificación de los trabajos presentados en la Sub-sección de Antropología y Etnología de las razas americanas

\begin{tabular}{|l|c|c|}
\hline Área & Temas Generales & Temas Especiales \\
\hline Antropología Física & 2 & 0 \\
\hline Arqueología & 1 & 6 \\
\hline Etnología y etnografía & 3 & 6 \\
\hline Lingüística & 1 & 1 \\
\hline Folklore & 0 & 2 \\
\hline Prehistoria & 3 & 2 \\
\hline Total & 10 & 17 \\
\hline
\end{tabular}

Fuente: Elaboración propia en base al Boletín del Primer Congreso Panamericano.

Otro congreso que incorpora el trabajo antropológico fue el Congreso Católico Araucano de Santiago, efectuado en diciembre de $1916^{100}$. Si bien el carácter del congreso no es científico es una expresión de la nueva política de relación y defensa del pueblo mapuche definida por la iglesia católica-, presentan sus resultados de investigación dos miembros del Museo Antropológico y Etnológico: Aureliano Oyarzún y Martín Gusinde. Oyarzún expone "La

\footnotetext{
99 Ciencias Médicas e higiene; Economía Política; Ciencias Químicas, Ciencias Físicas; Matemáticas puras y aplicadas; Ciencias jurídicas; Ciencias económicas y políticas; Ciencias pedagógicas y fillosofía; Agronomía y Zootecnia, Ingeniería, Derecho internacional y constitucional.

${ }^{100}$ Este congreso inspira el surgimiento de la Unión Araucana en 1926.
} 
sangre en las creencias y costumbres de los antiguos araucanos" y Gusinde, "Medicina e higiene de los antiguos araucanos".

\section{Set fotografía Nº7: Congreso Católico Araucano, realizado en Santiago en 1916.}
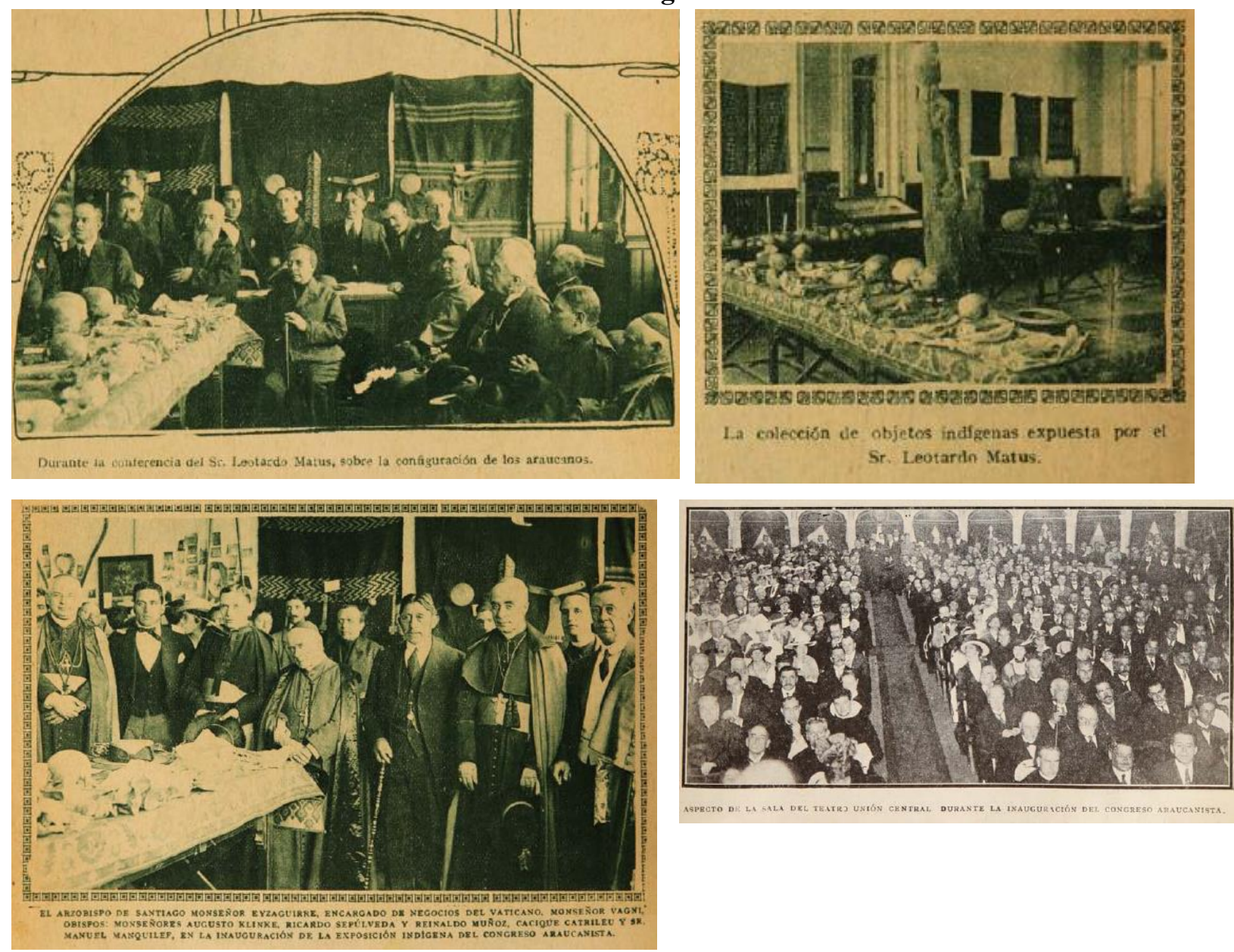

Fuente: Revista Sucesos Nº743. Noviembre de 1916

Congresos nacionales posteriores siguen la línea temática o disciplinaria, sólo se vuelven a registrar hasta la década de los '60 -específicamente 1963-, cuando tiene lugar el Primer Congreso Internacional de Arqueología en San Pedro de Atacama, Chile. Posterior a ello, y de alcance regional, en su primera versión (1963), encontramos las Primeras Semanas Indigenistas -que logra amplitud nacional en la década de los '80-; el Primer Congreso del Hombre Andino, realizado en el Norte de Chile en 1973 -entre Arica, Iquique y Antofagasta-, y en 1985, el Primer Congreso Chileno de Antropología, realizado en Santiago de Chile. 


\section{CAPÍTULO V}

\section{Dinámicas de campo en los inicios de la antropología científica en Chile}

Teniendo en consideración los antecedentes presentados, es difícil avalar la tesis sostenida por Garretón, quien indica que las Ciencias Sociales se institucionalizan en Chile hacia mediados de 1950 (Garretón 1997, 2015). Ya en 1941 el antropólogo Donald Brand en el artículo "The status of anthropology in Chile" señalaba que si bien en el país no existía a la fecha un entrenamiento formal en antropología ni tampoco un departamento universitario, era posible reconocer una práctica o cultivo de esta ciencia en la producción de material de investigación en distintos campos. En el capítulo anterior ya se han presentado varios antecedentes, en particular, referidos a las instituciones que hicieron posible la práctica antropológica, cuestión que se complementa con los antecedentes aportados en los capítulos II y III.

El no reconocimiento de antecedentes más tempranos relativos a la emergencia de las ciencias sociales en Chile se entiende a la luz de:

a) pensar toda actividad científica como vinculada al espacio universitario,

b) no atender a la diferenciación que es posible establecer entre institucionalización científica y disciplinaria -diferenciación conceptual abordada en el segundo capítulo.

Al respecto, señalar que tanto la investigación como el cultivo disciplinar pueden ser desarrollados al margen del espacio universitario - como ha sido el caso de Chile-, aun cuando se reconoce que esta última - la disciplina- cobra mayor sentido en instituciones académicas universitarias, donde se fijan los límites o territorios, los que se refuerzan en la formación profesional que se entrega a los iniciados (Becher 2001 [1989]).

Como se expresa en el capítulo anterior, el surgimiento y desarrollo de la antropología es posible al alero de algunas instituciones que nuclean el interés de estos primeros investigadores. Si bien estas no poseen un carácter exclusivamente antropológico, generan espacios de sociabilidad y formación -en la lógica de los colegios invisibles- que hacen posible canalizar el interés en el marco de instancias que obedecen a propósitos científicos. Estas instituciones resultan claves en la organización y producción científica, lo que ya hacía patente Humberto Fuenzalida en la década de los '60: 
"Para entender la evolución intelectual de Chile en las primeras décadas del presente siglo, habría que hacer un estudio de ellas, revivir el clima de sus sesiones, revisar sus problemáticas, sus discusiones, sus proyectos y sus realizaciones. Para el desarrollo de la investigación y la creación del nuevo espíritu ellas son más importantes que la Universidades" (Fuenzalida 1963: 2).

Ello permite ratificar que el interés por esta nueva ciencia era mucho más que una preocupación ocasional o hobby desarrollado por parte de un grupo de intelectuales excéntricos. Los 532 artículos publicados en revistas científicas de circulación en Chile -entre 1860 y 1954- lo avalan. De hecho, el profundo interés y esfuerzo particular por sostener tanto a la antropología como a la ciencia en general -incluso comprometiendo el patrimonio económico individual-, queda patente en el hecho que a inicios del siglo XX, una porción importante del material bibliográfico y de cultura material se encontraba en la colección particular de varios de los primeros investigadores. Al respecto Porter (1910) entrega algunos antecedentes:

"Los doctores Eichel y Oyarzún son poseedores de objetos de cerámica e instrumentos de piedra y hueso; M. Cañas Pinochet, de hachas de piedra, de discos perforados y una buena biblioteca; Latcham, una rica colección de cráneos y una abundante literatura y M. J. T. Medina, de cráneos, de cerámicas y una rica biblioteca. Todas estas personas residen en Santiago. Aníbal Echeverría, de Antofagasta, posee importantes objetos y documentos sobre lingüística. En Quilpué, el Doctor Francisco Fonck, con una buena colección de osteología, de hacha de piedra y vasijas; en Temuco, el rector del Liceo, Tomás Guevara, que acaba de publicar Psicología del Pueblo Araucano, posee una colección de cerámica..." (Porter 1910:208).

Desde la óptica de estos primeros investigadores, las colecciones privadas permiten la protección del patrimonio nacional frente al saqueo, comercialización y abandono que existe, siendo además un freno a la fuga de dicho material hacia colecciones extranjeras. Como se 
mencionó, muchos de estos materiales pasan vía donación en vida o póstuma a museos y bibliotecas, lo que permite dar inicio a secciones e incluso museos. De hecho, y como se interpreta en un informe de Gusinde (1916), estos primeros científicos también realizaron esfuerzos por promover la conservación a través de la sensibilización de la población:

"A nadie puede tomársele a mal que de un largo viaje por pueblos primitivos traiga consigo algunas armas, vasos, tallados u otros objetos de arte, a fin de embellecer su gabinete de estudio. Pero como el valor estético de tales cositas es muy dudoso y su dueño apenas si sabe apreciarlas, estos trofeos corren la misma suerte que cualquier otro objeto particular: se deterioran y fatalmente desaparecen... Debemos hacer comprender al público que los objetos de valor científico siempre pertenecen a las colecciones de un museo, aun cuando hayan sido adquiridos con dinero particular... Felizmente, hay en Chile patriotas desprendidos y generosos que tan pronto como se les dé la garantía de que sus colecciones privadas serán bien cuidadas y aprovechadas para el bien de la Nación, las cederán gustosos al nuevo museo" (p. 45).

Pese a la débil institucionalización de la investigación antropológica en el país -que se desprende del apoyo más bien fluctuante de los gobiernos para el periodo analizado-, los primeros científicos logran articular un campo de investigación que permite colectivizar los intereses individuales, y además difundirlos en el espacio público especializado y no especializado a través de revistas, periódicos, congresos, reuniones, seminarios, entre otros.

En esta dirección, Alexander Chamberlain, primer graduado como doctor en antropología en Estados Unidos, dedica un artículo a los estudios realizados en Chile sobre Folklore. Este artículo es publicado en 1910 en The Journal of American Folklore, de la Sociedad Americana de Folklore, en el cual hace referencia al trabajo de Rodolfo Lenz ${ }^{101}$, Ramón Laval y Julio Vicuña Cifuentes y de la Sociedad de Folklore Chileno, presentando además un catastro de las publicaciones desarrolladas en el país en dicha materia, el cual recoge los trabajos realizados

101 Al respecto Chamberlain señala "Remontándonos hacia 1905, el Dr. Lenz, de Santiago, muy conocido filólogo y etnólogo, organiza el estudio del folklore chileno por parte de la Comisión de Folklore Chileno y la publicación (primero como un apéndice de los Anales de la Universidad de Chile, y reimpresa como una separata) de una Revista de Folklore Chileno" (1910:383). 
por Lenz. En dicho artículo releva las áreas abordadas en estos estudios, haciendo énfasis en el uso de la lengua nativa para dar cuenta de temáticas relativas a celebraciones religiosas, canciones, cuentos, poesías, mitos, juegos, cocina y alimentos, enfatizando el interés que se otorga al proceso de chilenización de los indios. Agregar que Lenz formó parte del Comité Editorial de la Revista American Anthropologist -entre 1903 y 1914- y fue Miembro de las American Anthropologist Association, rol que también compartieron otros intelectuales latinoamericanos como Juan Ambrosetti -de Argentina- y Nicolás León-México ${ }^{102}$.

Algunos gobiernos nacionales también reconocen el estatus de especialistas de estos científicos en materias antropológicas, reconocimiento que traspasa las fronteras nacionales, a través de membresías y la invitación a congresos, estadías, seminarios. Ello se expresa en el impulso para el desarrollo de la antropología nacional, cuestión que se manifiesta a nivel estatal -pese a las crisis económicas que atravesaron sus mandatos- bajo los gobiernos de los Presientes Pedro Montt (1906-1910) y Ramón Barros Luco (1910-1915), y que se concreta con el apoyo para la participación del Congreso de Americanistas de Buenos Aires, celebrado en mayo de 1910 -congreso clave en la institucionalización de la antropología- y la fundación del Museo Etnológico y Antropológico -única institución especializada en la materia.

El Presidente Montt, por medio del Decreto Supremo $N^{\circ} 190$ del 17 de febrero de 1910, nombró a José Toribio Medina, Aureliano Oyarzún, Tomás Guevara y Aníbal Echeverría en calidad de representantes del Gobierno de Chile para asistir al Congreso Americanista de Buenos Aires. Acompaña a esta delegación en calidad de asistente el profesor del Instituto Pedagógico Rodolfo Lenz, ello, como representante de los estudios del Folklore chileno. En el informe presentado por la delegación chilena hacia junio de 1910 se señala:

“... la preparación variada de esta delegación ha sido causa de que se maneje en conjunto con éxito lisonjero, tanto en las reuniones públicas como las privadas, que han tenido por objeto, las últimas, acercar a los miembros del congreso, darse recíprocas informaciones, cambiar ideas, en suma, sobre los diversos problemas de carácter americanista. El doctor Oyarzún ha estado dentro de sus conocimientos interviniendo en los asuntos de antropología indígena, el señor

\footnotetext{
${ }^{102}$ La invitación para ser miembro de la American Anthropologist Association fue extendida por W. Mac Gee, quien fuera director del Bureau of American Ethnology y presidente de la asociación antes mencionada.
} 
Medina en los de bibliografía americana, el señor Guevara en los de etnolojia general i araucana, el señor Echeverría en los de instituciones aborigen relacionadas con el derecho i el señor Lenz en los de filología americana" (1910:634).

Respecto a los trabajos presentados en dicha ocasión, figuran un total de 13, de los cuales 12 están asociados directamente a población indígena en la línea de la lingüística, la arqueología, la prehistoria, entre otros:

Cuadro N9: Trabajos presentados por la delegación chilena en el XVII Congreso Americanista.

\begin{tabular}{|l|l|}
\hline Lenz & Los elementos indios del castellano en Chile. \\
\hline \multirow{4}{*}{ Oyarzún } & Los petroglifos del Llaima. \\
\cline { 2 - 3 } & $\begin{array}{l}\text { Contribución al estudio de la influencia de la civilización peruana sobre los } \\
\text { aborijenes en Chile. }\end{array}$ \\
\hline \multirow{4}{*}{ Medina } & El tabaco y las pipas prehispánicas en Chile. \\
\cline { 2 - 2 } & Los sacrificadores prehispánicos en Chile. \\
\cline { 2 - 2 } & Folklore Araucano (proverbios y refranes). \\
\cline { 2 - 3 } & Elementos estraños a los araucanos en el poema de Ercilla. \\
\hline \multirow{3}{*}{ Echeverría } & $\begin{array}{l}\text { Las monedas usadas por los indios de la América al tiempo de su } \\
\text { descubrimiento, según los antiguos documentos y cronistas españoles. }\end{array}$ \\
\cline { 2 - 3 } & Introducción a la imprenta en América \\
\cline { 2 - 3 } & El supuesto descubrimiento de Chile por los Frisios en el siglo XI \\
\hline & Influencia incaica en el norte de Chile. \\
\cline { 2 - 3 } & Datos sobre jeroglíficos de la Isla de Pascua. \\
\cline { 2 - 3 } & Noticias sobre la extinguida lengua cunza. \\
\hline
\end{tabular}

Fuente: Elaboración propia en base al Informe de la Delegación Chilena, Congreso Americanista de Buenos Aires, junio de 1910 .

Como señala el informe, la delegación chilena, junto con acudir al congreso, se ocupa de “... recoger informes sobre algunos servicios públicos relacionados con la enseñanza, muesos $i$ bibliotecas." (1910:902). Oyarzun y Guevara se dedicaron a visitar el Museo Arqueológico de la Universidad de Buenos Aires y el Museo de La Plata en el marco de la invitación que los directores de dichos establecimientos habían cursado a los miembros de la delegación. Respecto del primero señalan: "este Museo es una maravilla en su jénero. Colecciones valiosas de alfarería i piedra se ostentan cuidadosamente guardadas i clasificadas. Todas las 
rejiones indijenas antiguas tiene ahí su representación arqueológica en restos de admirable factura" (1910:902). En relación al Museo de La Plata el informe registra lo siguiente:

"Mucho más rico en material arqueológico es el Museo de La Plata, dirijido por el reputado etnólogo arjentino don Samuel A. Lafone Quevedo... Este Museo está instalado en un rejio edificio, dividió en secciones de arqueolojía, zoolojía i paleontolojía... Esta última sección es, con seguridad, la mejor de cuantas existan en el Continente Americano, i quizá en Europa. En la sección de arqueolojía, se encuentra agrupado un material abundantísimo i escojido; sobresalen, principalmente las colecciones de alfarería americana. La delegación se sorprendió, i tal vez se vió un tanto cohibida al encontrase con una colección de esqueletos de aborígenes chilenos tan completa que ni la décima parte puede verse en Chile" (1910:902-903).

La visita de los delegados chilenos, permite constar el avance que el Museo y la Universidad de La Plata ha generado en términos de formación de especialistas, consignando que: "Anexo a la Universidad de La Plata, hai un curso de Ciencias Naturales que comprende los siguientes ramos: Zoolojía, Botánica, Mineralojía, Jeología, Antropolojía, Paleontolojía, Etnolojía, Petrografía e Histolojía Práctica. Sirven esta cátedras distinguidos especialistas” (1910:903).

\section{Fotografía $\mathrm{N}^{\circ}$ 6: Recepción de los miembros del}

Congreso Americanista celebrado en Buenos Aires

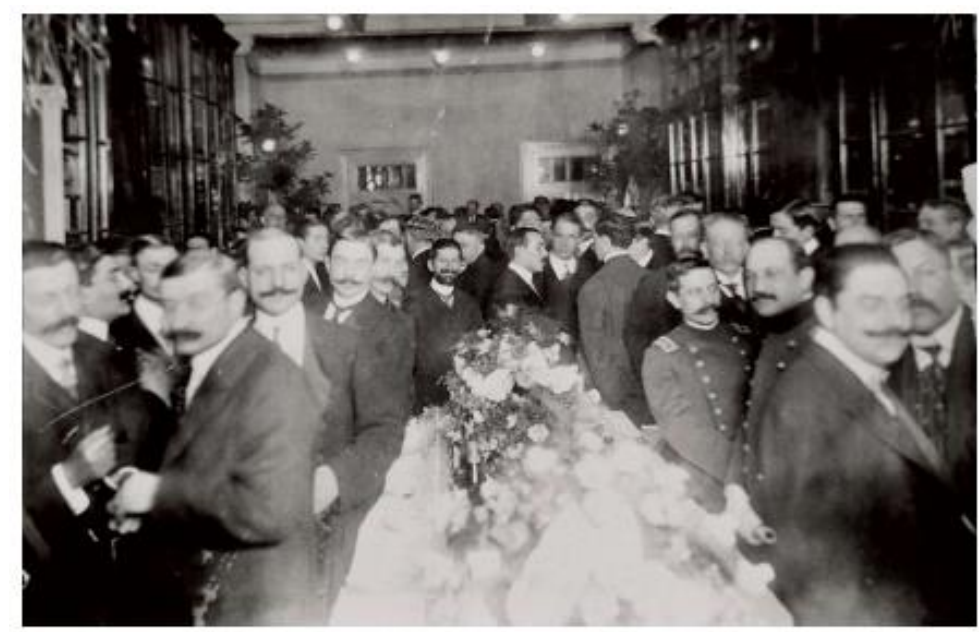

Fuente: Asúa, M. (2011). La fiesta de la ciencia. El Congreso Científico Internacional Americano de 1910. Revista Ciencia Hoy, 21 (125), 18-24. 
El Congreso de Americanistas resulta fundamental como primer paso en la institucionalización de la investigación científica en antropología, debido a que:

- Permite afianzar y validar el trabajo realizado a nivel nacional.

- Establecer redes de colaboración a nivel latinoamericano e internacional por medio del contacto con connotadas figuras de la época.

- Tomar conocimiento del avanzado desarrollo que tiene la investigación antropológica en los museos argentinos.

Se puede señalar que esta visita constituyó un notable impulso para el desarrollo de la antropología. Las observaciones contenidas en el informe permiten asentar la demanda de mayor compromiso por parte del gobierno en el desarrollo y promoción de esta ciencia, de gran avance en el país vecino. De hecho, a su regreso al país tanto Oyarzún como Guevara redactan una carta en la que señalan:

"se ha manifestado al señor presidente de la República, al Rector de la Universidad i al director del Museo Nacional, la necesidad que hai en Chile de organizar un Museo etnográfico, independiente de las otras secciones, aunque no en la dirección general, y rejentando por un especialista europeo, particularmente por un antropólogo que sepa reunir, preparar y clasificar un material abundante" (1910:904).

En el informe se constata el compromiso que había adquirido el Presidente Montt por dar curso a esta solicitud, consintiendo la contratación del sabio italiano Doctor Aldobrandino Mòchi de Florencia ${ }^{103}$-que había participado en el Congreso Americanista de Argentina-, encargando al Decano de la Facultad de Humanidades, Domingo Amunátegui, "que arreglara un proyecto de organización de este servicio científico, descuidado por completo entre nosotros" (1910:904). Sin embargo, la muerte de Montt no logra concretar la contratación de

\footnotetext{
103 Antropólogo, Etnólogo y Paleontólogo italiano originario de Florencia, quien contribuyó al desarrollo de la antropología en Italia, desempeñando labores investigativas y docentes en el Museo Nacional de Antropología, Instituto de Estudios Superiores de la Universidad de Florencia. Para mayores antecedentes, ver: http://www.persee.fr/doc/jsa_0037-9174_1931_num_23_2_1839
} 
Mòchi, y en su reemplazo, bajo el gobierno de Barros Luco, se contrata a Max Uhle -otro participante en dicho congreso-, cuyo trabajo colaborativo da origen al Museo Etnológico y Antropológico antes descrito. Sin embargo, la posibilidad de dictar formación en algunos campos antropológicos no se concreta.

\subsection{Los primeros actores en la producción antropológica}

Si bien entre 1910 y 1930 es el periodo en el cual se encuentra el mayor número de publicaciones de orientación antropológica a nivel nacional (cerca de un 53\% del total catastrado en esta investigación entre 1860 y 1954), ya hacia mediados del siglo XIX es posible identificar literatura que tiene como foco la población nativa del país -indígena o rural. En lo relativo a los primeros trabajos de orientación antropológica o etnológica, autores como Orellana $(1996,1997)$ y Berdichewsky $(1980,2004)$ establecen como hito "Los aborígenes de Chile”, publicación elaborada por el historiador José Toribio Medina Zavala (1852-1930) y que aparece en 1882. El propósito de este trabajo fue caracterizar a la población nativa de Chile, desarrollando una aproximación de corte comparativo que se elaboró en base a fuentes secundarias - principalmente relatos de cronistas, viajeros y análisis de propuestas teóricas de especialistas- y observación directa en territorio mapuche o araucano. Cinco de los doce capítulos -VI, XII, XIII, IX y X- tratan sobre esta última población, considerando temas como lengua, territorio, cultura material, religión, organización social; en tanto, el primer capítulo trata sobre el origen del nombre de Chile, el segundo desarrolla una discusión sobre los primeros pobladores contrastando distintos antecedentes y opiniones de intelectuales de la época, y el cuarto, sobre raza primitiva en América y Chile. Los dos últimos capítulos -XI y XII- refieren a los incas y las relaciones con el Perú, específicamente sobre la expansión, conquista, administración e influencia incásica en Chile.

Para Carlos Porter (1906) "Esta es la obra más notable que se haya escrito en Chile sobre Antropología i Etnografía chilenas” (p.115), en tanto Oyarzún (1979 [1947]), orientado por el canon del trabajo de campo etnográfico - vivir por un tiempo prolongado entre los nativos-, $\mathrm{y}$ teniendo como referente directo la etnografía que había desarrollado a la fecha Gusinde, ubica dicho trabajo en el área de la historia, señalando que: 
"De todos los autores nacionales del siglo pasado que se ocuparon de estos problemas y a quienes reconocemos sus méritos, mencionaremos en primer lugar a don José Toribio Medina que, libre de las influencias filosóficas de su tiempo, al escribir su libro sobre "Los Aborígenes de Chile", no hizo sino darnos un resumen de los escritos de los cronistas de la Colonia, mostrándonos los hechos de los indígenas y adoptando el método de la verdadera Historia, de tal manera que es curioso tener que reconocer que, ya en ese tiempo, se creía que el mejor modo de estudiar las acciones de nuestros aborígenes, era recurriendo a las fuentes de la Historia..." (p.251).

Si bien el trabajo de Medina no sigue el canon antropológico moderno, que implica trabajo de campo intensivo viviendo entre los habitantes del grupo estudiado ${ }^{104}$, transita por la vía de aquellos desarrollos antropológicos de la época. Tal como hicieron varios de los primeros antropólogos, Medina realiza una estancia breve -de unas cuantas semanas-, en territorio mapuche, lo que permite generar descripciones de primera mano que acompaña con reportes de informantes-colaboradores y literatura publicada sobre las poblaciones estudiadas -fuentes secundarias (Mora 2010) ${ }^{105}$. En la biografía de Medina realizada por Amunátegui (1932), éste declara que para componer su trabajo, Medina - con 30 años de edad- tuvo que recorrer la Araucanía, poniendo en riesgo su vida. Además, señala que "Los aborígenes de Chile" constituye la obra que permite a Medina ser nombrado Miembro Honorario de la Sociedad de Americanistas, establecida en Francia. Como referencia, señalar que el trabajo de Medina se

104 A ello se suma la incorporación de una perspectiva teórica tal como indicaron Rivers, Haddon, Boas, Malinowski, entre otros.

${ }^{105}$ Hay que constatar que los estudios históricos y etnológicos de Medina fueron prolijos y sistemáticos; realizó estadías en Perú, México, Norteamérica y Europa -Roma, Francia, Inglaterra-, y publicó su obra a través de editoriales de varios países de América Latina. Realizó trabajo de Archivos en el Archivo de Indias de Sevilla, donde pudo revisar los escritos sobre Chile y América, y visitó las bibliotecas de Turín, el Vaticano, el archivo del Museo Británico de Londres, Biblioteca Nacional de París, participando además en el Tercer Congreso de Americanistas (Nueva York) y otros encuentros de especialistas (Donoso 1915; Amunátegui 1932). Además, es relevante mencionar la estadía que Medina tiene en el Museo de La Plata - uno de los más importantes de América del Sur-, donde se moviliza por invitación de Francisco Pascasio Moreno, posterior a la derrota de Balmaceda en la revolución de 1891. Medina se hospeda en el Museo de La Plata por ocho meses (de marzo a octubre de 1892), y desde el Museo, se otorga financiamiento a la publicación de "Historia y bibliografía de la Imprenta en el antiguo Virreinato de Río de La Plata" y la realización de una tercera estadía en los Archivos de Indias en Sevilla (Donoso 1915; Amunátegui 1932). 
encuentra relativamente próximo a las contribuciones realizadas por quienes suelen ser reconocidos entre los pioneros en antropología mundial: el inglés Edward Burnett Tylor (1832-1917), que publicó “Anahuac or Mexico and the Mexican, Ancient and Modern” en 1861 y "Anthropology: An Introduction to the Study of man and civilization" en 1881; el Norteamericano Lewis Henry Morgan (1818-1881) quien publica "The League of the Ho-deno-sau-nee or Iroquois" en 1851, "System of Consanguinity and Affinity of the Human Family" en 1871 y “Ancient Society” en 1877; el escocés James George Frazer (1854-1941), cuya publicación The Golden Bough: A Study in Magic and Religion, aparece en 1890.

El aporte de Medina en el campo historiográfico resulta indiscutible, y sin duda "Los aborígenes de Chile" constituye una obra de carácter antropológico cuya magnitud y alcance no había tenido lugar en el país. Sin embargo, la exploración a la bibliografía de la época permite constar que desde mediados del siglo XIX ya se estaban publicando artículos sobre población indígena. Precisamente con el objetivo de promover el desarrollo de las ciencias antropológicas en el ambiente intelectual de la época, el Entomólogo y Zoólogo Carlos Porter -uno de los primeros científicos chilenos en llevar a cabo estudios sobre la producción y desarrollo de las ciencias y antropología nacional ${ }^{106}$-, confecciona un detallado inventario con 99 trabajos antropológicos y etnológicos publicados en Chile hasta $1906^{107}$, los que en 1910 amplia a 197 referencias. Porter publica estas compilaciones de la bibliografía antropológica y etnológica (1906, 1909 y 1910) en revistas de Chile, Argentina -Anales del Museo Nacional de Buenos Aires- y en la Journal de la Societè des Americanistes, de París.

El periodo que comprende este catastro se ubica entre 1845 y $1905^{108}$, y las fuentes correspondieron a revistas especializadas -como las actas de las Sociedad Científica de Chile, Anales de la Universidad de Chile, y otras revistas-, libros, periódicos -como El Ferrocarril y El Araucano-, folletos y cartas.

\footnotetext{
${ }^{106}$ Porter publica entre 1902 y 1910, cuatro trabajos que describen la literatura sobre temas de antropología y etnología y el quehacer de la sección de Ciencias Naturales y Antropológicas. Además, y bajo el formato de necrologías y biografías, entrega información de la obra y trayectoria de varios científicos nacionales e internacionales.

${ }^{107}$ En este sentido, Porter (1910) advierte la dificultad que tuvo que afrontar para reunir trabajos realizados en este periodo -muchos de ellos completamente desconocidos-, y la ayuda prestada para estos efectos por algunos colegas y amigos como Ramón Laval (Biblioteca Nacional), Alexander Cañas-Pinochet y Ricardo Latcham.

${ }^{108}$ Este ampliado se presentó en el marco del Cuarto Congreso Científico $\left(1^{\circ}\right.$ Congreso Panamericano) celebrado en Santiago de Chile entre el 25 de diciembre de 1908 y 5 de enero de 1909, y se publicó en la Revista de la Sociedad Americanista y en las Actas de la Sociedad Científica de Santiago.
} 
Figura $\mathrm{N}^{\circ}$ 1: Portadas de las publicaciones realizadas por Carlos Porter en diferentes revistas científicas
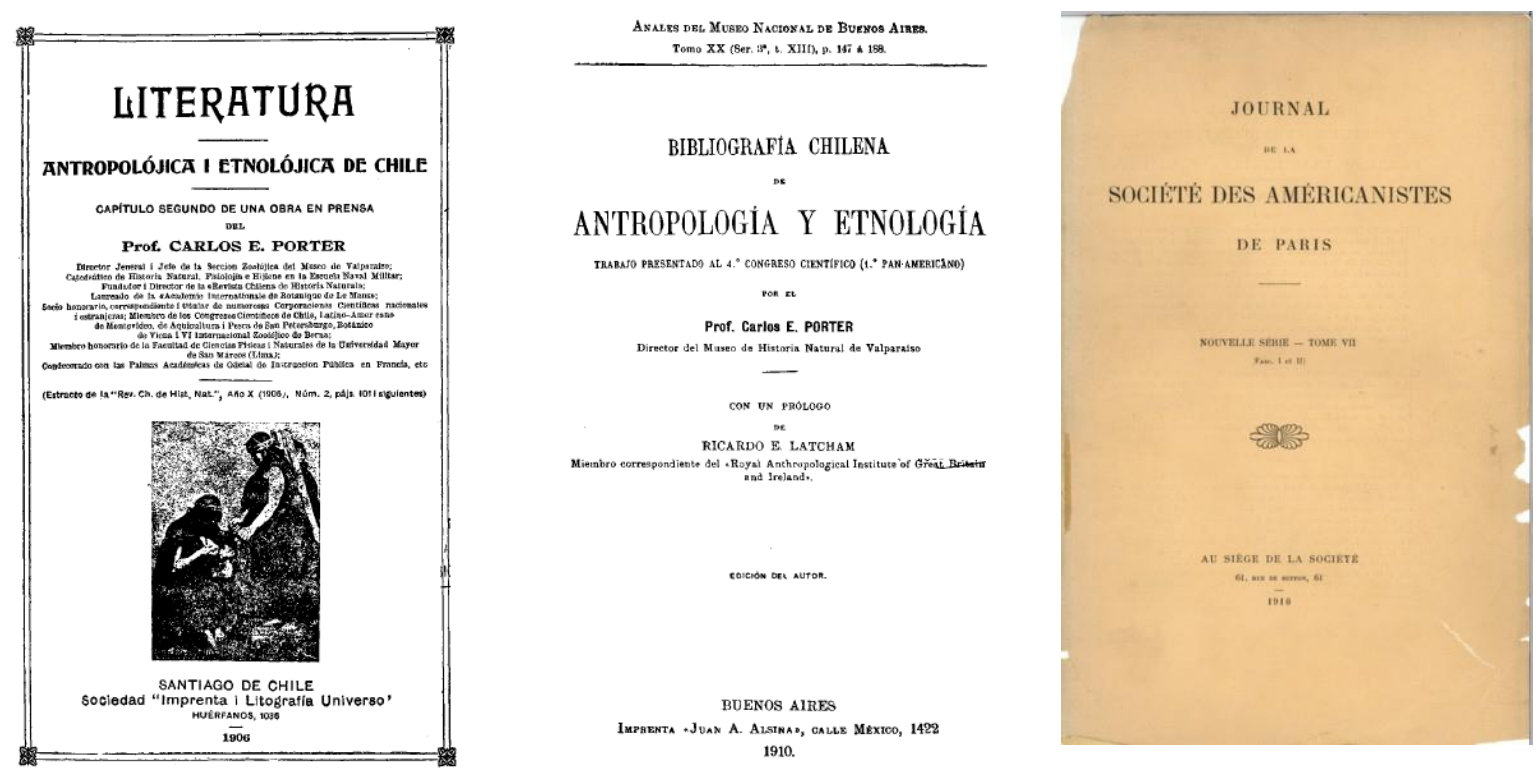

El trabajo más temprano identificado por Porter corresponde a libro escrito por Ignacio Domeyko "La Araucanía y sus habitantes", publicado 1845, que se organiza a la manera de un diario en el cual se narran, entre otros, aspectos relativos a las costumbres de los araucanos. En el comentario, Porter añade "Llamamos la atención del lector tan solo a la segunda Parte del libro del sabio Domeyko, titulada: Estado moral en que se hallan actualmente los indios araucanos, sus usos i costumbres; pues es la parte de la obra que puede mencionarse en el presente trabajo.” (1906: 110).

En el mismo catastro se consigna una de las primeras publicaciones realizadas en una revista de corte académico sobre temáticas antropológicas de época: "Antigüedades Americanas. Últimos trabajos a ellas relativos". Este artículo aparece publicado en los Anales de la Universidad de Chile en $1860^{109}$ siendo su autor el Sr. Adolfo Favry, profesor de idioma Francés de la Escuela Militar, Escuela de Artes y Oficios e Instituto Nacional. El texto presenta una discusión en torno a una serie de trabajos que se habían realizado referidos a la

\footnotetext{
${ }^{109}$ Este trabajo, que aparece en noviembre de 1860, es el producto de la lectura que Favry realizó en las sesiones de la Facultad de Humanidades el 30 de mayo y 27 de junio de ese año.
} 
población americana, específicamente del área de Mesoamérica - por ejemplo, la Historia de los pueblos de América Central publicada por el abate Brasseur de Bourbourg.

La revisión del catastro realizado por Porter (1910) hace posible organizar las publicaciones en 7 categorías:

Cuadro $\mathrm{N}^{\circ} 10$ : Clasificación de los trabajos identificados por Porter.

\begin{tabular}{|c|c|c|}
\hline Orientación & Número de trabajos & Porcentaje \\
\hline Exploración-etnología-etnografía & 95 & 48,2 \\
\hline Arqueológica & 30 & 15,2 \\
\hline Antropología Física & 17 & 8,6 \\
\hline Lingüística & 16 & 8,6 \\
\hline Folklore & 14 & 7,1 \\
\hline Prehistoria & 11 & 5,5 \\
\hline Otros & 14 & 7,1 \\
\hline Total & 197 & 100 \\
\hline
\end{tabular}

Fuente: Elaboración propia en base a Porter $(1910)^{110}$.

Del total de 197 publicaciones, un 48\% pueden ser definidas bajo la categoría "Exploraciónetnología-etnografía"; corresponden a aproximaciones que involucraron registros de campo, los cuales fueron construidos a través de la observación directa y descripción de algunas características de las poblaciones indígenas situadas en distintas regiones del país. Dichas expediciones se realizaron en el marco del reconocimiento de ciertas áreas geográficas poco conocidas o estudiadas, de modo de dar cuenta de recursos potenciales para el país -puertos, yacimientos, límites fronterizos, etc. Si bien muchos de estos son registros breves y que no cumplen con el canon del trabajo de campo etnográfico - vivir entre la población nativa por al menos un año-, brindan ciertos antecedentes que permiten ir configurando una panorama sobre estos grupos. A modo de ejemplo, Porter (1906) releva la importancia del Anuario Hidrográfico de la Marina de Chile, haciendo alusión a la información que presenta en su boletín de 1885, en el cual la comisión francesa abordo del Romanche aporta referencias sobre "tres razas" -Alacalufes, Yahaganes y Onas- tras su recorrido por el Cabo de Hornos entre septiembre de 1882 y septiembre de 1883. También destaca la figura de Francisco Vidal Gormaz -Miembro de la marina chilena y precursor de la hidrografía en el país-, quien realiza varias exploraciones en los canales australes publicando obras como: "El reconocimiento del

${ }^{110}$ En el cuadro se contabilizan sólo los trabajos que incluyen autor. 
Río Maullín” (1857), “Reconocimiento de los canales del sur de Chiloé” (1857), entre otras (Porter 1910).

El trabajo de Porter también permite identificar un 15\% de la producción bajo la categoría de Arqueología - un trabajo mayoritariamente vinculado a la descripción y clasificación de la cultura material que se reunía en las colecciones de los museos-, así mismo un 8,6\% en Antropología Física -asociado principalmente al área de la craneometría. También se registran un $8,6 \%$ de trabajos vinculados al estudio de las lenguas indígenas, así como al folklore entendido como recopilación de cuentos, mitos, leyendas, cantos, juegos.

Además, el trabajo de Porter (1910) hace posible visualizar quienes conformaban el campo de producción de orientación antropológica en dicha época, destacando hacia el primer decenio de siglo XX el naturalista Rodulfo Philippi, el médico Luis Vergara, el militar y geógrafo Alejandro Cañas, el ingeniero Barros Grez, el marino Francisco Vidal Gormaz entre otros.

Cuadro $\mathrm{N}^{\circ} 11$ : Autores de mayor producción entre 1845 y 1906.

\begin{tabular}{|l|l|c|}
\hline \multicolumn{1}{|c|}{ Autor } & \multicolumn{1}{|c|}{ Temáticas-Áreas } & Frecuencia \\
\hline Philippi, R. & Arqueología, Etnografía. & 13 \\
\hline Vergara Flores, L. & Antropología Física, Arqueología. & 12 \\
\hline Cañas Pinochet, A. & $\begin{array}{l}\text { Etnografía, Arqueología, Etnolingüística, Folklore, } \\
\text { Prehistoria. }\end{array}$ & 9 \\
\hline Barros Grez, D. & Arqueología, Prehistoria. & 7 \\
\hline Vidal Gormaz, F. & Etnografía. & 7 \\
\hline Schüller, R. & Lingüística, Folklore. & 6 \\
\hline Barros Arana, D. & Lingüística, Historia, Etnografía. & 5 \\
\hline Latcham, R. E. & Antropología Física, Etnología, Arqueología. & 5 \\
\hline Fonck, F. & Etnografía, Arqueología, Antropología Física & 4 \\
\hline Guevara, T. & Etnología, Folklore. & 4 \\
\hline Lenz, R. & Lingüística, Folklore. & 4 \\
\hline Echeverría, A. & Lingüística, Etnografía. & 6 \\
\hline C. Porter & Otros (estudios sobre antropología). & \\
\hline
\end{tabular}

Fuente: Elaboración propia en base a Porter (1910). El cuadro considera frecuencias iguales o superiores a 4. 


\subsection{Dinámicas de campo: algunas manifestaciones}

La inscripción de la antropología en el imaginario de época involucró el compromiso individual y colectivo privado orientado a la generación de un espacio material y simbólico. Ello implicó un esfuerzo por la legitimación de la antropología como ciencia moderna frente al Estado y a la elite político-intelectual de la época, lo cual dio lugar al desarrollo de sociedades científicas, museos, publicaciones y congresos. Más allá de los vínculos y la colaboración que implicó la etapa inicial del proceso de institucionalización, también se visibilizan ciertos debates o tensiones que se materializan en cartas, artículos, libros y comunicaciones, y que dan muestra de los distintos posicionamientos epistemológicos y teóricos que van teniendo lugar conforme el desarrollo de la antropología internacional.

Si bien no existe para la época analizada instituciones consolidadas que permitan la producción y reproducción de la antropología como disciplina y/o sub-campo de la ciencia, las tensiones identificadas dan lugar a dinámicas que llevan a recordar lo que Bourdieu (2008 [1997]) denominó campo científico, es decir, esa lucha por el monopolio legítimo del capital científico que se constituye en:

“... lugar de una lucha más o menos desigual entre agentes desigualmente provistos de capital específico, por tanto en condiciones desiguales para apropiarse del producto del trabajo científico (y también, en ciertos casos, de los beneficios externos tales como las gratificaciones económicas o propiamente políticas) que producen por su colaboración objetiva...” (p.32).

En esta dirección, tensiones o disputas más generales respecto a la definición legítima de la antropología como campo científico, se acompañan de debates particulares sobre la representación del sujeto indígena nativo referido a: su origen, especificidad, vínculos y carácter.

Es así como una de las primeras tensiones identificadas guarda relación con la puesta en escena de la demarcación y definición legítima del campo antropológico; es decir, lo que se entiende por antropología, lo que caracteriza a su objeto, su localización entre las demás ciencias y su finalidad o propósito. Esta cuestión deriva de las distintas concepciones que 
empiezan a circular en el espacio internacional, fruto de perspectivas desarrolladas en los enclaves intelectuales instituidos en países como Francia, Alemania e Inglaterra, y que dan origen en lo que Cardoso de Oliveira (1992) denomina matriz disciplinar.

Al respecto, uno de los primeros antecedentes se expresó en la controversia referida al destino de las colecciones etnológicas y arqueológicas, lo que tiene lugar en el marco de la redefinición del Museo Nacional como Museo de Historia Natural y al Museo Histórico como Museo Histórico Nacional de Chile. Al respecto Gusinde (1916) refiere de la siguiente manera, aludiendo al pronunciamiento de Aureliano Oyarzún:

"Tal petición está contenida en una memoria elevada a conocimiento supremo por el Director del Museo de Historia Natural. El Gobierno, por decreto numero 1.656 , del $1^{\circ}$ de mayo del presente año, solicitó mi opinión sobre esa memoria; la que contesté sólo en lo referente al Museo, del cual se me había nombrado director. Traté sólo lo que se relaciona con la traslación solicitada... Me opuse terminantemente, como era mi deber, ya que se pedía nada menos que la supresión del Museo de Etnología y Antropología. Yo agregaba, debo defender, conservar y acrecentar la obra el Dr. Max Uhle y, por lo tanto, pido al Gobierno mantenga la actual ubicación del Museo que dirijo... es fuera de propósito trasladar la colección formada por el Doctor Max Uhle a la Quinta Normal para traerla de nuevo en un par de años más al local que ocupará definitivamente. Además, hay que considerar que la sección de Etnología y Antropología del Museo Nacional no ha existido nunca ni existe hasta hoy tampoco con carácter oficial, y más aun, se ha ordenado que los materiales arqueológicos, antropológicos y etnológicos que poseía queden allí en calidad de depósito solamente.” (1916:33-34).

Ello puede ser interpretado como una de las primeras declaraciones manifiestas dirigidas a la identificación de un campo antropológico autónomo respecto de las Ciencias Naturales, así como de otras áreas de las ciencias sociales o ciencias humanas, y con ello, establecer una distancia con la tradición francesa iniciada por De Gerando y Broca, la que sitúa a la antropología como una ciencia natural. 
Fotografía $N^{\circ}$ 5: Representantes de la Escuela Histórico-Cultural ${ }^{111}$.

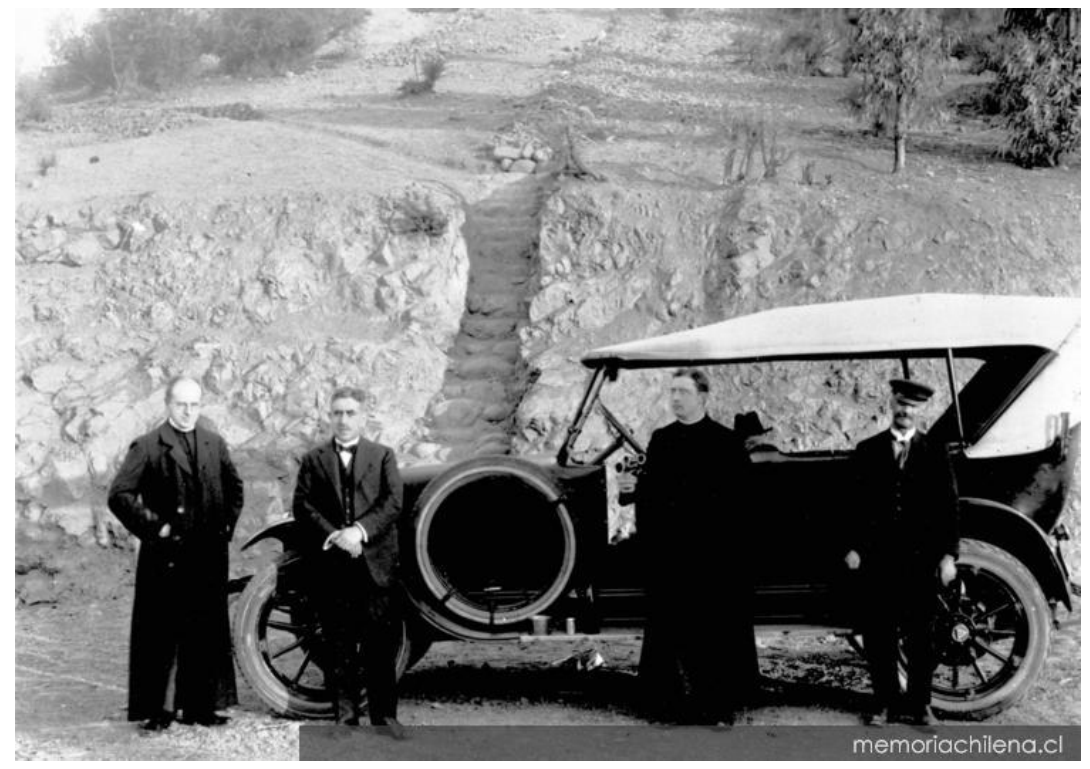

Fuente: http://www.memoriachilena.cl/602/w3-article-74652.html

La discusión dada por Oyarzún, no sólo tiene relación con salvaguardar la persistencia de una institución antropológica independiente; poner en escena un modelo que define la antropología como una ciencia humana y vinculada a la historia, tal y como planteaba el enfoque HistóricoCultural $^{112}$. Esta es la base para argumentar que el lugar más apropiado para las colecciones, en caso de desaparecer el Museo Etnológico y Antropológico, era el Museo Histórico del Palacio de Bellas Artes.

Tal es la convicción de Oyarzún, que vuelve nuevamente sobre este punto casi treinta años después, ello en una de sus últimas publicaciones, la que data de 1945:

"Es urgente, además, poner bajo una sola dirección las dos partes existentes hoy en los museos de prehistoria de la capital. Países más adelantados que el nuestro poseen Museos de Zoología, Botánica y Mineralogía. ¿Por qué a estas tres ramas

\footnotetext{
${ }^{111}$ De izquierda a derecha; Wilhelm Koppers, Aureliano Oyarzún, Martín Gusinde y P.Vera. Wilhelm Koppers fue un sacerdote de la Congregación Verbo Divino y etnólogo Alemán que realizó trabajo de campo en Tierra del Fuego entre 1921 y 1922. Fue director de la Revista Anthropos e impartió clase de etnología en Viena. Fotografía tomada en la cumbre del Cerro San Cristóbal, Santiago de Chile, hacia 1920.

${ }^{112}$ La perspectiva teórica histórico-cultural alemana que comienza a ser desarrollada en el Museo Etnológico y Antropológico, la que fue introducida por Max Uhle y Martín Gusinde, y profesada y difundida a nivel nacional por Aureliano Oyarzun (1979) -quien recibe formación en Alemania.
} 
de las ciencias naturales reunidas en el Museo de Historia Natural, se agrega todavía la prehistoria?" (1979 [1945]:260).

Sin embargo, la posibilidad de desarrollo de la antropología como campo autónomo desligado de las ciencias naturales- sólo se produce hacia mediados de los '50; desde el cierre y fusión del Museo Etnológico y Antropológico, el desarrollo de investigaciones antropológicas en los museos decae, manteniendo un impulso y desarrollo de la investigación en arqueología en el Museo Nacional de Historia Natural bajo la dirección de Ricardo Latcham y posteriormente de Grete Mostny, así como en otros museos regionales.

Otro debate de interés para la época es el que se desarrolla en torno a los estudios folklóricos. En el discurso inaugural de la Sociedad de Folklore Chileno, Lenz (1909) presenta su punto de vista al señalar que el folklore es una rama de la etnología

"que busca la mayor parte de los materiales que se necesitan para la aplicación del método inductivo i comparado en la etnología. Recoje los mitos i todas las manifestaciones de las creencias populares, las leyendas, las consejas, los cuentos, cantos y proverbios, las supersticiones i costumbres. Mientras la etnología general debe siempre tomar en cuenta todas las naciones del mundo, cualquiera sea su grado de civilización i parentesco, el folklore se limita a una sola nación o a un grupo de naciones que tiene historia común, pero puede limitarse hasta una sola provincia i aun a una sola clase de individuos...” (Lenz 1909:8).

Bajo esta definición, el folklore pasa a asumir ciertas características que posteriormente son atributos de la etnografía -puntualmente en lo que refiere a un trabajo inductivo de orientación descriptiva sobre un grupo particular- y cuya diferencia o especificidad está dada por lo que Lenz denomina el estudio del alma popular y las formas características de la vida del pueblo la ciencia que versa sobre el pueblo ${ }^{113}$.

\footnotetext{
${ }^{113}$ Por otro lado, la etnología correspondería al estudio comparativo que tiene como objeto al hombre en tanto ser cultural y social, y que se nutre de distintas ciencias: la antropología, la etnografía, la historia de la cultura, la sociología étnica y el folklore (Lenz 1909:6).
} 
Si bien Lenz recoge la idea de un ciencia del hombre integral en la dirección del modelo francés, incorpora una variante que tiene su base en la tradición alemana de la volkskunde y völkerkunde, iniciando investigaciones que no definieron exclusivamente su objeto en torno a la población indígena, incorporando al sujeto popular -saber popular- o al bajo pueblo chileno: pescadores, chilotes, marineros o el bandido chileno (Lenz 1909:8). Esta perspectiva se hace operativa a través de la Sociedad Chilena de Folklore, sociedad que canaliza investigaciones sobre la cultura popular e indígena en el país, lo que se plasma en un programa de investigación que considera las áreas de: literatura, música y coreografía, costumbres y creencias y lenguaje vulgar.

Como plantea Donoso (2006), el desarrollo de los estudios científicos del folklore gatillan una fuerte controversia con la elite intelectual y política de la época, lo que puede ser atribuido al enfoque científico que definió dichos estudios en el marco de los principios teóricos y metodológicos establecidos por la Sociedad Chilena del Folklore. Recoge de manera directa los relatos de los sujetos sociales y en sus propios términos genera reacciones, las que plantean que se trata de trabajos poco relevantes, los que sólo se ocupan de la desviación de las conductas y/o que no representan los rasgos propios de la nación chilena.

En esta dirección, se puede mencionar la crítica que tanto Eduardo de la Barra como Pedro Nolasco Cruz realizan al trabajo de Lenz (Donoso 2006). Estas críticas se dan en el marco del conjunto de estudios sistemáticos que Lenz inicia sobre las lenguas indígenas del país particularmente mapuche o araucana- y el lenguaje vulgar del pueblo. Dicho trabajo sostiene la tesis del carácter particular que alcanza la lengua castellana en Chile, cuestión que obedecía a la influencia indígena; ello exigía que las investigaciones recogieran el habla y sus expresiones tal y como la ejecuta el sujeto indígena y popular. Al respecto, en Ensayos Filológicos Americanos, publicados en los Anales de la Universidad de Chile, Lenz señala:

"I, ¡así es! En ningún otro país americano habla el pueblo bajo un lenguaje español tan dejenerado, para emplear una vez este término impropio, como en Chile. ¡Naturalmente! En los otros países hispano-americanos apenas hai un pueblo bajo de lengua castellana, visto que el papel de la plebe es desempeñado por indios casi puros... la fuerza nacional no reside en unos pocos gobernantes sino en la masa numérica del pueblo bajo, en esa fuerza rejeneradora que nunca se 
acaba... Chile debe lo que es a su pueblo bajo, a esa raza de sangre mezclada española y araucana, no parecerá ya un asunto de poca importancia el indagar las especialidades del lenguaje del huaso chileno (1894:132).

Las principales críticas elaboradas por de la Barra (1894) y Nolasco Cruz (1940) son dirigidas desde la ortodoxia lingüística, objetando la valoración que Lenz realizaba de las formas incorrectas y la promoción de la libertad del habla, lo cual no se ceñía a las normas de la comunicación y al lenguaje propio (Donoso 2006). De hecho, de la Barra (1894) ${ }^{114}$ resta mérito lingüístico y filológico al trabajo de Lenz, instándolo a constituir una línea de estudios folklóricos a través de una serie de recomendaciones -varios de los puntos aparecen posteriormente en el programa de la Sociedad Chilena de Folklore. Establece una dura crítica a la tesis del surgimiento de una nueva lengua o un dialecto del castellano, cuestión que era sostenida por Lenz.

$\mathrm{Al}$ respecto, de la Barra señala

“...jamás el castellano, más o menos alterado, se convertirá en un dialecto, y menos en lengua nueva. Encuentro destituida de todo fundamento esta opinión que Vd. Aventura, y me parece mui difícil que Vd. pueda sostenerla.

En cuanto a las especialidades del lenguaje del huaso que $\mathrm{Vd}$. busca, y cuya investigación proclama un deber patriótico... de allí por cierto, que no se derivarán grandes observaciones ni ventajas para la lingüística.

No obstante, ello servirá, al menos, como tema escolar para ejercitar a los jóvenes chilenos que se dediquen a la filología... Puede ser que conversando con nuestros huasos y anotando las peculiaridades de su lengua, descubran la raíz o causa determinante de algún vicio de pronunciación; puede que formen el pequeño vocabulario de sus arcaísmos y araucanismos; pero, nada de eso importa gran cosa a la filología y menos a la lingüística." (1894: 50-51).

\footnotetext{
${ }^{114}$ Eduardo de la Barra, fue un Ingeniero, literato y diplomático chileno, miembro de la Real Academia de la Lengua Española, exiliado en Rosario, Argentina entre 1891 y 1895 debido a la condena que realiza en la revolución de 1891contra la presidencia de Manuel Balmaceda (Browen 1993).
} 
Más allá de la pertinencia de algunas de las críticas realizadas por de la Barra, el trabajo de Lenz resulta pionero en Chile en la constitución de ramas de la lingüística que adquirirán relevancia posteriormente: la sociolingüística y la etnolingüística. En este sentido, ello puede ser considerado una subversión del campo, la incorporación de un nuevo punto de vista que disputa con las consideraciones convencionales y hegemónicas asociadas a la lingüística clásica.

Otra controversia de la época en torno al estudio del Folklore, se encuentra asociada a la definición del campo de los estudios folclóricos, lo que se vinculaba directamente con la comprensión, por parte de la élite intelectual y política, de lo que efectivamente corresponde a la cultura - la alta cultura como civilización que se opone a la cultura como cualidad humanay a la cultura nacional. Al respecto Donoso (2006) da cuenta de la reacción que una publicación de Eleodoro Flores, miembro de la Sociedad Chilena de Folklore, genera en la época, reacción que se canaliza a través de la prensa santiaguina. Flores publica en Anales de la Universidad de Chile el artículo "Adivinanzas corrientes de Chile", con el propósito de realizar "...una pequeña contribución que sobre este tema aporto al folklore nacional..." (Flores 1911:48) $^{115}$. Al respecto, en el diario ilustrado se señala que dicho estudio era un “... artículo torpe, grosero, repugnante, nauseabundo es un atentado contra la moral, un insulto contra la cultura nacional, una afrenta vergonzosa para la universidad" (Diario Ilustrado, Santiago 23 agosto de 1911, en Donoso 2006:27). En el diario La Unión se publica:

“...hemos visto una abundante colección de incidencias tan inmundas, tan asquerosas, tan repugnantes y tan burdas, que no es posible insinuar siquiera en qué consisten. So pretexto de adivinanzas, se estampan en letras de molde, en el órgano oficial de la Universidad del Estado, en el medio de comunicación con los centros científicos europeos, todo lo que constituye la delicia de los bajos fondos sociales, lo más grosero que pueda discurrir la malicia y la ignorancia populares, esos acertijos de doble sentido cuya miga está en su estructura brutalmente torpe, ya que las soluciones resultan totalmente imbéciles..." (Diario La Unión, Santiago 23 agosto de 1911, en Donoso 2006:27).

\footnotetext{
${ }^{115}$ Ver en: http://www.anales.uchile.cl/index.php/ANUC/article/view/24344/28087
} 
Donoso (2006) señala que los miembros de la Sociedad emitieron comunicados públicos a modo de respuesta a los emplazamientos realizados a través de la prensa, defendiendo el carácter científico de los estudios llevados a cabo. Advierte que a través de estos medios se solicitó la expulsión de Eleodoro Flores del Instituto Nacional y la suspensión del reparto internacional del número de los Anales de la Universidad de Chile que publicó dicho $\operatorname{artículo~}^{116}$.

Por último, señalar que también ocurren una serie de discusiones en torno a la tesis del origen y aspectos constitutivos de las poblaciones indígenas que habitaban el país, específicamente sobre aquellas que afirmaban la "Unidad etnográfica de los indios chilenos" (Barros Arana 1999 [1884]:47). Dicha tesis había sido sostenida por uno de los más grandes intelectuales chilenos de la época, el historiador Diego Barros Arana, quien en el primer tomo de la obra "Historia General de Chile" señala:

"Este fenómeno, sumamente raro en la etnografía americana, como hemos dicho anteriormente, merece llamar la atención. La existencia de una familia única, ocupando una gran extensión de territorio y hablando un solo idioma, que no tiene afinidad con las lenguas de las naciones vecinas, deja ver que Chile no estuvo sometido, como otras porciones de América, a invasores múltiples que habrían implantado lenguas diversas. Todo hace creer que esta familia ocupaba el territorio chileno desde una remota antigüedad... estas razas no habían recorrido más que las primeras escalas de la evolución.” (Barros Arana 1999 [1884]:47).

La tesis de Barros Arana era ampliamente aceptada por la elite política e intelectual de la época, y había sido reproducida y reafirmada por investigadores como Tomás Guevara, quien gozaba de prestigio nacional debido a sus trabajos referidos a los "Araucanos".

Estos postulados son rebatidos en varios trabajos por Ricardo Latcham, cuyos primeros planteamientos vierte en el artículo "Antropología Chilena", trabajo presentado en 1908 en el Cuarto Congreso Científico Chileno ( $1^{\circ}$ Panamericano) celebrado en Santiago de Chile. En el Latcham discute la existencia de una raza homogénea, señalando las evidencias encontradas a

\footnotetext{
${ }^{116}$ En correspondencia dirigía a Rodolfo Lenz en 1911, la Sociedad Nacional de Profesores ofrece el apoyo frente a los cuestionamientos que se realizan a la labor de la Sociedad de Folklore (Labarías y Hernando 1998).
} 
través de los estudios craneométricos, apoyado en las prescripciones de Paul Broca, quien establecía la primacía de los antecedentes físicos. Latcham señaló que la actual población es el producto de invasiones sucesivas venidas del norte y el este. Al respecto, indica que:

"Nuestra investigaciones nos han convencido de que, lejos de la homogeneidad concebida, Chile es un país donde más mezcla de razas ha habido. ¿A qué atribuir entonces esta convicción por tan largos años sostenida?

La constatación no es difícil. Los cronistas y misioneros de la conquista están de acuerdo con asegurar que en todo el país desde Atacama hasta Chiloé, sólo se hablaba una sola lengua, el chilidúgu, ó lengua de Chile de los antiguos, hoy llamada araucana. Por largos años la lingüística era el único criterio de los orígenes étnicos. La uniformidad de idioma era considerada como prueba de identidad de raza, y aun hoy día queda bastante arraigada esta idea. Luego se suponía que todos los habitantes de la parte central del país formaban un solo pueblo, con los mismos orígenes y caracteres físicos. Creemos que no será difícil desaprobar esta deducción" (1908:5).

Dieciséis años después, en el libro "Organización social y creencias religiosas de los antiguos araucanos" publicado en 1924, Latcham señala que la tesis sobre la no homogeneidad de los indígenas se ha reafirmado a través de la evidencia que ha reunido hasta la fecha. De este modo rebate las afirmaciones vertidas por Guevara y Oyarzún en diversos trabajos, en los cuales sostienen que los Incas penetraron con profundidad la cultura araucana; al respecto, presenta evidencias con base en antecedentes religioso-cosmovisionales y arqueológicos (Latcham 1924:37).

La exposición de estos cuatro casos, permite constatar la existencia de debates a distinto nivel, los cuales se promovieron a través de la producción nacional que circulaba en revistas y libros, cuestión que permitió dinamizar el espacio intelectual por medio de la inscripción de distintos puntos de vista sobre las ciencias, los quehaceres y las interpretaciones relativas a la población indígena y nacional. 


\section{CAPÍTULO VI}

\section{Las ciencias antropológicas a través de la producción en revistas especializadas de circulación nacional entre1860 y 1954}

Con ocasión de la conmemoración del vigésimo aniversario de la muerte de Ricardo Latcham, Humberto Fuenzalida ${ }^{117}$ (1963) señala:

"Hacia 1940, las Universidades del país seguían siendo organizaciones para el estudio de las carreras tradicionales y la investigación estaba relegada a la labor de individuos sin recibir el apoyo institucional necesario para asegurarles una adecuado futuro... Son los años teñidos todavía con la atmósfera intelectual de principios de siglo, romántica y nebulosa, en que se confiaba en el papel de los individuos y en los beneficios de la asociación libre y extraclaustral para cumplir las labores que corresponden al progreso de los conocimientos...”(p. 1).

Tal como plantea Fuenzalida (1963), y como se afirma en varios pasajes de este trabajo, para el periodo analizado la institucionalización de varias ramas de las ciencias es más bien débil; no existe inversión económica sustantiva por parte del Estado, de modo que su desarrollo se lleva a cabo con mucha dificultad al alero de algunos museos y sociedad científicas ${ }^{118}$. A modo de ejemplo, se puede agregar que en la sección "Dos palabras" del Boletín del Museo Nacional de Historia Natural del año 1929, Ricardo Latcham escribe:

"Por motivos de economía, el presupuesto del Museo Nacional de Chile ha sido reducido a un mínimum durante los últimos años, con el resultado que el "Boletín” del establecimiento no pudo publicarse. El último volumen, el Tomo XI (1918-1919) apareció en el año 1920 y sólo hoy se ha podido reanudar su publicación."(p. 8).

\footnotetext{
${ }^{117}$ Fuenzalida, fue Director del Museo Nacional de Historia Natural entre 1948 y 1964, y con anterioridad se desempeñó como Jefe de la Sección de Geología y Paleontología, ello entre 1934 y 1948.

${ }^{118}$ En el Boletín de 1929 Latcham señala con dureza que "A pesar de la escasez de fondos y la miseria de remuneración con que ha contado el personal del Museo, el establecimiento ha entrado en un periodo de gran actividad..." (p. 158).
} 
El espacio universitario estaba mayormente orientado a ciertas áreas del conocimiento y particularmente abocado al desarrollo profesional (Feliú 1969); pese a que varios de los primeros científicos se encontraban vinculados a las universidades, su labor académica no tenía directa relación con sus inquietudes investigativas. En la perspectiva de la elite política e intelectual, estas últimas no habían logrado el reconocimiento necesario para su inserción en las universidades nacionales en tanto áreas de conocimiento relevantes. Por ello, la mayor parte del trabajo científico - entre ellos el de carácter antropológico- se realiza en condiciones económicas y laborales precarias, siendo complemento de otras actividades remuneradas que permiten el sustento familiar y de la investigación: profesor de idiomas, de matemática, química, castellano, médico, abogado, etc. Al respecto, resulta muy iluminadora la descripción que Feliú (1969) realiza a propósito de la biografía de Ricardo Latcham, a quien tuvo la posibilidad de entrevistar antes de su muerte ${ }^{119}$ :

"Pero estos éxitos de la activa vida intelectual de Latcham están llenos de sufrimientos ocasionados por las dificultades económicas. Ha pasado sobre estos quebrantos silenciosamente, con dignidad, decoro y sin muestra de perder el sano y vigoroso optimismo que le animó siempre. Hubo momentos muy duros en este periodo de 1905 a 1908 y quizá hasta 1910. En lo más álgido de la crisis, la voluntad no flaquea para servir su vocación de estudioso... nada de su pluma aparece en el período de 5 años comprendido entre 1916 y 1921. Luchaba por rehacerse." (p.15).

Sin embargo, y pese a la débil institucionalización, los medios que permitieron generar investigación y divulgación del conocimiento derivan en muchos casos del aporte de privados, lo que hace posible contar con recursos económicos así como también generar canales de comunicación que hicieron posible la circulación pública de materiales e informes descriptivos -por medio de redes interpersonales- y la publicación de revistas -y libros.

\footnotetext{
${ }^{119}$ Latcham llega a Chile en 1888 contratado por el Gobierno con el objetivo de dirigir la construcción de las obras viales y demarcación de terrenos que permitieran la radicación de colones en la provincia de Malleco; hacia 1891 fue empleado en su calidad de ingeniero para construir el tramo de la línea férrea entre Santiago y Melipilla, asumiendo más tarde labores de docencia en idiomas en el Instituto Internacional (1892) y hacia 1897 en el Liceo de La Serena, cuestión que complementa con la prospección minera de la zona y el desarrollo de sus actividades arqueológicas (Fuenzalida 1963; Feliú 1969).
} 


\subsection{Las revistas científicas de la época}

La ideas de publicitar o hacer público los resultados de la investigación responde a una orientación que siguen las sociedades científicas europeas desde mediados de siglo XVII; las revistas -específicamente los artículos especializados- cobran relevancia ya que junto a los libros, se constituyeron en los medios por excelencia a través de los cuales comenzó la circulación y difusión del conocimiento científico, siendo el formato que finalmente reemplazó la comunicación epistolar y los informes de circulación privada (Schaffner $1994)^{120}$. En esta dirección, cada institución -sea sociedad científica, museo o universidadcontaba a su haber con una revista o boletín de divulgación, y sus miembros realizaban esfuerzos destinados a que estas mantuvieran cierta periodicidad ${ }^{121}$.

Según lo que se ha podido constatar, la revista de divulgación científica más antigua del país es la Revista Anales de la Universidad de Chile; se crea en 1843 e incorpora una sección denominada memorias, en la cual se presentan los resultados de los trabajos de grado otorgados por la universidad, otros relativos a investigación y algunos ensayos ${ }^{122}$.

La primera revista vinculada al campo de las ciencias antropológica, la segunda más antigua de Chile, es la Revista de la Sociedad de Arqueología -la sociedad científica más antigua del país-, la cual da a luz su primer y único número el $1^{\circ}$ de enero de 1880 . Este número contenía tres trabajos definidos bajo la categoría "antigüedades", el primero titulado "Antigüedades Bolivianas" elaborado por Nicolás Acosta, el segundo "Antigüedades Chilenas” de Luis Montt y el tercero "Antigüedades Ecuatorianas" de Rodulfo Philippi. Además, se incluyeron dos trabajos sin firma: "El araucano antiguo i el araucano moderno" y "La Jeografía antigua de Chile" (Orellana 1996).

\footnotetext{
${ }^{120}$ Varias de las primeras publicaciones en las revistas, refiere a correspondencia entre investigadores las que contenía el informe, debate o discusión sobre algún tópico. En muchos casos se trata de textos extensos, sobre las 20 páginas.

${ }^{121}$ De hecho la Sociedad Científica de Santiago (1878-1881), primera sociedad científica creada en Chile, lanza un primer y único número el primero de enero de 1880 (Orellana 1996).

${ }^{122}$ En el primer número destacan la investigación presentada por José Victorino Lastarria "Investigaciones sobre la influencia social de la conquista i del sistema colonial de los españoles en Chile", un ensayo sobre la disentería en Chile - producto de una memoria elaborada para optar al grado de Licenciado de la Facultad de Medicina-, una memoria sobre ortografía americana leída por Domingo Faustino Sarmiento, otra sobre la conveniencia y objeto de un congreso general americano leída por Juan Batista Alberdi para optar al grado de licenciado en la Facultad de Leyes.
} 
Cuadro $\mathrm{N}^{\circ} 12$ : Instituciones con publicación de revistas y artículos en áreas afines a las ciencias antropológicas entre 1860 y 1954

\begin{tabular}{|c|c|c|}
\hline Institución & $\begin{array}{l}\text { Año de } \\
\text { creación }\end{array}$ & Revista \\
\hline $\begin{array}{l}\text { Museo Nacional de Historia } \\
\text { Natural. }\end{array}$ & 1830 a la fecha & $\begin{array}{l}\text { Boletín del Museo Nacional de Historia Natural } \\
\text { (BMHN). Creada en } 1910 .\end{array}$ \\
\hline $\begin{array}{l}\text { Museo de Historia Natural de } \\
\text { Valparaíso }\end{array}$ & 1878 a la & $\begin{array}{l}\text { Revista Chilena de Historia Natural (RCHHN). } \\
\text { Creada en } 1897 .\end{array}$ \\
\hline $\begin{array}{l}\text { Museo Etnológico } \quad \mathrm{y} \\
\text { Antropológico }\end{array}$ & 1912 a 1928 & $\begin{array}{l}\text { Revista del Museo Etnológico y Antropológico } \\
\text { (BMEA). Creada en } 1916 .\end{array}$ \\
\hline Sociedad Científica Alemana & $1885-1936$ & $\begin{array}{l}\text { Sociedad Científica Alemana (SCA). Creada en } \\
1885 .\end{array}$ \\
\hline Sociedad Científica de Chile. & 1891 a 1956 & $\begin{array}{l}\text { Anales de la Sociedad Científica de Chile } \\
(\text { ASCCH). Creada en 1891. }\end{array}$ \\
\hline $\begin{array}{l}\text { Sociedad Chilena de Historia y } \\
\text { Geografía. }\end{array}$ & 1911 a la fecha & $\begin{array}{l}\text { Revista Chilena de Historia y Geografía (RHYG). } \\
\text { Creada en } 1911 .\end{array}$ \\
\hline $\begin{array}{l}\text { Sociedad Biológica } \mathrm{de} \\
\text { Concepción. }\end{array}$ & 1927 a la fecha & $\begin{array}{l}\text { Anales de la Sociedad Biológica de Concepción } \\
\text { (ASBC). Creada en } 1927 .\end{array}$ \\
\hline Universidad de Chile & 1843 a la fecha & $\begin{array}{l}\text { Anales de la Universidad de Chile (AUCH). } \\
\text { Creada en } 1843 .\end{array}$ \\
\hline $\begin{array}{l}\text { Academia Chilena de Ciencias } \\
\text { Naturales (Universidad } \\
\text { Católica de Chile) }\end{array}$ & 1926 a 1968 & $\begin{array}{l}\text { Anales de la Academia de Ciencias Naturales } \\
\text { (AACHCN). Aparece desde } 1936 \text { como Anales, } \\
\text { que se desprende de la Revista Universitaria } \\
\text { creada en } 1915 .\end{array}$ \\
\hline
\end{tabular}

Fuente: Elaboración propia.

La mayoría de los trabajos de carácter antropológico comienzan a circular en estas primeras revistas (ver cuadro $\mathrm{N}^{\circ} 12$ ), las que a pesar de estar -en su mayoría- orientadas hacia las ciencias naturales, incorporaban -como se argumentó en el capítulo anterior- una visión amplia de la ciencia. De hecho, dar cuenta del espacio antropológico de la época demanda conocer el contenido de estas publicaciones, más aun considerando que varios libros hoy clásicos referidos a población nativa del país, circulaban primero como artículos en estas revistas - particularmente en los Anales de la Universidad de Chile y en la Revista de Historia y Geografía-, siendo entregados en varios números (Ver anexo II). A modo de ejemplo, se pueden mencionar, entre otros: "Historia de la civilización araucana", publicada por Tomás Guevara a través de 35 entregas en los Anales de la Universidad de Chile entre 1898 y 1903; "Las últimas familias y costumbres araucanas" publicada por Tomás Guevara a través de 6 entregas en Anales de la Universidad de Chile en 1912; "Estudios Araucanos" publicado por Rodolfo Lenz a través de 16 entregas entre 1895 y 1897; "Vida y costumbre de los araucanos 
en la segunda mitad del siglo XIX”, publicado por el Padre Ernesto Wilhelm de Moesbach en la Revista de Historia y Geografía a través de 9 entregas entre 1929 y 1935.

Cuadro $\mathrm{N}^{\circ} 13$ : Revistas nacionales y número de artículos publicados en áreas afines a las ciencias antropológicas entre 1860 y 1954

\begin{tabular}{|l|l|c|}
\hline \multicolumn{1}{|c|}{ Revista } & \multicolumn{1}{|c|}{ Orientación principal de las publicaciones } & $\mathbf{N}^{\circ}$ \\
\hline $\begin{array}{l}\text { Boletín del Museo Nacional de } \\
\text { Historia Natural (BMHN) }\end{array}$ & $\begin{array}{l}\text { Ciencias naturales (Botánica, Zoología, Geología, } \\
\text { Paleontología) }\end{array}$ & 36 \\
\hline $\begin{array}{l}\text { Revista Chilena de Historia Natural } \\
\text { (RCHHN) }\end{array}$ & Ciencias naturales & 70 \\
\hline $\begin{array}{l}\text { Revista del Museo Etnológico y } \\
\text { Antropológico (BMEA) }\end{array}$ & $\begin{array}{l}\text { Ciencias sociales (antropología, etnología, } \\
\text { arqueología). }\end{array}$ & 12 \\
\hline $\begin{array}{l}\text { Sociedad Científica Alemana } \\
\text { (SCA) }\end{array}$ & Ciencias naturales & 7 \\
\hline $\begin{array}{l}\text { Anales de la Sociedad Científica de } \\
\text { Chile (ASCCH) }\end{array}$ & Ciencias naturales Hecistes (Historia, & 134 \\
\hline $\begin{array}{l}\text { Revista Chilena de Historia y } \\
\text { Geografía (RHYG) }\end{array}$ & $\begin{array}{l}\text { Humanidades y Ciencias sociales } \\
\text { geografía, antropología, lingüística, Folklore). }\end{array}$ \\
\hline $\begin{array}{l}\text { Anales de la Sociedad Biológica de } \\
\text { Concepción (ASBC) }\end{array}$ & $\begin{array}{l}\text { Ciencias naturales (bilogía, físiología, bactereología, } \\
\text { anatomía, zoología, botánica, inmunología, química) }\end{array}$ & 15 \\
\hline $\begin{array}{l}\text { Anales de la Universidad de Chile } \\
\text { (AUCH) }\end{array}$ & Miscelánea (Humanidades y Ciencias en general) & 179 \\
\hline $\begin{array}{l}\text { Anales de la Academia de Ciencias } \\
\text { Naturales (AACHCN) }\end{array}$ & Ciencias naturales & 41 \\
\hline
\end{tabular}

Fuente: Elaboración propia.

En el cuadro $\mathrm{N}^{\circ} 13$ podemos advertir que el mayor número de publicaciones se encuentra en la Revista Anales de la Universidad de Chile (33,6\%) y en la Revista Chilena de Historia y Geografía (25,2\%). Estas son revistas que se ubican en líneas temáticas de las ciencias y humanidades o de áreas específicas como la historia y geografía, por lo cual puede resultar lógico que representen el 58,8\% del total de artículos catastrados. Sin embargo, el 40\% restante fue publicado en revistas que definían sus lineamientos en el marco de las ciencias de la naturaleza o la historia natural; esto se explica debido al modelo de ciencia que se hace operativo hacia fines del siglo XIX e inicios del XX, y que la define como ciencia integral una especie de monismo que agrupa todas las ramas del saber-, donde el hombre es definido como un ser biológico-natural (ver capítulo anterior).

\footnotetext{
${ }^{123}$ Reemplaza a la publicación de Anales del Museo Nacional de Chile (creada en 1891), un boletín monográfico que incluye en 1903 un especial sobre la Isla Mocha, en el cual publican, entre otros trabajos: Los habitantes antiguos de la Isla Mocha -Carlos Reiche-, Arqueolojia -Federico Philippi- y Tres cráneos de la Isla Mocha Luis Vergara.
} 
Más allá de esta observación, el importante volumen de publicaciones que refieren a la población indígena o habitantes prehistóricos y a la población popular o bajo pueblo, permiten identificar un campo de interés científico; existe un grupo social con la voluntad de investigar y publicar. En este sentido, se define un objeto -lo indígena, lo material, lo popular-, se discute sobre las formas legítimas de representación y se definen prácticas desde cánones científicos de época ligados al ¿qué y cómo investigar?, y al escribir y comunicar o difundir los resultados. En palabras de Becher (1989), se puede hablar de un territorio y una tribu que demarca un espacio fuera del ámbito académico-universitario; si bien no hay formaciónsocialización a través de un sistema formal o de cátedra -no tiene lugar la disciplina-, ello se reproduce en el plano informal a la manera de un colegio invisible. Al respecto, se puede advertir que en el seno de varias instituciones se produce el intercambio formativo; por ejemplo, Martín Gusinde y Aureliano Oyarzún declaran lo fundamental que fue en su formación la figura de Max Uhle.

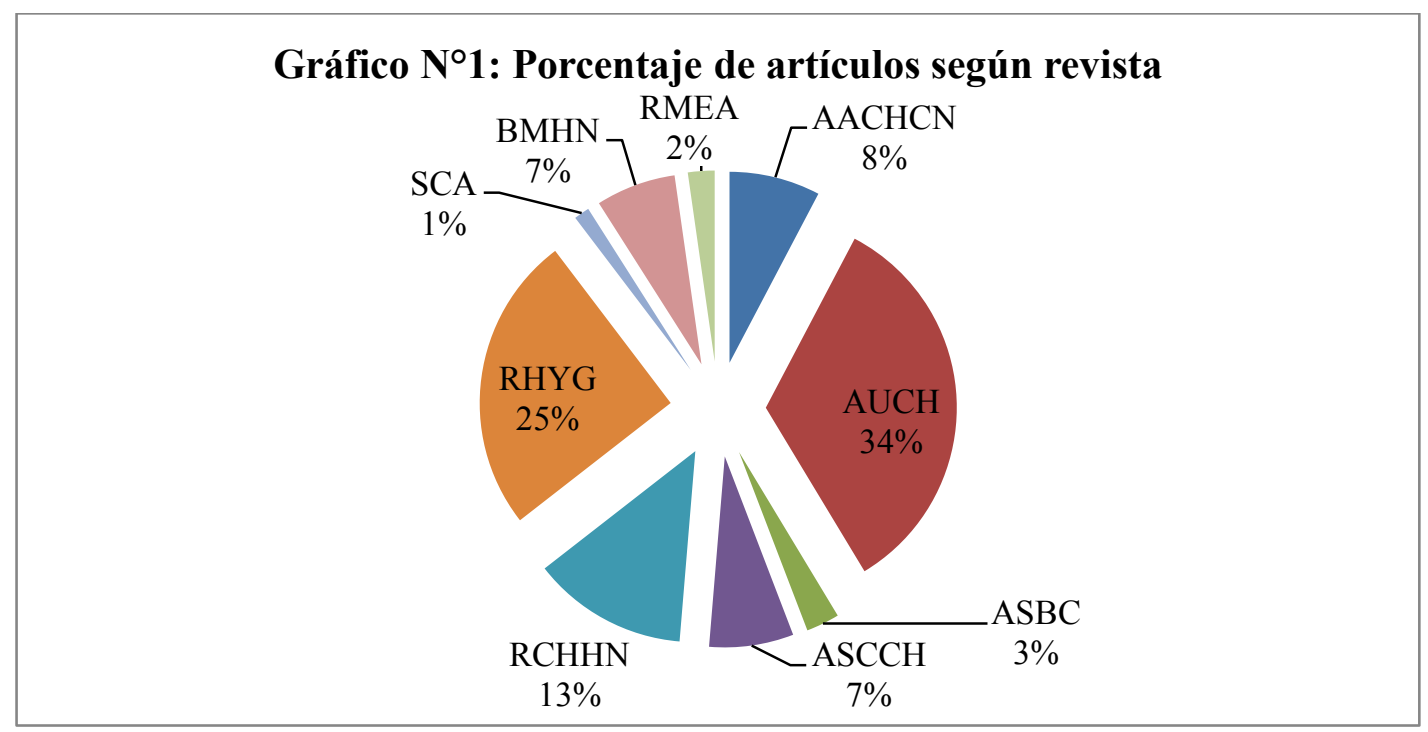

Por otro lado, considerando la tendencia en las publicaciones según áreas temáticas, la distribución es la siguiente:

- Arqueología-Prehistoria, Revista Chilena de Historia Natural (45 trabajos, 29\%);

- Historia-Etnohistoria, Revista Anales de la Universidad de Chile (56 trabajos, 72\%);

- Etnología y Etnografía, Anales de la Universidad de Chile (70 trabajos, 54\%);

- Antropología Física, Revista Chilena de Historia Natural (11 trabajos, 24\%); 
- Folklore, Revista de Historia y Geografía (61 trabajos, $60 \%$ );

- Lingüística, Anales de la Universidad de Chile (10 trabajos, 52\%).

Por otro lado, aludiendo al carácter de la institución, el $41 \%$ corresponde a publicaciones realizadas en revistas universitarias -específicamente en los Anales de la Universidad de Chile-, $37 \%$ en sociedades científicas y el $22 \%$ en museos. Esto resulta de interés, pues si bien no existían cátedras universitarias ni incorporación de líneas de investigación formalizadas, la revista Anales de la Universidad de Chile constituye un espacio relevante para la difusión de la investigación de orientación antropológica.

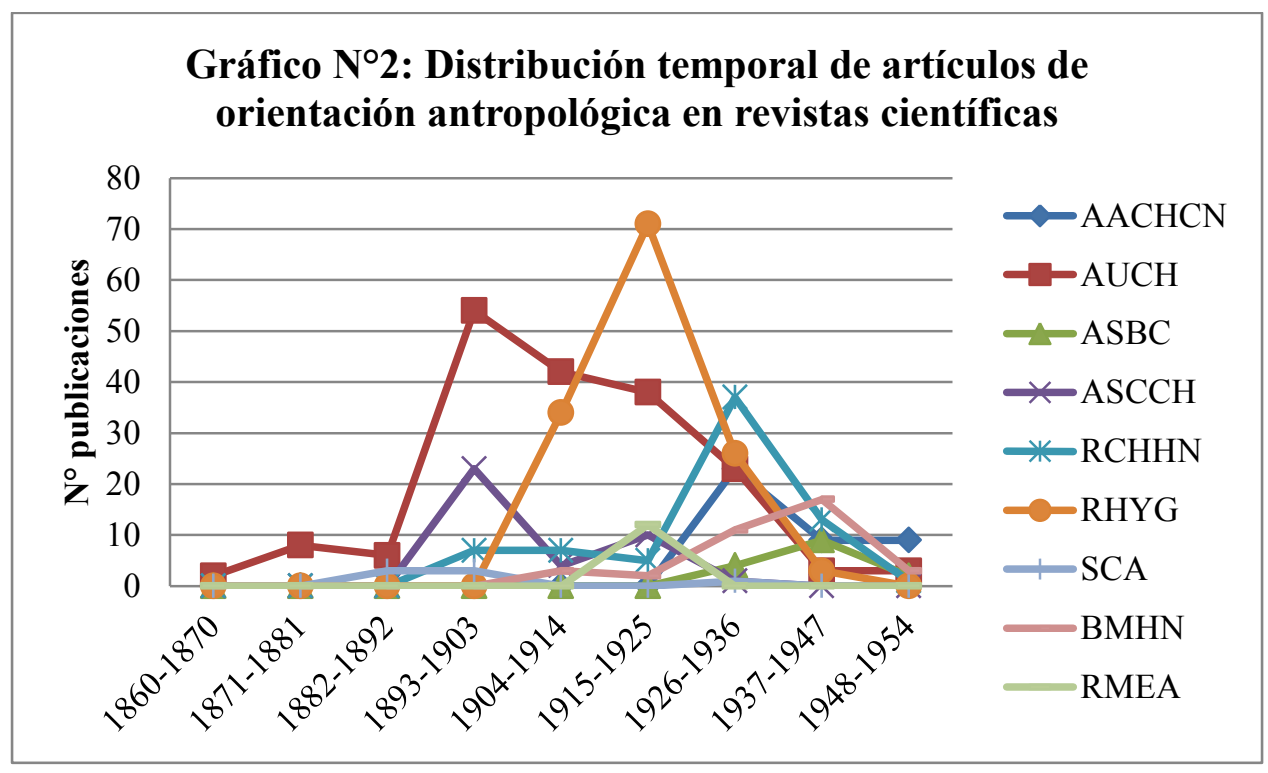

Respecto de la distribución temporal de artículos de orientación antropológica en revistas científicas (ver gráfico $\mathrm{N}^{\circ} 2$ ), es posible observar que el mayor volumen de la producción está vinculado al periodo comprendido entre 1883 y 1947 -año a partir del cual se produce un declive. En 1883 ya se había retomado la normalidad tras la finalización de la denominada Guerra del Pacifico (1879-1881), y si bien la Revista Anales de la Universidad de Chile sigue publicando sin interrupciones, la Revista de la Sociedad de Arqueología de Santiago creada en 1881 y la Sociedad que le da origen desaparecen -algunos de sus miembros dan origen a nuevas sociedades científicas a partir de 1887 (Sociedad Científica Alemana) y 1891 (Sociedad Científica de Chile). 
La mayor cantidad de artículos de orientación antropológica corresponden a los periodos comprendidos entre 1893-1903 y 1904-1914, destacando la revista Anales de la Universidad de Chile (54 y 42 publicaciones respectivamente). De hecho, el 54\% de la producción publicada en la revista se ubica entre 1893 y 1914 -es decir, en 20 de los 94 años de vigencia. Para el caso de la Revistas de Historia y Geografía, el mayor número de publicaciones alcanza a 71 (52\%) en el decenio comprendido entre 1915 y 1925; los Anales de la Asociación Chilena de Ciencias Naturales registra su mayor número entre 1926 y 1936 (56\%), lo mismo que la Revista Chilena de Historia Natural (53\%); la Sociedad Científica de Chile registra el 61\% en el decenio 1893-1903, y el Boletín del Museo Nacional de Historia Natural el 47\% entre 1937 y 1947.

Respecto a las tendencias temáticas que se expresan en los artículos de las revistas, Anales de la Universidad de Chile evidencia mayor número de publicaciones en Historia-Etnohistoria (31\%) y en Etnología-Etnografía (39\%), misma tendencia que muestra la Revista del Museo Etnológico y Antropológico (42\%) respectivamente; la Revista de Historia y Geografía, publica mayormente en Folklore (46\%) y Etnología-Etnohistoria (19\%); la Revista Chilena de Historia Natural en Arqueología y Prehistoria (64\%), lo mismo que el Boletín del Museo Nacional de Historia Natural (81\%), los Anales de la Asociación Chilena de Ciencias Naturales (56\%), los Anales de la Sociedad Científica de Chile (45\%) y la Sociedad Científica Alemana (57\%). Los Anales de la Sociedad Biológica de Concepción registran el 67\% de sus publicaciones en Antropología Física.

Conforme a lo anterior, es posible señalar que aun cuando muchas de las revistas publican en distintas áreas, las revistas de orientación naturalista concentran las publicaciones en áreas afines como la arqueología-prehistoria y antropología física. Anales de la Universidad de Chile (siendo una publicación en ciencias y humanidades) concentra sus publicaciones en Historia-Etnohistoria, Etnología-Arqueología y Folklore, misma tendencia que la Revista de Historia y Geografía, la cual además concentra el 17\% de sus publicaciones en ArqueologíaPrehistoria. 


\subsection{Tendencias en la investigación en ciencias antropológicas}

Como ya se ha señalado, el catastro de artículos que refieren a temáticas afines a la antropología permitió identificar 532 trabajos. Si bien no se incluye la totalidad de la producción impresa o publicada en Chile para el periodo 1860 a 1954 -por ejemplo, artículos en otras revistas y libros-, se considera que el material constituye una muestra representativa tanto de las tendencias temáticas como de los investigadores, permitiendo configurar un panorama del espacio antropológico previo a la institucionalización académica.

Como se puede apreciar en el gráfico $\mathrm{N}^{\circ} 3$, el volumen de la producción en ciencias antropológicas es heterogéneo, con fluctuaciones importantes en ciertos periodos -1909 y 1925-, donde la distribución muestra un incremento a partir de 1893 y un declive a partir de 1945. Entre 1860 y 1892 se registra un total de 19 trabajos -menos de un artículo al año en promedio; la primera publicación identificada figura en Anales de la Universidad de Chile y corresponde al artículo de Adolfo Favry "Antigüedades Americanas", trabajo ya comentado en el capítulo anterior. En este segmento temporal publican migrantes europeos residentes en Chile, viajeros y nacionales, entre los cuales podemos mencionar, entre otros, a: Adolfo Favry (Francés residente en Chile, Bachiller en Humanidades), Manuel Thomson (Marino chileno), Enrique Simpson (Marino chileno), Rudolfo Philippi (Alemán residente en Chile, médico), Francisco Vidal Gormaz (Marino chileno), Diego Barros Arana (Educador e historiador chileno) y Luis Darapsky (Geólogo Alemán que residió en Chile entre 1881 y 1899). La mayoría de estos primeros trabajos corresponde a descripciones de cultura material contenida en las colecciones de los museos o adquiridas por particulares, y referencias a población indígena o a manifestaciones culturales descritas en el marco de viajes de exploración o prospecciones del territorio nacional.

El incremento que se produce a partir de 1893 representa 7 trabajos de los cuales 5 son publicados por Ramón Barros Grez (Ingeniero), y los dos restantes por Francisco Fonk (Médico) y Alphonse Nogues (Geólogo e ingeniero). Se trata de trabajos descriptivos sobre líticos pertenecientes a colecciones, trabajos publicados por Barros Grez en la Revista de la Sociedad Científica de Chile (dos sobre la Piedra del Olimpo, uno sobre la Piedra de la Huaca y dos sobre escritura jeroglífica), un trabajo de Fonk denominado "Un informe del conocimiento de la edad de piedra en Chile medio" y un trabajo sobre "Descendencia del 
hombre y darwinismo" cuyo autor fue Nogues. Este incremento marca el inicio de la primera de cuatro etapas de mayor producción de artículos de corte antropológico en las revistas científicas analizadas. Estas etapas se ubican en los siguientes periodos: 1)1893-1903; 2)19101924; 3) 1927-1931; 4) 1933-1944.

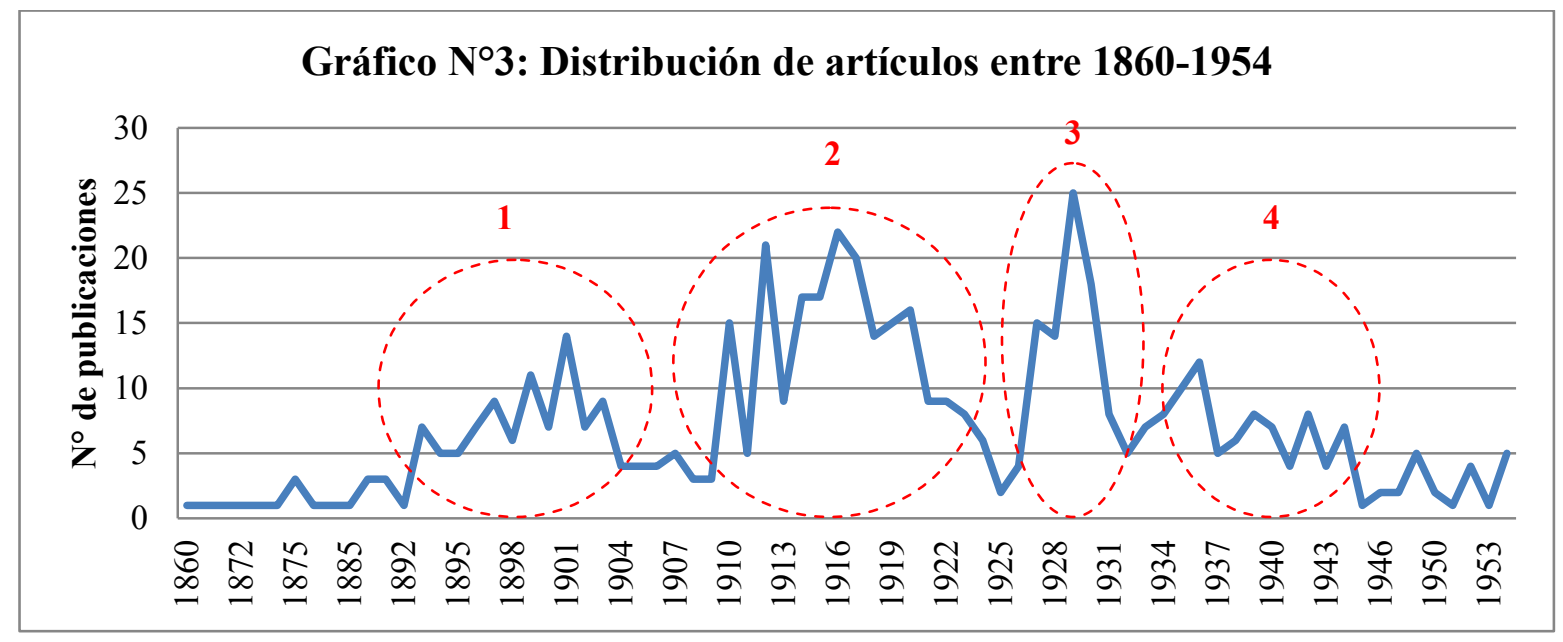

En la primera etapa (1893-1903) se registran un total de 87 publicaciones, produciéndose el mayor número de estas en 1901, con un total de 14 trabajos. En esta etapa destaca la figura de los araucanistas profesor Tomás Guevara (entre 1898 y 1904 publica 35 trabajos), el filólogo Rodolfo Lenz (entre 1895 y 1899 publica 20 trabajos) y el médico Luis Vergara Flores (11 trabajos entre 1894 y 1902). Estos trabajos corresponden a una serie de investigaciones de corte etnológica e historiográfica realizados por Guevara respecto a la "civilización araucana", e investigaciones de orientación folklórica y lingüística realizados por Lenz relativas a los araucanos -recolectando y traduciendo cuentos, cantos y relatos, los que acompaña con notas relativas al idioma nativo. Por otro lado, Vergara Flores realiza trabajos craneométricos y estudios comparativos de cráneos indígenas aimaras, araucanos, y bolivianos entre otros.

La segunda etapa (1910-1924) registra un total de 194 publicaciones, con aumentos iguales o superiores a 20 trabajos en los años 1912 (20 artículos), 1916 (22 artículos) y 1917 (20 artículos). En este periodo destaca la producción de Tomás Guevara (29 trabajos); del ingeniero Ricardo Latcham (21 trabajos, en los cuales desarrolla aproximaciones de orientación arqueológica, etnológica e histórica); el Fraile Pedro Armegol Valenzuela (13 trabajos en los que desarrolla un glosario sobre personas, plantas, ríos y lugares indígenas); la 
italiana Sperata De Sauniére (12 trabajos relativos a cuentos araucanos y chilenos); Ramón Laval -con estudios en caligrafía y teología- publica 11 trabajos relativos a la compilación de tradiciones, leyendas y cuentos populares, y el Bachiller en Filosofía y Letras, y Director de la Biblioteca Nacional Tomás Thayer Ojeda, publica 11 trabajos referidos a una aproximación histórica de la conquista de Chile con información sobre la población nativa. Además de ser la etapa de mayor productividad, se caracteriza por ser la que involucra el mayor número de investigadores, destacando Guevara y Latcham; es además la etapa donde los estudios de Folklore tienen un desarrollo importante.

El tercer periodo (1927 a 1931) comprende un total de 80 publicaciones. Destacan Ricardo Latcham (33 trabajos en las líneas antes señaladas), el botánico Gualterio Looser (13 trabajos, en su mayoría de orientación arqueológica) y el entomólogo francés Claude Joseph (8 trabajos de orientación folklórica y etnológico-etnográfica sobre los araucanos).

El cuarto periodo (1933 a 1944) registra 86 publicaciones -el mayor incremento tiene lugar en 1936 e involucra 12 artículos-, destacando Ricardo Latcham (15 publicaciones); la arqueóloga austríaca radicada en Chile Grete Mostny (9 publicaciones), y el médico alemán radicado en Chile Carlos Hackel ( 7 publicaciones). En este periodo el trabajo de Latcham es sólo de orientación arqueológica -mayoritariamente vinculado a la alfarería- y con referencia al área norte del país, misma tendencia que expresa el trabajo de Grete Mostny -corresponde al periodo en que ambos trabajan en el Museo Nacional de Historia Natural, Latcham como Director y Mostny como encargada de la Sección de Arqueología. El trabajo de Heckel expresa una línea diferente, desarrollando investigaciones de antropología física en anatomía e histología de la población indígena, particularmente del sur del país - Heckel es profesor de la Facultad de Medicina de la Universidad de Concepción.

Podemos señalar que la alta productividad en estas etapas se encuentra asociada a la figura y trayectoria de algunos investigadores, quienes realizan publicaciones de manera sistemática y articulan el "campo de las ciencias antropológicas nacionales"; por ejemplo, Latcham publica en total 75 artículos, Guevara 68 y Lenz 28. De hecho, la disminución de la producción total asociada a los periodos identificados, se vincula al retiro de la actividad intelectual o muerte de estos investigadores - por ejemplo, Latcham fallece en 1943, siendo director del Museo Nacional de Historia Natural; también hay factores de tipo político y económico que influyen, pero no permiten explicar totalmente las fluctuaciones en la producción, a lo que se agregan 
los desastres naturales -asociados a la escasez de recursos. Un aspecto que puede iluminar la baja producción entre 1922 y 1928 se expresa en algunos antecedentes contenidos en una comunicación de Latcham al Director General de Bibliotecas, Archivos y Museos ${ }^{124}$. Señala que a su llegada a la Dirección del Museo de Historia Natural "El edificio estaba en ruinas, resultado del temblor del 14 de abril de 1927 y, como consecuencia, cerrado al público.” (p. 153), agregando que:

"El Museo carecía de muchos servicios indispensables, sin que, con los fondos para gastos y para fomento, tan exiguos que llegan a ser irrisorios, se pueda remediar este estado de cosas. El personal científico, compuesto de especialistas, que habían pasado sus mejores años en investigaciones y en labor técnica intensa, estaba desilusionado por los míseros sueldos que ganaba, inferiores al de muchos artesanos, y desganado por el abandono al que estaban relegados durante años" (1929:153).

En esta dirección, y frente a la inexistencia de instituciones formales, son los individuos como Latcham, Guevara, Lenz, Oyarzún, entre otros- y sus esfuerzos los que motivan e incentivan el cultivo de la antropología. En el segundo periodo, la alta productividad se entiende por la confluencia de varios intelectuales quienes establecen fuertes lazos de amistad y cooperación, llevando a cabo la creación de instituciones de la talla del Museo Etnológico y Antropológico de Santiago, la Sociedad Chilena de Historia y Geografía y la Sociedad de Folklore Chileno; podríamos aventurar que este periodo corresponde a la "edad de oro" de la antropología en Chile.

\footnotetext{
${ }^{124}$ Señala que hasta 1926 , el presupuesto anual del Museo era de $\$ 4.000$; el entonces Ministro Juan Eduardo Barrios -Escritor y dramaturgo, Premio Nacional de Literatura en 1946-, aumenta dicho presupuesto a $\$ 20.000$ y destina \$200.000 para la reparación del establecimiento. Barrios fue Ministro de Educación bajo el Gobierno de Carlos Ibáñez del Campo (1927-1931) hasta 1927. Latcham acusa que su sucesor, el Radical Pablo Ramírez Rodríguez realiza un nuevo recorte presupuestario en 1928.
} 


\subsection{Las áreas temáticas en la investigación en ciencias antropológicas}

El trabajo de clasificación temática involucró la creación de seis categorías bajo las cuales se codificó el contenido de los artículos analizados. Las seis categorías recogen las áreas clásicas de la antropología (Borca 1870), estando además en concordancia con la terminología que se utilizó a inicios del siglo XX en el círculo intelectual chileno (Porter 1909; Lenz 1911), y en base a la cual se pueden realizar las siguientes definiciones:

a) Etnografía: descripción de los pueblos, en tanto conocimientos de las distintas razas que pueblan o han poblado el territorio chileno.

b) Antropografía (antropología física): descripción anatómica, física y patológica del hombre.

c) Lingüística: estudio gramatical y etimológico de las voces indígenas.

d) Arqueología y prehistoria: estudio del origen de las antiguas razas del país a partir de los objetos materiales.

e) Folklore: estudio del conjunto de las tradiciones, creencias y costumbre de las razas, descripciones de fiestas y ceremonias, y de los incidentes de la vida diaria del pueblo.

A estas categorías se suma la historia-etnohistoria, que recoge los estudios documentales -de archivos o fuentes escritas y orales- que dan cuenta de las tradiciones, costumbres y vida indígenas del pasado.

La clasificación ha seguido la amplitud conceptual de la época, dejando de lado las concepciones contemporáneas que se desprenden de prescripciones y estandarizaciones conceptuales y metodológicas que tienen lugar hacia mediados del siglo XX. En esta dirección, y desde un punto de vista operacional, el análisis de los artículos utilizó las siguientes definiciones:

a) Etnografía-Etnología: referencias descriptivas breves o extensas referidas a cualquier grupo indígena, y que involucran la presencia u observación directa del "investigador", y cuyo trabajo buscara caracterizar y/o comparar las costumbres y tradiciones de estos grupos.

b) Antropología Física: trabajos que consideraran estudios craneométricos, anatómicos y/o histológicos de la población indígena. 
c) Lingüística: trabajos que tratan sobre el idioma y etimología de la lengua indígena, ya sea a través de estudios de tipo léxico y/o gramaticales.

d) Folklore: trabajos que refieran a la compilación de relatos-cuentos, historias, canciones, consejas, adivinanzas- recogidos de la población indígena y de los sectores rurales o populares.

e) Arqueología-Prehistoria: trabajos que incluyan descripción/interpretación de objetos, ya sea contenidos en colecciones o a través de la prospección y excavación.

f) Historia-Etnohistoria: trabajos que incorporen descripciones/interpretaciones sobre la población indígena, particularmente orientadas a caracterizar su forma de vida y relación con la sociedad nacional, lo cual se desprende de un trabajo de fuentes escritas $\mathrm{u}$ orales.

Conforme lo anterior, las áreas temática contenidas en las publicaciones se distribuyen según expresa el gráfico $\mathrm{N}^{\circ} 4$.

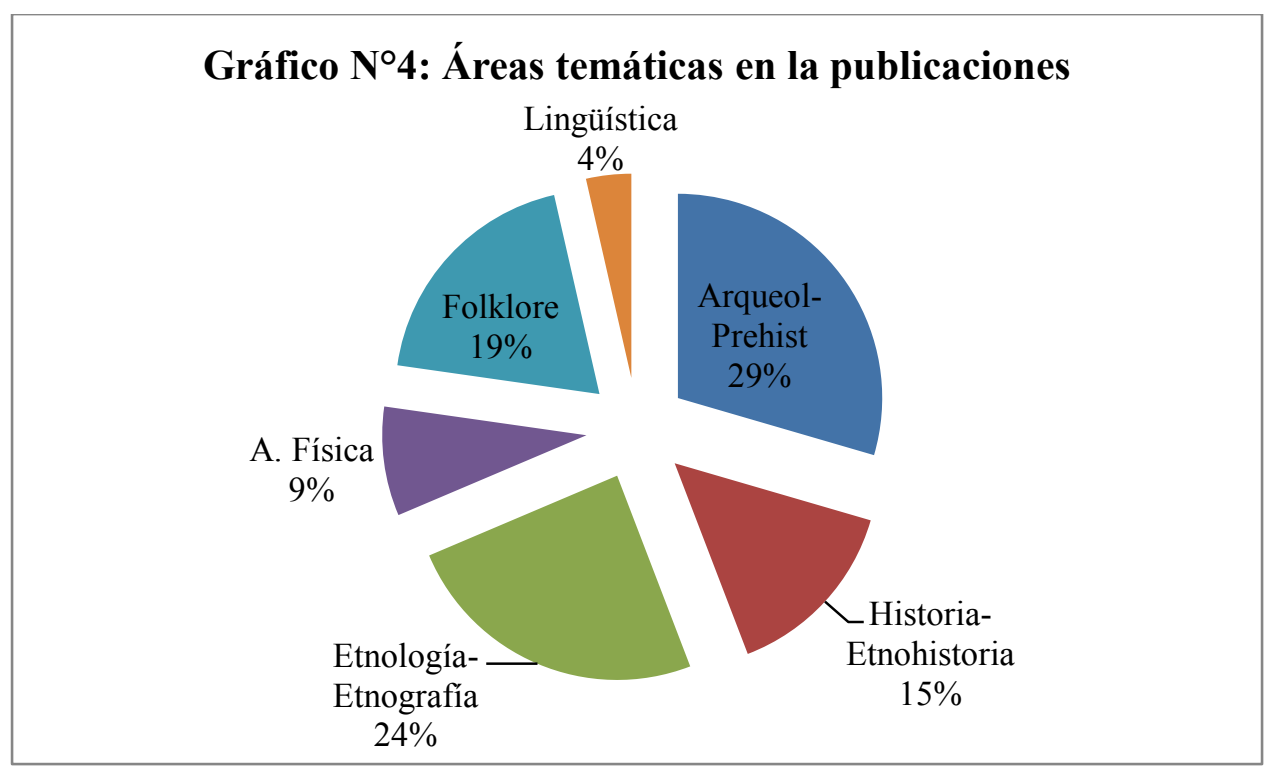

La distribución permite apreciar que la mayor cantidad de trabajos se concentra en el área de arqueología-prehistoria (29\%) y etnología-etnografía (24\%), seguidos de Folklore (19\%) e historia-etnohistoria (15\%). La menor se encuentra en las áreas de Antropología Física (9\%) y lingüística (4\%). De hecho, y como ya se mencionó, el trabajo más antiguo identificado en las publicaciones corresponde al de Favry denominado "Antigüedades americanas" (1860), 
trabajo de orientación etnológica que trata de manera comparativa la situación de pueblos aborígenes del continente. Otros dos trabajos (1863 y 1871) corresponden a informes de exploración llevados a cabos por miembros de la marina de Chile (Thompson y Simpson), y que dan cuenta, el primero, de los habitantes de la zona del afluente del Bío-Bío y el segundo, de los indígenas de las Guaitecas y Chonos.

El trabajo de orientación arqueológica más antiguo identificado corresponde a "Antigüedades Americanas. Una cabeza adorada por los dioses" (1872); descripción que realiza Rodulfo Philippi; un segundo trabajo pertenece al mismo Philippi y trata sobre los jeroglíficos encontrados en la Isla de Pascua (1875). En lo referido a antropología física, el primero aparece en 1894, y fue publicado por el Doctor Luis Vergara Flores bajo la denominación "Un cráneo boliviano", seguido de otros dos trabajos referidos a estudios descriptivos y comparativos de cráneos bolivianos publicados también en 1894. En esta dirección, anteriormente, Alphonse Nogues entregaba algunas reflexiones en torno al darwinismo y la descendencia del hombre (1892).

El primer trabajo en la línea del Folklore se registra en 1895; se trata de "Diálogos araucanos en dialecto Huilliche" publicado por Lenz, y que se sitúa en la intersección entre el folklore y la lingüística, tal y como fue la tónica de la mayoría de sus investigaciones. Respecto a los desarrollos en la línea Histórica-Etnohistórica, uno de los primeros artículos corresponde a "Historia de la Civilización Araucana. La conquista" publicado en 1900 por Tomás Guevara.

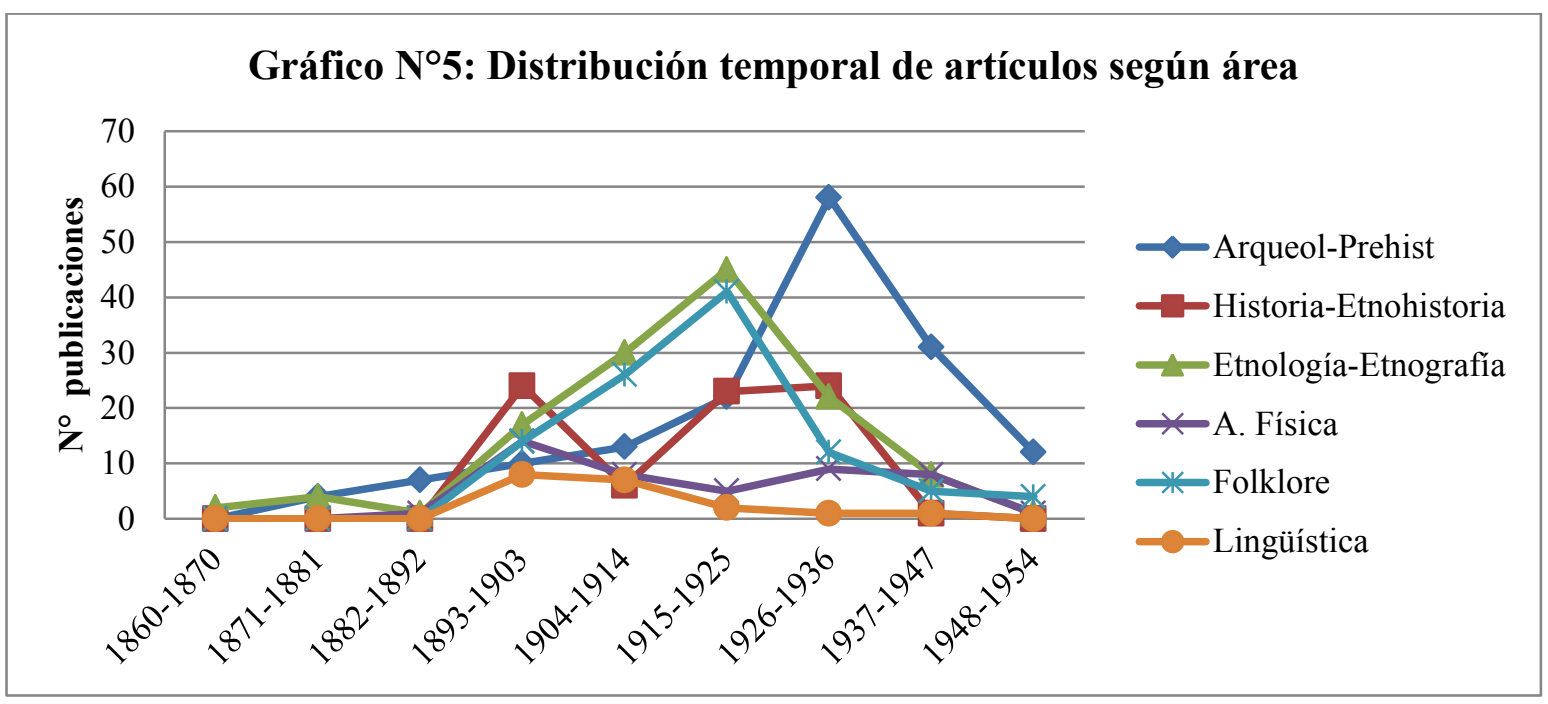


Respecto a la distribución temporal de las temáticas, en ellas se expresa la tendencia en el volumen de producción descrita en el acápite anterior, y que se refleja en un aumento que se inicia a partir de 1892 y que decrece hacia los años '40. Si observamos el gráfico anterior, se puede advertir que a diferencia de las demás temáticas -que decaen hacia los años '40-, Arqueología-Prehistoria aumenta hacia los años 20, lo que se asocia a la figura de Latcham así como a la persistencia de las publicaciones en investigaciones arqueológicas en el Museo Nacional de Historia Natural por parte de Grete Mostny.

\subsection{Los investigadores en temática de orientación antropológica}

En el periodo analizado se registran 91 investigadores que publican en conjunto un total de 532 artículos. Respecto de su procedencia, 30 (33\%) corresponden a inmigrantes europeos radicados o en tránsito por Chile, los cuales provienen de países como Alemania (16), Francia (4), Austria (2), Inglaterra (2), Italia (2), Suiza (1), Suecia (1). Estos publican el 43\% de los trabajos, con un predominio en temáticas en la línea de la arqueología y prehistoria, destacando también los trabajos en Etnología-Etnografía (46) y Folklore (42).

Los investigadores chilenos alcanzan a 58 (64\%), en tanto se registran dos publicaciones realizadas por investigadores argentinos (José Imbelloni y María de las Mercedes Constanzó), un investigador peruano (Juan E. Durand) y dos investigadores procedentes de EEUU (J. Pack Harrison y Dillman Bullock), todos ellos conformando la categoría América. La tendencia de estos investigadores se centra en estudios de orientación etnológica y etnográfica, la que alcanza a un total de 84 publicaciones (16\% de total y al 65\% de la categoría temática); también destacan las áreas temáticas de Arqueología-Prehistoria (76 publicaciones) y Folklore (60 publicaciones). 


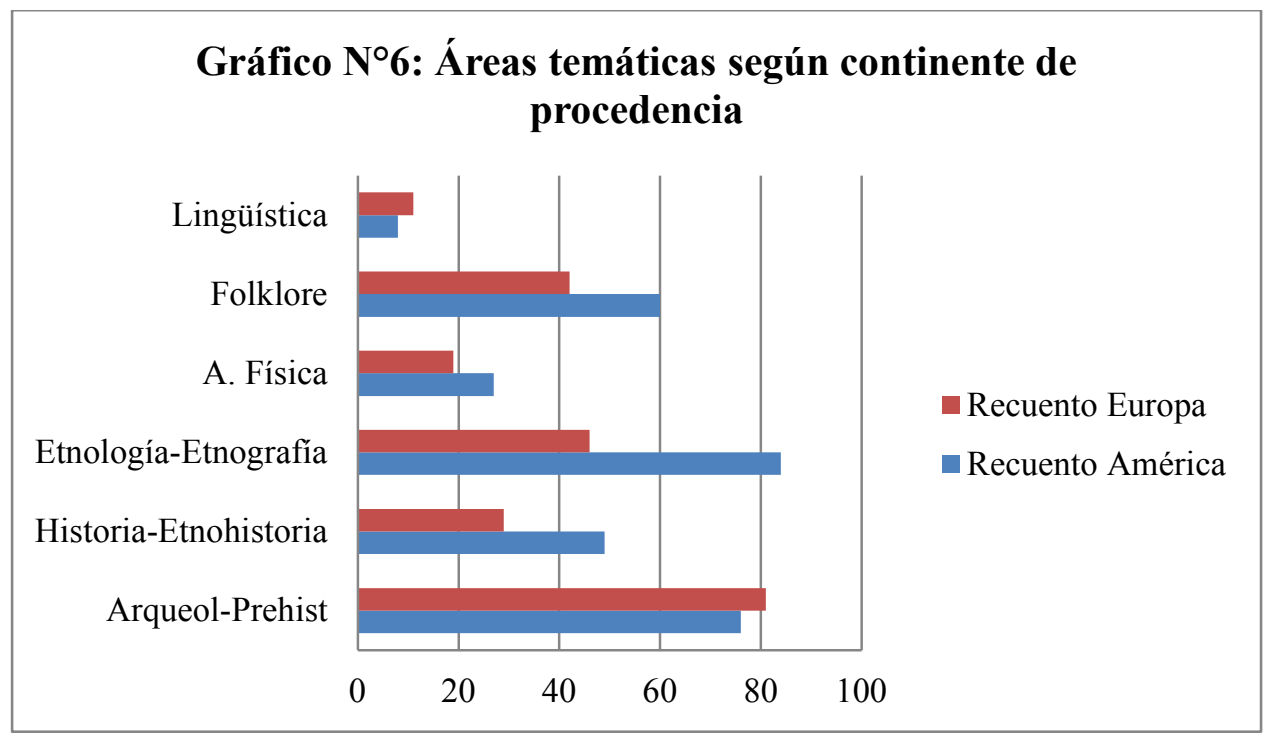

En lo referido a la formación u oficio de origen de estos investigadores, los que más destacan son: médicos (18), educadores - con formación en pedagogía- (14), sacerdotes -entre los sacerdotes hay médicos, teólogos, etnólogos, entre otros- (12), ingenieros (7), botánicos (5), abogados (4), militares y marinos (4) y arqueólogos (4). En términos del volumen de producción -los 8 recuentos más altos-, 97 artículos son producidos por ingenieros -78 de ellos por Latcham-, 90 por investigadores vinculados al campo de la educación -68 corresponden a Guevara-, 65 por médicos, 60 por sacerdotes, 43 por filólogos -28 corresponden a Lenz-, 28 por arqueólogos y 17 por abogados.

Respecto a lo que podríamos denominar trayectoria y volumen de publicaciones por investigador o productividad, la composición es la siguiente: 41 investigadores $(45 \%)$ con un sólo artículo ${ }^{125} ; 12$ investigadores entre 2 y $3 ; 9$ entre 4 y $5 ; 7$ entre 6 y $7 ; 9$ entre 8 y 9 ; y 13 investigadores sobre 10 artículos $^{126}$.

\footnotetext{
${ }^{125}$ En este punto, habría que consignar que algunos de estos poseen trayectorias y una productividad mayor referida a su contexto nacional. Podemos exponer el caso de José Imbelloni, de María de las Mercedes Constanzó y de Juan Durand, quienes publican en las revistas de sus respectivos países.

${ }^{126}$ Un recuento de la totalidad de los investigadores y su producción puede ser consultada en el Anexo $\mathrm{N}^{\circ} 3$.
} 


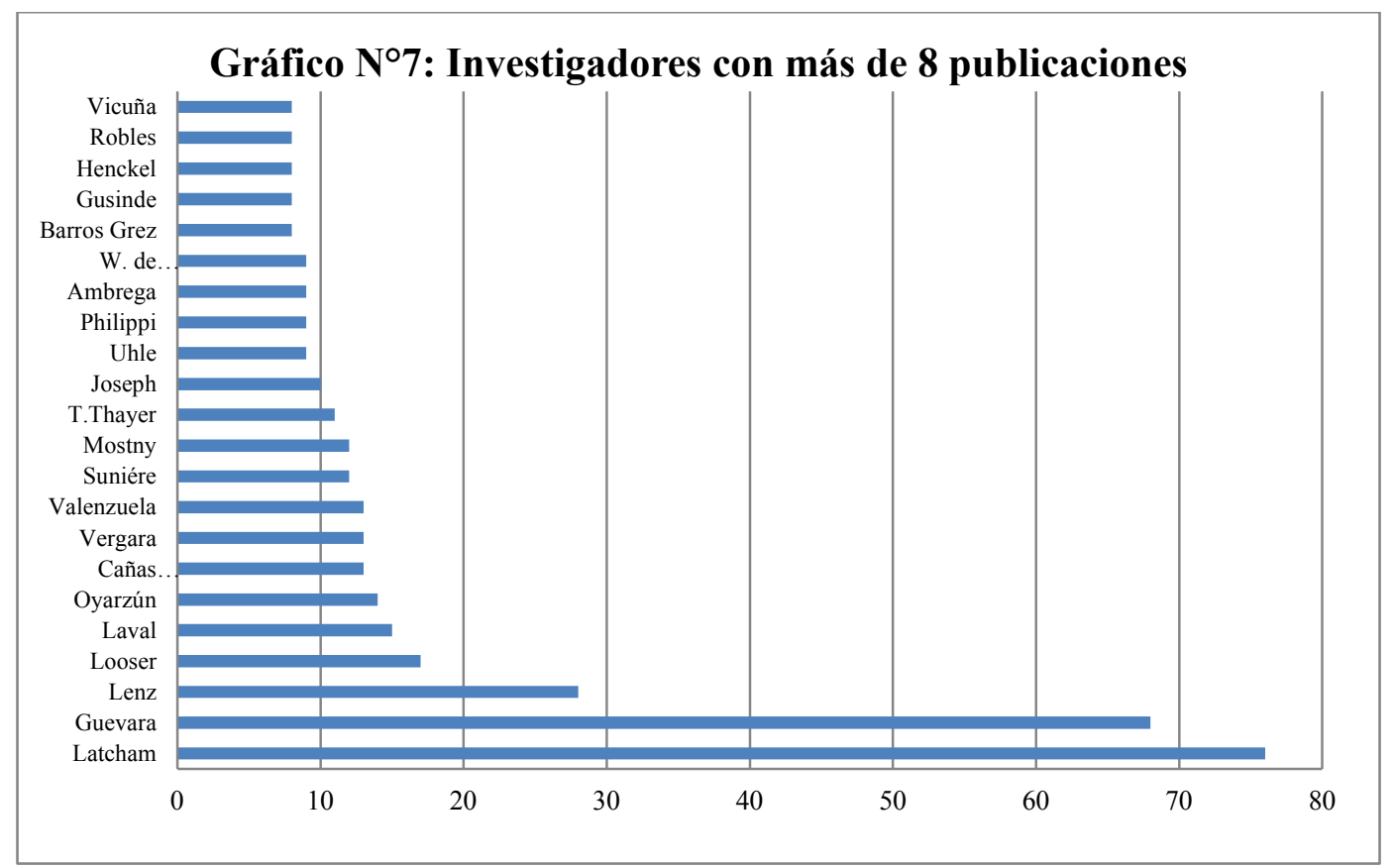

En consideración de lo anterior, se puede señalar que el campo de las publicaciones -en específico, de la productividad- expresa una composición desigual. En este sentido, 172 publicaciones, que representan el $32 \%$ de 532, pertenecen a tres investigadores: Ricardo Latcham (1869-1943) con 76 publicaciones, Tomás Guevara (1865-1935) con 68 publicaciones, y Rodolfo Lenz (1863-1938) con 28 publicaciones. Dichos investigadores comparten la particularidad de haber sido contemporáneos, realizando su actividad en el periodo en el cual se publica el mayor número de artículos en las revistas analizadas.

Las publicaciones de Latcham abarcan cuatro de las seis áreas del conocimiento antropológico identificadas: Arqueología-Prehistoria (35 publicaciones), Historia-Etnohistoria (22 publicaciones), Etnología-Etnografía (16 publicaciones) y Antropología Física (3 publicaciones). En tanto Guevara publica mayoritariamente en Etnología-Etnografía (40 publicaciones) e Historia-Etnohistoria (27), y Lenz en Folklore (19 publicaciones) y Lingüística (6 publicaciones). Además, Latcham y Guevara encarnan el debate de época en torno al origen y características de la población indígena del sur del país, debate que puede ser entendido como una pugna por la hegemonía del campo (ver capítulo anterior).

Los trabajos de Latcham se centran en el ámbito arqueológico, los que dan lugar a 49 publicaciones; entre 1931 y 1942 -un año antes de su muerte- todos los artículos examinados versan sobre la arqueología de la zona norte, zona donde residió hasta 1902 y posteriormente 
visitó en sus investigaciones ${ }^{127}$. Su interés y trabajo sobre los araucanos, se nutren de la experiencia de campo desarrollada entre 1888 y 1890 y entre 1892 y 1895, llevando anotaciones de campo sobre la vida araucana en su estancia en Malleco, Lonquimay, Llaima, Traiguién, Cautín y Chol-Chol; "Vivió en las habitaciones con ellos, comió en su mesa, intervino en sus juegos, penetró en sus ciencias, se familiarizó con sus costumbres..." (Feliú 1969:9). Además, y en su calidad de miembro del Royal Anthropological Institute of Great Britain and Ireland, publicó en el The Journal of the Anthropological Institute of Great Britain and Ireland siete artículos: dos en arqueología, tres en antropología física craneometría y antropometría- y dos en etnología. La perspectiva de trabajo de Latcham puede ser definida como descriptiva y empirista -que caracteriza la tradición intelectual inglesa de esa época-, con un trabajo sistemático con fuerte apego a la data recolectada ${ }^{128}$.

Por otro lado, las publicaciones de Tomás Guevara se orientan en un 59\% al área de la Etnología-Etnografía (40 publicaciones) y en un 40\% a la de Historia-Etnohistoria; ellas se desarrollan entre 1898 y 1930. La totalidad del trabajo de Guevara, que el autor sitúa en el marco de la etnología y la historia, tratan sobre la vida y costumbre de la población araucana, incorporando en sus interpretaciones orientaciones psicológicas de corte determinista que se enmarcan en la corriente evolucionista de fines del siglo XIX. Sus investigaciones se nutren del trabajo de archivo y consulta de fuentes históricas, como de la observación -lo que denomina excusiones- y registro de relatos de informantes, así como de las anotaciones e informes que realizan los que Guevara denomina como sus colaboradores, mencionando a Lorenzo Coliman, Felipe Reyes, Manuel Manquilef (Guevara 1911) ${ }^{129}$. Su vinculación con la

\footnotetext{
${ }^{127}$ Ricardo Latcham figura como socio de la Sociedad Chilena de Folklore, y además como colaborador del Museo Etnológico y Antropológico de Santiago.

${ }^{128}$ Latcham reside cinco años en la Araucanía (Temuco), en su labor como jefe en prospección y construcción de caminos para la colonización, época en la cual toma contacto directo y cercano con la población mapuche, lo que le permitió hablar el araucano antes que el castellano (Feliú 1969:7). En 1893 se traslada a Santiago, donde ocupa la plaza de profesor de inglés en el Instituto Nacional hasta 1897, año en que se traslada a La Serena (Norte del país). Allí ejerce como profesor de inglés en el Liceo de La Serena y como ingeniero en tareas de prospección minera hasta 1902, cuando retorna a Santiago. En 1927 es nombrado profesor de Arte Indígena en la Escuela de Bellas Artes y posteriormente de la Facultad de Artes de la Universidad de Chile y en 1935 dicta un curso sobre prehistoria americana en dicha universidad (Lathrop 1945). Dirige el Museo Nacional de Historia Natural entre 1928 y 1943.

${ }^{129}$ La mención de la figura del colaborador resulta importante para la época, puesto que no es una referencia que se estile y/o se declare de manera explícita en el texto. En 1924, Eduard Lindeman define a estos colaboradores como observadores participantes, señalando que "Con propósitos experimentales llamamos "observadores participantes" a los observadores que colaboran con nosotros. El término no implica que los observadores participen en el estudio sino que participan en las actividades del grupo observado [...] Hay pocas personas disponibles para una tarea de esta índole y las que existen deben ser entrenadas, lo cual tiene sus propias difi-
} 
población mapuche se generó tras su llegada en 1892 a la zona de Malleco, donde se desempeñó como profesor del Liceo de Angol y secretario de la intendencia. En 1899 pasa a ocupar el cargo de Rector del Liceo de Temuco hasta 1913 (Gazmuri 2006), fecha en que se traslada a Santiago para asumir como Director del Liceo José Victorino Lastarria ${ }^{130}$.

Otro investigador reconocido y con una amplia producción científica en la época analizada fue Rodolfo Lenz; las áreas de mayor producción en las revistas consultadas corresponden a estudios folklóricos y lingüísticos (89\%), ambos aspectos íntimamente relacionados desde la concepción científica que el autor define. La perspectiva epistemológica adscrita por Lenz, considera los estudios folklóricos como un trabajo de recolección de la tradición cultural desde el punto de vista de los propios sujetos; por ello, el lenguaje es fundamental en tanto vehículo y expresión de la cultura y de las formas de comunicación de la tradición de un grupo. De allí el hecho de atender, recoger, e indagar en el contenido y diferencias dialectales con las cuales se comunican los cuentos, poesías y consejas: el mapuzugu de los Araucanos -en el dialecto picunches, pehuenches, huilliches, moluches- ${ }^{131}$, y el castellano del bajo pueblo de Chile en tanto variedad dialectal. Si bien su labor profesional se desarrolló en el ámbito de la docencia en el Instituto Pedagógico, Instituto Nacional y en la Universidad de Chile en la materias de idiomas extranjeros y gramática castellana, su interés investigativo lo lleva a realizar estadías en la Araucanía, de modo de investigar sobre la cultura y lengua de los Araucanos ${ }^{132}$. En el verano de 1891 y 1894 visita las cercanías de Collipulli -donde se hace amigo del Caciquillo Juan Amasa-, realizando estadías en Perquenco -en el Fundo de Víctor Manuel Chiappa ${ }^{133}$, donde conoce a Calvun llamado Segundo Jara-, y otra estancia en 1897 en Chol-Chol -por invitación del misionero Inglés Charles Sadlier-, recorriendo además Nueva Imperial, Boroa y Quepe (Escudero 1963). Lenz basa la recolección de datos en la observación directa y sobre

cultades. ¿Había que preparar al observador participante para que busque exactamente los mismos factores por los que se interesa el observador que permanece fuera del campo? Este método conducirá inevitablemente a errores, porque el observador participante debe tener libertad para percibir muchas cosas que nunca podría ver el observador que permanezca afuera" (Lindeman 1924 en Bruyn 1972: 37).

${ }^{130}$ Tomás Guevara fue socio y presidente de la Sociedad Chilena de Historia y Geografía.

${ }^{131}$ El 86\% de sus trabajos refieren a esta población.

${ }^{132}$ Lenz tiene toda una línea de trabajo paralela sobre lengua y gramática castellana, y sobre lingüística y métodos de enseñanza de la lengua (Escudero 1963).

${ }^{133}$ Chiappa (1869-1932) fue un empresario maderero de ascendencia italiana nacido en Temuco y asentado en Victoria (Región de La Araucanía), graduado del Instituto Nacional. Feliú (1969) señala que Chiappa manifestó tempranamente su habilidad como investigador, particularmente, asociadas al campo bibliográfico -como bibliógrafo o estudioso de la producción bibliográfica- publicando varios trabajos. Además de mantener contacto con Lenz, sostuvo intercambios epistolares con Ramón Laval, Enrique Matta Vial, Enrique Blanchard Chessi, entre otros, siendo además miembro de la Sociedad Chilena de Folklore. 
todo en trabajo con los denominados informantes -que eran colaboradores entre los que cuentan Amasa (Picunche), Calvun (Pehuenche) y Quintrupai (Huilliche)-, procedimientos a los que refiere en la publicación "Sobre el estudio de los idiomas” (1918).

Por otro lado, Gualterio Looser (1898-1982) registra 17 publicaciones de las cuales 10 (59\%) se sitúan en el área de arqueología y prehistoria ${ }^{134}$, las que se extienden entre 1926 hasta $1938^{135}$. Lo interesante es que a diferencia de Guevara y Latcham -más cercano a Lenz, que publica en lingüística y gramática-, Looser posee una trayectoria académica y científica consagrada en otro campo -la botánica. De formación inicial Bachiller en Humanidades por la Universidad de Chile (1916), se vincula a la botánica realizando un sinnúmero de investigaciones y publicaciones que alcanzan reconocimiento internacional -138 publicaciones en total (Martínez 1983)-, lo cual lleva a que en 1977 la Universidad de Zürich le conceda el grado de Doctor Honoris Causa en Filosofía (Martínez 1983) ${ }^{136}$. La primera relación de Looser con la Antropología se gesta en 1923, cuando ocupa por ocho años la plaza de ayudante y posteriormente de jefe ad honorem de la Sección de Antropología, Etnología y Arqueología del Museo Nacional de Historia Natural ${ }^{137}$, sucediendo en dicho cargo a Leotardo Matus. Las publicaciones de Looser, en su mayoría, resultan descripciones de los objetos materiales contenidos en las colecciones del Museo Nacional o de informes elaborados por otros investigadores; en tal dirección se encuentra el trabajo de 1926 "Las tabletas para tomar rape del Museo Nacional", "Notas sobre alfarería chilena" en el cual describe algunas piezas encontradas en una excavación en Lampa -actual comuna de Santiago de Chile- realizada por Leotardo Matus.

\footnotetext{
${ }^{134}$ Además, registra 3 publicaciones en etnología-etnografía, 2 publicaciones en Folklore, 1 en A. Física y 1 en Historia-etnohistoria.

${ }^{135}$ En las revistas analizadas, el último trabajo en el campo de las ciencias antropológicas aparece en 1954. Hay una brecha entre 1938 y 1954 en que no aparecen trabajo en temáticas asociadas a estas ciencias. El trabajo de 1954 se denomina "Esbozo sobre los estudios de los Indios de Chile", publicado en los Anales de la Asociación Chilena de Ciencias Naturales.

${ }^{136}$ Además, Looser figura como miembro de la Sociedad de Americanistas.

${ }^{137}$ En el Boletín de 1929 Latcham explicita que en 1923 el cargo de Jefe de Sección se suprime por motivos económicos. En 1928 el Ministerio de Educación Pública reabre el cargo, y nombra a Looser en calidad de Jefe de Sección Ad honorem, y a Ricardo Latcham como Director del Museo. (p.164).
} 
Cuadro $N^{\circ} 14$ : Referencias de investigadores con más de 8 publicaciones

\begin{tabular}{|c|c|c|c|c|c|}
\hline Nombre & Prof./oficio & País & Institución & $\begin{array}{l}\text { Membrecía } \\
\text { Sociedad } \\
\text { Científica } \\
\end{array}$ & Área \\
\hline Ramón Laval & $\begin{array}{ll}\text { Estudios } & \text { en } \\
\text { Teología } & \end{array}$ & Chile & $\begin{array}{lr}\text { Funcionario } & \text { y } \\
\text { Director de la } \\
\text { Biblioteca } \\
\text { Nacional. }\end{array}$ & $\begin{array}{l}\text { Sociedad Chilena } \\
\text { de Folklore. } \\
\text { Sociedad Chilena } \\
\text { de Historia y } \\
\text { Geografía. }\end{array}$ & $\begin{array}{l}\text { Folklore }(15 \\
\text { trabajos, 100\%). }\end{array}$ \\
\hline $\begin{array}{l}\text { Aureliano } \\
\text { Oyarzún }\end{array}$ & Médico & Chile & $\begin{array}{l}\text { Profesor de } \\
\text { Anatomía } \\
\text { Patológica en la } \\
\text { Universidad de } \\
\text { Chile. } \\
\text { Museo } \\
\text { Etnológico y } \\
\text { Antropológico, } \\
\text { Museo Histórico } \\
\text { Nacional } \\
\end{array}$ & $\begin{array}{l}\text { Sociedad Chilena } \\
\text { de Historia y } \\
\text { Geografía. } \\
\text { Sociedad Chilena } \\
\text { de Folklore. }\end{array}$ & $\begin{array}{l}\text { Arqueología- } \\
\text { Perhistoria (9 y } \\
\text { Etnología- } \\
\text { etnografía 5) }\end{array}$ \\
\hline $\begin{array}{l}\text { Pedro } \\
\text { Valenzuela }\end{array}$ & $\begin{array}{l}\text { Sacerdote } \\
\text { Mercedario/Estud } \\
\text { ios en teología, } \\
\text { Filosofía, } \\
\text { Arqueología y } \\
\text { Lenguas Clásicas } \\
\text { y Modernas en } \\
\text { Universidad } \\
\text { Georgiana de } \\
\text { Roma }\end{array}$ & Chile & $\begin{array}{l}\text { Se desempeña } \\
\text { en varias } \\
\text { Instituciones y } \\
\text { cargos } \\
\text { religiosos. }\end{array}$ & Sin información & $\begin{array}{l}\text { Folklore }(13 \\
\text { trabajos, } 100 \%)\end{array}$ \\
\hline Luis Vergara & Médico & Chile & $\begin{array}{l}\text { Residente en } \\
\text { Tocopilla. }\end{array}$ & $\begin{array}{l}\text { Sociedad Científica } \\
\text { de Chile. }\end{array}$ & $\begin{array}{l}\text { Antropología } \\
\text { Física } \\
\text { trabajos, 92\%). }\end{array}$ \\
\hline $\begin{array}{l}\text { Grete } \\
\text { Mostny }\end{array}$ & $\begin{array}{l}\text { Arqueóloga } \\
\text { (Egiptología, } \\
\text { Africanística y } \\
\text { Prehistoria, Dr. en } \\
\text { Filología) }\end{array}$ & Austria & $\begin{array}{l}\text { Museo Nacional } \\
\text { de Historia } \\
\text { Natural. Jefa de } \\
\text { sección y } \\
\text { posteriormente } \\
\text { directora. }\end{array}$ & Sin información. & $\begin{array}{l}\text { Arqueología } \\
\text { trabajos } 92 \%)\end{array}$ \\
\hline $\begin{array}{l}\text { Alejandro } \\
\text { Cañas- } \\
\text { Pinochet }\end{array}$ & $\begin{array}{l}\text { Funcionario } \\
\text { Público } \\
\text { geógrafo } \\
\text { (Aparecen } \\
\text { referencias como } \\
\text { militar). }\end{array}$ & Chile & $\begin{array}{l}\text { Ministerio de } \\
\text { Hacienda, } \\
\text { Inspector } \\
\text { Oficinas } \\
\text { Fiscales. }\end{array}$ & $\begin{array}{l}\text { Sociedad Científica } \\
\text { de Chile } \\
\text { Sociedad Chilena } \\
\text { del Folklore }\end{array}$ & $\begin{array}{l}\text { Arqueología- } \\
\text { Prehistoria } \\
\text { trabajos), } \\
\text { Etnología- } \\
\text { etnografía } \\
\text { trabajos }) \\
\text { Lingüística } \\
\text { trabajos). }\end{array}$ \\
\hline $\begin{array}{l}\text { Sperata } \\
\text { Ravillo De }\end{array}$ & Sin Información & Italia & $\begin{array}{l}\text { Sin } \\
\text { Información. }\end{array}$ & $\begin{array}{l}\text { Sociedad Chilena } \\
\text { del Folklore }\end{array}$ & $\begin{array}{l}\text { Folklore }(12 \\
\text { trabajos, } 100 \%) .\end{array}$ \\
\hline
\end{tabular}




\begin{tabular}{|c|c|c|c|c|c|}
\hline Sauniere & & & & & \\
\hline $\begin{array}{l}\text { Tomás } \\
\text { Thayer }\end{array}$ & $\begin{array}{l}\text { Bachiller en } \\
\text { Filosofía y Letras. }\end{array}$ & Chile & $\begin{array}{l}\text { Biblioteca } \\
\text { Nacional. }\end{array}$ & $\begin{array}{l}\text { Sociedad Científica } \\
\text { de Chile. } \\
\text { Sociedad Chilena } \\
\text { del Folklore. } \\
\text { Sociedad Chilena } \\
\text { de Historia y } \\
\text { Geografía. } \\
\text { Academia Chilena } \\
\text { de Historia. } \\
\text { Correspondiente de } \\
\text { la Sociedad } \\
\text { Española } \\
\text { Historia. }\end{array}$ & $\begin{array}{l}\text { Historia- } \\
\text { Etnohistoria } \\
(100 \%) .\end{array}$ \\
\hline $\begin{array}{l}\text { Claude } \\
\text { Joseph }\end{array}$ & $\begin{array}{l}\text { Sacerdote } \\
\text { Capuchino/Entom } \\
\text { ólogo }\end{array}$ & Francia & $\begin{array}{l}\text { Orden } \\
\text { Capuchina } \\
\text { Araucanía. } \\
\end{array}$ & $\begin{array}{lr}\text { Academia } & \text { Chilena } \\
\text { de } & \text { Ciencias } \\
\text { Naturales. } & \\
\end{array}$ & $\begin{array}{l}\text { Folklore }(6 \\
\text { trabajos, } 60 \%) .\end{array}$ \\
\hline Max Uhle & Arqueólogo & $\begin{array}{l}\text { Alemania, } \\
\text { residente } \\
\text { entre } \\
1912 \quad \text { y } \\
1919 .\end{array}$ & $\begin{array}{l}\text { Museo } \\
\text { Etnológico y } \\
\text { Antropológico } \\
\text { de Santiago. }\end{array}$ & $\begin{array}{l}\text { Sociedad Chilena } \\
\text { de Historia y } \\
\text { Geografía. }\end{array}$ & $\begin{array}{l}\text { Arqueología }(9 \\
\text { trabajos, 100\%). }\end{array}$ \\
\hline $\begin{array}{l}\text { Rodulfo A. } \\
\text { Philippi }\end{array}$ & Médico & $\begin{array}{l}\text { Alemania, } \\
\text { radicado } \\
\text { en Chile }\end{array}$ & $\begin{array}{lr}\text { Museo } & \text { Nacional } \\
\text { de } & \text { Historia } \\
\text { Natural. }\end{array}$ & $\begin{array}{l}\text { Sociedad } \\
\text { Arqueológica de } \\
\text { Santiago. } \\
\text { Sociedad Científica } \\
\text { Alemana. }\end{array}$ & $\begin{array}{l}\text { Arqueología- } \\
\text { Historia } \\
\text { trabajos, } 78 \%)\end{array}$ \\
\hline $\begin{array}{l}\text { Jerónimo de } \\
\text { Ambrega }\end{array}$ & Sacerdote & Alemania & Sin información. & Sin información & $\begin{array}{l}\text { Historia- } \\
\text { Etnohistoria } \\
\text { trabajos, } 33 \%) \text {, } \\
\text { Etnología- } \\
\text { Etnografía } \\
\text { trabajos, 33\%). }\end{array}$ \\
\hline $\begin{array}{l}\text { Eernesto } \\
\text { Wilhelm de } \\
\text { Moesbach }^{138}\end{array}$ & $\begin{array}{l}\text { Sacerdote } \\
\text { Capuchino/Filoso } \\
\text { fía y Teología }\end{array}$ & $\begin{array}{l}\text { Alemania } \\
\text { Radicado } \\
\text { en Chile } \\
(1920- \\
1963) \text {. }\end{array}$ & $\begin{array}{ll}\text { Misión } & \text { de } \\
\text { Puerto } & \\
\text { Domínguez, } & \\
\text { Araucanía } & \end{array}$ & Sin información & $\begin{array}{l}\text { Etnología } \\
\text { (psicología del } \\
\text { araucano) }\end{array}$ \\
\hline $\begin{array}{l}\text { Daniel } \\
\text { Barros Grez }\end{array}$ & Ingeniero & Chile & $\begin{array}{l}\text { Universidad de } \\
\text { Chile }\end{array}$ & $\begin{array}{l}\text { Sociedad Científica } \\
\text { de Chile. }\end{array}$ & $\begin{array}{l}\text { Arqueología- } \\
\text { prehistoria } \\
\text { trabajos, } 75 \%)\end{array}$ \\
\hline $\begin{array}{l}\text { Martín } \\
\text { Gusinde }\end{array}$ & $\begin{array}{l}\text { Sacerdote } \\
\text { Salesiano/ } \\
\text { Etnólogo }\end{array}$ & $\begin{array}{l}\text { Alemania } \\
\text { (residente } \\
\text { en Chile } \\
\text { entre }\end{array}$ & $\begin{array}{lr}\text { Profesor } & \text { del } \\
\text { Liceo Alemán. } & \\
\text { Museo } & \\
\text { Etnológico } & \text { y }\end{array}$ & Sin información. & $\begin{array}{ll}\text { Etnología- } & \\
\text { Etnografía } & (4 \\
\text { trabajos, } & 50 \%), \\
\text { Historia- } & \end{array}$ \\
\hline
\end{tabular}

\footnotetext{
${ }^{138} \mathrm{Si}$ bien mucho del trabajo presentado por Moesbach resulta de su rol de compilador y editor -recoge, organiza y transcribe- de los relatos de Pascual Coña - con la asistencia de Rodolfo Lenz-, realiza estudios de la lengua indígena y publica diversos trabajos, entre los que destaca su Botánica Indígena de Chile, publicada en 1992 por Editorial Andrés Bello.
} 


\begin{tabular}{|l|l|l|l|l|l|}
\hline & & $\begin{array}{l}1912 \text { y } \\
1926) .\end{array}$ & $\begin{array}{l}\text { Antropológico } \\
\text { de Santiago. }\end{array}$ & $\begin{array}{l}\text { Etnohistoria } \\
\text { trabajos, 38\%). }\end{array}$ \\
\hline $\begin{array}{l}\text { Eulogio } \\
\text { Robles }\end{array}$ & $\begin{array}{l}\text { Abogado, } \\
\text { Protector } \\
\text { Indígenas } \\
\text { Cautín. }\end{array}$ & $\begin{array}{l}\text { Chile } \\
\text { de }\end{array}$ & $\begin{array}{l}\text { Juzgado de } \\
\text { Letras. }\end{array}$ & $\begin{array}{l}\text { Sociedad Chilena } \\
\text { del Folklore. }\end{array}$ & $\begin{array}{l}\text { Etnología- } \\
\text { Etnografía } \\
\text { trabajos, 100\%). }\end{array}$ \\
\hline $\begin{array}{l}\text { Carlos } \\
\text { Heckel }\end{array}$ & Médico & $\begin{array}{l}\text { Alemania } \\
\text { radicado } \\
\text { en Chile }\end{array}$ & $\begin{array}{l}\text { Universidad de } \\
\text { Concepción. }\end{array}$ & $\begin{array}{l}\text { Sociedad Biológica } \\
\text { de Concepción. }\end{array}$ & $\begin{array}{l}\text { Antropología } \\
\text { Física (8 trabajos, } \\
\text { 100\%). }\end{array}$ \\
\hline Julio Vicuña & Abogado & Chile & $\begin{array}{l}\text { Universidad de } \\
\text { Chile. }\end{array}$ & $\begin{array}{l}\text { Sociedad Chilena } \\
\text { del Folklore } \\
\text { Sociedad Chilena } \\
\text { de Historia y } \\
\text { Geografía. } \\
\text { Real Academia } \\
\text { Española de la } \\
\text { Lengua. }\end{array}$ & $\begin{array}{l}\text { Folklore } \\
\text { trabajos, 100\%). }\end{array}$ \\
\hline
\end{tabular}

Fuente: Elaboración propia

\subsection{El espacio de la producción en ciencias antropológicas en Chile}

En los acápites anteriores se ha brindado un panorama respecto de cómo se configura la producción en ciencias antropológicas entre 1860 y 1954, identificando tendencias en lo que refiere a revistas, volúmenes de producción, temáticas e investigadores. Frente a esto, resulta de interés incorporar una mirada relacional de modo de reunir antecedentes en torno a interrogantes orientadas a conocer algunas particularidades de lo que se puede denominar "espacio de la producción de orientación antropológica", el cual puede ser tomado como una analogía del "espacio científico antropológico". En particular, el análisis busca responder a las siguientes interrogantes: ¿cómo se configura este espacio?, ¿se trata de un espacio heterogéneo u homogéneo?, ¿se visualizan relaciones entre variables que permitan identificar una estructura en el espacio de las publicaciones?

Lo anterior se vuelve relevante, considerando que en la etapa analizada no ha tenido lugar la institucionalización disciplinaria, es decir, no ha operado la división académico-departamental conforme a áreas de especialización del conocimiento en ciencias antropológicas. En esta dirección, no existe formación académico-profesional a nivel nacional, ni cátedras universitarias, y en tal sentido, tanto las instituciones como las publicaciones incorporan, en la 
generalidad, a sujetos y artículos vinculados o cuyo origen se sitúa en varios campos de conocimiento. Por ende, se podría plantear la hipótesis de que el espacio de las publicaciones es un espacio heterogéneo, sin una estructura relacional que muestre la vinculación entre áreas temáticas, profesiones y publicaciones, es decir, que exprese la emergencia de especializaciones o áreas de desempeño claramente distinguibles.

Desde el punto de vista topológico, el espacio se construye a la manera de una representación geométrica multidimensional que establece la vinculación entre distintos puntos, los cuales están representados por la relación de las modalidades-propiedades activas que se proyectan en él (Bourdieu 1989). Dicho espacio permite generar una reflexión en torno a las particularidades del conocimiento antropológico de la época estudiada, de modo de apreciar esta configuración a la luz de la relación entre temáticas, profesiones, etapas, actores, publicaciones, orígenes de los autores y localización geográfica de los estudios.

Para explorar la configuración del espacio de las publicaciones, se recurrió al análisis de correspondencias múltiples (ACM) asistido por el programa SPAD, el cual agrupa un conjunto de técnicas que permiten apoyar la representación/interpretación de una tabla de datos -tabla en codificación disyuntiva completa de individuos x variables categóricas- en función de las proximidades y distancias en tanto expresión de relaciones alcanzadas, en este caso, por un conjunto de variables/modalidades ${ }^{139}$. Este tipo de análisis corresponde a la familia factorial, al permitir la reducción de una gran cantidad de datos en un número menor de dimensiones procurando la menor pérdida de información (Crivisqui 1999; Abad, Muñiz y Cervantes 2003). Entre sus objetivos cuentan (Crivisqui 1999):

- Elaborar tipologías de individuos mediante la comparación y resumen de todas las unidades de observación a través de todas las modalidades de las características observadas.

- Estudiar la relación existente entre las características observadas, así como de las modalidades de dicha características.

Entre las variables a considerar en este análisis encontramos:

\footnotetext{
139 En este caso, se procederá a la exploración e interpretación de las proximidades entre variables/modalidades (es decir, de los perfiles columna). Los perfiles líneas de la tabla de datos están constituidos por los 532 artículos analizados -títulos de los artículos y un ID-, por lo cual su representación en el plano factorial se torna compleja - gran cantidad de individuos- y de escaza relevancia -al ser los títulos de los artículos.
} 
Cuadro $\mathrm{N}^{\circ}$ 15: Definición de las variables y modalidades en la representación del espacio de las publicaciones.

\begin{tabular}{|c|c|c|c|}
\hline Variable & Definición & Modalidades & Peso modalidad (\%) \\
\hline \multirow{5}{*}{$\begin{array}{l}\text { Área temática } \\
\text { de } \\
\text { conocimiento }\end{array}$} & \multirow{5}{*}{$\begin{array}{l}\text { Clasificación del área de } \\
\text { conocimiento en que se sitúa el } \\
\text { artículo }\end{array}$} & Etnología-Etnografía & 24,4 \\
\hline & & Arqueología-Prehistoria & 29,5 \\
\hline & & Antropología Física & 8,6 \\
\hline & & Folklore-Lingüística & 22,7 \\
\hline & & Historia-Etnohistoria & 14,7 \\
\hline \multirow{9}{*}{ Revista } & \multirow{9}{*}{$\begin{array}{l}\text { Revista en que se publican los } \\
\text { artículos }\end{array}$} & AACHCN & 7,7 \\
\hline & & AUCH & 33,6 \\
\hline & & ASBC & 2,8 \\
\hline & & $\mathrm{ASCCH}$ & 7,1 \\
\hline & & RCHHN & 13,2 \\
\hline & & RHYG & 25,2 \\
\hline & & SCA & 1,3 \\
\hline & & BMHN & 6,8 \\
\hline & & RMEA & 2,3 \\
\hline \multirow{8}{*}{ Localiza } & \multirow{8}{*}{$\begin{array}{l}\text { Localización y población } \\
\text { referida en el estudio }\end{array}$} & PI Norte & 23,5 \\
\hline & & PI Centro & 3,0 \\
\hline & & PI Sur & 41,9 \\
\hline & & PI Extremo sur & 3,0 \\
\hline & & PI América & 7,3 \\
\hline & & PI No indígena & 6,4 \\
\hline & & PI Varios grupos & 12 \\
\hline & & PI Rapa Nui & 2,8 \\
\hline \multirow{4}{*}{$\begin{array}{l}\text { Etapas } \\
\text { producción }\end{array}$} & \multirow{4}{*}{$\begin{array}{l}\text { Etapas de producción } \\
\text { antropológica (artículos de } \\
\text { revistas). }\end{array}$} & $1860-1903$ & 19,9 \\
\hline & & 1904-1924 & 42,5 \\
\hline & & $1925-1931$ & 16,2 \\
\hline & & $1932-1954$ & 21,4 \\
\hline \multirow{7}{*}{$\begin{array}{l}\text { Áreas } \\
\text { Profesional de } \\
\text { origen }\end{array}$} & \multirow{7}{*}{$\begin{array}{l}\text { Área profesional o de formación } \\
\text { de base del investigador-autor }\end{array}$} & Medicina & 12,6 \\
\hline & & Ingeniería & 18 \\
\hline & & Esp. CCNN & 14,3 \\
\hline & & Abogacía & 3,2 \\
\hline & & Arqueología & 5,3 \\
\hline & & Esp. Humanidades & 43,6 \\
\hline & & Militar/Armada & 3,0 \\
\hline \multirow{6}{*}{$\begin{array}{l}\text { Origen del } \\
\text { autor }\end{array}$} & \multirow{6}{*}{ País de origen del autor } & Inglaterra & 14,5 \\
\hline & & Francia & 17,3 \\
\hline & & Alemania & 36,1 \\
\hline & & Chile & 55,3 \\
\hline & & EEUU & 1,3 \\
\hline & & Otro & 1,1 \\
\hline
\end{tabular}




\begin{tabular}{|l|l|l|c|}
\hline & & Italia & 2,6 \\
\cline { 3 - 4 } & Austria & 3,6 \\
\hline
\end{tabular}

Respecto a sus particularidades, el análisis toma en consideración la distancia entre los elementos de la tabla disyuntiva completa y las relaciones baricéntricas particulares, de modo de calcular la contribución y calidad de representación de cada modalidad (contribuciones, cosenos cuadrados, coordenadas), siendo de interés aquellas que se desprenden de:

- La proximidad entre modalidades de variables en términos de asociación, las que corresponde a puntos medios de los individuos que las presentan y están próximas entre sí ya que la componen individuos semejantes.

- La proximidad entre dos modalidades de una misma variable en términos de sus semejanzas, donde la proximidad se interpreta como semejanzas entre grupos e individuos que las presentan.

El análisis considera la descomposición de la inercia de la nube de modalidades $^{140}$, a partir de la cual se calcula la contribución de una variable q al factor $\alpha$, sumado el aporte de cada modalidad a ese factor. Junto con las modalidades que constituyen la formación de los ejes factoriales, es posible encontrar las variables que han participado en la definición del factor, obteniendo un indicador de relación entre variable y factor (Abad, Muñiz y Cervantes 2003). La propuesta de construcción del espacio de las publicaciones incorpora cuatro variables activas y tres variables ilustrativas, las cuales se identifican a continuación:

- Activas: Área temática de conocimiento, Etapa de producción antropológica y Área profesional de origen. Estas variables son consideradas en el cómputo realizado a través del software.

- Ilustrativas: Autor del artículo, Revista, Origen del autor y Localiza. No forman parte el cómputo, pero se utilizan con el objetivo de establecer criterios de comparación en el sistema de coordenadas factoriales.

\footnotetext{
${ }^{140} \mathrm{La}$ inercia se puede entender como la variabilidad o dispersión de la nube de puntos respecto del baricentro o centro de gravedad, y se define como la suma de las contribuciones de cada punto respecto del baricentro ponderado por su peso en la nube de puntos. En este sentido, la inercia total esta en relación con el número de características observadas y del número total de modalidades que presentaron tal característica.
} 
El análisis implica la consideración de cada eje por separado, observando la inercia o variabilidad explicada, las modalidades que más contribuyen a su formación y aquellas que muestren una mejor representación en cada eje, de modo de interpretar y conceptualizar cada uno de estos, para posteriormente desarrollar la conceptualización de los planos considerados en el análisis.

Una primera apreciación refiere a la dificultad que presenta realizar el análisis de correspondencias teniendo modalidades con pesos bajos. Si bien esto se suele sobrellevar realizando una recategorización de las variables, ello se torna muy complejo en este análisis debido a que ciertas distinciones resultan ser irreductibles entre sí. Por ejemplo, abogacía $(3,2 \%)$ no se puede subsumir en arqueología $(5,3 \%)$ o viceversa. Esto tiene un efecto en la calidad de la representación de algunas modalidades, lo que tiene como causa el aumento de la inercia.

El gráfico $\mathrm{N}^{\circ} 8$ muestra el histograma de los trece valores propios, lo que indica que la totalidad de la variabilidad de los datos se puede explicar en 13 ejes, lo que indica la existencia de una estructura relacional. Si bien no existe un criterio univoco respecto de cuantos ejes retener para el análisis, el gráfico aporta información que puede ser de utilidad. Uno de los criterios más populares es la denominada "regla del codo" (Chatfield y Collins 1980); sin embargo Crivisqui (1999) señala que dicha decisión se vincula a las posibilidades de interpretación que proporciona cada eje en el análisis, debido a lo cual el investigador puede considerar todos los ejes que sean interpretables.

\section{Gráfico N$^{\circ} 8$ : Histograma de valores propios}

\begin{tabular}{|c|c|c|c|c|c|c|c|c|c|c|}
\hline \multicolumn{11}{|c|}{ HISTOGRAM OF THE FIRST 13 EIGENVALUES } \\
\hline I & NUMBER & 1 & EIGENVALUE & I & PERCENTAGE & i & CUMULATED & I & & i \\
\hline i & & I & & I & & 1 & PERCENTAGE & । & & I \\
\hline i & 1 & i & 0.6639 & 1 & 15.32 & i & 15.32 & I & - & 1 \\
\hline i & 2 & i & 0.5434 & i & 12.54 & i & 27.86 & i & 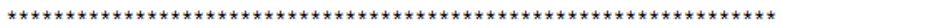 & i \\
\hline 1 & 3 & I & 0.4702 & I & 10.85 & 1 & 38.71 & 1 & & I \\
\hline I & 4 & 1 & 0.4166 & I & 9.61 & 1 & 48.33 & I & 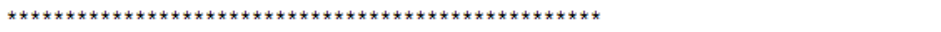 & i \\
\hline 1 & 5 & I & 0.3855 & 1 & 8.90 & 1 & 57.22 & 1 & 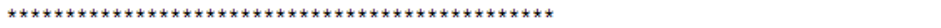 & I \\
\hline I & 6 & I & 0.3555 & I & 8.20 & 1 & 65.42 & I & 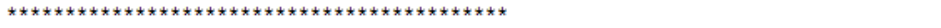 & I \\
\hline 1 & 7 & 1 & 0.2969 & 1 & 6.85 & 1 & 72.28 & 1 & 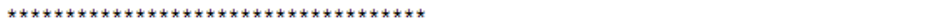 & 1 \\
\hline I & 8 & 1 & 0.2638 & I & 6.09 & 1 & 78.36 & I & 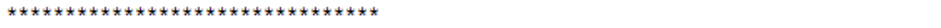 & 1 \\
\hline i & 9 & i & 0.2433 & i & 5.61 & i & 83.98 & i & 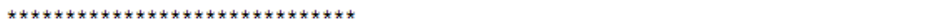 & i \\
\hline I & 10 & 1 & 0.2240 & I & 5.17 & 1 & 89.15 & I & 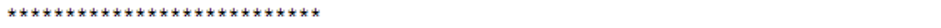 & 1 \\
\hline i & 11 & i & 0.1945 & i & 4.49 & i & 93.64 & i & 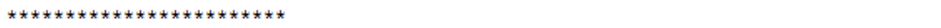 & i \\
\hline 1 & 12 & 1 & 0.1673 & I & 3.86 & 1 & 97.50 & I & 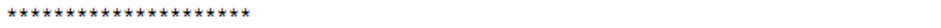 & 1 \\
\hline I & 13 & 1 & 0.1084 & I & 2.50 & 1 & 100.00 & I & 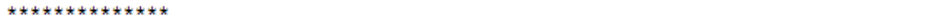 & 1 \\
\hline
\end{tabular}

Como se señaló, la interpretación de los ejes se desprende de tres fuentes de información: coordenadas, contribuciones y cosenos cuadrados; la formula $\mathrm{N}^{\circ} 1$ establece un criterio 
orientador que permite fijar el valor estimativo para seleccionar la contribución de una modalidad a la conformación de un factor. Este valor señala que una buena contribución se encuentra cercana a 12,5 .

\section{Formula $\mathbf{N}^{\circ} 1$}

$$
C T A \geq \frac{2}{j} x 100 \quad C T A \geq \frac{2}{16} \times 100=12,5
$$

La siguiente tabla contiene información relevante para interpretar la contribución de las modalidades en cada uno de los ejes o factores considerados.

Tabla $\mathbf{N}^{\circ} 1$ : Coordenadas, contribuciones y cosenos cuadrados de las modalidades activas.

\begin{tabular}{|c|c|c|c|c|c|c|c|c|c|c|c|c|c|c|c|c|c|c|}
\hline \multicolumn{3}{|l|}{ CATEGORIES } & i & \multicolumn{3}{|c|}{ LOADINGS } & \multicolumn{2}{|r|}{ । } & \multicolumn{4}{|c|}{ CONTRIBUTIONS } & \multicolumn{2}{|r|}{ I } & \multicolumn{4}{|c|}{ SQUARED COSINES } \\
\hline I IDEN - LABEL & REL. WT. & DISTO & 1 & 2 & 3 & 4 & 5 & i & 1 & 2 & 3 & 4 & 5 & i & 2 & 3 & 4 & 5 \\
\hline \multicolumn{19}{|l|}{ 3. Área Conocimiento } \\
\hline I AR01 - Arqueol-Prehist & 9.84 & 2.39 & । 1.15 & 0.31 & 0.32 & -0.20 & -0.31 & 1 & 19.6 & 1.8 & 2.1 & 0.9 & 2.5 & | 0.55 & 0.04 & 0.04 & 0.02 & 0.04 \\
\hline I AR02 - Historia-Etnohistori & 4.89 & 5.82 & | -0.42 & 0.72 & -1.28 & -0.34 & 0.09 & i & 1.3 & 4.7 & 17.0 & 1.4 & 0.1 & 10.03 & 0.09 & 0.28 & 0.02 & 0.00 \\
\hline AR03 - Etnología-Etnografía & 8.15 & 3.09 & | -0.51 & 0.04 & 0.18 & 1.17 & -0.38 & i & 3.1 & 0.0 & 0.6 & 26.7 & 3.0 & 10.08 & 0.00 & 0.01 & 0.44 & 0.05 \\
\hline I AR04 - A. Física & 2.88 & 10.57 & I 0.74 & -2.31 & -0.81 & 0.31 & 1.00 & i & 2.4 & 28.4 & 4.1 & 0.7 & 7.5 & 10.05 & 0.51 & 0.06 & 0.01 & 0.10 \\
\hline I AR05 - Folk-Lingüística & 7.58 & 3.40 & $1-0.96$ & -0.04 & 0.52 & -0.89 & 0.37 & 1 & 10.6 & 0.0 & 4.4 & 14.5 & 2.7 & | 0.27 & 0.00 & 0.08 & 0.23 & 0.04 \\
\hline \multicolumn{19}{|c|}{ | 11 Área profesional de origen } \\
\hline I PR01 - Médicina & 4.20 & 6.94 & । 0.85 & -1.92 & -0.51 & 0.29 & 0.54 & I & 4.6 & 28.5 & 2.3 & 0.9 & 3.2 & 10.10 & 0.53 & 0.04 & 0.01 & 0.04 \\
\hline | PR02 - Ingeniería & 6.02 & 4.54 & I 0.71 & 0.93 & -0.74 & 0.20 & -0.20 & i & 4.6 & 9.7 & 7.0 & 0.6 & 0.6 & 0.11 & 0.19 & 0.12 & 0.01 & 0.01 \\
\hline I PR03 - Esp. CCNN & 4.76 & 6.00 & 10.60 & 0.54 & -0.09 & 0.33 & 0.64 & i & 2.6 & 2.5 & 0.1 & 1.2 & 5.0 & 10.06 & 0.05 & 0.00 & 0.02 & 0.07 \\
\hline I PR04 - Abogacía & 1.07 & 30.29 & | -0.76 & 0.24 & 1.26 & 3.73 & -0.27 & 1 & 0.9 & 0.1 & 3.6 & 35.5 & 0.2 & 10.02 & 0.00 & 0.05 & 0.46 & 0.00 \\
\hline I PR05 - Arqueología & 1.75 & 18.00 & I 1.71 & 0.32 & 2.26 & -1.05 & -0.89 & I & 7.8 & 0.3 & 19.1 & 4.6 & 3.6 & | 0.16 & 0.01 & 0.28 & 0.06 & 0.04 \\
\hline I PR06 - Esp. Humanidades & 14.54 & 1.29 & $1-0.85$ & 0.00 & 0.15 & -0.43 & 0.15 & i & 15.8 & 0.0 & 0.7 & 6.4 & 0.8 & 0.56 & 0.00 & 0.02 & 0.14 & 0.02 \\
\hline I PR07 - Militar/Armada & 1.00 & 32.25 & । -0.55 & -0.94 & -0.50 & 0.09 & -4.35 & 1 & 0.4 & 1.6 & 0.5 & 0.0 & 49.3 & | 0.01 & 0.03 & 0.01 & 0.00 & 0.59 \\
\hline 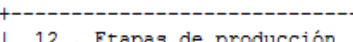 & & & & & 33.3 & 49.2 & 62.8 & & & & & \\
\hline $\begin{array}{l}12 \cdot \text { Etapas de pr } \\
\text { ET01 - 1860-1903 }\end{array}$ & & & $1-0.31$ & -0.79 & -0.84 & -0.47 & -0.98 & 1 & 1.0 & 7.7 & 10.1 & 3.5 & 16.4 & 10.02 & 0.16 & 0.18 & 0.05 & 0.24 \\
\hline | ET02 - 1904-1924 & 14.16 & 1.35 & | -0.64 & 0.03 & 0.43 & 0.28 & 0.25 & i & 8.6 & 0.0 & 5.6 & 2.6 & 2.3 & 10.30 & 0.00 & 0.14 & 0.06 & 0.05 \\
\hline | ET03 - 1925-1931 & 5.39 & 5.19 & । 0.52 & 1.19 & -1.10 & 0.08 & 0.43 & I & 2.2 & 14.0 & 14.0 & 0.1 & 2.6 & 10.05 & 0.27 & 0.24 & 0.00 & 0.04 \\
\hline | ET04 - 1932-1954 & 7.14 & 3.67 & | 1.16 & -0.22 & 0.76 & -0.17 & 0.09 & i & 14.5 & 0.6 & 8.8 & 0.5 & 0.1 & 0.37 & 0.01 & 0.16 & 0.01 & 0.00 \\
\hline
\end{tabular}

Conforme a lo anterior y siguiendo el criterio de interpretabilidad señalado por Crivisqui (1999), es que se estima que la representación más adecuada se obtiene de las lectura de los dos primeros ejes que conforma el primer plano factorial (27,6\%). En esta dirección, el eje semipositivo del primer factor se encuentra definido por las modalidades: área de Arqueología-Prehistoria -con una buena representación-, Profesión Ingeniería, Profesión Arqueología y Etapa 1932-1954. El semieje negativo está conformado por las modalidades: Especialidad de la Humanidades -que representa a la variable formación de origen del autor de 
los artículos-, por Etapa 1904-1924 y por las áreas de conocimiento Folklore-Lingüística y Etnología-Etnografía.

Tabla N²: Descripción del primer factor

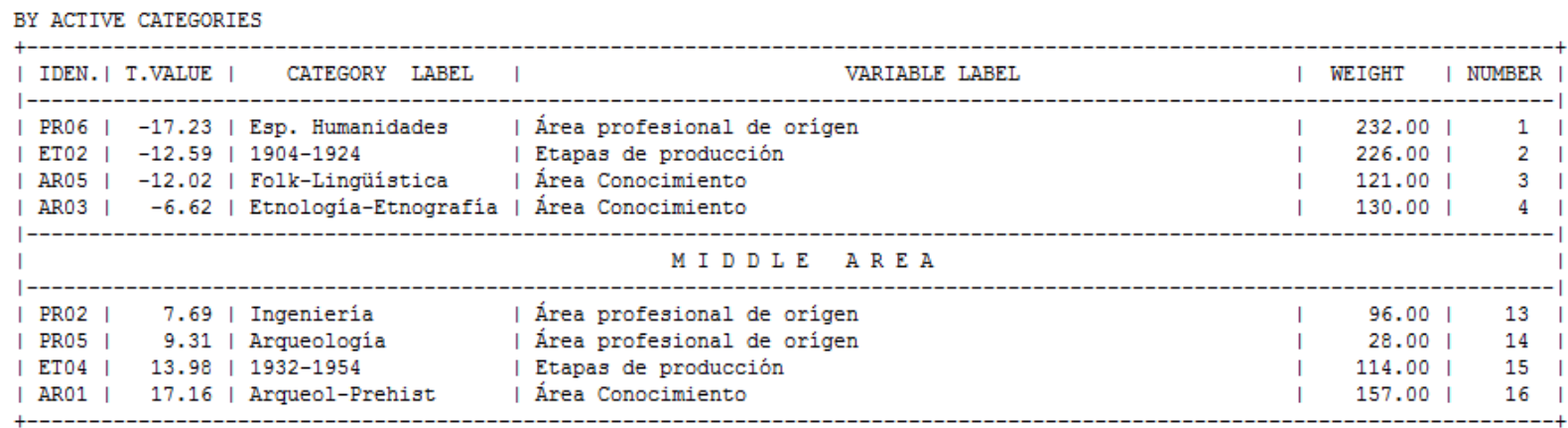

Este factor puede ser interpretado como especialización, distinguiendo una antropología sociocultural de una arqueología, distinción que se encuentra asociada a las etapas de producción, al predominio de un área de conocimiento y la orientación profesional de estos primeros investigadores.

El semieje negativo del segundo factor se encuentra conformado por el área de la Antropología Física, la formación en Medicina, el área de desempeño profesional militararmada, y la etapa que va entre 1860-1903. A la conformación del semieje positivo contribuyen aquellos con estudios en especialidades de las ciencias naturales y la ingeniería, el Área de conocimiento de la Historia-Etnohistoria y la etapa de producción que va entre 1925 y 1931.

\section{Tabla N³: Descripción del segundo factor}

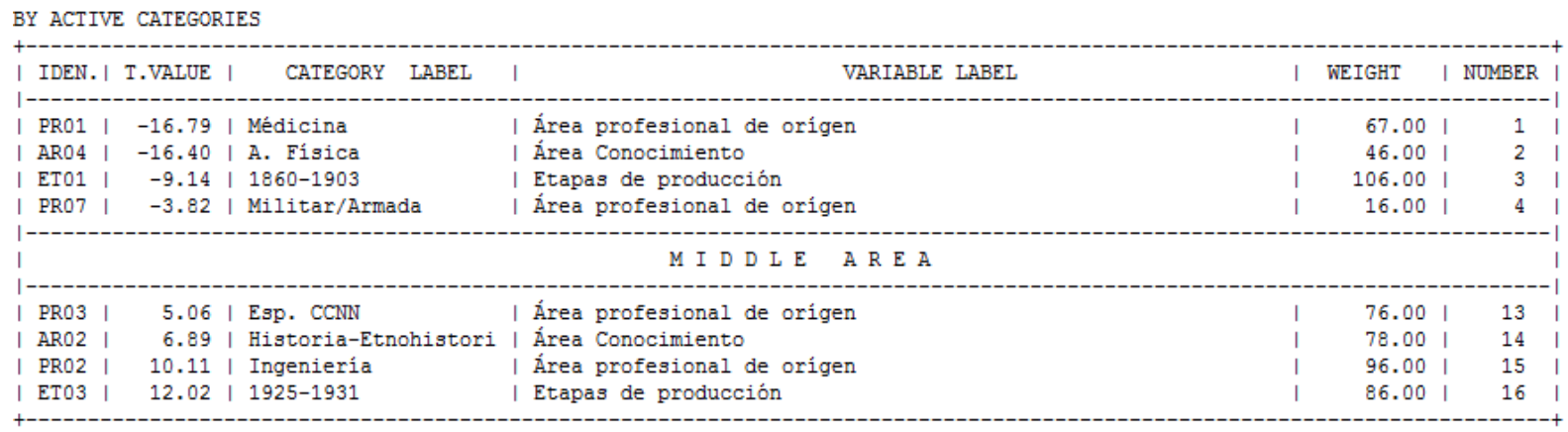


En este eje se diferencia o distingue con mayor claridad lo referido a la componente médica que se vincula al desarrollo de la especialidad de la antropología física, que precisamente registra su mayor producción temática en las revistas analizadas en la etapa que se ubican entre 1860 y 1903.

Gráfico N$^{\circ}$ : Primer plano factorial. Modalidades activas, complementarias y trayectos

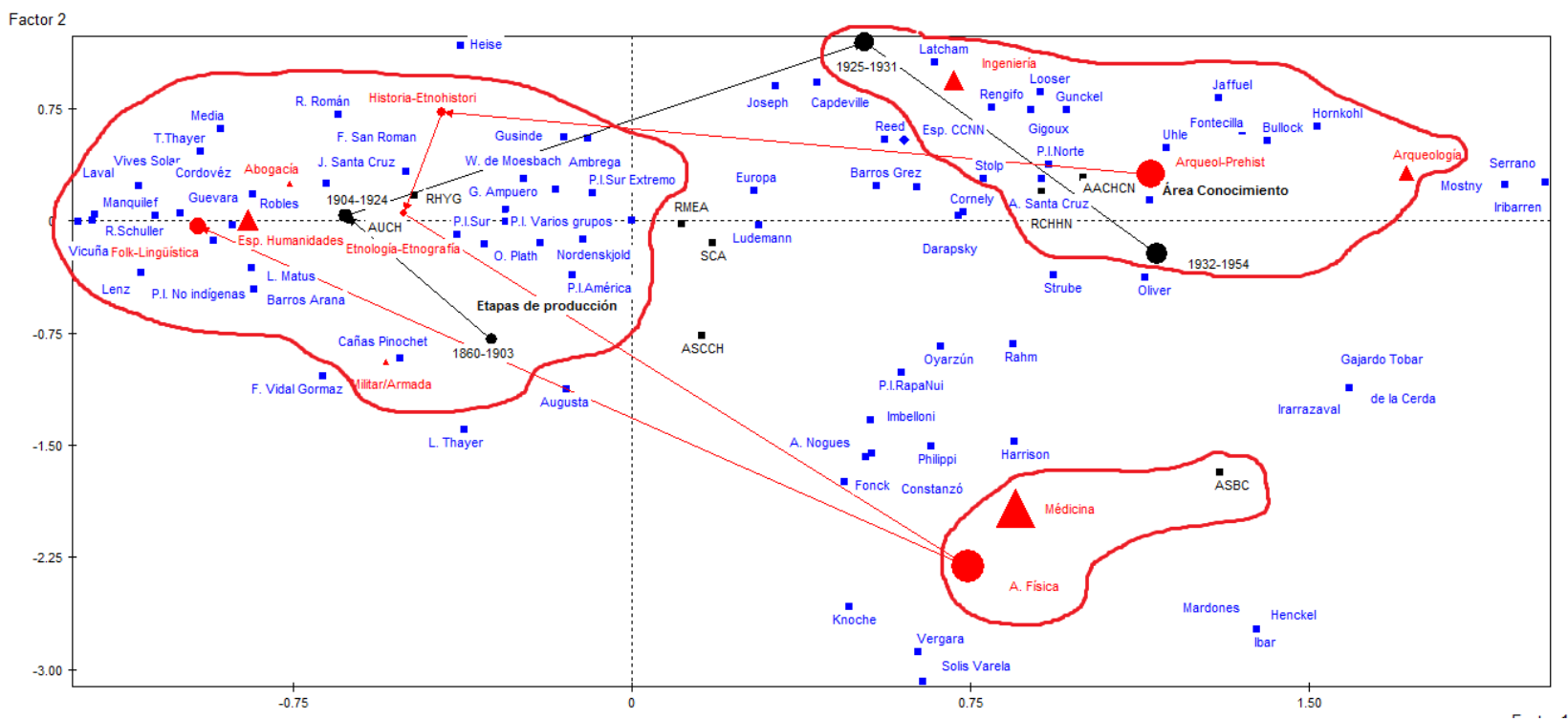

Teniendo en consideración los antecedentes anteriores, y con el apoyo en el Gráfico $\mathrm{N}^{\circ} 9$-que expone la representación de relaciones entre variables/modalidades que se expresan en el primer plano factorial-, es posible indicar la emergencia de cierto grado de especialización en la producción antropológica.

A pesar de no existir una normalización disciplinaria, el espacio de la investigación se encuentra definido por la formación de base de estos primeros investigadores -que es también una expresión indirecta de sus intereses- y el área de estudio sobre la cual se vuelcan; es decir, la formación profesional o quehacer se vincula con el área de estudios hacia la cual estos se orientan y la etapa o temporalidad de producción. Lo anterior permite fundamentar la idea de que la producción de ciertos temas está vinculada a algunos periodos, tal y como se indicó en el gráfico $\mathrm{N}^{\circ} 5$.

Como se puede observar en el primer plano factorial (Gráfico $\mathrm{N}^{\circ}$ ), en el espacio de la producción se expresan al menos tres grupos interpretables como áreas de especialización 
temática, configuración que se obtiene por la relación que expresan las variables activas Área temática de conocimiento, Etapa de producción antropológica y Área profesional de origen). Dicha representación se enriquece y complementa por medio de la incorporación de las variables suplementarias: Autor, Revista, Origen del autor y Localización del trabajo.

La lectura del plano permite distinguir sobre el cuadrante $N^{\circ}$ II una estructura definible como especialización humanista, que se manifiesta a través de la proximidad de áreas temáticas como Folklore-Lingüística, Etnología-Etnografía e Historia-Etnohistoria; ello es expresión de lo que actualmente se denominaría antropología sociocultural en tanto ramas o subdisciplinas de la antropología. Quienes contribuyen a definir esta área-especialización son investigadores con formación en humanidades (Educación, Idiomas, Historia, filosofía, entre otros) y abogacía, siendo el periodo que más caracteriza esta producción el que se encuentra entre 1904-1924, destacando las revistas Anales de la Universidad de Chile y Revista de Historia y Geografía. Entre los autores asociados a esta área figuran Eulogio Robles, Tomás Guevara, Ramón Laval, Manuel Manquilef, Rodolfo Lenz, Rodolfo Schuller, Julio Vicuña, Martín Gusinde, Leotardo Matus, entre muchos otros. Respecto de la localización de los trabajos, resulta ser más heterogénea, refiriendo a población indígena -del sur, extremo sur, y de América- así como no indígena - para el caso de los estudios del folklore del bajo pueblo.

En oposición, el cuadrante I se encuentra definido por la producción de investigadores formados en las Ciencias Naturales y la Ingeniería -también se puede mencionar la arqueología-, con trabajos que mayoritariamente se publicaron entre 1925 y 1931, los que se vinculan a la temática de Arqueología-Prehistoria. Los artículos refieren principalmente a la población indígena del norte de Chile -que se opone a la investigación etnológica, etnográfica, folklórica y lingüística desarrollada en el sur-, los que han sido publicados en los Anales de la Asociación Chilena de Ciencias Naturales y en la Revista de Historia Natural. A este grupos se asocian investigadores como Ricardo Latcham, Gualterio Looser, Hugo Gunckel, Ramón Barros Grez, Francisco Cornely, Luis Darapsky, Manuel Rengifo, Augusto Capdeville, Max Uhle, Dillman Bullock, Grete Mostny, Jorge Iribarren, entre otros. El cuadrante IV se encuentra caracterizado por sujetos con formación en el área de la medicina y cuyos trabajos publicados se vinculan a la Antropología Física -principalmente en craneometría, osteología y fisiología-; en esta línea, los artículos se asocian mayoritariamente a los Anales de la Sociedad 
Biológica de Concepción ${ }^{141}$, destacando investigadores como Luis Vergara Flores, Walter Knoche, Francisco Fonk, Rodulfo Philippi, Carlos Henckel, entre otros.

También esta representación permite observar algunos elementos que no se definen o asocian con un área particular. Estos son revista o sujetos que no se caracterizan por dar lugar a publicaciones o publicar en áreas específicas; por ejemplo, las Publicaciones del Museo de Etnología y Antropología no se perfilan por en función de un área particular, incorporando estudios arqueológicos con aquellos de tipo etnográfico, etnohistórico o etnológicos. Para el caso de la posición de los sujetos, se puede mencionar a Aureliano Oyarzún, quien es de profesión médico, y realiza aportes a los estudios arqueológicos como a los de tipo etnológico y etnográfico.

141 Si bien el enclave de mayor producción en el área se encuentra vinculado a esta sociedad y a sus publicaciones, los estudios craneométricos realizados por Vergara Flores se publican en la Revista del Museo de Historia Natural y de las Sociedad Científica de Chile. 


\section{Conclusiones}

En Chile, sólo en los últimos veinte años se ha constatado la aparición de una serie de trabajos sobre "nosotros", es decir sobre la "tribu de los antropólogos" ${ }^{142}$, con ello situando a la antropología como objeto de estudio en su expresión académica y profesional. Es una reacción tardía si consideramos que la antropología consolida su institucionalización en el campo científico-académico hacia mediados de los años ' 50 , y como disciplina, es decir abocada a la formación profesional, hacia mediados de los '60. La podemos considerar como tardía, además, porque este tipo de problematizaciones tuvo lugar a nivel internacional a partir de un primer gran impulso que se inicia hacia fines de los años 50 y un segundo que se gesta hacia fines de los años $70^{143}$, lo que ha traído consigo un volumen considerable de producción materializada en artículos y libros que analizan las experiencias desarrolladas en México, Brasil, Colombia, Argentina, entre otras.

En esta dirección, en los últimos 25 años podemos encontrar sólo algunos trabajos, que en base a una indagación sistemática, han buscado articular una mirada histórica y/o analítica sobre la antropología y la arqueología en Chile, teniendo en consideración dinámicas organizativas y cierta trayectoria de sus primeros exponentes, lo que ha dado lugar a algunos artículos y documentos (Berdichewsky 1980, 2004; Arnold et al 1991; Orellana 1991; Troncoso, Salazar y Jackson 2008; Gudeman y González 2010; Palestrini, Ramos y Canales 2010; Pavez 2004, 2012, 2013; Bengoa 2014; Castro 2014, Mora 2014) o libros (Orellana 1996; Pavez 2015).

Lo interesante de estos trabajos es que además de llenar un vacío producido por la ausencia de información sobre la antropología en el país, permite dinamizar el campo a través de discusiones que disputan sentido respecto de la representación legítima de disciplina. Cada interpretación plasmada en un texto exhibe un posicionamiento teórico-epistemológico que permite abrir un debate no sólo sobre la reconstrucción histórica de la disciplina -y con ello

\footnotetext{
${ }^{142}$ En los últimos años, han tenido lugar investigaciones que han redefinido el "objeto clásico" de la antropología, ya sea problematizado las configuraciones empresariales ligadas al desarrollo y expansión forestal (Carrasco 2012), o investigando la perspectiva de los hacendados en los proceso de reforma agraria en Chile (Proyecto Fondecyt "Tenencia de tierra e imaginarios colectivos entre los dueños de los fundos araucanos: reforma, contrarreforma y modernización agraria desde las subjetividades esquivadas de los hacendados" adjudicado por el Dr. José Díaz Diego en 2013).

${ }^{143}$ Podemos mencionar la crítica al "indigenismo de Estado", la problematización de la "autoridad etnográfica" y la "crisis de la representación", "el giro decolonial" y la propuesta de los estudios "postcoloniales".
} 
sobre etapas, hechos relevantes, actores, instituciones, etc.; se puede discutir sobre los referentes analíticos que se ponen en escena en tanto categorías que se sitúan en la tensión presentismo/historicismo (Stocking 1982 [1968]), y desde las cuales se "visita el pasado" a través de las huellas que ha dejado en el texto: artículos, cartas, documentos oficiales, informes, etc.

Si nos remitimos al pasado - etapa previa a la institucionalización académica- ya era posible encontrar algunos estudios sobre la producción antropológica, pudiendo mencionar los trabajos de compilación bibliográfica desarrollados por Porter (1906, 1909, 1910, 1931), a los que podríamos sumar el estado de situación de la antropología elaborado por Donald Brand (1941) y los catastros clasificatorios llevados a cabo por Gualterio Looser (1939) y por Julio Montané (1963, 1964, 1965a, 1965b). Esta temprana preocupación es sin duda indicativa de la necesidad de promocionar los estudios antropológicos mostrando la amplia producción que existía para el periodo, ello, considerando el escaso interés mostrado por el Estado u otras instituciones internacionales, el que sólo se hace sentir con fuerza hacia fines de los años '50 para el desarrollo de disciplinas como la sociología, la economía y las ciencias políticas, ello a la luz de la ideología desarrollista ${ }^{144}$. Como consta en este informe, la falta de apoyo por parte del Estado es explícita, lo que fue evidenciado por investigadores que ocuparon posiciones directivas en sociedades científicas y museos, entre los cuales se encuentran Carlos Porter, Aureliano Oyarzún, Martín Gusinde, Rodolfo Lenz, Humberto Fuenzalida, Ricardo Latcham, entre otros. De hecho, la época de mayor riqueza en la producción intelectual, que se ubica entre 1910 y $1940^{145}$, coincide con tres gobiernos que prestan atención a las demandas de estos investigadores, lo que incide en la fundación del único museo especializado de la época -

\footnotetext{
144 Este apoyo al desarrollo de las ciencias sociales por parte del Estado como de organismos internacionales (CEPAL, UNESCO, FAO, FLACSO), contribuyeron a que Chile se perfilara como una "cosmopolis intelectual", ofreciendo condiciones adecuadas para el florecimiento de estas ciencias, producto del escenario de estabilidad política, la temprana modernización del sistema educacional universitario y la gestión de redes internacionales tejidas desde algunas universidades (Garretón 2007; Franco 2007; Beigel 2010). Esto trajo a Chile a intelectuales latinoamericanos, europeos y norteamericanos que se insertaron en estas instituciones con el objetivo de fortalecer dichas iniciativas, como también moviliza a aquellos interesados en analizar los procesos sociopolíticos que estaban teniendo lugar, o conocer las particularidades socioculturales de su población (Beigel 2010).

145 En esta época se encuentra el mayor volumen de artículos y el mayor número de investigadores-autores, siendo también destacada por investigadores como Orellana (1996).
} 
Museo Etnológico y Antropológico-, y de un gran dinamismo que decanta en la creación de la Sociedad Chilena de Folklore y de la Sociedad Chilena de Historia y Geografía.

En tal sentido, y a diferencia de otras experiencias latinoamericanas, las ciencias antropológicas en Chile tienden a desarrollarse en condiciones de precariedad institucional, siendo fundamental para su desarrollo el impulso de intelectuales-filántropos y de asociaciones que logran canalizar las motivaciones científicas de la época Por ello, no es casual que Humberto Fuenzalida insista en el rol que desempeñaron las Sociedades Científicas, agregando que:

"Para entender la evolución intelectual de Chile en las primeras décadas del presente siglo, habría que hacer un estudio de ellas, revivir el clima de sus sesiones, revisar sus problemáticas, sus discusiones, sus proyectos y sus realizaciones. Para el desarrollo de la investigación y la creación del nuevos espíritu ellas son más importantes que la Universidades” (1963: 2).

Las sociedades científicas, que se sitúan al margen de los aportes directos del Estado, son efectivamente las que animan y promueven el desarrollo de las ciencias en general, donde las temáticas vinculadas a la antropología ocupan un lugar no menos significativo. Se podría señalar que en tanto articuladoras de la ciencia y la investigación, poseen una importancia mayor o similar a la de algunos museos, aun cuando comparten las condiciones de precariedad económica para el desenvolvimiento de sus actividades.

Si bien el concepto de disciplina cobra pleno sentido en la demarcación de áreas de conocimiento y formación que se expresan en el especio académico-universitario (Beyer y Lodahl 1976; Apostel 1979; Heckhausen 1979; Clark 1983; Greenhalgh 1997; Dogan 2001; Stichweh 2001; Siler 2005), las declaraciones y principios regulatorios que establecen las sociedades científicas hacen pensar en ciertas características vinculadas a la dimensión organizativa y formativa que caracteriza a las disciplinas. Al constituirse en espacio de producción de conocimiento, estas sociedades dictan lineamientos generales respecto del quehacer de sus miembros, posibilitando en muchos casos la formación no formalizada a través de disciplinamiento científico y/o en torno a saberes específicos. En su mayoría 
mantienen una vocación "multidisciplinaria" e incluso "interdisciplinaria""146, al no articular el desenvolvimiento de sus miembros y sus dinámicas internas en tono a un área específica de conocimiento. Estas características también pueden ser observadas en instituciones como los museos, donde se conjugan diversas áreas de conocimiento, y se produce -en la convivencia diaria- el traspaso e intercambio de saberes fuera del espacio de instrucción académica ${ }^{147}$.

Esto correspondería a la característica de fusión o "vocación interdisciplinaria" de la antropología reconocida por el historiador de la ciencia George Stocking (2002), para quien ha sido “...profundamente interdisciplinaria tanto en su origen como en su constitución” (p.14). Ello se aprecia en el cruce de fronteras y acople a instituciones que albergan a ciencias diversas así como la orientación en la producción y publicación de artículos, lo que se vincula en muchos casos a la formación y los intereses de estos primeros investigadores. Como señalaron Dogan y Pahre (1993), existen itinerarios individuales que revelan una fuerte creatividad, la cual se apoya en la combinación de dos o más sub-disciplinas. Se trata de investigadores "híbridos" e "híbridos secuenciales", quienes utilizan la fortaleza de varias subdisciplinas o disciplinas formales, estudiando todo lo que está a su paso, situándose en los intersticios para llenar un campo vació o desarrollando paralelamente investigaciones en varios campos. Esto aplica para las ciencias en general como para el espacio de la producción de orientación antropológica. Por ejemplo, si observamos la trayectoria de Gualterio Looser ${ }^{148}$, en ésta se aprecia una destacada contribución y reconocimiento internacional en el campo de la botánica, llegando a ser reconocido Doctor Honoris Causa en la Universidad de Zürich en 1977. A partir de 1928 Looser fue jefe de la sección de antropología del Museo Nacional de Historia Natural, y en esta línea, su trabajo de investigación orientó hacia la arqueología. Algo similar sucede con Rodolfo Lenz, con una destacada labor en el campo de la gramática y la lingüística, así como una contribución relevante y reconocida a nivel internacional en torno a

\footnotetext{
${ }^{146}$ En el sentido que en ellas tienen expresión varias ciencias o saberes, articuladas ya sea en tanto integrantes de las ciencias en general o de áreas específicas de conocimiento -humanidades. Esto hace sentido mucho sentido en función de las consideraciones que Etzkowitz y Leydesdorff (2000) han señalado respecto de la organización de la ciencia. Para estos autores, esta funcionaba a través del establecimiento de redes e intercambios que permitían la conexión de saberes y campos diversos.

${ }^{147}$ Como ejemplo, se puede exponer el caso del Museo Etnológico y Antropológico, en el cual Oyarzun y Gusinde reconocen el aporte formativo de Max Uhle, siendo estos exponentes y defensores del enfoque históricocultural.

${ }^{148}$ De formación inicial Bachiller en Humanidades por la Universidad de Chile (1916), se vincula a la botánica realizando un sinnúmero de investigaciones y publicaciones que alcanzan reconocimiento internacional -138 publicaciones en total (Martínez 1983)-, lo cual lleva a que en 1977 la Universidad de Zürich le conceda el grado de Doctor Honoris Causa en Filosofía (Martínez 1983).
} 
los estudios etnológicos y de folklore. Por otro lado Aureliano Oyarzún, médico de profesión, desarrolla -incluso de manera paralela al ejercicio de médico- una trayectoria de investigación en distintas áreas de la antropológica (trabajos etnológicos, etnográficos y arqueológicos), trayectoria similar a la que siguen otros investigadores como el ingeniero Ricardo Latcham.

Si bien el espacio institucional permite advertir la comunicación y coexistencias entre distintas área de conocimiento o ciencias, el espacio de la producción en antropología muestra tendencias a la especialización, lo que se observa en la existencia de áreas temáticas las cuales se definen en relación a periodos o etapas de producción, formación profesional u oficio de origen del autor, revista y áreas geográficas. Tal y como se advirtió, estas áreas temáticas pueden ser interpretadas como área humanista a la manera de una antropología sociocultural (proximidad entre temas folclórico-lingüísticos, etnológico-etnográfico e históricoetnohistórico), arqueológico-prehistórico y física. En estas áreas se visualiza la existencia de especialistas, que se definen en torno a su formación de base (humanistas y abogados; cercanos a la ingeniería y a la arqueología, cercanos a la medicina). También se aprecian investigadores que no se definen según un área específica, tensionados en la configuración del espacio por su producción en distintas temáticas, así como por su formación de origen, las revistas en que publica, la etapa de producción, etc.

Podríamos concluir señalando que esta primera antropología se acopla y subsiste en distintos espacios, conviviendo legítimamente con otras ciencias y saberes. En este sentido, se advierte una producción intelectual y publicaciones que permiten advertir condiciones de emergencia disciplinaria en tanto ámbito especializado de conocimientos, lo que se expresa específicamente en la persistencia de una dimensión cognoscitiva, aspecto que prima en ciertas conceptualizaciones de disciplina (Toulmin 1977; Boisot 1979; Morin 2001).

.En esta dirección, se torna significativo el concepto de "Colegios invisibles" (Price 1972 [1973]; Crane 1972), en tanto se manifiestan redes de cooperación que decantaron en la fundación de sociedades científicas y de equipos de trabajo en los museos, y que permitieron el mantenimiento de lazos que se mantuvieron fuera de la adscripción orgánica a determinadas sociedades y museos - por ejemplo, el contacto entre Oyarzún y Gusinde una vez que este último deja Chile.-, así como de la difusión de prescripciones formativas a través del intercambio epistolar o en la reuniones que se extendían más allá de las sesiones de las mismas sociedades o equipos de trabajo. Cómo se planteó en el capítulo IV, esta interconexión y flujo 
se vio favorecida por la adhesión a un modelo de ciencia integral desde el cual se trazó una continuidad entre las denominadas ciencias naturales y ciencias humanas. Una expresión de ello fue la concepción de la antropología como ciencia integral, que versó sobre el hombre en tanto animal biológico y social.

Por otro lado, y en lo que se refiere a la situación que exhibe la antropología en Chile respecto de otras experiencias latinoamericanas, es posible advertir puntos en común como también profundas diferencias. En el Capítulo II se han identificado 6 factores que permitieron la institucionalización de las Ciencias Antropológicas en distintos países de América Latina, los cuales se enumeran a continuación:

a) El surgimiento de una agenda estatal e internacional que hace posible el financiamiento de instancia abocadas a la conservación y valoración del patrimonio nacional.

b) La definición de una 'política científica' nacional.

c) El establecimiento de una comunidad de especialistas y redes de cooperación.

d) La presencia y consagración de investigadores extranjeros y la especialización de nacionales -con formación inicial en distintos campos de conocimiento.

e) La generación de una serie de investigaciones sistemáticas sobre un campo específico y diferenciable, y en particular sobre la historia y conservación de la cultura indígena.

f) La fundación de instituciones especializadas como los museos, la conformación de sociedades científicas, la generación de cátedras y la divulgación de la producción intelectual.

$\mathrm{Al}$ respecto, un punto en común en el proceso de institucionalización experimentado en varios países, guarda relación con la incorporación de lo indígena en el proyecto de nación, lo que ha llevado a identificar estas antropologías con el compromiso de la construcción de la nación (Peirano 1981; Stocking 1982; Gerholm y Hannerz 1982). En este sentido, el peso que lo indígena tendría en el imaginario romántico de las elites intelectuales y políticas locales, se torna en oportunidad para el desarrollo de la disciplina en el marco de un gobierno y/o de una política de Estado, considerando que la arqueología y la etnología definieron su territorio disciplinario en el continente en torno a la "otredad radical próxima". A ello se asocia la "monumentalidad" de los vestigios materiales producidos por las sociedades indígenas 
situadas en los distintos territorios, que motiva tanto a gobiernos como a científicos nacionales y extranjeros a rescatar y conservar lo que desaparece, así como a levantar preguntas sobre el origen, evolución y relación entre las culturas -la motivación de las antropologías hasta los años '40.

Si bien lo anterior aplica con claridad para el caso mexicano, peruano y en cierta medida para el colombiano y brasileño (ver Capítulo II), no es del todo claro en el caso chileno. A lo argumentado anteriormente, se suma el escaso o nulo interés que manifiesta la elite política por conocer la "realidad indígena de la época" o fomentar el desarrollo de un campo de conocimiento que permitiera orientar su integración al proyecto nacional a través del impulso de una política pública específica (Samaniego y Ruiz 2007). Por otro lado, las investigaciones y orientaciones interpretativas contenidas en la producción de orientación antropológica de época, generan tensiones con el pensamiento e imagen de nación que buscaba reproducir la elite política. El caso de los estudios del Folklore realizados en el seno de la Sociedad Chilena de Folklore o la discusión sobre la homogeneidad indígena de Chile son manifestaciones de ello (ver capítulo V).

De hecho, en Chile no se crean instituciones de carácter indigenista hasta inicios de 1970, específicamente a partir del Decreto Ley N²568 promulgado en el gobierno de Salvador Allende. Para el Estado, lo indígena es reducido a un vestigio del pasado prehispánico, y por tanto comprendido en el marco de las antigüedades americanas y de las políticas de museo; resultan ser minorías aritméticas que desaparecen frente al mestizaje civilizatorio (Samaniego y Ruiz 2007), siendo el interés de fondo la eliminación de la propiedad indígena a través de una política de división de comunidades que garantizarán la explotación productiva de estas (Almonacid 2008). La elite construye una visión estereotípica que visualiza al indígena, en el mejor de los casos, como el otro exótico y en el peor, como un salvaje que se debe civilizar e integrar a la sociedad. Estos estereotipos son los mismos que justifican la ocupación de La Araucanía y la política de colonización europea-nacional y radicación del indígena -que se promulgó en 1866 y se hizo efectiva hacia 1880-, abriendo el territorio al dominio efectivo del Estado de Chile y a la producción agropecuaria nacional (Pinto 2000).

Por tanto, pensar el desarrollo de las ciencias antropológicas en Chile como comprometidas con la construcción de la noción genera serias dudas. Sin embargo, hay otros saberes reclutados en la marco de una política de Estado, lo que implica la búsqueda y contratación de 
especialistas extranjeros que a través de sus conocimientos en botánica, mineralogía, geología, geografía, ingeniería, educación, contribuyeran a catastrar los recursos contenidos en el territorio nacional e instruyeran a los ciudadanos a través de la formación en ciertas áreas del conocimiento en institutos secundarios o en la Universidad de Chile. Lo anterior permite afirmar que el impulso estatal privilegia ciertos campos de conocimiento -sólo basta examinar las áreas de formación que estructuran las diferentes universidades que se fundan desde fines del siglo XIX-, sobre los cuales, en épocas de inestabilidad económica, prioriza el gasto fiscal. Respecto a dichos campos sitúa el interés, de modo de establecer las bases de una ciencia nacional $^{149}$, en tanto se levanta tempranamente un sistema nacional de investigación y comunicación científica que busca su consolidación a nivel nacional e internacional -en América Latina y Europa.

Haciendo referencia a los primeros investigadores, el interés por lo indígena se situaba más en el plano científico -legitimar su quehacer conforme al canon- que en una defensa y promoción explícita respecto de los derechos de estas poblaciones -siendo muchas veces registrado como comentarios generales relativos a la situación nativa ${ }^{150}$ - o una identificación explícita con el proyecto de nación. Inspirados por el pensamiento de época, definieron como objeto de estudio las expresiones de vida del otro indígena -vestigios materiales pasado y presentes: características físicas, lengua, costumbres y acervo cultura-, asumiendo un compromiso moral con la necesidad de registrar, y con ello perpetuar, los rasgos que desaparecían frente al progreso. Si bien no existe evidencia en el material analizado respecto del posicionamiento ético y político por parte de estos primeros investigadores, la dedicación -que para algunos implicó gran parte de su vida- y el trabajo exhaustivo contribuyó a dar a conocer y dejar registro - no libre de ciertos prejuicios- de varios aspectos relativos a la vida de estas poblaciones, lo que sin duda constituyó un aporte que se proyecta hasta nuestros días. En lo relativo al posicionamiento político, este es más bien tardío en Chile, aun cuando tiene su más temprana manifestación en los trabajos que el Médico Alejandro Lipschutz escribe hacia mediados de los '50 (Berdichewsky 2004). En este marco, Lipschutz fue promotor del

\footnotetext{
${ }^{149}$ Si bien los parámetros de legitimidad emanan del modelo de ciencia europeo, el esfuerzo del Estado fue formar científicos de modo que a través del conocimiento generado en el territorio nacional se contribuyera al progreso de la nación.

${ }^{150} \mathrm{Al}$ respecto, y entre otros, se puede consultar el libro "Expedición a la Tierra del Fuego" de Martín Gusinde, texto que compila las notas de campo e informes de sus expediciones a esa área en su calidad de funcionario del Museo Etnológico y Antropológico de Santiago.
} 
Instituto Indigenista Chileno ${ }^{151}$ y colaborador del Instituto Indigenista Interamericano, desarrollando trabajos pioneros en la línea de los derechos y la autodeterminación de los pueblos indígenas (Samaniego y Ruiz 2007) ${ }^{152}$. Sin embargo, el distanciamiento del academicismo o cientificismo como crítica al quehacer de la antropología se comienza a desplegar con fuerza hacia fines de los '60, ello bajo la visión que concibe a la antropología como motor de cambio y aplicada a problemas concretos de las poblaciones. A través de la resignificación del concepto de antropología social -que no guarda relación con la orientación de la antropología inglesa-, se establece una diferencia con la antropología clásica - de orientación etnológica, arqueológica o biológica-, en tanto pasa a ser concebida como una puesta en práctica que implica la revolución en el campo, aspecto que aparece nítidamente en la antropología argentina, colombiana y mexicana. Estos "estilos” de antropología, que para Jimeno (2002) resultan constitutivos de la "antropología latinoamericana", contrastan con aquellos que fundan su legitimidad y compromiso en el plano científico.

Por otro lado, la debilidad en la institucionalización de la ciencia en Chile, también guarda relación con los periodos de estabilidad e inestabilidad en el ámbito político y económico, los cuales pueden ser considerados como obstáculos en la consolidación y/o continuidad de varias iniciativas en el campo de la ciencia y la cultura. El auge económico que tiene lugar en la segunda mitad del siglo XIX (Cariola y Sunkel 1982), y que posibilita un primer impulso a las ciencias, se ve afectado por una serie de enfrentamientos internos y externos como la Guerra contra la Confederación Perú-Boliviana (1837-1839), la revolución de 1851, la revolución regionalista de 1859, la guerra del Pacífico (1879), la revolución de 1891, así como por el desplome de los mercados internacionales que generan una fuerte crisis económica (18571861), a lo cual se suma la denominada crisis del salitre en 1930. Precisamente estos aspectos son los que se utilizan para explicar el lento desarrollo y dificultades de consolidación de las ciencias en América Latina, siendo características comunes la fragilidad, fragmentación e incoherencia (Vessuri 1995). Sin embargo, los distintos gobiernos no escatiman esfuerzos por reproducir instituciones científicas y educativas al estilo europeo occidental en diversas áreas -no precisamente en aquellas que tratan sobre población nativa- , en tanto ellas se constituyen

\footnotetext{
${ }^{151}$ Dicho Instituto se crea en septiembre de 1949, y sin reconocimiento oficial; como antecedente señalar que el gobierno de Chile no adhiere a la declaración de Pátzcuato de 1942, que buscaba establecer una política de integración indígena en América Latina (Almonacid 2008).

${ }^{152}$ Entre otros, se puede destacar el libro editado en 1956 "La comunidad Indígena en América y en Chile. Su pasado histórico y sus perspectivas" prologado por Alfonso Caso, Director del Instituto Indigenista de México.
} 
en indicadores de modernidad y progreso (Vessuri 1995); su puesta en marcha hace posible la ilustración del pueblo y la reunión de antecedentes para impulsar el desarrollo y gestionar los recursos nacionales.

En lo que refiere al proceso de institucionalización, esta investigación ha aportado evidencia que permite sostener que en el país se manifestaron los aspectos concernientes a los puntos c), d) y e) presentes en el Capítulo II. Varias de las sociedades científicas y equipos de museos se nuclean en función de vinculaciones que se establecen en el marco de compartir intereses por estudiar el pasado y presente de la población indígena de Chile y América. Se han identificado 532 publicaciones en revistas, a las que se suman un volumen considerable de libros -que no han sido catastrados-, los cuales fueron producidos por un total de 91 investigadores en su mayoría vinculados a sociedades científicas, museos y universidades. De los mencionados en el Capítulo VI, habría que agregar a dos sujetos que destacan como articuladores de la ciencia en Chile en distintas etapas: Rodulfo Philippi y Carlos Porter. Estos forman parte de diversas sociedades y museos, así como cumplen los roles de directores de algunas de las revistas de la época; además de las donaciones que realizan a los museos -colecciones privadas y bibliotecas-, incentivan el desarrollo de la actividad científica. Particularmente Porter, actúa como bibliógrafo de la ciencia nacional (Feliú 1969a), y como se expresa en el Capítulo V, elaborar el más temprano registro de textos de orientación antropológica escritos en el país. Sin embargo, y si bien el modelo de ciencia que se comienza a implementar en América Latina a partir del siglo XIX es el europeo, ciertas expresiones de su concreción no siguen el mismo camino en Chile. Tal como ocurrió en Europa, en varios países latinoamericanos se instalan hacia mediados del siglo XIX museos especializados desde donde se realiza investigación, se dictan cátedras generales, se generan publicaciones científicas, se organizan reuniones y se exponen los resultados a la comunidad. Dicho modelo se desarrolla con la presencia y participación activa de investigadores europeos y norteamericanos que como señalamos, instruyen a los antropólogos, arqueólogos y etnólogos de oficio sobre técnicas de investigación y museografía por medio de la formación en aula y en campañas de investigación. Connotadas figuras de la antropología internacional -por ejemplo, como es el caso de Franz Boas en México, de Paul Rivet en Colombia, de Roger Bastides en Brasil-, impulsan la profesionalización de investigadores locales en universidades norteamericanas y europeas a través de becas, y contribuyen a la gestión de financiamiento vía fondos de 
universidad, fundaciones y gobiernos. Ello permite el establecimiento de redes que hacen posible la circulación de antropólogos latinoamericanos y no latinoamericanos por el continente y fuera de este, así como la conformación de una comunidad de antropólogos que se coordina a nivel nacional e internacional.

Además, las concepciones antropológicas derivadas de modelos de institucionalización también marcan el desarrollo de estas ciencias; el peso inicial de la tradición europea naturalista, que enfatiza la antropología física y la arqueología, y que promueve la concepción de la antropología que populariza primero Broca y luego Boas -la ciencia integral del hombre compuesta por varias ramas-, se hace presente en varios países latinoamericanos. Sin embargo, tal nivel de desarrollo no tuvo lugar en Chile, produciéndose una adecuación de dicho modelo. Salvo el Museo Etnológico y Antropológico - con un poco más de 10 años de duración-, prácticamente todas las demás experiencias integran varios campos científicos donde la antropología -etnología, etnografía, antropología física- ocupa una sección de manera intermitente, la cual tiende a desaparecer convirtiéndose hacia fines de los '40 en una especialidad arqueológica, y que es una muestra de la disolución de modelo integral en lo que comenzaría a constituirse en ramas con desarrollos independientes. Una cuestión similar ocurre con las Sociedades Científicas, las cuales animadas inicialmente por una concepción de ciencia integral, albergaban varias áreas de conocimiento, en tanto aquellas de orientación humanista - la Sociedad Chilena de Folklore o la Sociedad Chilena de Historia y Geografíaconcedían un espacio no menor a quienes desarrollaban investigaciones sobre la población nativa del país.

En esta dirección, la primera Sociedad Científica propiamente antropológica se crea en Santiago de Chile el 31 de octubre de 1963 bajo el nombre de Sociedad Chilena de Antropología - una sociedad de carácter privada e independiente-, cuya primera reunión se lleva a cabo en las dependencias del Colegio Médico de Chile. El objetivo de la sociedad, según figura en su acta de constitución, fue el de fomentar y perfeccionar el estudio de las materias que integran esta disciplina, con el solo y único fin de hacer ciencia pura $\mathrm{y}$ aplicada $^{153}$. La sociedad estuvo conformada por varios investigadores vinculados a la

\footnotetext{
${ }^{153}$ En sus estatutos figura: a) promover y alentar el intercambio y difusión de información de los trabajos de los socios nacionales o extranjeros en cualesquiera de las ramas que integran la antropología en sentido lato; b) convocar a reuniones periódicas para discutir problemas antropológicos, c) alentar la investigación científica de problemas antropológicos, d) intentar la estandarización de los métodos y nomenclaturas utilizadas en la
} 
Universidad de Chile, entre quienes se encontraban Luis Sandoval (Presidente), Bernardo Berdichewsky (Secretario General), Gustavo Jirón, Alejandro Lipschutz, Francisco Hoffman, Ismael Silva-Fuenzalida, Tomás Lago, Ximena Bunster, Francisco Reyes y Carlos Hidalgo.

Otra diferencia importante, es la tardía aparición de cursos de formación especializada y profesional en comparación con lo que sucede en otros países del continente. La formación antropológica se consolida en Chile a partir de la segunda mitad del siglo XX (Berdichewsky 1980, 2004; Orellana 1997), a pesar que se imparten de forma esporádica o con poca regularidad algunas materias y seminarios tanto en el Instituto Pedagógico de la Universidad de Chile como en la Universidad de Concepción (1934), destacado la cátedra de prehistoria de América, y la escuela de verano en la cual se ofrece un curso de antropología (1936), esto, en la Universidad de Chile (Brand 1941). A partir de 1950 se comienzan a dictar algunos cursos de formación general y seminarios en las áreas de arqueología, prehistoria y/o arqueología. Entre ellos, destacan los impartidos en la Universidad de Chile por Grete Mostny -en antropología-, por Richard Schaedel e Ismael Silva -en antropología histórica y social- en la Facultad de Filosofía y Educación sección Geografía (en 1953), Oswald Menghin (entre 19571958), Mario Orellana (en 1959), a lo que se suma, en 1962, la creación de un curso de arqueología en la sección de historia, organizado por Grete Mostny, Bernardo Berdichewsky y Mario Orellana (Orellana 1996). Ello sirvió de base para dar inicio a la apertura de algunos centros de investigación en instituciones universitarias, destacando el Centro de Estudios Antropológico de la Universidad de Chile (1954), el Centro de Antropología y Arqueología en la Universidad de Concepción (1964) ${ }^{154}$, y el Centro de Estudios de la Realidad Regional en Temuco (1970). En el contexto de la reforma universitaria, todos estos centros darán origen a la formación de carreras profesionales en antropología en Chile, y marcarán la institucionalización académica de esta disciplina ${ }^{155}$. El primer currículo formativo en antropología en Chile fue implementado en la Universidad de Concepción en el año 1966

especialidad; e) promover el mejor conocimiento de los principios científicos básicos de la Antropología entre los técnicos y colaboradores no graduados de las distintas ramas de la ciencia; f) difundir públicamente los principios y trabajos de la investigación antropológica (Comas 1963).

${ }^{154}$ El Centro de Antropología y Arqueología fue creado el 24 de mayo de 1964, iniciando su primer año de trabajo en marzo de 1965. Contó con la dirección de Carlos Henckel, siendo jefa del departamento la arqueóloga Sra. Zulema Seguel, y contando con Anny Tual como profesora de etnología.

${ }^{155}$ En el año 1971 se reportan una serie de actividades realizadas en instituciones orientadas al cultivo de la antropología y la arqueología. Entre ellas figura el Departamento de Antropología de la Universidad del Norte, Sede Arica, en el cual figuran cursos de especialización y seminarios impartidos a estudiantes universitarios como a la comunidad en general. 
(Dreyfus Gamelon 1965; Garbulsky 2000). Esta propuesta se inicia a partir de la fundación del Centro de Antropología y Arqueología y la puesta en marcha en 1965 de un programa propedéutico, contando para ambos propósitos con la asistencia técnica de Simone DreyfusGamelon (especialista en etnología) y Anette Emperarie (especialista en arqueología), ambas enviadas por la UNESCO (Dreyfus Gamelon 1965). En tanto, en agosto de 1971 se abre el programa de Licenciatura en Antropología en la Universidad de Chile, en el marco del recién creado Departamento de Ciencias Antropológicas y Arqueológicas (Arnold et al. 1990) ${ }^{156}$. En las Escuelas Universitarias de la Frontera se abre en 1970 una especialización en Ciencias Sociales con una clara orientación antropológica, el cual a partir de 1973 se transforma en una Licenciatura en Antropología, siendo claves en este proceso el antropólogo Checo Milan Stuchlik, el profesor Adalberto Salas, el sociólogo Maurice Hebert y el psiquiatra Martín Cordero (Mora 2014).

Por último, los antecedentes expuestos a lo largo de este trabajo, permiten concluir que varias de las tesis sostenidas por parte de antropólogos nacionales pueden ser rebatidas:

- Se ha mostrado que si bien existe un aporte científico extranjero, la dinámica del campo antropológico se hace posible por la contribución que realizan intelectuales nacionales quienes generan aportes a través de diversas publicaciones.

- Si bien no se puede desconocer la importancia de los museos, resulta sustancial el trabajo desarrollado en el marco de las sociedades científicas; en términos de difusión de la producción, la Universidad de Chile a través de los Anales tiene un peso importante.

- El rol que juega la antropología en la construcción de la nación es más bien marginal; es un quehacer que se nutre fundamentalmente del aporte y esfuerzo de sujetos concretos, quienes asumen liderazgos comprometidos con el desarrollo de esta ciencia, aún cuando el impulso se encuentra en gran medida cruzado por la búsqueda de reconocimiento (Hastrom 1965).

\footnotetext{
${ }^{156}$ En un reporte sobre actividades antropológica en Chile, para el Panamerican Institute of Geography and History, se dan a conocer una serie de iniciativas realizadas en 1971 en el Departamento de Antropología de la Universidad del Norte, Sede Arica, el que clasifica actividades de investigación, docencia, extensión y trabajos a congresos. En docencia, se informa que se impartieron asignatura semestrales como: Introducción a la Antropología cultural, Introducción a la Arqueología, Arqueología regional, Etnohistoria Latinoamericana. No se han encontrado antecedentes para determinar si se trataba de un programa de formación en antropología o cursos dictados como seminarios o cátedras abiertas.
} 
- La antropología se entiende como ciencia integral, y su desarrollo se produce en la relación con otras ramas de las ciencias. Lo que opera y hace sentido para la época es una idea de ciencia que agrupa todas las ramas del saber. Ello se refuerza debido a que muchos de sus cultores son investigadores fecundos en distintas ramas de las ciencias naturales.

- A pesar de esta visión integral, la práctica que se evidencia a través de las publicaciones muestra tendencias a la especialización temática, que se vincula a la producción en ciertas revistas y espacios. Sin embargo, lejos de una desconexión, las sociedades y la sociabilidad de la época motiva la intercomunicación y el debate entre los distintos tipos de conocimiento, aún cuando se reproduce la imagen del científico solitario - en la mayoría de los casos no existen co-autorias.

- La institucionalización de las ciencias antropológicas se manifiesta débil marcando sus inicios en las primeras décadas del siglo XX, con la creación de sociedades científicas, museos, revistas, congresos. Se ponen en práctica ciertos marcos epistemológicos y teóricos que pugnan de manera simultánea en el espacio científico: evolucionismo, el enfoque histórico-cultural, el empirismo, círculos culturales y difusionismo, y funcionalismo.

- Si bien la antropología en Chile no constituye un estilo propiamente tal, expresa una nivel de desarrollo y unos procesos que le dan cierta particularidad; se diferencia claramente de la situación vivida en países como México, Brasil, Colombia y Argentina. Sería más bien una antropología subalterna o periférica.

A modo de cierre, hay que precisar que tal como han sostenido distintas perspectivas en estudios sociales de la ciencia, y más allá de la posibilidad de esgrimir cierta autonomía del campo científico (Bourdieu 1999), existen condicionantes socio-históricas que imprimen particularidades al desarrollo de las ciencias (Kreimer y Thomas 2004; Salomon 2008 [2006]; Beigel 2010), y que evidencian la profunda relación que existió entre las dinámicas del propio campo científico - ligadas a la delimitación, definición del objeto de estudio, tensiones y organización interna del campo- y aspectos locales y globales vinculados a proceso sociales, económicos y políticos. Algunos antecedentes ya han sido relevados, sin embargo hay que señalar que aquello que estructura la agenda científica de las potencias antropológicas en 
Latinoamérica, no sólo remite al interés que suscita el trabajo de campo en áreas que albergan la riqueza cultural conforme el canon del "otro exótico-distante" -que inscriben investigaciones que buscan reconstruir el pasado, rescatar aquello que desaparece y monitorear los procesos de cambio social. La geopolítica es sin duda gravitante, y adquiere vital importancia en el marco de la estrategia que en distintos momentos de la historia pusieron los gobiernos metropolitanos, siendo diferenciables aquellas puestas en juego antes, durante y con posterioridad a la segunda guerra mundial, las que afectan de distintas maneras el desarrollo de las antropologías en Latinoamérica (Beigel 2010; Kemper 2011; Gil 2012; Medina 2013). Por otro lado, los vaivenes en la institucionalización y desarrollo de la antropología y las ciencias sociales en general, puede ser entendida conforme a los contextos históricos y las dinámicas que tienen lugar en cada país. Lo gravitante que fue para la antropología en México la revolución, el apoyo del gobierno de Cárdenas, la vocación aplicada que asume en el marco del indigenismo y el campo profesional que se abre en las instituciones del Estado; el papel de las ciencias sociales en la modernización de Brasil pensada desde la elite paulista, que trae consigo la fundación de varias instituciones en las que se comienza a gestar la profesionalización del campo antropológico. Ciertos acontecimientos internacionales y nacionales vinculados a guerras, revoluciones y dictaduras, y dependiendo de cada contexto, promueven u obstaculizan la institucionalización y desarrollo de la antropología. Por ejemplo, la segunda guerra mundial permite el asentamiento de científicos europeos en el continente, realizando un gran aporte hacia las antropologías locales, en tanto dictaduras y gobiernos de facto intervienen ciertas instituciones, e imposibilitan el desarrollo de ciertas ciencias, cerrando carreras, modificando planes y exiliando a sus cultores -como son los casos argentino y chileno. Además, una cuestión fundamental para el desarrollo de la disciplina se asocia a la estructura del sistema y la política de educación superior de cada país.

En base a lo anterior, no podríamos menos que afirmar en un sentido más amplio que la antropología -pese a los impulsos individuales y las asociaciones-, vive una consolidación tardía respecto de lo que acontece en América Latina para el siglo XIX y mediados del XX. Si bien la investigación como actividad surge y se desenvuelve en la misma época en que se desarrolla en otros países de América Latina, el escaso o fluctuante respaldo institucional por parte del Estado y su tardía inserción en el espacio universitario, no permiten su consolidación. En tal sentido, ocuparía una posición "periférica en la periferia", si tomamos en consideración 
los indicadores que Cardoso de Oliveira (1999) plantea, y entre los cuales destacan para el caso chileno: la debilidad institucional -carencias en infraestructura y financieras-, dependencia formativa de académicos y profesionales en el extranjero, un dominio de teorías formuladas fuera del ámbito local.

Si bien la antropología en Chile comparte procesos sociales y dinámicas de carácter internacional e incorpora un modelo de ciencia y teorías o enfoques que tiene su génesis en el campo internacional -evolucionismo, historicismo cultural, empirismo-, expresa particularidades nacionales o locales que se nutren de un estilo intelectual, de las preocupaciones de la elite política, del apoyo y fomento estatal, del imaginario acerca de la población nativa, entre otros. 


\section{Bibliografía}

Abad, J., Muñiz, N., Cervantes M. (2003). Análisis de correspondencias simples y múltiples.

En: Lévy, JP. Varela, J. (Eds.). Análisis multivariante para las ciencias sociales. Madrid:

Pearson, Prentice Hall.

Almonacid, F. (2008). La división de las comunidades indígenas del sur de Chile, 1925-1958: un proyecto inconcluso. Revista de Indias, 68, (243), 115-150.

Álvarez, J. (2008). La antropología y las ciencias sociales en la comprensión de la región central el Perú: balance de investigaciones. En Diez, A. (Coord.). La antropología ante el Perú de hoy: Balances regionales y antropologías latinoamericanas (pp. 127-144). Lima: Pontificia Universidad Católica del Perú.

Amunátegui, D. (1932). José Toribio Medina. Santiago de Chile: Universidad de Chile.

Apostel, L. (Comp.) (1979). Interdisciplinariedad. Problemas de la enseñanza y de la investigación en las universidades. México: ANUIES. Disponible en http://biblio2.colmex.mx/bibdig/interdisciplinariedad/base2.htm [Accessed: 15/01/2009].

Arenas, P. (1990). La antropología en la Argentina a fines del siglo XIX y principios del XX. Runa, 19, 147-160.

Arias, J. (2007). Nación y diferencia en el siglo XIX colombiano. Orden nacional, racismo y taxonomias poblacionales. Bogotá: Universidad de Los Andes.

Arnold, M., Haefner, C., Quiroz, D., y Radrigán, M. (1990). Antropología social en Chile: producciones y representaciones. Santiago, Mimeo.

Auge, M. (1998 [1994]). Hacia una antropología de los mundos contemporáneos. Barcelona: Gedisa. 
Asad, T. (1973). Introduction. En: Talal Asad (ed.). Anthropology and the Colonial Encounter (p.p 1-19). Atlantic Highlands: Humanities Press.

Azcona, J. (1987). Para comprender la antropología. Estella: Verbo Divino.

AAVV (1986). La antropología en México y las prácticas de campo en la ENHA. Comité preparatorio de las prácticas de campo. En García, C. y Medina, A. (Eds.). La quiebra política de la antropología social en México (pp. 79-86). México: Universidad Autónoma de México.

Báez-Jorge, F. (1980). Reflexiones sobre el quehacer de la antropología en México. América Indígena, 40 (2), 367-380.

Báez Landa, M. (2005). La ciencia imposible. La antropología mexicana entre la academia y la acción. Presentado en Coloquio "La Otra antropología toma la palabra. El oficio del antropólogo en contextos extraacadémicos". Universidad Autónoma Metropolitana-Iztapalapa, 21 y 22 de septiembre.

Bahamonde, N. (1983). Don Carlos Emilio Porte Mosso. Sabio naturalista chileno (18671942). En Revista Chilena de Historia Natural, (56), 7-9.

Barros Arana, D. (1876). Don Claudio Gay. Su vida i sus obras. Santiago de Chile: Imprenta Nacional.

Barros Arana, D. (1888). Introducción. En Moraleda i Montero, J. Esploraciones jeorgráficas e hidrográficas. Santiago de Chile: Imprenta Nacional.

Barros Arana, D. (1904). El Doctor Don Rodulfo Amando Philippi. Su vida i sus obras. Santiago de Chile: Imprenta Cervantes. 
Barros Arana, D. (1999 [1884]). Historia General de Chile. Tomo I. Santiago: Editorial Universitaria.

Barth, F. (2005 [2012]). Inglaterra y la Commonwealth. En: Barth, F.; Parkin, R.; Silverman, S.; Gingrich, A. Una disciplina, cuatro caminos. Antropología británica, alemana, francesa, estadounidense. Buenos Aires: Prometeo.

Bartolomé, L. (1980). La antropología en Argentina: problemas y perspectivas. América Indígena 40 (2), 207-216.

Bartolomé, L. Guber, R. Soprano, G., Otero, N. y Prol, L. (2007). Argentina: le enseñanza de la antropología social en el contexto de las ciencias antropológicas. Informe para la investigación "A Distributed and Collective Ethnography of Academy Trianing in Latin American Anthropologies". Latin American Working Group of the WAN Collective.

Beattie, G. (1964 [1986]). Otras culturas. México: Fondo de Cultura Económica.

Becher, T. (1987). The disciplinary shaping of the profession. En Clark, Burton R. (Comp.) The Academic Profession. Berkley: University of California press.

Becher, T. (2001 [1989]). Tribus y territorios académicos. La indagación intelectual y las culturas de las disciplinas. Barcelona: Gedisa.

Beigel, F. (2006). Vida, muerte y resurrección de la teoría de la dependencia. En Beigel, F.; Falero, A; Gandarilla, J. et al. Crítica y teoría en el pensamiento social latinoamericano, (pp.287-326). Buenos Aires: Clacso.

Beigel, F. (2010). Dependency Analysis: The creation of New social Theory in Latin America. En Patel, S. (Ed.). The International Handbook on Diverse Sociological Traditions (pp.189201) London: Sage. 
Beigel, F. (2010). Autonomía y dependencia académica. Universidad e investigación científica en un circuito periférico: Chile y Argentina (1950-1980). Buenos Aires: Biblos.

Beleé, W. (2009). The Four-Field Model of Anthropology in the United State. Amazónica, Revista de Antropología, 1, (1), 1-15.

Ben-Ari, E. (1999). Colonialism, anthropology and the politics of professionalisation. En: Van Bermen, J. \& Shimizu, A. Anthropology and Colonialism in Asia and Oceania (pp.382-409). Hong Kong: Curzon. URL: http://www.unc.edu/ aparicio/WAN/BenAriColonialism.pdf [Accessed 2/1/2011]

Bengoa, J. (2014). La trayectoria de la antropología en Chile. Revista antropologías del sur, 1, $15-42$.

Benedict, R. (1971). El hombre y la cultura. Buenos Aires: Sudamericana.

Berdichewsky, B. (1977). Perspectivas de la antropología aplicada: el caso de Chile. Nueva Antropología, 2 (6): 43-85.

Berdichewsky, B. (1980). Situación y problemática de la antropología en Chile». América Indígena 40 (2): 309-328.

Berdichewsky, B. (2000). Notas críticas en torno a la historia de la antropología. Actas del Tercer Congreso Chileno de Antropología, Santiago de Chile, 184-192.

Berdichewsky, B. (2004). Alejandro Lipschutz: su visión indigenista y antropológica. Santiago, Universidad Católica Silva Henríquez.

Berger, G. (1979). Opiniones y Realidades. En Apostel, L. (Comp.). Interdisciplinariedad. Problemas de la enseñanza y de la investigación en las universidades. México: ANUIES. 
Disponible en http://biblio2.colmex.mx/bibdig/interdisciplinariedad/base2.htm [Accessed: 15/01/2009].

Bernstein, J. (2002). First Recipients of Anthropological Doctorates in the United State, 18911930. American Anthropologist, 104 (2), 551-564.

Beyer, J. y Lodahal, T. (1976). A Comparative Study of Patterns of Influence in United States and English Universities. Administrative Science Quarterly, 21, 104-129.

Bloor, D. (1971 [1998]). Conocimiento e imaginario social. Barcelona: Gedisa.

Boas, F. (1919). Report on the Academic Teaching of Anthropology. American Anthropologist, New Series, 21, (1), 41-48. URL: http://www.jstor.org/stable/660021

Boas, F. (1920 [1997]). Los métodos en etnología. En Bohannan, P. \& Glazer, M. Antropología, Lecturas (pp. 85-100). Madrid: McGraw Hill.

Boas, F. (1924 [1997]). Las limitaciones del método comparativo de la antropología. En Bohannan, P. \& Glazer, M. Antropología, Lecturas (pp. 85-100). Madrid: McGraw Hill.

Boisot, M. (1979). Disciplina e interdisciplinar. En Interdisciplinariedad. Problemas de la enseñanza y de la investigación en las universidades, compilado por L. Apostel, ANUIES, México. http://biblio2.colmex.mx/bibdig/interdisciplinariedad/base2.htm. Accesed 15 de diciembre de 2009.

Boletín Cuarto Congreso Científico Latinoamericano y Primer Congreso Científico Panamericano. Bases, Programas y Cuestionario General. Santiago de Chile, 1908.

Bourdieu, P. (2008 [1984]). Homo academicus. Buenos Aires: Siglo XXI.

Bourdieu, P. (2008 [1997]). Los usos sociales de la ciencia. Buenos Aires: Nueva Visión. 
Bourdieu, P. (2006 [1999]). Intelectuales, política y poder. Buenos Aires: Eudeba.

Bourdieu, P. (2003 [2001]). El oficio del científico. Ciencia de la ciencia y reflexividad. Barcelona: Anagrama.

Bouza, J. (1988). Una interpretación del proceso de institucionalización de las ciencias sociales: La antropología y el modelo francés. Barcelona: Universidad de Barcelona.

Bovini, M.; Rosato, A. \& Arribas, A. (1998). Constructores de otredad. Buenos Aires: Eudeba.

Bowker, G. y Latour, B. (1987). A Booming Discipline Short of Discipline: (Social) Studies of Science in France. Social Studies of Science, 17, (4), 715-748.

Brand, D. (1941). The Status of Anthropology in Chile. New Mexico Anthropologist, 5 (3): $55-71$.

Broca, P. (1870). Histoire des progrès des études anthropologiques depuis la fondation de la Société : compte rendu décennal (1859-1869). Paris: A. Hennuyer.

Broca, P. (1871). Mémoires D'Anthropologie, Tome Premier. Paris: C. Reniwald.

Browen, A. (1993). Homenaje a Don Eduardo de la Barra. Discurso pronunciado con ocasión de la inauguración del Retrato de Don Eduardo de la Barra, en la Escuela de Derecho de la Universidad de Valparaiso, 2 de agosto de 1993. URL: http://www.memoriachilena.cl/602/w3-article-82228.html

Bruna, A. y Larroucau, A. (2008). La epopeya de un sabio: Rodulfo Amado Philippi en el desierto de Atacama. En Philippi, R. Viaje al desierto de Atacama. Santiago de Chile: Biblioteca Fundamentos de la Constricción de Chile. 
Burgess, R. (1984). In the Field. An Introduction to Field Research. London: Routledge.

Bustamante, J. (2005). La conformación de la antropología como disciplina científica, el Museo Nacional de México y los Congresos Internacionales Americanistas. Revista de Indias, 65 (234), 303-318.

Cajaraville, M. (1998). Los procesos informacionales en la constitución del campo de la Antropología Social en la Argentina: un abordaje bibliotecológico sobre las revistas especializadas en el período 1983-1995. Redes, 5 (11), 207-230.

Callon, M.; Courtial, J. P. y Penan, H. (1993 [1995]). Cienciometría. El estudio cuantitativo de la actividad científica: de la bibliometría a la vigilancia tecnológica. Gijón: Trea.

Calvia, O. (2005). La fábula de las tres ciencias. Antropología, etnología e historia en Brasil. Revista de Indias, 65 (234), 337-354.

Cancino, R. y Morales, R. (2003). La antropología desbordada: las huellas y marcas del hacer antropología en territorio mapuche. En Richard, N. (Ed.). Movimientos de campo en torno a cuatro fronteras de la antropología en Chile (pp.91-108). Guatemala: Ediciones ICAPI.

Cardoso de Oliveira, R. (1995). Estilos nacionais da antropologia? Reflexioes partir da ciencia. En Cardoso de Oliveira, R. \& Ruben, G. (orgs.) Estilos da antropologia. Campinas: Unicamp.

Cardoso de Oliveira, R. (1996). La antropología latinoamericana y la crisis de los modelos explicativos: paradigmas y teorías. Maguare, 11 (12), 9-23.

Cardoso de Oliveira, R. (1999). Antropologías periféricas "versus" antropologías centrales. Conferencia central en: Conferencias y participaciones de investigadores invitados al $\mathrm{V}$ Congreso Argentino de Antropología Social. La Plata, Argentina, 19-37. 
Cardoso de Oliveira, R. (2004). El movimiento de los conceptos en antropología. En Grimson, A.; Lins Ribeiro, G. y Semán, P. La antropología brasileña contemporánea. Contribuciones para un diálogo latinoamericano (pp. 35-52). Buenos Aires: Prometeo.

Cariola, C. y Sunkel, O. (1982). Un siglo de historia económica de Chile, 1830-1930: dos ensayos y una bibliografía. Madrid: Ediciones Cultura Hispánica del Instituto de Cooperación Iberoamericana.

Carrasco, N. y Eyzaguirre, L. (2005). La antropología vista por la epistemología política. Comentarios a la antropología aplicada chilena. Revista Anthropos, 207, 185-200.

Carrasco, N. (2012). Horizontes de la reflexividad etnográfica. Revelaciones y tensiones para el estudio antropológico del desarrollo en Chile. Tabula Rasa, 17, 113-129.

Castro, M. (2014). A sesenta años de la antropología en Chile. Revista antropologías del sur, $1,43-64$.

Castro-Gómez, S.; Schiwy, F. y C. Walsh (2002). Introducción. En Walsh, C.; Schiwy, F. y S. Castro-Gómez. Indisciplinar las ciencias sociales. Geopolíticas del conocimiento y colonialidad del poder. Perspectivas desde lo andino (pp.7-16). Quito: Abya-yala.

Chamberlain, A. (1910). The Chilian Flok-Lore Society and Recent Publications on Chilian Folk-Lore. The Jurnal of American Floklore, 23 (89), 383-391.

Chatfield, Ch. y Collins, A. (1980). Introduction to multivariate analysis. New York: Chapman and Hall.

Clarac Briceño, J. (1993). Estatutos y características cognitivas de la antropología en Venezuela. Alteridades, 3 (6), 17-26. 
Clark, B. (1983). The Higher Education System. Academic Organization in Cross-National Perspective. California: University of California Press.

Clifford, J. (1992 [1988]). Sobre la autoridad etnográfica. En Reynoso, C. (Comp.). El surgimiento de la antropología posmoderna (pp. 141-170). Barcelona: Gedisa.

Comas, J. (1962). Estatutos de la Sociedad Chilena de Antropología. Boletín Bibliográfico de Antropología Americana, Instituto Panamericano de Historia y Geografía, (23/25), 1, 51-53.

Correa, M. (1993). Breve esbozo de la antropología brasileña reciente. Alteridades, 3 (6), 1316.

Collins, H. (1981). Introduction. Stages in the Empirical Programme of Relativism. Social Studies of Science, Special Issue: 'Knowledge and Controversy: Studies of Modern Natural Science' (11), 1, 3-10. URL: http://www.jstor.org/stable/284733 [20-11-2009].

Crane, D. (1969). Social structure in a group of scientists: A test of the "invisible college". American Sociological Review, 34(3), 335-352.

Crane, D. (1972). Invisible colleges: Diffusion of knowledge in scientific communities. Chicago: University of Chicago Press.

Crivisqui, E. (1999). Iniciación a la estadística exploratoria multidimensional. Universidad Libre de Bruselas. Material de trabajo Seminario "Programa de investigación y enseñanza de la estadística aplicada”, PRESTA, Europa y América Latina.

Cunningham, W. y Kelly, P. In memoriam Donald Dilworth Brand. URL: http://www.utexas.edu/faculty/council/2000-2001/memorials/SCANNED/brand.pdf

Cuche, D. (1999 [1996]). La noción de cultura en las ciencias sociales. Buenos Aires: Nueva Visión. 
Dannemann, M. (2010). Tres buscadores de la chilenidad: Lenz, Laval y Vicuña Cifuentes. Anales de Literatura Chilena, 14, 57-92.

De Araujo, W. (2010). A antropologia brasileira: breves indagacoes sobre la historia de um campo em expansao. Boletín de Antropología, 24 (41), 432-452.

Decreto Fuerza de Ley $N^{\circ} 5.200,18$ de noviembre de 1929. URL: http://www.leychile.cl/Navegar?idNorma=129136

De la Barra, E. (1894). Ensayos filológicos americanos. Carta al profesor Rodolfo Lenz, sobre su Estudio del lenguaje vulgar en Chile. Rosario de Santa Fé.

Degregori, C. y Sandoval, P. (2007). Dilemas y tendencias en la antropología peruana: del paradigma indigenista al paradigma intercultural. En Degregori, C. y Sandoval, P. (Comps.). Saberes periféricos: Ensayos sobre la antropología en América Latina. (pp. 19-72). Lima: Instituto de Estudios Peruanos.

Degregori, C. (2008). ¿Cómo despertar a la bella durmiente?: por una antropología para comprender un país escindido. En Diez, A. (Coord.). La antropología ante el perú de hoy: Balances regionales y antropologías latinoamericanas (pp. 15-36). Lima: Pontificia Universidad Católica del Perú.

De Gérando, J. M. (1800). Les Considérations sur les diverses méthodes à suivre dans l'observation des peuples sauvages. Paris: Société des observateurs de l'homme. URL: http://gallica.bnf.fr/ark:/12148/bpt6k6544113q/f1.image

De la Cadena, M. (2007). La producción de otros conocimientos y sus tensiones: ¿de una antropología andinista a la interculturalidad?. En Degregori, C. y Sandoval, P. (Comps.). Saberes periféricos. Ensayos sobre la antropología en América Latina (pp. 107-152). Lima: Instituto de Estudios Peruanos. 
De la Peña, (2008). La antropología social y cultural en México. Ponencia preparada para el Seminario Antropología en Europa, Madrid.

De Novo y Colson, P. (Ed.) (1885). Viaje político-cientifico alrededor del mundo por las corbetas Descubierta y Atrevida al mando de los Capitanes de navío Alessando Malaspina y Don José de Bustamante y Guerra desde 1789 a 1794. Madrid: Imprenta de la Viuda e hijos de Abienzo.

Dillon, P. (2008). A pedagogy of connection and boundary crossings: methodological and epistemological transactions in working across and between disciplines. Innovations in Education and Teaching International, 45 (3), 255-262.

Dogan, M. y Pahre, R. 1993. Las nuevas ciencias sociales. La marginalidad creadora. México: Grijalbo.

Dogan, M. (2001). Specialization and Recombination of Specialties in the social sciences. Smelser, N. J. \& Baltes, P. B. (Eds.). International Encyclopedia of Social and Behavioral Sciences (pp. 14851-14855). London: Pergamon-Elsevier Science.

Donoso, A. (1915). Vida y Viajes de un erudito. Recuerdos de Don José Toribio Medina. Santiago de Chile: Zig-Zag.

Donoso, K. (2006). La batalla del Folklore: los conflictos por la representación de la cultura popular chilena en el siglo XX. Tesis para optar al grado de Licenciada en Historia, Facultad de Humanidades, Departamento de Historia, Universidad de Santiago de Chile.

Durán, T. (2005). Antropología interactiva: un estilo de antropología aplicada en la IX región de La Araucanía, Chile. Revista CUHSO, 6 (1), 23-57.

Durán, T.; Carrasco, N. y Berho, M. (2005). Reflexividad y contexto en el quehacer antropológico. Revista CUHSO, 1 (9), 25-36. 
Dreyfus-Gamelon, S. 1965. Chili. Anthropologie à l'université de Concepcion. Paris, Unesco.

Estatutos de la Sociedad Arqueológica de Santiago. Santiago de Chile, 1878.

Etcheverry, M. (1988). Los Anales del Museo de Historia Natural de Valparaíso-Chile. Revista Chilena de Historia Natural, 61, 113-126.

Etcheverry, M. (1990). Índice de las publicaciones del Museo Regional de Concepción. Revista Chilena de Historia Natural, 63, 119-124.

Etcheverry, M. (1991). Índice de las publicaciones relacionadas con los "Congresos científicos generales chilenos", realizados entre 1893 y 1944. Revista Chilena de Historia Natural, 64, 353-376.

Etcheverry, M. y Peña, R. (1997). Índices de la Revista "Verhandlungen des Deutschen Wissenschaftlichen Vereins zu Santiago de Chile" publicada por la Sociedad Científica Alemana entre 1885 y 1936. Revista Chilena de Historia Natural, 70, 153-165.

Etzkowitz, H. y Leydesdorff, L. (2000): "The dynamics of innovation: from National Systems and 'Mode 2' to a Triple Helix of university-industry-government relations", Research Policy, $29,(2), 109-123$.

Falero, A. (2006). El paradigma renaciente de América Latina: una aproximación sociológica a legados y desafíos de la visión centro-periferia. En Beigel, F.; Falero, A; Gandarilla, J. et al. Crítica y teoría en el pensamiento social latinoamericano, pp.217-286. Buenos Aires: Clacso.

Farro, M. (2009). La formación del Museo de La Plata. Coleccionistas, comerciantes estudiosos y natruralistas viajeros a fines del siglo XIX. Rosario: Prehistoria Ediciones. 
Feliú, G. (1969a). Carlos E. Porter (1867-1942). La bibliografia de las ciencias naturales. Santiago de Chile: Bibliógrafos Chilenos.

Feliú, G. (1969b). Ricardo E. Latcham (1869-1943). La bibliografia de las ciencias antropológicas. Santiago de Chile: Bibliógrafos Chilenos.

Feliú, G. (1969c). Victor Manuel Chiappa (1869-1943). La bibliografia de Diego Barros Arana y José T. Medina. Santiago de Chile: Bibliógrafos Chilenos.

Feliú, G. (1970). Martín Gusinde. La bibliografía de la Isla de Pascua y la de Antropología Chilena. Santiago de Chile: URL: http://www.memoriachilena.cl/archivos2/pdfs/MC0008159.pdf

Fernández, E. (2008) Las resistencias a la penetración del Estado moderno en Chile en el siglo XIX: de la resistencia militar a la resistencia político-cultural de los mapuches. Pandora: reveu d'etudes hispaniques, $\mathrm{N}^{\circ} 8,239-256$.

Fígoli, L. (2004). Origen y desarrollo de la antropología en la Argentina: desde la organización nacional hasta mediados del siglo XXI. Anuario de Estudios en Antropología Social, Instituto de Desarrollo Económico y Social y Centro de Antropología Social.

Firth, R. (1951 [2001]). Elementos de la antropología social. Buenos Aires: Amorrortu.

Flores, E. (1911). Adivinanzas corrientes en Chile. Revista Anales de la Universidad de Chile, $128,765-844$.

Foucault, M. (2008 [1969]). La arqueología del saber. Buenos Aires: Siglo XXI.

Foucault, M. (2002 [1975]). Vigilar y castigar: nacimiento de la prisión. Buenos Aires: Siglo XXI. 
Fowler, D. y D. Wilcox. (2000). De Thomas Jefferson a la Conferencia de Pecos: las cambiantes agendas antropológicas en el suroeste de Norteamérica. Revista Relaciones, 21(82), 85-118.

Franco, R. (2007). La FLACSO clásica (1957-1973). Vicisitudes de las Ciencias Sociales latinoamericanas. Santiago de Chile: Catalonia.

Fuenzalida, H. (1919). Notas administrativas. Boletín del Museo Nacional, Tomo XII, 149150.

Fuenzalida, H. (1936) Boletín del Museo Nacional, Tomo XV, 196-199.

Fuenzalida, H. (1964). Don Ricardo Latcham y el ambiente científico de Chile a comienzos de siglo. Publicaciones ocasionales del Museo Nacional de Historia Natural. Santiago de Chile: Museo Nacional de Historia Natural.

Gamio, M. (1942). Boas en México. Boletín Bibliográfico de Antropología Americana (19371948), 6, (1/3) 35-42, Pan American Institute of Georgraphy and History. URL: http://www.jstor.org/stable/40977511

Garbulsky, E. (1993). La antropología social en Argentina. En Arizpe, L. y Serrano, C. (Comps.) Balances de la antropología en América Latina y el Caribe (p.p. 455-482). México: Universidad Nacional Autónoma de México.

Garbulsky, E. (2000). La antropología en la Universidad de Concepción (1967-1973). Apuntes de un participante. Actas III Congreso de chileno de antropología, Santiago de Chile, 200210.

Garbulsky, E. (2003). La antropología argentina en su historia y perspectivas. El tratamiento de la diversidad desde la negación/omisión a la opción emancipadora. Ponencia presentada a 
las I Jornadas Experiencias de la Diversidad, Centro de Estudios sobre Diversidad Cultural, Facultad de Humanidades y Artes, Universidad Nacional de Rosario. Rosario.

Garbulsky, E. (2004). La producción de conocimiento antropológico-social en la Facultad de Filosofía y Letras de la Universidad Nacional del Litoral entre 1956-1966. Vínculos y relaciones nacionales. Cuadernos de Antropología, 20, 41-60.

García, F. (2011). La construcción del pensamiento antropológico ecuatoriano: derroteros y perspectivas. Alteridades, 21 (41), 61-68.

García, C. y Medina, A. (1986). La quiebra política de la Antropología Social en México. México: Universidad Autónoma de México.

Garretón, M. 2007, Las Ciencias Sociales en Chile. Institucionalización, rupturas y renacimiento. En Trindade, H. (Coord.) Las ciencias sociales en América latina. Perspectiva comparada. 193-248. México, Siglo XXI.

Garretón, M. (2015). Las ciencias sociales en la trama de Chile y América Latina. Santiago de Chile: Lom.

Gazmuri, C. (2006). La historiografía chilena (1842-1970), Tomo I (1842-1920). Santiago de Chile: Taurus y Centro Editorial Diego Barros Arana.

Geertz, C. (1989 [1988]). El antropólogo como autor. Barcelona: Paidós.

Geertz, C. (1992). Géneros confusos. La refiguración del pensamiento social. En Reynosos, C. (Comp.). El surgimiento de la antropología posmoderna (pp.63-77). Barcelona: Gedisa.

Geertz, C. (1995 [1996]). Tras los hechos. Dos países, cuatro décadas, un antropólogo. Barcelona: Paidós. 
Geertz, C. (2002). A Inconstant Profesión: The Anthropological Life in interesting Times. Annual Reviews of Anthropology, 31, 1-19.

Gerholm, T. y Hannerz, U. (1982). Introduction: The Shaping of National Anthropologies. Ethnos. 47(1), 1-35.

Gieryn, T. (1983). Boundary-Work and the Demarcation of Science from Non-Science: Strains and Interests in Professional Ideologies of Scientists. American Sociological Review, 48, (6), 781-795. URL: http://www.jstor.org/stable/2095325. [Accessed: 12/01/2009].

Gil, J. (2006). Ideología, reprensión e investigación de campo. La carrera de Antropología de Mar del Plata (1971-1977). Anuario de Estudios en Antropología Social. Cas-IDES, 53-73.

Gil, J. (2008). Una facultad que no fue. Las ciencias sociales en la Universidad de Mar del Plata (1968-1977). Propuesta Educativa, (31), 81-89.

Gil, J. (2012). Antropología, espionaje y contrainsurgencia. Los debates sobre al éticaen la antropología noerteamericana de los sesenta. Estudios en Antropología Social, CAS-IDES, 2 (1), 55-68.

Gingrich, A. (2012[2005]). Los países germanoparlantes. En: Barth, F.; Parkin, R.; Silverman, S.; Gingrich, A. (2005 [2012]). Una disciplina, cuatro caminos. Antropología británica, alemana, francesa, estadounidense (pp. 85-197). Buenos Aires: Prometeo.

Gluckman, M. y Eggan, F. (1966 [1999]). Presentación. En Banton, M. (Comp.). Antropología social de las sociedades complejas (pp.9-18). Madrid: Alianza Editorial.

González, E. (1982). La antropología en Ayacucho: informe preliminar. Debates en Sociología, (8), 128-140.

González, A. (1987). La construcción teórica en antropología. Barcelona: Anthropos. 
González, J. y Andrade, B. (2008). Geografía física de la República de Chile por Pedro José mado Pissis Marín 1812-1889. En Pissis, P. Geografía Física de la República de Chile. Santiago de Chile: Biblioteca Fundamentos de la Constricción de Chile.

Goddard, V., Llobera J. y Shore, Ch. (1996). Introduction: The Anthropology of Europe. En: V. Goddard, J. Llobera and C. Shore, (eds). The Anthropology of Europe. (pp. 1-40). Oxford: Berg.

Goodenough, W. (1956). Componential analysis and the study of meaning. Language, 32 (1), 195-216. URL: http://www.jstor.org/stable/410665. [Accessed: 22/10/2009].

Granovetter, M. (1973). The strength of weak ties. American Journal of Sociology, 78(6), 1360-1380.

Greenhalgh, S. (1996). The Social Construction of Population Science: An Intellectual, Institutional, and Political History of Twentieth-Century Demography. Comparative Studies in Society and History, 38, (1), 26-66. URL: http://www.jstor.org/stable/179337 Accessed: 20/10/2009

Grimson, A.; Lins Ribeiro, G. y Semán, P. (2004) La antropología brasileña contemporánea. Contribuciones para un diálogo latinoamericano (Eds.). Buenos Aires: Prometeo.

Guber, R. (2002). Antropología Social: An Argentine Diaspora between Revolution and Nostalgia. Anthropology Today, 18, (4) 8-13. URL: http://www.jstor.org/stable/3694972

Guber, R. (2007). Crisis de presencia, Universidad y política en el nacimiento de la antropología social en Buenos Aires, Argentina. Revista Colombiana de Antropología, 43, 263-298. 
Guber, R. (2009). Política nacional, institucionalidad estatal y hegemonía socio-antropológica en las periodizaciones de la antropología argentina. Cuadernos de Ides, 16, 3-28.

Guber, R. y Visacovsky, S., Gurevich, E. (1997). Modernidad y tradición en el origen de la carrera de Ciencias Antropológicas de la Universidad de Buenos Aires. Redes, 4 (19), 213257.

Guber, R. y Visacovsky, S. (1999). Imágenes etnográficas de la nación. La antropología social Argentina de los tempranos años setenta. Trabajo presentado en el Seminário Internacional "Uma Agenda para a Antropologia a partir da América Latina", realizado con los auspicios del Departamento de Antropologia, Brasília, 28 y 29 de septiembre.

Guber, R. y Visacovsky, S. (2006). The Birth of Ciencias Antropologicas at the University of Buenos Aires, 1955-1965. Histories of Anthropology Annual II (pp. 1-32). Lincoln NE: University of Nebraska Press.

Guevara, T. (1911). Folklore Araucano. Refranes, cuentos, cantos, procedimientos industriales, costumbres prehispanas. Santiago: Imprenta Cervantes.

Gunderman, H. y González, H. (2009). Sociedades indígenas y conocimiento antropológico. Aymaras y atacameños de los siglos XIX y XX. Chunagara, Revista de Antropología Chilena, 41 (1): 113-164.

Gusinde, M. (1916). El Museo de Etnología y Antropología de Chile. Revista Chilena de Historia y Geografía, Tomo XIX, 23, 30-47.

Gusinde, M. (2014). Expedición a Tierra del Fuego. Santiago de Chile: Editorial Universitaria.

Gutiérrez, C. (2011). Educación, ciencia y artes en Chile, 1797-1843. Revolución y contrarrevolución en las ideas y políticas. Santiago de Chile: Ril Editores. 
Hagstrom, W. (1965). The scientific community. New York: Basic Books.

Haenke, T. (1942). Descripción del Reyno de Chile. Santiago de Chile: Editorial Nascimiento.

Hamp, T. (1998) Max Uhle y los orígenes del Museo de Historia Nacional. En: Kaulike, M. (Ed.). Max Uhle y el Antiguo Perú (p.p. 139-165). Lima: Pontificia Universidad Católica del Perú. URL: www.iai.spk-berlin.de/fileadmin/.../Indiana/...15/IND_15 Martinez.pdf.

Hanneman, R. (2000). Introducción a los métodos de análisis de redes sociales. Departamento de Sociología de la Universidad de California Riverside. Disponible en http://wizard.ucr.edu/ rhannema/netwprks/text/textindex.html (Versión en castellano en http://www.redes-sociales.net/materiales.)

Hannerz, U. (1980 [1986]). Exploración de la ciudad. Madrid: Fondo de Cultura Económica.

Hanisch, W. (1974). Juan Ignacio Molina, sabio de su tiempo. Caracas: Universidad Católica Andrés Bello.

Harris, M. (1968 [2006]). El desarrollo de la teoría antropológica. México: Siglo XXI.

Harrison, F. (1991). Anthropology as ana gent of transformation: introductory comments and queries. En Harrison, F. (ed.). Descolonizing anthropology moving further Howard and anthropology of Liberation (pp. 1-15). Washintong D.C.: AAA.

Heckhausen, H. (1979). Disciplina y interdisciplinariedad. Apostel, L. (Comp.) (1979). Interdisciplinariedad. Problemas de la enseñanza y de la investigación en las universidades. México: ANUIES. Disponible en http://biblio2.colmex.mx/bibdig/interdisciplinariedad/base2.htm [Accessed: 15/01/2009]. 
Hernández de Alba, G. (1947). El Instituto Etnológico del Cauca. Boletín Bibliográfico de Antropología Americana (1937-1948), 10, 20-22. Pan American Institute of Geography and History. URL: http://www.jstor.org/stable/40977707

Hernández, R. (2003). Antropología rural en Chile. En Richard, N. (Ed.). Movimientos de campo en torno a cuatro fronteras de la antropología en Chile (pp.61-79). Guatemala: Ediciones ICAPI.

Hernández, R. (2004). La antropología chilena: ¿Qué identidad? Una mirada desde afuera y desde adentro. Actas del V Congreso de Chileno de Antropología, Tomo II, 982-987.

Hernández, R. y Pezo, L. (2009) La antropología rural chilena en las dos últimas décadas: situación y perspectivas. AIBR. Revista de Antropología Iberoamericana, 4, (2), 204-228.

Hogbin, I. (1974 [1957]). La antropología como servicio público En: Firth, Raymond; Meyer Fortes, E. R. Leach y otros. Hombre y cultura: La obra de Bronislaw Malinowski. Madrid: Siglo XXI.

Imilan, W. y Lange, C. (2003). Aproximaciones a la antropología urbana chilena: lo urbano y el trabajo de campo en la ciudad. En Richard, N. (Ed.). Movimientos de campo en torno a cuatro fronteras de la antropología en Chile (pp.27-44). Guatemala: Ediciones ICAPI.

Informe Delegación chilena. (1910). El congreso de los americanistas en Buenos Aires: mayo de 1910. Anales de la Universidad de Chile, 127, 633-735.

Jaksic, I. (2013). Rebeldes académicos. La filosofía chilena desde la independencia hasta 1989. Santiago de Chile: Universidad Diego Portales.

Jaramillo, R. (1987). Juan Ignacio Molina. Primer científico nacional y la gran edición, jamás traducida, de su Ensayo sobre la historia natural de Chile. En Molina J. Ensayo sobre la historia natural de Chile. Santiago de Chile: Ediciones Maule. 
Jimeno, M. (2005). La vocación crítica de la antropología en Latinoamérica. Antípoda, (1), 4365.

Jociles, M. (1999). Las técnicas de investigación en antropología. Mirada antropológica y proceso etnográfico. Revista Gazeta de Antropología, 15, 1-35. URL: http://www.ugr.es/ pwlac/G15 01MariaIsabel_Jociles_Rubio.html [Accessed: 10/5/2005].

Jones, D. (1988). Towards a Native Anthropology. En: Cole, J. Anthropology for the nineties. Introductory readings (pp. 30-41). New York: the Free Press.

Kaplan, D. y Manners, R. (1968). Theory in anthropology. A source book. London: Routledge \& Kegan Paul Limited.

Kemper, R. (2011). Estado y antropología en México y Estados Unidos: reflexiones sobre los Proyectos Tarascos. Relaciones, 128 (32), 209-241.

King, A. R., y Brownell, J. (1966). The Curriculum and the Discipplines of Knowledge. Nueva York: John Wiley.

Klimovsky, G. (2005 [1994]). Las desventuras del conocimiento científico. Una introducción a la epistemología. Buenos Aires: A Z.

Knorr-Cetina, K. (1992). Scientific Communities or Transepistemic Arenas of Research? A Critique of Quasi-Economic Models of Science. Social Studies of Science, 12 (1), 101-130.

Knorr-Cetina, K. (2005). La fabricación del conocimiento científico. Bernal: Universidad Nacional de Quilmes.

Kreimer, P. y Thomas, H. (2004). Un poco de reflexividad o ¿de dónde venimos? Estudios Sociales de la Ciencia y la Tecnología en América Latina. En: Kreimer, P., Thomas, H., 
Rossini, P. \& Lalouf, A. (Eds.). Producción y uso social del conocimiento. Estudios de sociología de la ciencia y la tecnología en América Latina. Bernal: Universidad Nacional de Quilmes.

Krotz, E. (1993). La producción de la antropología en el sur: características, perspectivas, interrogantes. Alteridades, 3 (6), 5-11.

Krotz, E. (1995). La Crisis permanente de la antropología mexicana. Nueva Antropología, 14 (48), 10-18.

Krotz, E. (1996). La generación de teoría antropológica en América Latina: Silenciamientos, tensiones intrínsecas y puntos de partida. Revista Maguare, (11) 12, 25-39.

Krotz, E. (1997). Antropología mexicana actual y futura. Nueva Antropología, 15 (51), 12-22.

Krotz, E. (2002 [1994]). La otredad cultural entre utopía y ciencia. Un estudio sobre el origen, desarrollo y reorientación de la antropología. México: Fondo de Cultura Económica.

Krotz, E. (2006). La diversificación de la antropología universal a partir de las antropologías del sur. Boletín Antropológico, Universidad de los Andes, Venezuela, 24 (66), 7-20.

Kuhn, T. (1962 [2007]). La estructura de las revoluciones científicas. México: Fondo de Cultura Económica.

Kuper, A. (1973 [1996]). Anthropology and anthropologist. The Modern British School. New York: Routledge.

Kuper, A. (1999 [2001]). Cultura. La versión de los antropólogos. Barcelona: Paidós.

Kuwayama, T. (2004). Native Anthropology. The Japanese Challenge to Western Academic Hegemony. Melbourne: Trans Pacific Press. 
Labarías, M. y Hernando, J. (1998). Documentos auténticos de Rodolfo Lenz. Catálogo crítico. Cuadernos de la Facultad. Facultad de Historia, Geografía y Letras, Universidad Metropoloitana de las Ciencias de la Educación.

Lamo de Espinosa, E., J. M. García y C. Torres (1994). La sociología del conocimiento y de la ciencia. Madrid: Alianza Editorial.

Lamont, M. y Molnár, V. (2002). The Study of Boundaries in the Social Science. Annual Reviews Sociology, 28, 167-195. URL: http://arjournals.annualreviews.org. [11/12/2009].

Lander, E. (2000). Ciencias sociales: saberes eurocéntricos y coloniales. En Lander, E. (comp.). La colonialidad del saber: eurocentrismo y ciencias sociales, pp.11-40. Buenos Aires: Clacso.

Laplantine, F. (2010 [1996]). L'enquête et ses méthodes. La description ethnographique. Paris: Armand Colin.

Latcham, R. (1935). Boletín del Museo Nacional, Tomo XIV,

Latcham, R. (1936) Boletín del Museo Nacional, Tomo XV, 190.

Larraín, J. (2001). Identidad chilena. Santiago de Chile: LOM.

Lathrope, S. (1945). Richard E. Latcham 1869-1943. American Anthropologist, (47) 4, 603608. URL: http://www.jstor.org/stable/663378. Accessed: 18/5/2013.

Latour, B. y Woolgar, S. (1995 [1979]). La vida en el laboratorio. Madrid: Alianza.

Latoru, B. (1992). Ciencia en acción. Barcelona: Labor. 
Latoru, B. (2001 [1999]) La esperanza de Pandora. Ensayos sobre la realidad de la ciencia. Barcelona: Gedisa.

Latoru, B. (2008 [2005]). Reensamblar lo social. Una introducción a la teoría del actor-red. Buenos Aires: Manantial.

Latucca, L. (2001). Creating Interdisciplinarity. Interdisciplinary Research and Teaching among College and University Faculty. Nashville: Vanderbilt University press.

Lazzari, A. (2004). Antropología en el Estado: el Instituto Étnico Nacional (1946-1955). En: Neiburg, F. y M. Plotkin (comps.) Intelectuales y expertos. La constitución del conocimiento social en la Argentina (pp. 203-230). Buenos Aires: Paidós.

Leach, E. (1975). El método comparativo en antropología. En José Llobera (Ed.), La antropología como ciencia (pp.167-178). Barcelona: Anagrama.

L'École anthropolgie de Paris: 1876-1906 (1907). Paris: F. Alcan.

Lenz, R. (1909). Etnolojía i Folklore. En Programa de la Sociedad de Folklore Chileno. Santiago de Chile: Imprenta y Encuadernación Lourdes.

Lenz, R. (1918). Sobre el Estudio de los idiomas. Carta al Señor Julio Saavedra Molina. Anales de la Universidad de Chile, Tomo 142 ,173-239.

L'Estoile, B., Neiburg, F. y Sigaud, L. (2002). Antropologia, impérios e estados nacionais: uma abordagem comparativa. En: L'Estoile, B., Neiburg, F. \& Sigaud, L (Org.). Antropologia, Impérios e Estados Nacionais (pp. 9-37). Rio de Janeiro: Relume Dumara.

Lévi-Strauss, C. (1995[1968]). Antropología estructural. Barcelona: Paidós. 
Lévy, J. P. y Varela J (2004) (Eds). Análisis multivariante para la Ciencias sociales. Madrid: Pearson Educación.

Lewis, O. (1975). Controles y experimentos en el trabajo de campo. En José Llobera (Ed.), La antropología como ciencia (pp.97-128). Barcelona: Anagrama.

Linton, R. (1945 [1959]). Cultura y personalidad. México: Fondo de Cultura Económica.

Looser, G. (1939). Publicaciones chilenas sobre antropología, etnología, folklore, arqueología y lingüística. Boletín Bibliográfico de Antropología Americana, Instituto Panamericano de $\begin{array}{llll}\text { Geografia Historia, 228-230. } & \text { URL: }\end{array}$ http://www.jstor.org/stable/40976158?seq=1\#page_scan_tab_contents

Luque, E. (1985 [1990]). Del conocimiento antropológico. Madrid: Siglo XXI.

Llobera, J. (1974). Some Provisional Theses on the Nature of Anthropology. Critique of Anthropology, 1, 3-23.

Malinowski, B. (1929). Practical Anthropology. Africa. Journal of the International African Institute, 2 (1), 22-38.

Maltrás, B. (2003). Los indicadores bibliométricos. Fundamentos y aplicaciones al análisis de la ciencia. Gijón: Ediciones Trea.

Mair, L. (1970). Introducción a la antropología social. México: Alianza.

Marcus, G. y Cushman, D. (1992 [1982]). Las etnografías como textos. En Reynosos, C. (Comp.). El surgimiento de la antropología posmoderna (pp.171-213). Barcelona: Gedisa.

Marcuse, G. y Fischer, M. (2000 [1986]). La antropología como crítica cultural. Un momento experimental en las ciencias humanas. Buenos Aires: Amorrortu. 
Martin, O. (2001 [2000]). Sociología de las ciencias. Buenos Aires: Nueva Visión.

Martínez, J. (2007). Gualterio Looser Schallemberg. Un Naturalista Botánico (1898-1982). Revista Chilena de Historia Natural, 56, 91-95.

Martínez, C. (2007). Antropología indigenista en el ecuador desde la década de 1970: compromisos políticos, religiosos y tecnocráticos. Revista Colombiana de Antropología, (43), 335-366.

Martínez, H. (1990). Apuntes acerca de la evolución de la antropología en San Marcos. Revista Apuntes, 26, 59-76.

Martínez, S. (1986). Presentación. Índice de la Revista Chilena de Historia y Geografía. Santiago: Editorial Andrés Bello.

Matrurana, F. (2003). La antropología visual chilena fuera de foco. En Richard, N. (Ed.). Movimientos de campo en torno a cuatro fronteras de la antropología en Chile (pp.141-154). Guatemala: Ediciones ICAPI.

Matus, L. (1916). Las colecciones existentes en la sección de Antropología y Etnología del Museo Nacional. Boletín Museo Nacional, Tomo IX, 1, 134-140.

Mauss, M. (2006 [2002]). Manual de etnografía. México: Fondo de Cultura Económica.

Mead, M. (1984). Antropología, la ciencia del hombre. Paidós: Buenos Aires.

Medina, A. (1989). Crisis de la antropología y antropología de la crisis. Revista de la Coordinación de Estudios de Postgrado, Universidad Nacional Autónoma de México, (15). URL: http://www.posgrado.unam.mx/publicaciones/ant_omnia/15/ 
Medina, A. (1995). Los paradigmas de la antropología mexicana. Nueva Antropología, 14 (48), 19-37.

Medina, A. (2013). Estudio preliminar. La trama, los hilos y los nudos de un proyecto de investigación. La Universidad de Chicago en los Altos de Chiapas. En Guber, R. La articulación etnográfica. Descubrimiento y trabajo de campo en la investigación de Esther Hermitte (pp. 11-34). Buenos Aires: Biblos.

Melatti, J (1980). Situacao e problematica da antropología do Brasil. América Indígena, 11, (2), 225-279.

Melatti, J. (1983). A antropología no Brasil. Um roteiro. Serie Antropología, 38, Universidad de Brasilia.

Mellafe, R.; Rebolledo, A. y Cárdenas, M. (1992). Historia de la Universidad de Chile. Santiago de Chile: Ediciones Universidad de Chile.

Menéndez, E. (1991). Definiciones, indefiniciones y pequeños saberes. Alteridades, 1 (1), 21 32.

Mercier, P. (1966 [1969]). Historia de la antropología. Barcelona: Península.

Merton, R. (1977 [1973]). La sociología de la ciencia. Madrid: Alianza.

Merton, R. (1970 [1984]). Ciencia, tecnología y sociedad en la Inglaterra del siglo XVII. Madrid: Alianza.

Mignolo, W. (2000). La colonialidad a lo largo y a lo ancho: el hemisferio occidental en el horizonte colonial de la modernidad. En Lander, E. (comp.). La colonialidad del saber: eurocentrismo y ciencias sociales, pp.55-86. Buenos Aires: Clacso. 
Mignolo, W. (2002). Colonialidad global, capitalismo y hegemonía epistémica. En Walsh, C.; Schiwy, F. y S. Castro-Gómez. Indisciplinar las ciencias sociales. Geopolíticas del conocimiento y colonialidad del poder. Perspectivas desde lo andino (pp.215-244). Quito: Abya-yala.

Mingming, W. (2002). The Third Eye: Towards a Critique of the 'Nativist Anthropology', Critique of Anthropology 22 (2), 149-74.

Mitra, P. (1933). A History of American Anthropology. Calcuta: Calcuta University press.

Mitchell, C. (1966 [1999]). Orientaciones teóricas de los estudios urbanos en África. En Michael Banton (Ed.), Antropología social de las sociedades complejas (pp.53-81). Madrid: Alianza.

Mitchell, C. (1967 [1969]). On quantification in social anthropology. En Arnold L. Epstein (Ed.) The craft of social anthropology (pp.17-46). London: Tavistock.

Molina, A. (1999). El programa fuerte de la sociología de la ciencia. Un estudio crítico. Granada: Universidad de Granada.

Montané, J. (1963). Bibliografía selectiva de la Antropología Chilena. Primera Parte. La Serena: Museo de La Serena.

Montané, J. (1964). Bibliografía selectiva de la Antropología Chilena. Segunda Parte. La Serena: Museo de La Serena.

Montané, J. (1965a). Bibliografía selectiva de la Antropología Chilena. Tercera Parte. La Serena: Museo de La Serena.

Montané, J. (1965b). Bibliografía selectiva de la Antropología Chilena. Cuarta Parte. La Serena: Museo de La Serena. 
Moore, E. (1910). Informe del Museo Nacional. Boletín del Museo Nacional, Tomo I, 1, 4-13.

Mora, H. (2014). Descentrar las miradas. Institucionalización de la antropología académica en la sede Temuco de la Pontificia Universidad Católica de Chile (1970-1978). Tabula Rasa, 21, 197-227.

Morin, E. (2001). La cabeza bien puesta. Repensar la reforma reformar el pensamiento. Buenos Aires: Nueva Visión.

Moreno, S. (1992). Antropología ecuatoriana. Pasado y presente. Quito: Colección Primicias de la Cultura de Quito.

Mostny, G. (1980). El Museo Nacional de Historia Natural 1830-1980. Boletín del Museo Nacional de Historia Natural, 37, 5-7.

Mulkay, M. (1974). Conceptual displacement and migration in science: A prefatory paper. Science Studies, 4(3), 205-234.

Mulkay, M. (1977). Sociology of the scientific research community. In I. Spiegel-Rosing \& D. Price, (eds.), Science, technology, and society: A cross-disciplinary perspective (pp.93-148). London: Sage.

Mullins, N. (1968). The distribution of social and cultural properties in informal communication networks among biological scientists. American Sociological Review, 33(5), 786-797.

Mullins, N. (1972). The development of a scientific specialty: The phage group and the origins of molecular biology. Minerva, 10, 51-82. 
Munizaga, C. y Thomas, C. (1984). Breve análisis acerca de las investigaciones en antropología sociocultural y folklore circumpeñas. Definición de problemática y recientes aportes. Estudios Atacameños, 7, 363-371.

Murdock, P. (1975). Muestra etnográfica mundial. En José Llobera (Ed.), La antropología como ciencia (pp.203-230). Barcelona: Anagrama.

Name, M. (2012). La historia que construimos. Reflexiones a propósitos de una investigación sobre la historia de la antropología en la Argentina. Runa, 33 (1), 53-69.

Narayan, K. (1993). How Native is a 'Native' Anthropologist?, American Anthropologist, 95 (3), 671-86. URL: http://www.jstor.org/stable/679656 [Accessed: 12/02/2011]

Orellana, M. (1979). Compilación, introducción, notas y Bibliografía. En Oyarzún, A. Estudios antropológicos y arqueológicos. Santiago de Chile: Editorial Universitaria.

Orellana, M. (1991). Reflexiones sobre el desarrollo de la Arqueología en Chile. Revista Chilena de Antropología, (10), 11-23.

Orellana, M. (1996). Historia de la arqueología en Chile. Santiago: Bravo y Allende Editores.

Ortner, S. (1984). Theory in Anthropology since the Sixties. Comparative Studies in Society and History, 26 (1), 126-166.

Oyarzún, A. (1979). Estudios Antropológicos y Arqueológicos. Santiago: Editorial Universitaria.

Palerm, A. (2004). Historia de la etnología. Tylor y los profesionales. México: Editorial Universidad Iberoamericana. 
Palestrini, S., Ramos, C. y Canales, A. (2010). La producción de conocimiento antropológico social en Chile postransición: discontinuidades del pasado y debilidades del presente. Estudios Atacameños, 34, 101-120.

Palerm, A. (1967). Introducción a la teoría etnológica. México: Editorial Universidad Iberoamericana.

Palma, H. (2008). Filosofía de la Ciencia. Temas y problemas. San Martín: Universidad Nacional de San Martín.

Parkin, R. (2012 [2005]). Los países francoparlantes. En: Barth, F.; Parkin, R.; Silverman, S.; Gingrich, A. (2005 [2012]). Una disciplina, cuatro caminos. Antropología británica, alemana, francesa, estadounidense. Buenos Aires: Prometeo.

Pavez, J. (2012). Fetiches kongo, momias atacameñas y soberanía colonial. Trayectoria de Gustavo Le Paige s.j. (1903-1980). Estudios Atacameños, 44, 35-72.

Pavez, J. (2014). Disciplina científica colonial y coproducción etnográfica: Las expediciones de Martín Gusinde entre los yamana de Tierra del Fuego. Magallania, 40, 2, 61-87.

Pavez, J. (2015). Laboratorios etnográficos. Los archivos de la antropología en Chile (18801980). Santiago: Ediciones Alberto Hurtado.

Peacock, J. (1989). El enfoque de la antropología: luz intensa, foco difuso. Barcelona: Herder.

Pegoraro, A. y Spolinasky, B. (2013). El archivo del Museo Etnográfico Juan B. Ambrosetti: documentos para la historia institucional y disciplinar. Revista Electrónica de Fuentes y Archivos, 4 (4), 180-189. 
Peirano, M. (1981). The anthropolgy of anthropology: The Brazilian case. Tesis presentada para la obtención del grado de Doctor en Filosofía en el tema de Antropología, Universidad de Harvard.

Peirano, M. (1998). When the Anthropology is at Home: The Different Context of a Single Discipline. Annual Reviews of Anthropology, 27, 105-128.

Peirano, M. (1999). Alteridade em contexto: a antropología como ciencia social no Brasil. Série antropologia, 255, 2-35. Brasil: Brasilia.

Peirano, M. (2004). Otherness in context: a guía to anthropology in Brazil. Série antropologia, 348, 2-32. Brasil: Brasilia.

Peirano, M. (2008). Antropología sin culpa: una visión desde Brasil. En Degregori, C. y Sandoval, P. (Comp). Saberes periféricos. Ensayos sobre la antropología en América Latina (pp.227-247). Perú: Instituto de Estudios Peruanos.

Peña, N. (1902 [1716]). Prólogo del traductor. En Frazier, A. Relación del viaje por el mar del sur a las costas de Chile y Perú. Santiago de Chile: Imprenta Mejía.

Pereira, E. (1945). Los estudios folklóricos y el folklore musical en Chile. Revista Musical, (1) $1,4-12$.

Pérez, B. (2000). Rethinking Venezuelan Anthropology. Ethohistory, 47 (3-4), 513-533.

Pereyra, D. (2010). Los científicos sociales como empresarios académicos. En Pereyra, D. (Comp.). El desarrollo de las ciencias sociales. Tradiciones, actores e instituciones en Argentina, Chile, México y Centroamérica (pp. 35-54). Cuaderno de ciencias sociales 153, Facultad Latinoamericana de Ciencias Sociales, sede Costa Rica. 
Perry, J. (2006). Los caminos de la antropología en Colombia. Gregorio Hernández de Alba. Universidad de los Andes, Facultad de Ciencias Sociales, Departamento de Antropología, Centro de Estudios Socioculturales e Internacionales. Bogotá: Ediciones Uniandes.

Philippi, R. (19014). Historia del Museo Nacional de Chile. Boletín del Museo Nacional, Tomo VI, (1), 13-47.

Pineda, R. (2004). La escuela de antropología colombiana. Notas sobre la enseñanza de la antropología. Maguaré, 18, 59-85.

Pino, E. (1969). Historia de Temuco. Biografia de la capital de La Frontera. Temuco: Ediciones Universitarias de la Frontera.

Pinto, J. (2000). De la inclusión a la exclusión. La formación del Estado, la Nación y el pueblo Mapuche. Santiago de Chile: Universidad de Santiago de Chile.

Pinto J. (2010). Ignacio Domeyko. Viaje a La Araucanía en el año 1845 y otros documentos sobre la frontera. En Domeyko, I. Araucanía y sus habitantes. Santiago de Chile: Biblioteca Fundamentos de la Constricción de Chile.

Podgorny, I. (1995). De razón a facultad. Ideas acerca de las funciones del Museo de La Plata en el periodo 1890-1918. Runa, 22, 89-104.

Podgorny, I. (2008). Los medios de la arqueología. Revista Redes, (28), 97-111.

Podgorny, I., Farro, M. Martínez, A. y Ballestero, D. (2014). Caballeros de la noche. Antropología y museos en la Argentina de las últimas décadas del siglo XIX (pp. 201-228). En Carreras, S. y Carrillo, K. (Coord.). Las ciencias en la formación de las naciones americanas. Berlín: Iberoamericana. 
Porter, C. (1906) Literatura antropolójica y etnolójica de Chile. Revista Chilena de Historia Natural, 10 (2), 101-127.

Porter, C. (1909) Estado actual de las Ciencias Antropológicas en Chile. Revista Chilena de Historia Natural, 13 (1), 110-122.

Porter, C. (1910). Le éstudes anthropolgique au Chili. Journal de la Société des Américanistes, (7): 203-219.

Porter, C. (1931). Notas bibliográfica. Los estudios sobre las ciencias naturales relativos a países extranjeros publicados en Chile. Anales de la Universidad de Chile, 7, 540-547.

Price, D. (1963). Little science, big science. New York: Columbia University Press.

Pirce, S (1991). Subject areas, disciplines and the concept of authority. LISR [Library and Information Science Research], 13, 21-35.

Prego, C. (1992). Las bases sociales del conocimiento científico. La revolución cognitiva en sociología de la ciencia. Buenos Aires: Centro Editor de América Latina.

Quijano, A. (2000). Colonialidad del poder, eurocentrismo y América Latina. En Lander, E. (comp.). La colonialidad del saber: eurocentrismo y ciencias sociales, pp.201-246. Buenos Aires: Clacso.

Radcliffe-Brown, A. (1975). Antropología social. En José Llobera (Ed.), La antropología como ciencia (pp.47-76). Barcelona: Anagrama.

Ramírez, P. (2011). Reflexiones sobre la enseñanza de la antropología social en México. Alteridades, 21 (41), 79-96. 
Ratier, H. y Guebel, C. (2004). Las antropologías argentina y brasileña según algunos testimonios: exilios, tránsitos y permanencias. Raízes, 23 (1-2), 140-158.

Reeves, P. (2000 [2002]). El paradigma etnográfico. En Catalina Denman \& Jesús Haro (Eds.), Por los rincones. Antología de métodos cualitativos en investigación social (pp.207226). Sonora: Colegio de Sonora.

Rencoret, B. (1875). Apuntes que debe acompañar a la colección arqueológica americana que el R. P. Visitador apostólico Fr. Benjamín Reconret manda a la exposición internacional de Chile. Quito: Imprenta Nacional.

Restrepo, E. y Escobar, A. (2004). Antropologías en el mundo. Jangwa Pana, 3, 110-131.

(2005). Other Anthropologies and Anthropology Otherwise. Step to a World Anthropologies framework. Critique of Anthropology, 25 (2), 99-129.

Restrepo, E. (2007). Antropología y colonialidad. En: Castro-Gómez, S. y Grosfoguel, R. (eds.), El giro decolonial. Reflexiones para una diversidad epistémica más allá del capitalismo global (p.p 289-304). Siglo del Hombre, Iesco-Pensar.

Rex González, A. (1992). A cuatro décadas del comienzo de una etapa. Apuntes marginales para la historia de la antropología Argentina. Runa, 20, 91-110.

Reyna, J. (2004). La institucionalización y profesionalización de las Ciencias Sociales en América Latina. Estudios Sociológicos, 21 (2), 483-493.

Reynoso, C. (1998). Corrientes antropológicas contemporáneas. Buenos Aires: Biblos.

Ribeiro de Andrade, A. (2007). Para que servem os estudios sociais da ciência na América Latina? Revista Redes, 13 (26), 65-73. 
Ribeiro, G. (1988). Caminos de la antropología en Brasil. Contribución para una interpretación cultural mutua. Runa 17 (17), 65-82.

Ribeiro, G. (2004). A antropologia brasileira entre políticas neoliberais e a globalizacao. Série Antropologia, 367, 2-15.

Ribeiro, G. (2007). World Anthropologies. Cosmopolitics for a New Global Scenario in Anthropology. Critics of Anthropology, 26 (4): 363-386.

Richard, N. (2003). Introducción. En Rchard, N. (Ed.). Movimientos de campo en torno a cuatro fronteras de la antropología en Chile (pp.11-23). Guatemala: Ediciones ICAPI.

Richards, S. (1987 [1983]). Filosofía y sociología de la ciencia. México, Siglo xxI.

Rivers, W. H. (1913). Report on anthropological research outside America. En Williams Rivers, Albert E. Jenks \& Sylvanus G. Morley (Eds.), Reports on the present condition and future needs of the science of anthropology (pp.5-28). Washington, DC: Carnegie Institution, http://classes.yale.edu/0304/anth500b/projects/project_sites/99_Song/Rivers1913.htm

Robles, R. (2008). Balance del desarrollo de la antropología en la region de Lima desde la Universidad Nacional Mayor de San Marcos. En Diez, A. (Coord.). La antropología ante el perú de hoy: Balances regionales y antropologías latinoamericanas (pp. 37-66). Lima: Pontificia Universidad Católica del Perú.

Rodríguez, R. y González, A. (2007). Estudio introductorio. En Ruiz, H. Relación del viaje hecho a los reinos del Perú y Chile. Madrid: Catarata.

Rosaldo, R. (2004) Reflexiones sobre la interdisciplinariedad. Revista de Antropología Social, Universidad Complutense de Madrid, 13, 197-215. 
Rossi, I. y O’Higgins, E. (1980 [1981]). Teorías de la cultura y métodos antropológicos. Barcelona: Anagrama.

Sadler, M. y Acuña, M. (2003). Traslaciones y aproximaciones: desarrollo de la antropología del género. En Richard, N. (Ed.). Movimientos de campo en torno a cuatro fronteras de la antropología en Chile (pp.211-224). Guatemala: Ediciones ICAPI.

Sagasti, F. y Pavéz, A. (1989). Ciencias y tecnología en América Latina a principios del siglo XX: Primer congreso científico panamericano. Quipu, 6 (2), 189-216.

Sagredo, R. (2007) De la historia natural a la historia nacional. La historia física y política de Claudio Gay y la nación chilena. En Gay, C. Historia fisica y política de Chile. Historia Tomo I. Santiago de Chile: Biblioteca Fundamentos de la Constricción de Chile.

Salazar, C. (2007). No hay antropología más diversa: La antropología francesa en los Andes peruanos. Saberes periféricos: Ensayos sobre la antropología en América Latina (pp. 153200). Lima: Instituto de estudios Peruanos.

Saldivia, Z. (2004). La ciencia en el Chile decimonónico. Santiago de Chile: Ediciones Universidad Tecnológica Metropolitana.

Salomon, (2008). Los cientificos. Entre el poder y saber. Bernal: Universidad Nacional de Quilmes.

Samaniego, A. y Ruiz, C. (2007). Mentalidades y politicas wingka. Pueblo Mapuche, entre golpe y golpe (De Ibañez a Pinochet). Madrid: Consejo Superior de Investigaciones Científicas.

Sánchez, M. (1984). Introducción. Boletín Museo Regional de la Araucanía. Dirección de Bibliotecas, Archivos y Museos, Ministerio de Educación Pública, 1, 7-10. 
Subercaseaux, B. 2002. Nación y Cultura en América Latina. Diversidad cultural y Globalización. Santiago de Chile, LOM.

Schaedel, R. (1990). Homenaje a Alberto Medina Rojas. Revista Chilena de Antropología, 9: $11-13$.

Schaffner, A. (1994). The future of scientific journals: lessons from the past. Information Technology and Libraries, 13 (4), 239-247.

Serrano, S. (1994). Universidad y Nación. Chile en el siglo XIX. Santiago de Chile: Editorial Universitaria.

Shils, E. (1970). Tradition, Ecology, and Institution in the History of Sociology. Daedalus. The Making of Modern Science: Biographical Studies, 99, (4), 760-825. URL: http://www.jstor.org/stable/20023974

Schell, P. (2009). Museos, exposiciones y la muestra de lo chileno en el siglo XIX. En Cid, G, y San Francisco, G. (Eds.). Nación y Nacionalismo en Chile. Siglo XIX. Vol I. Chile: Centro de Estudios Bicentenario.

Siler, K. (2005). Whither Disciplines? Consequences and Functions of The Disciplinary Organization of Knowedge in Academia. Paper presented at the annual meeting of the American Sociological Association, Marriott Hotel, Loews Philadelphia Hotel, Philadelphia, PA, diciembre de 2004. URL: http://www.allacademic.com/meta/p22921 index.html [Accessed: 05/06/2009].

Silver, H. (2003). Does a University Have a Culture?. Studies in Higher Education, 28, (2), 157-169. URL: http://www.youtem.com/module2/silver.pdf [Accessed: 08/01/2009].

Soprano, G. (2006). Continuidad y cambio en los estudios en etnología de poblaciones indígenas contemporáneas y comunidades folk en la Facultad de Ciencias Naturales y Museo 
de la Universidad Nacional de La Plata (1930-1976). Anuario de Estudios en Antropología Social, CAS-IDES, 23-51.

Soprano, G. (2008) Política, instituciones y trayectorias académicas en la universidad argentina. Antropólogos y antropología en la Universidad Nacional de La Plata entre las décadas de 1930 y 1960. En: Mazzola, C.; Marquina, M.; Soprano, G. (Eds.). Proyectos, instituciones y protagonistas de la universidad argentina. Universidad Nacional Sarmiento: Prometeo.

Soprano, G. (2009). Autonomía universitaria e intervención política en la trayectoria de liderazgos y grupos académicos en Ciencias Naturales de la Universidad Nacional de La Plata 1930-1955. Anuario del Instituto de Historia Argentina, Facultad de Humanidades y Ciencias de la Educación, Universidad Nacional de La Plata, (9), 97-147.

Stagnaro, A. (1993). La antropología en la comunidad científica: entre el origen del hombre y la caza de cráneos-trofeos (1870-1910). Alteridades, 3 (6), 53-65.

Stichweh, R. (2001). Scientific Disciplines, History of. En Smelser, N. J. \& Baltes, P. B. (eds.). International Encyclopedia of the Social and Behavioral Sciences. (pp. 13727-13731). Oxford: Elsevier Science.

Stocking, G. (1982). Afterword: A View from the Center. Ethnos, 47 (1), 173-186.

Stocking, G. (2002). Delimitando la antropología: reflexiones históricas acerca de las fronteras de una disciplina sin fronteras. Revista de Antropología Social, (2), 11-38.

Storer, N. (1966). The social system of science. New York: Holt, Rinehart \& Winston. Strauss, A. \& Corbin, J. (1998 [2002]). Bases de la investigación cualitativa. Técnicas y procedimientos para desarrollar la teoría fundamentada. Medellín: Editorial Universidad de Antioquia. 
Sztompka, P. (2009). One sociology or many?. En Patel, S. (Ed.). The Isa Handbook of Diverse Sociological Traditions. Sage: Los Angeles.

Shumway, D. R. y E. Messer-Davidow (1991). Disciplinarity: An Introduction. Poetics Today, 12 (2): 201-225.

Thompson, L. (1961 [1965]). Hacia una ciencia del hombre. Roble: México.

Trinchero, H. (2007). Aromas de lo exótico (Retornos al objeto). Para una crítica del objeto antropológico y sus modos de reproducción. Buenos Aires: SB.

Trindade, H. (2007). Las ciencias sociales en Brasil. Fundación, consolidación y expansión. En Trindade, H. (Coord.) Las ciencias sociales en América latina. Perspectiva comparada (109-192). México: Siglo XXI.

Troncoso, A., Salazar, D. y Jackson, D. (2008). Arqueología suramericana, 4 (2), 122-154.

Toulmin, S. (1977 [1972]). La Comprensión humana I. El uso colectivo y la evolución de los conceptos. Madrid: Alianza.

Tylor, E. (1889) On a Method of Investigating the Development of Institutions; Applied to Laws of Marriage and Descent. The Journal of the Anthropological Institute of Great Britain and Ireland (18): 245-272. URL: http://www.jstor.org/stable/2842423 (14 de mayo de 2010). Ulin, R. (1984 [1990]). Antropología y teoría social. México: Siglo XXI

Uribe, C. (1980). La antropología en Colombia. América Indígena, 11, (2), 280-308.

Urry, J. (1984). A history of field methods. En Roy Ellen (Ed.), Ethnographic research. A guide to general conduct (pp.35-62). London: Academic press. 
Valderrama, R. y Escalante, C. (2008). Balance de las investigaciones antropológicas en el Cusco. En Diez, A. (Coord.). La antropología ante el perú de hoy: Balances regionales y antropologías latinoamericanas (pp. 67-82). Lima: Pontificia Universidad Católica del Perú.

Valcárcel, L. (1981). Memorias. Lima: Instituto de Estudios Peruanos.

Valero, J. (2004). Sociología de la ciencia: un análisis posmertoniano. En Valero, J. (Coord.). Sociología de la ciencia (pp.81-137). Madrid: Edaf.

Vanti, N. (2000). Métodos cuantitativos de evaluación de la ciencia: bibliometría, cienciometría e infometría. Investigación bibliotecológica, 14 (29), 9-23.

Visacovsky, S. Guber, R. y Gurevich, E. (1997). Modernidad y tradición en el origen de la carrera de Ciencias Antropológicas de la Universidad de Buenos Aires. Revista Redes, 4 (10), 213-257.

Vessuri, H (1993). Intercambios internacionales y estilos nacionales periféricos: aspectos de la mundialización de la ciencia. En: Lafuente, A. Elena, A. y Ortega, M. (Eds). Mundialización de la ciencia y cultura nacional, pp. 725-733. Madrid: Editorial Doce.

Vessuri, H. (1996). ¿Estilos nacionales en antropología? Reflexiones a partir de la sociología de la ciencia. Maguare, 11 (12), 58-73.

Vessuri, H. (2007). “O inventamos o erramos." La ciencia como idea-fuerza en América Latina”. Bernal: Editorial Universidad Nacional de Quilmes.

Vicuña Mackenna, B. (1874). Álbum del Santa Lucía. Colección de las principales vistas, monumentos, jardines, estatuas i obras de arte de este paseo. Santiago de Chile: Imprenta de la Librería del Mercurio. 
Vidich, A. y Lyman, S. (1994). Qualitative methods, their history in sociology and anthropology. En: Norman Denzin \& Yvonna Lincoln (Eds.), Handbook of qualitative research (pp.22-44). Thousand Oaks: Sage.

Visacovsky, S. Guber, R. y Gurevich, E. (1997). Modernidad y tradición en el origen de la carrera de Ciencias Antropológicas de la Universidad de Buenos Aires. Revista Redes, 4 (10), 213-257.

Wallerstein, I. (2005 [2004]). Las incertidumbres del saber. Barcelona: Gedisa.

Warman, A., Nolasco, M., Bonfil, G., Olivera de Vásquez, M., y Valencia, E. (1970). De eso que llaman antropología mexicana. México: Nuestro Tiempo.

Whitley, R. (2000 [1984]). The intellectual and social organization of the sciences. Oxford: Oxford University press.

Woolgar, S. (1991 [1988]). Ciencia: Abriendo la caja negra. Barcelona: Anthropos.

Wolf, Eric (1984). Culture: panacea or problem?. American Antiquity, 49 (2), 393-400.

Walsh, C. (2002). Las geopolíticas del conocimiento y la colinialidad de saber. Entrevista a Walter Mignolo. En Walsh, C.; Schiwy, F. y S. Castro-Gómez. Indisciplinar las ciencias sociales. Geopolíticas del conocimiento y colonialidad del poder. Perspectivas desde lo andino (pp.17-44). Quito: Abya-yala.

Yañez, P. (1950). El profesor Carlos Oliver Schneider, un precursor de la Bilogía Marina en Chile. Revista de Biología Marina, (2), 2 y 3, 97-116.

Zabalza, M. (1987). Diseño y desarrollo curricular para profesores de enseñanza básica. Madrid: Narea. 


\section{Anexo}

\section{Lista de artículos analizados}

\begin{tabular}{|c|c|c|c|}
\hline Artículo & Autor & Revista & Año \\
\hline Notas sobre algunos antiguos cráneos chilenos y otros aspectos & Latcham & RCHHN & 1903 \\
\hline Hasta dónde alcanzó el dominio efectivo de los incas en Chile & Latcham & RCHHN & 1908 \\
\hline El comercio precolombino en Chile y otros países. & Latcham & $\mathrm{AUCH}$ & 1909 \\
\hline La fiesta de Andacollo y sus danzas & Latcham & $\mathrm{AUCH}$ & 1910 \\
\hline Quienes eran los Changos & Latcham & AUCH & 1910 \\
\hline Capítulo de la prehistoria Chilena & Latcham & RCHHN & 1910 \\
\hline Los cráneos de paredes gruesas & Latcham & RHYG & 1912 \\
\hline Elementos indígenas de la raza chilena & Latcham & RHYG & 1912 \\
\hline Una metrópoli prehistórica en la América del Sur & Latcham & RHYG & 1914 \\
\hline Una estación paleolítica en Tal Tal & Latcham & RHYG & 1915 \\
\hline Capacidad guerrera de los araucanos. Usa armas y métodos militares. & Latcham & RHYG & 1915 \\
\hline Uso y preparación de pieles entre los indios de Chile y otros países de Sudamérica & Latcham & RHYG & 1915 \\
\hline Costumbres mortuorias de los indios de Chile y otras partes de América & Latcham & AUCH & 1915 \\
\hline Costumbres mortuorias de los indios de Chile y otras partes de América (Continuación 1). & Latcham & $\mathrm{AUCH}$ & 1915 \\
\hline Costumbres mortuorias de los indios de Chile y otras partes de América (Continuación 2). & Latcham & $\mathrm{AUCH}$ & 1915 \\
\hline Costumbres mortuorias de los indios de Chile y otras partes de América (Continuación 3). & Latcham & $\mathrm{AUCH}$ & 1915 \\
\hline Costumbres mortuorias de los indios de Chile y otras partes de América (Continuación 4). & Latcham & $\mathrm{AUCH}$ & 1916 \\
\hline Costumbres mortuorias de los indios de Chile y otras partes de América (Continuación 5). & Latcham & AUCH & 1916 \\
\hline La existencia de la propiedad en el antiguo imperio de los Incas. & Latcham & $\mathrm{AUCH}$ & 1922 \\
\hline El perro doméstico en Chile & Latcham & RHYG & 1922 \\
\hline El perro doméstico en América precolombina & Latcham & RHYG & 1922 \\
\hline Historia Natural de los mitos araucanos & Latcham & RCHHN & 1923 \\
\hline Creencias religiosas de los araucanos & Latcham & RHYG & 1923 \\
\hline ¿Quién era mancocapac? & Latcham & RHYG & 1924 \\
\hline La historia natural en la alfarería chilena & Latcham & RCHHN & 1925 \\
\hline Los indios antiguos de Copiapó y Coquimbo & Latcham & $\mathrm{AACHCN}$ & 1926 \\
\hline El culto del tigre entre los antiguos pueblos andinos & Latcham & RCHHN & 1926 \\
\hline Las influencias de la cultura Tiahuanaco en la antigua alfarería & Latcham & $\mathrm{AACHCN}$ & 1927 \\
\hline Tembetá hallada en una sepultura indígena chilena & Latcham & $\mathrm{RCHHN}$ & 1927 \\
\hline El trinacrio o trisquelión en la alfarería chileno-argentina & Latcham & RCHHN & 1927 \\
\hline Las influencias chinchas en la antigua alfarería chilena & Latcham & RCHHN & 1927 \\
\hline El dominio de la tierra y el sistema tributario en él antiguo imperio de los Incas & Latcham & RHYG & 1927 \\
\hline La alfarería de los antiguos atacameños & Latcham & $\mathrm{AACHCN}$ & 1927 \\
\hline Alfarería negra de la región atacameña & Latcham & AACHCN & 1927 \\
\hline El problema de los orígenes araucanos & Latcham & $\mathrm{AACHCN}$ & 1927 \\
\hline La cronología de las culturas indígenas de Chile & Latcham & AACHCN & 1927 \\
\hline
\end{tabular}


Tubos para aspirar rapé, con decoración centroamericana

Los incas su origen y sus ayllus 1

Los incas su origen y sus ayllus 2

Los incas su origen y sus ayllus 3

Los incas su origen y sus ayllus 4

Notas preliminares sobre las excavaciones arqueológicas de tiltil

Chile prehispano

Las creencias religiosas de los antiguos peruanos 1

Las creencias religiosas de los antiguos peruanos 2

Las creencias religiosas de los antiguos peruanos 3

Las creencias religiosas de los antiguos peruanos 4

Notas sobre alfarería de Tal tal

Figuras que parecen geroglifos en la alfarería Proto-Nazca

Los indios de la cordillera y la pampa en el siglo XVI 1

Los indios de la Cordillera y la pampa en el siglo XVI 2

Las piedras de tacitas de Chile y la Argentina

Las creencias religiosas de los antiguos peruanos 5

Las creencias religiosas de los antiguos peruanos 6

Las creencias religiosas de los antiguos peruanos 7

Las creencias religiosas de los antiguos peruanos 8

Influencias atacameñas en las antigua alfarería diaguita-chilena

Los indios de la Cordillera y la pampa en el siglo XVI 3

La dalca de Chiloé y los canales patagónicos

Nuevas notas sobre la alfarería de Tal Tal

Alfarería diaguita arcaica

Alfarería del nuevo tipo del valle de ica

Notas preliminares sobre un viaje arqueológico a Quillagua

Alfarería Arcaica de Ica

Alfarería de Ica

Notas sobre la alfarería atacameña

Ruinas preincaicas en el norte de Chile.

Metalurgia atacameña. Objetos de bronce y de cobre

Alfarería proto chimu en el Museo Nacional de Chile

Arqueología de los indios diaguitas

Algunos tipos de alfarería Diaguita

Tejidos atacameños

La edad de piedra en tal-tal

Algunos tejidos atacameños

Observaciones acerca de la cultura del Molle

Antropografía prehistórica del Norte de Chile.

Noticias sobre la agricultura de la provincia de Tarapacá

\begin{tabular}{|c|c|c|}
\hline Latcham & RCHHN & 1927 \\
\hline Latcham & $\mathrm{AUCH}$ & 1928 \\
\hline Latcham & $\mathrm{AUCH}$ & 1928 \\
\hline Latcham & AUCH & 1928 \\
\hline Latcham & $\mathrm{AUCH}$ & 1928 \\
\hline Latcham & RCHHN & 1928 \\
\hline Latcham & RHYG & 1928 \\
\hline Latcham & AUCH & 1929 \\
\hline Latcham & AUCH & 1929 \\
\hline Latcham & $\mathrm{AUCH}$ & 1929 \\
\hline Latcham & AUCH & 1929 \\
\hline Latcham & RCHHN & 1929 \\
\hline Latcham & BMHN & 1929 \\
\hline Latcham & RHYG & 1929 \\
\hline Latcham & RHYG & 1929 \\
\hline Latcham & AACHCN & 1929 \\
\hline Latcham & AUCH & 1930 \\
\hline Latcham & AUCH & 1930 \\
\hline Latcham & AUCH & 1930 \\
\hline Latcham & $\mathrm{AUCH}$ & 1930 \\
\hline Latcham & RCHHN & 1930 \\
\hline Latcham & RHYG & 1930 \\
\hline Latcham & BMHN & 1930 \\
\hline Latcham & RCHHN & 1931 \\
\hline Latcham & RCHHN & 1932 \\
\hline Latcham & RCHHN & 1933 \\
\hline Latcham & RCHHN & 1933 \\
\hline Latcham & RCHHN & 1934 \\
\hline Latcham & RCHHN & 1935 \\
\hline Latcham & RCHHN & 1936 \\
\hline Latcham & BMHN & 1936 \\
\hline Latcham & BMHN & 1936 \\
\hline Latcham & RCHHN & 1937 \\
\hline Latcham & BMHN & 1937 \\
\hline Latcham & RCHHN & 1938 \\
\hline Latcham & RCHHN & 1939 \\
\hline Latcham & BMHN & 1939 \\
\hline Latcham & RCHHN & 1940 \\
\hline Latcham & BMHN & 1940 \\
\hline Latcham & BMHN & 1942 \\
\hline Cañas Pinochet & $\mathrm{ASCCH}$ & 1901 \\
\hline
\end{tabular}


Noticias sobre los guajiros

La religión en los pueblos primitivos; el culto a la piedra en Chile y como se hallaba

difundida por el globo

Estudios etimológicos de palabras indígenas usadas en el lenguaje vulgar que se habla en

Chile.

Noticias sobre los guajiros

La deformación artificial de los cráneos

Un punto en la prehistoria de Chile. Hasta donde alcanzaron la definitiva dominación los incas.

Las piedras horadadas

La lengua Veliche. Su probable origen

Pequeño diccionario de la lengua Veliche

La lengua Veliche. Sus caracteres principales.

En la edad de piedra, un punto de la arqueología prehistórica argentina

Nuevas opiniones sobre el origen y sitios de aparición del hombre

Arqueología sudamericana

Los indios atacameños

Tableta de madera Chiu-chiu

Los tubos y tabletas de rapé en Chile

Sobre la estación paleolítica de Tal Tal

Sobre la estación paleolítica de Tal Tal

Fortalezas incaicas: Incallacata-Machupichu

Los aborígenes de Arica y el hombre americano

El problema paleolítico americano.

Antropología americana. Una cabeza humana adorada como dios entre los jíbaros.

La isla de Pascua y sus habitantes

De las escritura Jeroglífica de los indígenas de las Isla de Pascua

Descripción de los ídolos peruanos del Museo Nacional

Sobre las piedras horadadas de Chile

Aborígenes del Perú

Aborígenes chilenos. Artículo sobre un pretendido ídolo de ellos.

Artículos sobre la momia egipcia

Observaciones sobre una clase de ornamentación pehistórica y sobre pinzas prehistóricas

Noticias y comentarios arqueológicos

Los chiles. Arqueología de chalinga

Origen de los cetros en Chile

El primitivo ecuador terrestre y el origen polar del hombre

Observaciones sobre conchales de Talcahuano

Una interesante colección arqueológica de Ovalle

Nuevos hallazgos arqueológicos de la cultura el Molle

Un hacha de piedra de forma no común

Revisión de los petroglifos del valle del río Hurtado

Revisión de los petroglifos del valle del río Hurtado II

\begin{tabular}{|c|c|c|}
\hline Cañas Pinochet & $\mathrm{ASCCH}$ & 1901 \\
\hline Cañas Pinochet & $\mathrm{ASCCH}$ & 1902 \\
\hline Cañas Pinochet & $\mathrm{ASCCH}$ & 1902 \\
\hline Cañas Pinochet & RCHHN & 1902 \\
\hline Cañas Pinochet & $\mathrm{ASCCH}$ & 1903 \\
\hline Cañas Pinochet & $\mathrm{ASCCH}$ & 1903 \\
\hline Cañas Pinochet & $\mathrm{ASCCH}$ & 1903 \\
\hline Cañas Pinochet & $\mathrm{ASCCH}$ & 1904 \\
\hline Cañas Pinochet & $\mathrm{ASCCH}$ & 1905 \\
\hline Cañas Pinochet & $\mathrm{ASCCH}$ & 1905 \\
\hline Cañas Pinochet & RCHHN & 1908 \\
\hline Cañas Pinochet & $\mathrm{ASCCH}$ & 1918 \\
\hline Uhle & RHYG & 1912 \\
\hline Uhle & RHYG & 1913 \\
\hline Uhle & RHYG & 1913 \\
\hline Uhle & RHYG & 1915 \\
\hline Uhle & RHYG & 1916 \\
\hline Uhle & RMEA & 1916 \\
\hline Uhle & RHYG & 1917 \\
\hline Uhle & RHYG & 1918 \\
\hline Uhle & RHYG & 1929 \\
\hline Philippi & $\mathrm{AUCH}$ & 1872 \\
\hline Philippi & AUCH & 1873 \\
\hline Philippi & $\mathrm{AUCH}$ & 1875 \\
\hline Philippi & AUCH & 1879 \\
\hline Philippi & $\mathrm{AUCH}$ & 1884 \\
\hline Philippi & $\mathrm{AUCH}$ & 1886 \\
\hline Philippi & $\mathrm{AUCH}$ & 1886 \\
\hline Philippi & $\mathrm{AUCH}$ & 1886 \\
\hline Philippi & $\mathrm{AUCH}$ & 1889 \\
\hline Rengifo & $\mathrm{ASCCH}$ & 1919 \\
\hline Rengifo & $\mathrm{ASCCH}$ & 1920 \\
\hline Rengifo & $\mathrm{ASCCH}$ & 1920 \\
\hline Rengifo & $\mathrm{ASCCH}$ & 1920 \\
\hline Rengifo & $\mathrm{ASCCH}$ & 1935 \\
\hline Iribarren & $\mathrm{AACHCN}$ & 1949 \\
\hline Iribarren & AACHCN & 1952 \\
\hline Iribarren & $\mathrm{AACHCN}$ & 1953 \\
\hline Iribarren & $\mathrm{AACHCN}$ & 1954 \\
\hline Iribarren & AACHCN & 1954 \\
\hline
\end{tabular}




\begin{tabular}{|c|c|c|c|}
\hline $\begin{array}{l}\text { Los petroglifos de las estancias Zorrilla y Las Peñas en departamento de Ovalle y una } \\
\text { teoría de vinculación cronológica }\end{array}$ & Iribarren & AACHCN & 1954 \\
\hline Las tabletas para tomar rape del museo nacional & Looser & RCHHN & 1926 \\
\hline Notas sobre alfarería chilena & Looser & RCHHN & 1926 \\
\hline Supervivencia prehispánicas en Chile central moderno & Looser & RCHHN & 1927 \\
\hline Sobre algunos objetos que venden los habitantes de las islas de Juan Fernández & Looser & RCHHN & 1927 \\
\hline Las variantes de la greca en los tejidos araucanos & Looser & RCHHN & 1928 \\
\hline Dos cráneos marcados y otros objetos de la isla de Pascua & Looser & RCHHN & 1928 \\
\hline Algunos petroglifos de la provincia de Coquimbo & Looser & RCHHN & 1929 \\
\hline La representación de figuras humanas y de animales por los araucanos. & Looser & BMHN & 1929 \\
\hline Notas de arqueología chilena & Looser & BMHN & 1930 \\
\hline Una estatua araucana notable & Looser & RCHHN & 1930 \\
\hline Algunos interesantes vasos de piedra de la arqueología chilena & Looser & $\mathrm{AACHCN}$ & 1931 \\
\hline Objetos etnológicos fueguinos & Looser & RCHHN & 1931 \\
\hline Estatuita de piedra hallada en la isla de Chiloé & Looser & RCHHN & 1932 \\
\hline Los misteriosos túmulos de Copiapó & Looser & RCHHN & 1934 \\
\hline Objetos líticos ictioformos de la arqueología chilena & Looser & RCHHN & 1935 \\
\hline Balsa de cuero de lobos de la costa de Chile & Looser & RCHHN & 1938 \\
\hline Esbozos sobre los estudios de los indios de Chile & Looser & $\mathrm{AACHCN}$ & 1954 \\
\hline La piedra de la Huaca & Barros Grez & $\mathrm{ASCCH}$ & 1893 \\
\hline La piedra del Olimpo & Barros Grez & ASCCH & 1893 \\
\hline La piedra del Olimpo & Barros Grez & $\mathrm{ASCCH}$ & 1893 \\
\hline Los gerorglífos de la piedra de la batalla & Barros Grez & $\mathrm{ASCCH}$ & 1893 \\
\hline Le escritura entre los cañaris & Barros Grez & $\mathrm{ASCCH}$ & 1893 \\
\hline Escritura de los colchaquis & Barros Grez & $\mathrm{ASCCH}$ & 1894 \\
\hline El dios viracocha & Barros Grez & ASCCH & 1895 \\
\hline El pilar esculpido del subterráneo de Chavin & Barros Grez & $\mathrm{ASCCH}$ & 1902 \\
\hline Una maza polinésica hallada entre los araucanos & Fontecilla & RCHHN & 1934 \\
\hline Insignia lítica hallada en Linares & Fontecilla & RCHHN & 1935 \\
\hline Contribución al estudio sobre petroglifos cordilleranos & Fontecilla & RCHHN & 1936 \\
\hline Datos históricos sobre la isla de Pascua & Fontecilla & RCHHN & 1938 \\
\hline Tras de describir el misterio de la isla de Pascua & Fontecilla & RCHHN & 1939 \\
\hline Un cántaro antiguo de Angol & Bullock & RCHHN & 1927 \\
\hline Un cántaro para pintura & Bullock & $\mathrm{AACHCN}$ & 1936 \\
\hline Estatuas de piedra de Angol & Bullock & RCHHN & 1936 \\
\hline Algunos tipos de cachimbas antiguas chilenas & Bullock & BMHN & 1944 \\
\hline Dos cántaros de tipo peruano encatrados en Angol y Carahue & Bullock & ASBC & 1949 \\
\hline Un estatua de piedra de Nahuelbuta & Bullock & $\mathrm{ASBC}$ & 1952 \\
\hline Contribución al estudio de la civilización peruana sobre los aborígenes de Chile & Oyarzún & BMHN & 1910 \\
\hline Los petroglifos del Llaima & Oyarzún & BMHN & 1910 \\
\hline El trincario & Oyarzún & RHYG & 1912 \\
\hline Estación paleolítica de Tal Tal & Oyarzún & RHYG & 1916 \\
\hline
\end{tabular}


Estación paleolítica de Tal Tal

La sangre en las creencias y costumbres de los antiguos araucanos

Cay cay y ten ten, o sea, tradición del diluvio universal

La piedra santa de retricura

Los aborígenes de Chile

Los aborígenes de la Tierra del Fuego y de la Patagonia Occidental.

Cestería de los antiguos atacameños

Las tabletas y los tubos para preparar la paricá en Atacama.

Los Onas o Selknam de tierra del fuego

La quinoa

Contribución a la arqueología chilena

Observaciones sobre la fabricación de alfarería en Chañaral de Carén. Provincia de

Coquimbo

La alfarería chilena de Coquimbo considerada desde el punto de vista decorativo

El niño fueguino y su educación

Tembetas encontrados en el norte de Chile

Una superviviente prehispánica en Chile

Sobre un objeto enigmático de los conchales chilenos

Contribuciones a la arqueología chilena

Dos tupus de cobre encontrados en la región de Valdivia

Antropofagia entre los primitivos mapuches

Tres canciones infantiles mapuches de la región de Boroa

Descripción de una clava cefaloforma de piedra encontrada en Casa Blanca

Petroglifos de Elqui.

Pideras de tacitas o de mortero del valle de Casablanca

Las piedras perforadas

Pueblos prehistóricos de la zona marítima de tal-tal

Cómo descubrí la industria paleolítica de los sílices negros

El puente inca en la cordillera de Mendoza

La piedra de los sabios

Las piedras pintadas del cajón de los cipreses

Algo más sobre las tabletas de la Isla de Pascua y una posible interpretación

El cementerio indígena el Olivar La Serena.

Un cementerio indígena en la Bahía Salada.

Nuevos descubrimientos arqueológicos en la provincia de Coquimbo

Mapa Arqueológico del Valle de Elqui y adyacentes

Cultura de El Molle

Cultura diaguita-chilena

Los indígenas del norte de Chile antes de la conquista española

Las piedras horadadas

Los indígenas del Ecuador 1

Los indígenas del Ecuador 2

\begin{tabular}{|c|c|c|}
\hline Oyarzún & RMEA & 1916 \\
\hline Oyarzún & RHYG & 1917 \\
\hline Oyarzún & RMEA & 1920 \\
\hline Oyarzún & RMEA & 1924 \\
\hline Oyarzún & AACHCN & 1927 \\
\hline Oyarzún & RHYG & 1929 \\
\hline Oyarzún & RHYG & 1930 \\
\hline Oyarzún & RHYG & 1931 \\
\hline Oyarzún & $\mathrm{AUCH}$ & 1932 \\
\hline Oyarzún & RHYG & 1933 \\
\hline Ludemann & $\mathrm{AACHCN}$ & 1934 \\
\hline Ludemann & AACHCN & 1938 \\
\hline Ludemann & AACHCN & 1939 \\
\hline Ludemann & AACHCN & 1943 \\
\hline Ludemann & AACHCN & 1946 \\
\hline Ludemann & AACHCN & 1947 \\
\hline Gunckel & RCHHN & 1928 \\
\hline Gunckel & $\mathrm{AACHCN}$ & 1929 \\
\hline Gunckel & AACHCN & 1942 \\
\hline Gunckel & ASBC & 1943 \\
\hline Gunckel & AACHCN & 1949 \\
\hline Gajardo Tobar & RCHHN & 1937 \\
\hline Gajardo Tobar & RHYG & 1938 \\
\hline Gajardo Tobar & RCHHN & 1939 \\
\hline Gajardo Tobar & AACHCN & 1940 \\
\hline Capdeville & $\mathrm{ASCCH}$ & 1925 \\
\hline Capdeville & RCHHN & 1928 \\
\hline Darapsky & SCA & 1885 \\
\hline Darapsky & SCA & 1889 \\
\hline Jaffuel & RCHHN & 1930 \\
\hline Jaffuel & $\mathrm{AACHCN}$ & 1934 \\
\hline Cornely & BMHN & 1936 \\
\hline Cornely & BMHN & 1936 \\
\hline Cornely & BMHN & 1940 \\
\hline Cornely & BMHN & 1942 \\
\hline Cornely & RCHHN & 1944 \\
\hline Cornely & RCHHN & 1949 \\
\hline J. Santa Cruz & RHYG & 1913 \\
\hline J. Santa Cruz & RHYG & 1915 \\
\hline J. Santa Cruz & RHYG & 1921 \\
\hline J. Santa Cruz & RHYG & 1921 \\
\hline
\end{tabular}


Los indígenas en el Perú y Bolivia

Los indígenas del Ecuador 3

Plantas mágicas mapuches

La alimentación entre los mapuches antes de la conquista

Los colorantes usados por los indígenas

Un informe del conocimiento de la edad de piedra en Chile medio

Cráneos de paredes gruesas según L. Vergara. Un dato más

La lanceta de Quilpué

Formas especiales de los utensilios caseros de los aborígenes

Cráneos de paredes gruesas según L. Vergara Flores, con un dato más.

Cráneos marcados de la Isla de Pascua

Dos ejemplares de piedras morteros en Santiago

Medicina e higiene de los antiguos araucanos

Medicina e higiene de los antiguos araucanos 1

Medicina e higiene de los antiguos araucanos 2

Expedición a tierra del fuego

Estado actual de la cueva del milodon

Tercera expedición a tierra del fuego

Tres meses entre los indios Onas

Cuarta expedición a tierra del fuego

Un cráneo de indígena boliviano

Tres cráneos de indígenas bolivianos

Cráneos indígenas bolivianos

Un cráneo sifílico de indígena

Dos cráneos antiguos de Aimaráes

Dos cráneos antiguos de Aimaráes

Dos cráneos antiguos de Aimaráes

Piedras de quillagua

Triangulación del cráneo

Nuevas mediciones de trece cráneos antiguos de Aimaráes

Estudios comparativos sobre cráneos araucanos y antiguos Aimaráes

Sobre craneometría y origen de las razas americanas

Cráneos de paredes gruesas (nuevas investigaciones de 63 cráneos de quillagua)

Comunicación sobre los restos arqueológicos de la cordillera de Millahue

Signos indígenas en la cordillera de Chile

Piedras escritas de la provincia de Coquimbo

Los Jeroglíficos de la Isla de Pascua

Sepulturas de caja

Estado intelectual, moral y económico del araucano

El pueblo indígena en la historia

Estudio y enseñanza del mapuche en la era colonial

\begin{tabular}{|c|c|c|}
\hline J. Santa Cruz & RHYG & 1922 \\
\hline J. Santa Cruz & RHYG & 1923 \\
\hline A. Santa Cruz & RCHHN & 1937 \\
\hline A. Santa Cruz & ASBC & 1942 \\
\hline A. Santa Cruz & ASBC & 1944 \\
\hline Fonck & SCA & 1893 \\
\hline Fonck & RCHHN & 1906 \\
\hline Fonck & BMHN & 1910 \\
\hline Fonck & RHYG & 1912 \\
\hline Fonck & RHYG & 1912 \\
\hline Knoche & RHYG & 1914 \\
\hline Irarrazaval & $\mathrm{AACHCN}$ & 1938 \\
\hline Gusinde & RMEA & 1916 \\
\hline Gusinde & RHYG & 1917 \\
\hline Gusinde & RHYG & 1917 \\
\hline Gusinde & RMEA & 1920 \\
\hline Gusinde & RCHHN & 1921 \\
\hline Gusinde & RMEA & 1922 \\
\hline Gusinde & RHYG & 1923 \\
\hline Gusinde & RMEA & 1924 \\
\hline Vergara & $\mathrm{ASCCH}$ & 1894 \\
\hline Vergara & $\mathrm{ASCCH}$ & 1894 \\
\hline Vergara & $\mathrm{ASCCH}$ & 1894 \\
\hline Vergara & $\mathrm{ASCCH}$ & 1895 \\
\hline Vergara & RCHHN & 1898 \\
\hline Vergara & RCHHN & 1898 \\
\hline Vergara & RCHHN & 1898 \\
\hline Vergara & $\mathrm{ASCCH}$ & 1899 \\
\hline Vergara & $\mathrm{ASCCH}$ & 1900 \\
\hline Vergara & RCHHN & 1901 \\
\hline Vergara & RCHHN & 1902 \\
\hline Vergara & RCHHN & 1904 \\
\hline Vergara & RCHHN & 1905 \\
\hline de la Cerda & $\mathrm{AACHCN}$ & 1935 \\
\hline Stolp & SCA & 1889 \\
\hline Peña Villalón & RHYG & 1919 \\
\hline Harrison & $\mathrm{AUCH}$ & 1875 \\
\hline Amberga & RHYG & 1913 \\
\hline Amberga & RHYG & 1913 \\
\hline Amberga & RHYG & 1914 \\
\hline Amberga & RHYG & 1914 \\
\hline
\end{tabular}




\begin{tabular}{|c|c|c|c|}
\hline La epopeya de Boroa & Amberga & RHYG & 1916 \\
\hline Educación indígena en los Estados Unidos & Amberga & RHYG & 1916 \\
\hline Agricultura araucana & Amberga & RHYG & 1917 \\
\hline Una figura china encontrada en la Araucanía & Amberga & RHYG & 1920 \\
\hline Una flauta de pan araucana & Amberga & RHYG & 1921 \\
\hline Contribución a la arqueología chilena & Oliver & RMEA & 1922 \\
\hline El campo arqueológico de Millahue & Oliver & $\mathrm{AACHCN}$ & 1935 \\
\hline Algunos caracteres observados en mandíbulas de pescadores neolíticos & Oliver & $\mathrm{AACHCN}$ & 1935 \\
\hline Sobre el origen de la apófisis hipocondiliana en algunos cráneos de indígenas chilenos & Oliver & $\mathrm{AACHCN}$ & 1936 \\
\hline Tejidos araucanos & Joseph & $\mathrm{AACHCN}$ & 1928 \\
\hline La platería araucana & Joseph & AUCH & 1928 \\
\hline Los adornos araucanos & Joseph & $\mathrm{AACHCN}$ & 1930 \\
\hline Antigüedades araucanas & Joseph & $\mathrm{AACHCN}$ & 1930 \\
\hline Un hermosos cántaro indígena & Joseph & RCHHN & 1930 \\
\hline Las ceremonias araucanas. & Joseph & BMHN & 1930 \\
\hline La vivienda araucana & Joseph & AUCH & 1931 \\
\hline La vivienda araucana 2 & Joseph & $\mathrm{AUCH}$ & 1931 \\
\hline Costumbres araucanas & Joseph & $\mathrm{AACHCN}$ & 1933 \\
\hline Costumbres araucanas & Joseph & $\mathrm{AACHCN}$ & 1934 \\
\hline Cronología diaguita & Serrano & $\mathrm{RCHHN}$ & 1936 \\
\hline Los changos de Loa & Ovalle & $\mathrm{ASCCH}$ & 1920 \\
\hline Historia de la civilización araucana I. Geografía Física_1_T101 & Guevara & $\mathrm{AUCH}$ & 1898 \\
\hline Historia de la civilización araucana II. Geografía Física 2_T101 & Guevara & $\mathrm{AUCH}$ & 1898 \\
\hline Historia de la civilización araucana III. La edad de piedra_3_T103 & Guevara & $\mathrm{AUCH}$ & 1899 \\
\hline Historia de la civilización araucana V. la lengua y la literatura araucana_4_T103 & Guevara & $\mathrm{AUCH}$ & 1899 \\
\hline Historia de la civilización araucana VII. Organización político y social_5_T103 & Guevara & $\mathrm{AUCH}$ & 1899 \\
\hline $\begin{array}{l}\text { Historia de la civilización araucana VII. Organización político y social_5_T103 } \\
\text { (Continuación) }\end{array}$ & Guevara & $\mathrm{AUCH}$ & 1899 \\
\hline $\begin{array}{l}\text { Historia de la civilización araucana VIII. Los mitos y las ideas religiosas de los } \\
\text { indios_6_T103. }\end{array}$ & Guevara & $\mathrm{AUCH}$ & 1899 \\
\hline $\begin{array}{l}\text { Historia de la civilización araucana VIII. Los mitos y las ideas religiosas de los } \\
\text { indios_7_T104 (continuación). }\end{array}$ & Guevara & $\mathrm{AUCH}$ & 1899 \\
\hline $\begin{array}{l}\text { Historia de la civilización araucana VIII. Los mitos y las ideas religiosas de los } \\
\text { indios_8_T104 (continuación). }\end{array}$ & Guevara & $\mathrm{AUCH}$ & 1899 \\
\hline Historia de la civilización araucana X. El arte militar_9_T104. & Guevara & $\mathrm{AUCH}$ & 1899 \\
\hline Historia de la civilización araucana. Descubirmiento de arauco_10_T104. & Guevara & $\mathrm{AUCH}$ & 1899 \\
\hline Historia de la civilización araucana. La conquista_11_T106. & Guevara & $\mathrm{AUCH}$ & 1900 \\
\hline Historia de la civilización araucana. Primer levantamiento general_12_T106. & Guevara & $\mathrm{AUCH}$ & 1900 \\
\hline $\begin{array}{l}\text { Historia de la civilización araucana. Primer levantamiento general_13_T107 } \\
\text { (Continuación). }\end{array}$ & Guevara & $\mathrm{AUCH}$ & 1900 \\
\hline $\begin{array}{l}\text { Historia de la civilización araucana. Primer levantamiento general_14_T107 } \\
\text { (Continuación). }\end{array}$ & Guevara & $\mathrm{AUCH}$ & 1900 \\
\hline $\begin{array}{l}\text { Historia de la civilización araucana. Estado social del sur después del primer } \\
\text { levantamiento_15_T107. }\end{array}$ & Guevara & $\mathrm{AUCH}$ & 1900 \\
\hline $\begin{array}{l}\text { Historia de la civilización araucana. Estado social del sur después del primer } \\
\text { levantamiento_16_T107. }\end{array}$ & Guevara & $\mathrm{AUCH}$ & 1900 \\
\hline
\end{tabular}


Historia de la civilización araucana. Continuación de la guerra_17_T108.

Historia de la civilización araucana. Continuación de la guerra_18_T108.

Historia de la civilización araucana. Continuación de la guerra_19_T108.

Historia de la civilización araucana. Estados social del sur después del segundo

levantamiento_20_T108.

Historia de la civilización araucana. Tercer levantamiento general_21_T108.

Historia de la civilización araucana. Tercer levantamiento general_22_T109.

(Continuación).

Historia de la civilización araucana. Cuarto y quinto levantamiento_23_T109.

Historia de la civilización araucana. Estado social del sur a fines del siglo

XVIII_24_T109.

Historia de la civilización araucana. Estado social del sur a fines del siglo

XVIII_25_T109 (Continuación).

Historia de la civilización araucana. Sesto levantamiento. Los araucanos contra los

patriotas desde 1813 a 1825_26_T109.

Historia de la civilización araucana. Sesto levantamiento. Los araucanos contra los

patriotas desde 1813 a 182527 T109.

Historia de la civilización araucana. Sesto levantamiento. Los araucanos contra los

patriotas desde 1813 a 1825_28_T110 (Continuación).

Historia de la civilización araucana. Sesto levantamiento. Los araucanos contra los

patriotas desde 1813 a 1825_29_T111 (Continuación).

Historia de la civilización araucana. La ocupación de la araucanía_30_T112.

Historia de la civilización araucana. Prolongación de las líneas del Malleco y el

Litoral 31 T112.

Historia de la civilización araucana. Octavo levantamiento, desde 1868 hasta

1871_32_T112.

Historia de la civilización araucana. Octavo levantamiento, desde 1868 hasta

1871_33_T113.

Historia de la civilización araucana. La línea de Traiguien_34_T113.

Costumbres judiciales y enseñanzas de los Araucanos_35_T114.

Costumbres judiciales y enseñanzas de los Araucanos_36_T114.

Los araucanos en la revolución de la independencia

Folklore Araucano. Refranes, cuentos y cantos

Las últimas familias y costumbres araucanas.

Las últimas familias y costumbres araucanas (Continuación 2).

Las últimas familias y costumbres araucanas (Continuación 3).

Las últimas familias y costumbres araucanas (Continuación).

Las últimas familias y costumbres araucanas (Continuación 4).

Las últimas familias y costumbres araucanas (Anexos).

La mentalidad araucana 1

La mentalidad araucana 2

La mentalidad araucana 3

La mentalidad araucana 4

La mentalidad araucana 5. Algunos rasgos psíquicos especiales de los araucanos.

La mentalidad araucana 6. La moral y el carácter de los araucanos.

La mentalidad araucana 7. Divergencia de razas

Etnología araucana en el poema de Ercilla 1

Etnología araucana en el poema de Ercilla 2

\begin{tabular}{|c|c|c|}
\hline Guevara & $\mathrm{AUCH}$ & 1901 \\
\hline Guevara & AUCH & 1901 \\
\hline Guevara & $\mathrm{AUCH}$ & 1901 \\
\hline Guevara & AUCH & 1901 \\
\hline Guevara & AUCH & 1901 \\
\hline Guevara & $\mathrm{AUCH}$ & 1901 \\
\hline Guevara & AUCH & 1901 \\
\hline Guevara & AUCH & 1901 \\
\hline Guevara & AUCH & 1901 \\
\hline Guevara & AUCH & 1901 \\
\hline Guevara & $\mathrm{AUCH}$ & 1901 \\
\hline Guevara & AUCH & 1902 \\
\hline Guevara & AUCH & 1902 \\
\hline Guevara & AUCH & 1903 \\
\hline Guevara & $\mathrm{AUCH}$ & 1903 \\
\hline Guevara & AUCH & 1903 \\
\hline Guevara & AUCH & 1903 \\
\hline Guevara & AUCH & 1903 \\
\hline Guevara & AUCH & 1904 \\
\hline Guevara & AUCH & 1904 \\
\hline Guevara & AUCH & 1910 \\
\hline Guevara & AUCH & 1910 \\
\hline Guevara & $\mathrm{AUCH}$ & 1912 \\
\hline Guevara & $\mathrm{AUCH}$ & 1912 \\
\hline Guevara & AUCH & 1912 \\
\hline Guevara & AUCH & 1912 \\
\hline Guevara & AUCH & 1912 \\
\hline Guevara & AUCH & 1912 \\
\hline Guevara & AUCH & 1916 \\
\hline Guevara & AUCH & 1916 \\
\hline Guevara & AUCH & 1916 \\
\hline Guevara & AUCH & 1917 \\
\hline Guevara & AUCH & 1917 \\
\hline Guevara & $\mathrm{AUCH}$ & 1917 \\
\hline Guevara & AUCH & 1917 \\
\hline Guevara & AUCH & 1918 \\
\hline Guevara & AUCH & 1918 \\
\hline
\end{tabular}




\begin{tabular}{|c|c|c|c|}
\hline Etnología araucana en el poema de Ercilla 3 & Guevara & $\mathrm{AUCH}$ & 1918 \\
\hline Etnología araucana en el poema de Ercilla 4 & Guevara & $\mathrm{AUCH}$ & 1918 \\
\hline Etnología araucana en el poema de Ercilla 5 & Guevara & $\mathrm{AUCH}$ & 1919 \\
\hline Etnología araucana en el poema de Ercilla 6 & Guevara & $\mathrm{AUCH}$ & 1919 \\
\hline Etnología araucana en el poema de Ercilla 7 & Guevara & $\mathrm{AUCH}$ & 1919 \\
\hline Etnología araucana en el poema de Ercilla 8 & Guevara & AUCH & 1919 \\
\hline Etnología araucana en el poema de Ercilla 9 & Guevara & $\mathrm{AUCH}$ & 1919 \\
\hline Etnología araucana en el poema de Ercilla 10 & Guevara & $\mathrm{AUCH}$ & 1919 \\
\hline Etnología araucana en el poema de Ercilla apéndice III & Guevara & $\mathrm{AUCH}$ & 1920 \\
\hline Historia de la justicia araucana 1 & Guevara & $\mathrm{AUCH}$ & 1920 \\
\hline Historia de la justicia araucana 2 & Guevara & $\mathrm{AUCH}$ & 1920 \\
\hline El weke araucano (Etnografía zoológica). & Guevara & RCHHN & 1921 \\
\hline Sobre el origen de los araucanos & Guevara & RHYG & 1928 \\
\hline Sobre el origen de los araucanos & Guevara & RHYG & 1930 \\
\hline Estudios araucanos. Diálogos araucanos en dialecto Huilliche_2_T90 & Lenz & $\mathrm{AUCH}$ & 1895 \\
\hline Estudios araucanos. Viaje al país de los manzaneros_1_T90 & Lenz & $\mathrm{AUCH}$ & 1895 \\
\hline Estudios araucanos. Diálogos araucanos en dialecto Picunche_3_T91 & Lenz & $\mathrm{AUCH}$ & 1895 \\
\hline Estudios araucanos IV. Trozos menores en Picunche y Huilliche_4_T93 & Lenz & $\mathrm{AUCH}$ & 1896 \\
\hline Estudios araucanos V. Diálogos en dialecto Picunche Chileno_5_T93 & Lenz & $\mathrm{AUCH}$ & 1896 \\
\hline Estudios araucanos VI. Cuentos araucanos referidos al indio Calvun_6_T94 & Lenz & $\mathrm{AUCH}$ & 1896 \\
\hline Estudios araucanos VI. Cuentos araucanos referidos al indio Calvun (conclusión)_7_T94 & Lenz & AUCH & 1896 \\
\hline Estudios araucanos VII. Cuentos araucanos II. Cuentos míticos_8_T94 & Lenz & $\mathrm{AUCH}$ & 1896 \\
\hline Estudios araucanos VII. Cuentos araucanos II. Cuentos míticos (conclusión)_9_T94 & Lenz & $\mathrm{AUCH}$ & 1896 \\
\hline Cuentos araucanos y relatos comunicados por Segundo Jara & Lenz & SCA & 1896 \\
\hline Estudios araucanos VIII. Cuentos en dialecto pehuenche chileno III_10_T97 & Lenz & AUCH & 1897 \\
\hline Estudios araucanos VIII. Cuentos en dialecto pehuenche chileno III (conclusión)_11 T97 & Lenz & $\mathrm{AUCH}$ & 1897 \\
\hline $\begin{array}{l}\text { Apéndice de los estudios araucanos VI, VII, VIII. La filiación de los cuentos de } \\
\text { Calvun_12_T97 }\end{array}$ & Lenz & AUCH & 1897 \\
\hline Apéndice de los cuentos araucanos I, II y III. Estudios Araucanos VI, VII, VII. 13_T98 & Lenz & $\mathrm{AUCH}$ & 1897 \\
\hline Estudios araucanos IX. Cuentos en dialecto pehuenche chileno IV. 14_T98 & Lenz & AUCH & 1897 \\
\hline $\begin{array}{l}\text { Estudios araucanos X. Cantos araucanos en moluche y pehuenche chileno, con } \\
\text { introducción sobre la poesía araucana.15_T98 }\end{array}$ & Lenz & AUCH & 1897 \\
\hline $\begin{array}{l}\text { Estudios araucanos XI. Trozos descriptivos y documentos para el estudios del folklore } \\
\text { araucano. 16_T98. }\end{array}$ & Lenz & $\mathrm{AUCH}$ & 1897 \\
\hline Estudios araucanos XII. 17_T98. & Lenz & $\mathrm{AUCH}$ & 1897 \\
\hline Crítica de la lengue Auca del señor Raoul de la Grasserire.18_T101. & Lenz & $\mathrm{AUCH}$ & 1898 \\
\hline Crítica de la lengua Auca del señor Raoul de la Grasserie & Lenz & SCA & 1899 \\
\hline Un grupo de consejas chilenas & Lenz & $\mathrm{AUCH}$ & 1911 \\
\hline Cuentos chilenos de nunca acabar & Lenz & $\mathrm{AUCH}$ & 1911 \\
\hline Tradiciones e ideas de los araucanos acerca de los terremotos & Lenz & $\mathrm{AUCH}$ & 1912 \\
\hline Tradiciones e ideas de los araucanos acerca de los terremotos2 & Lenz & $\mathrm{AUCH}$ & 1912 \\
\hline Un grupo de consejas chilenas (Continuación) & Lenz & $\mathrm{AUCH}$ & 1912 \\
\hline Un grupo de consejas chilenas (Continuación)2 & Lenz & AUCH & 1912 \\
\hline
\end{tabular}




\begin{tabular}{|c|c|c|c|}
\hline Sobre la poesía popular imperas de Santiago de chile & Lenz & $\mathrm{AUCH}$ & 1919 \\
\hline Estudio sobre los indios de Chile & Lenz & RMEA & 1924 \\
\hline Del latín al folklore Chileno & Laval & AUCH & 1909 \\
\hline Cuentos chilenos de nunca acabar & Laval & AUCH & 1909 \\
\hline $\begin{array}{l}\text { Oraciones populares en salmos y conjuros chilenos comparados con los que se dicen en } \\
\text { España }\end{array}$ & Laval & $\mathrm{AUCH}$ & 1910 \\
\hline Tradiciones, leyendas y cuentos populares recogidos en Carahue 1 & Laval & RHYG & 1920 \\
\hline Tradiciones, leyendas y cuentos populares recogidos en Carahue 2 & Laval & RHYG & 1920 \\
\hline Tradiciones, leyendas y cuentos populares recogidos en Carahue 3 & Laval & RHYG & 1920 \\
\hline Tradiciones, leyendas y cuentos populares recogidos en Carahue 4 & Laval & RHYG & 1920 \\
\hline Tradiciones, leyendas y cuentos populares recogidos en Carahue 5 & Laval & RHYG & 1921 \\
\hline Tradiciones, leyendas y cuentos populares recogidos en Carahue 6 & Laval & RHYG & 1921 \\
\hline Cuentos populares en Chile recogidos de la tradición oral 1 & Laval & RHYG & 1922 \\
\hline Cuentos populares en Chile recogidos de la tradición oral 2 & Laval & RHYG & 1923 \\
\hline Cuentos populares de Chile 1 & Laval & RHYG & 1923 \\
\hline Cuentos populares de Chile 2 & Laval & RHYG & 1923 \\
\hline Cuentos populares de Chile 3 & Laval & RHYG & 1924 \\
\hline Sobre dos cantos chilenos derivados de un antiguo romance español. & Laval & RHYG & 1929 \\
\hline Cuentos araucanos y chilenos recogidos de la tradición oral & Suniére & RHYG & 1916 \\
\hline Cuentos araucanos y chilenos recogidos de la tradición oral 2 & Suniére & RHYG & 1916 \\
\hline Cuentos araucanos y chilenos recogidos de la tradición oral 3 & Suniére & RHYG & 1916 \\
\hline Cuentos araucanos y chilenos recogidos de la tradición oral 4 & Suniére & RHYG & 1916 \\
\hline Cuentos araucanos y chilenos recogidos de la tradición oral 5 & Suniére & RHYG & 1917 \\
\hline Cuentos araucanos y chilenos recogidos de la tradición oral 6 & Suniére & RHYG & 1917 \\
\hline Cuentos araucanos y chilenos recogidos de la tradición oral 7 & Suniére & RHYG & 1917 \\
\hline Cuentos araucanos y chilenos recogidos de la tradición oral 8 & Suniére & RHYG & 1917 \\
\hline Cuentos araucanos y chilenos recogidos de la tradición oral 9 & Suniére & RHYG & 1918 \\
\hline Cuentos araucanos y chilenos recogidos de la tradición oral 9 & Suniére & RHYG & 1918 \\
\hline Cuentos araucanos y chilenos recogidos de la tradición oral 9 & Suniére & RHYG & 1918 \\
\hline Cuentos araucanos y chilenos recogidos de la tradición oral 10 & Suniére & RHYG & 1918 \\
\hline $\begin{array}{l}\text { La disposición de las crestas papilares de las falangitas en los indígenas de la provincia de } \\
\text { cautín }\end{array}$ & Henckel & ASBC & 1933 \\
\hline Cráneos encontrados en el conchal Darwin de Talcahuano & Henckel & ASBC & 1933 \\
\hline Observaciones antropológicas acerca de la Isla de Pascua & Henckel & ASBC & 1939 \\
\hline Observaciones histológica acerca del integumento de los indios mapuches & Henckel & ASBC & 1941 \\
\hline Observaciones histológicas acerca del pigmento cutáneo en los indios mapuches & Henckel & RCHHN & 1941 \\
\hline $\begin{array}{l}\text { Algunas observaciones de la proporción de grupos sanguíneos m y n entre los indios } \\
\text { mapuche }\end{array}$ & Henckel & ASBC & 1942 \\
\hline Observaciones histológicas sobre el ojo de los indios mapuches & Henckel & ASBC & 1942 \\
\hline Contribuciones craneológicas a la antropología de la Isla Mocha & Henckel & AACHCN & 1954 \\
\hline Costumbres y creencias araucanas. Entierro de Huilío Lienan_T119. & Robles & AUCH & 1906 \\
\hline Costumbres y creencias araucanas. Un machitun. & Robles & $\mathrm{AUCH}$ & 1908 \\
\hline Costumbres y creencias araucanas. El funeral de mujeres. & Robles & AUCH & 1910 \\
\hline
\end{tabular}


Costumbres y creencias araucanas. Los Guillatunes.

Costumbres y creencias araucanas. Baile de Machis.

Costumbres y creencias araucanas. Machiluhun.

Costumbres y creencias araucanas. Juego de Chueca.

Costumbre y creencias araucanas. El brujo traipi

Los héroes indígenas de la araucana

Ensayo crítico sobre algunas obras históricas utilizables para el estudio de la conquista de

Chile (Continuación)_T74

Ensayo crítico sobre algunas obras históricas utilizables para el estudio de la conquista de

Chile (Continuación)_T74_2

Ensayo crítico sobre algunas obras históricas utilizables para el estudio de la conquista de

Chile (Continuación)_T140_1

Ensayo crítico sobre algunas obras históricas utilizables para el estudio de la conquista de

Chile (Continuación)_T140_2

Ensayo crítico sobre algunas obras históricas utilizables para el estudio de la conquista de

Chile (Continuación)_T141

Ensayo crítico sobre algunas obras históricas utilizables para el estudio de la conquista de

Chile (Continuación)_T143

Ensayo crítico sobre algunas obras históricas utilizables para el estudio de la conquista de

Chile (Continuación)_T143 2

Ensayo crítico sobre algunas obras históricas utilizables para el estudio de la conquista de

Chile (Continuación)_T144

Ensayo crítico sobre algunas obras históricas utilizables para el estudio de la conquista de

Chile (Continuación)_T144_2

Ensayo crítico sobre algunas obras históricas utilizables para el estudio de la conquista de

Chile (Continuación)_T144_3

El vocabulario araucano de 1642-1643_T119.

Sobre los mitos y leyendas de los indios sudamericanos_T119.

El vocabulario araucano de 1642-1643_T120.

El vocabulario araucano de 1642-1643_2_T120.

El vocabulario araucano de 1642-1643_3_T120.

El comienzo del arte en las selvas virgenes_T120.

Desollar la piel del cráneo y análogas costumbres de guerra en América

Descendencia del hombre y Darwinismo 1

Descendencia del hombre y Darwinismo 2

Vida y costumbres de los araucanos, en el siglo XIX.1

Costumbres de los araucanos en la segunda mitad del siglo XIX.2

Costumbres de los araucanos en la segunda mitad del siglo XIX.3

Costumbres de los araucanos en la segunda mitad del siglo XIX.4

Costumbres de los araucanos en la segunda mitad del siglo XIX.5

Costumbres de los araucanos en la segunda mitad del siglo XIX.6

Costumbres de los araucanos en la segunda mitad del siglo XIX.7

Costumbres de los araucanos en la segunda mitad del siglo XIX.8

Costumbres de los araucanos en la segunda mitad del siglo XIX.9

Las momias egipcias conservadas en el museo

Informe sobre las excavaciones efectuadas en La Serena

Las transiciones y los pronombres personales e el idioma mapuche

\begin{tabular}{|c|c|c|}
\hline Robles & AUCH & 1910 \\
\hline Robles & AUCH & 1911 \\
\hline Robles & AUCH & 1912 \\
\hline Robles & AUCH & 1914 \\
\hline Robles & AUCH & 1940 \\
\hline T.Thayer & RHYG & 1915 \\
\hline T.Thayer & $\mathrm{AUCH}$ & 1916 \\
\hline T.Thayer & AUCH & 1916 \\
\hline T.Thayer & $\mathrm{AUCH}$ & 1917 \\
\hline T.Thayer & AUCH & 1917 \\
\hline T.Thayer & AUCH & 1917 \\
\hline T.Thayer & AUCH & 1919 \\
\hline T.Thayer & AUCH & 1919 \\
\hline T.Thayer & $\mathrm{AUCH}$ & 1919 \\
\hline T.Thayer & AUCH & 1919 \\
\hline T.Thayer & $\mathrm{AUCH}$ & 1919 \\
\hline R.Schuller & AUCH & 1906 \\
\hline R.Schuller & AUCH & 1906 \\
\hline R.Schuller & AUCH & 1907 \\
\hline R.Schuller & AUCH & 1907 \\
\hline R.Schuller & AUCH & 1907 \\
\hline R.Schuller & AUCH & 1907 \\
\hline R.Schuller & RCHHN & 1907 \\
\hline A. Nogues & AUCH & 1892 \\
\hline A. Nogues & $\mathrm{AUCH}$ & 1893 \\
\hline W. de Moesbach & RHYG & 1929 \\
\hline W. de Moesbach & RHYG & 1929 \\
\hline W. de Moesbach & RHYG & 1930 \\
\hline W. de Moesbach & RHYG & 1931 \\
\hline W. de Moesbach & RHYG & 1932 \\
\hline W. de Moesbach & RHYG & 1933 \\
\hline W. de Moesbach & RHYG & 1934 \\
\hline W. de Moesbach & RHYG & 1935 \\
\hline W. de Moesbach & RHYG & 1935 \\
\hline Mostny & BMHN & 1940 \\
\hline Mostny & BMHN & 1941 \\
\hline Mostny & RCHHN & 1941 \\
\hline
\end{tabular}




\begin{tabular}{|c|c|c|c|}
\hline Un nuevo estilo arqueológico & Mostny & BMHN & 1942 \\
\hline Informe preliminar sobre las excavaciones efectuadas en la costa del Norte de Chile. & Mostny & BMHN & 1942 \\
\hline Informe sobre excavaciones en Arica & Mostny & BMHN & 1943 \\
\hline Excavaciones en Arica. & Mostny & BMHN & 1943 \\
\hline Excavaciones en Arica II & Mostny & BMHN & 1944 \\
\hline Un nuevos estilo arqueológico II & Mostny & BMHN & 1944 \\
\hline Un cementerio incásico en Chile central & Mostny & BMHN & 1947 \\
\hline Ciudades atacameñas & Mostny & BMHN & 1949 \\
\hline Una tumba de Chiuchiu & Mostny & BMHN & 1952 \\
\hline Antiguedades Americanas & Favry & $\mathrm{AUCH}$ & 1860 \\
\hline $\begin{array}{l}\text { Observaciones somatológicas e histológicas acerca de la mancha mongólica en la } \\
\text { población chilena }\end{array}$ & Mardones & ASBC & 1937 \\
\hline Apuntes sobre la etnografía de Chile. & Barros Arana & AUCH & 1875 \\
\hline Nanas o canciones de cuna corrientes en Chile & Flores & RHYG & 1915 \\
\hline Mitología chilota & Molina & AUCH & 1950 \\
\hline $\begin{array}{l}\text { Exploración de las costas occidentales de Patagonia y de los archipiélagos de Chonos y } \\
\text { Guaitecas }\end{array}$ & Simpson & $\mathrm{AUCH}$ & 1871 \\
\hline Relaciones de la antropología y la etnología con las apreciaciones sobre sanidad pública & Taulis & $\mathrm{AACHCN}$ & 1940 \\
\hline Apuntes folklóricos de Malleco & E. Figueroa & $\mathrm{AUCH}$ & 1950 \\
\hline Folklore de la provincia de Bio-Bío. & E. Rivadeneira & RHYG & 1939 \\
\hline La lengua kunza en los naturales de atacama & F. San Roman & RHYG & 1922 \\
\hline Reconocimiento del río Maullín por la comisión exploradora. & F. Vidal Gormaz & $\mathrm{AUCH}$ & 1874 \\
\hline Repertorio folklórico de Chiloé & G. Ampuero & $\mathrm{AUCH}$ & 1952 \\
\hline Sobre mitología americana & Feliú-Cruz & RHYG & 1920 \\
\hline Las reliquias de Arauco & G.González & $\mathrm{AUCH}$ & 1944 \\
\hline Los petroglifos de la Finca de Chañaral & Hornkohl & BMHN & 1951 \\
\hline Procedencia de los araucanos & Durand & RHYG & 1928 \\
\hline Consideraciones anatómicas sobre cráneos de indios de Paquita y Chiu Chiu & Ibar & $\mathrm{AUCH}$ & 1934 \\
\hline Los últimos descubrimientos sobre escritura indescifrable de la Isla de pascua & Imbelloni & $\mathrm{AUCH}$ & 1935 \\
\hline Comunicación preliminar sobre antropología serológica entre los Pascuenses & Sandoval & $\mathrm{ASBC}$ & 1945 \\
\hline Algunas medidas del cráneo y la cara tomadas en chilenos & Solis Varela & $\mathrm{ASCCH}$ & 1894 \\
\hline El hombre americano & Strube & BMHN & 1929 \\
\hline Presentación de dos cráneos de raza indígenas sudamericanas & Amaral & $\mathrm{ASCCH}$ & 1921 \\
\hline Algunos cráneos procedentes de Arica & Constanzó & BMHN & 1944 \\
\hline Los indios chonquis de la Patagonia & Cordovéz & $\mathrm{ASCCH}$ & 1905 \\
\hline El camino del inca & Magallanes & RHYG & 1912 \\
\hline Informe de la comisión exploradora del Biobío y sus afluentes_T23 & Thompson & $\mathrm{AUCH}$ & 1863 \\
\hline Los brujos de Chillan en 1749 & O. Emeth & RHYG & 1920 \\
\hline $\begin{array}{l}\text { Algunos datos sobre la parte austral del continente sudamericano según estudios hechos } \\
\text { por la comisión científica sueca }\end{array}$ & Nordenskjold & $\mathrm{ASCCH}$ & 1897 \\
\hline Folklore chileno. Aspectos populares infantiles. & O. Plath & $\mathrm{AUCH}$ & 1946 \\
\hline $\begin{array}{l}\text { Observaciones de algunos caracteres morfológicos de la dentadura de los indios } \\
\text { mapuches }\end{array}$ & Muñoz & ASBC & 1936 \\
\hline Huro o Rapanui. Costumbres de la isla de Pascua. & Englert & RHYG & 1939 \\
\hline
\end{tabular}




\begin{tabular}{|c|c|c|c|}
\hline Informe sobre la excursión antropológica y patológica entre los indios del sur de Chile. & Westenhoefer & $\mathrm{AUCH}$ & 1910 \\
\hline Los indios en el archipiélago fueguino 2 & Coiazzi & RHYG & 1914 \\
\hline Los indios en el archipiélago fueguino 1 & Coiazzi & RHYG & 1914 \\
\hline Notas, observaciones y recuerdos de los indígenas de Atacama & Gigoux & $\mathrm{AACHCN}$ & 1927 \\
\hline Contribuciones a la conchilología arqueológica & Gigoux & BMHN & 1936 \\
\hline Tierra del fuego y sus habitantes & Rahm & SCA & 1931 \\
\hline Observaciones de los grupos sanguíneos de la Isla de Pascua & Rahm & ASBC & 1932 \\
\hline El descubrimiento de Chile por los Frisios & Media & $\mathrm{AUCH}$ & 1910 \\
\hline Las monedas usadas por los indios de América al tiempo de su descubrimiento & Media & $\mathrm{AUCH}$ & 1910 \\
\hline Una antigua guerra en Isla de Pascua & Vives Solar & RHYG & 1919 \\
\hline El niño pascuense & Vives Solar & RHYG & 1923 \\
\hline Elementos étnicos de raza blanca que han intervenido en la población de Chile & L. Thayer & $\mathrm{ASCCH}$ & 1918 \\
\hline Raza chilena & L. Thayer & $\mathrm{ASCCH}$ & 1918 \\
\hline La formación de la raza chilena & L. Thayer & RHYG & 1918 \\
\hline Folklore de la antigua provincia de Colchagua 1 & R. Román & RHYG & 1929 \\
\hline Folklore de la antigua provincia de Colchagua 2 & R. Román & RHYG & 1929 \\
\hline Folklore de la antigua provincia de Colchagua 3 & R. Román & RHYG & 1929 \\
\hline Vida y costumbre de los indios araucanos & L. Matus & RHYG & 1912 \\
\hline Instrucciones para el estudio de la antropología araucana & L. Matus & BMHN & 1915 \\
\hline Juegos y ejercicios de los antiguos araucanos & L. Matus & $\mathrm{BMHN}$ & 1918 \\
\hline Exploración antropológica del valle río Copiapó. & L. Matus & RCHHN & 1921 \\
\hline Comentarios del pueblo araucano. La faz social. & Manquilef & $\mathrm{AUCH}$ & 1910 \\
\hline Versión al araucano del poema del último cacicuqe de Samuel Lillo & Manquilef & $\mathrm{AUCH}$ & 1911 \\
\hline Comentarios del pueblo araucano. La gimnasia nacional. & Manquilef & $\mathrm{AUCH}$ & 1914 \\
\hline Comentarios del pueblo araucano. La cuarta familia. & Manquilef & $\mathrm{AUCH}$ & 1914 \\
\hline Taza y ordenanzas sobre el trabajo de los indios en Chile 1 & Heise & $\mathrm{AUCH}$ & 1929 \\
\hline Taza y ordenanzas sobre el trabajo de los indios en Chile 2 & Heise & $\mathrm{AUCH}$ & 1929 \\
\hline Taza y ordenanzas sobre el trabajo de los indios en Chile 3 & Heise & $\mathrm{AUCH}$ & 1929 \\
\hline Taza y ordenanzas sobre el trabajo de los indios en Chile 4 & Heise & $\mathrm{AUCH}$ & 1929 \\
\hline Taza y ordenanzas sobre el trabajo de los indios en Chile 5 & Heise & $\mathrm{AUCH}$ & 1930 \\
\hline Chiloé y los chilotes. Estudio de folklore y lingüísticas & Cavada & RHYG & 1912 \\
\hline Chiloé y los chilotes. Estudio de folklore y lingüísticas. Continuación & Cavada & RHYG & 1912 \\
\hline Chiloé y los chilotes. Estudio de folklore y lingüísticas. Continuación 2 & Cavada & RHYG & 1913 \\
\hline Chiloé y los chilotes. Estudio de folklore y lingüísticas. Continuación 3 & Cavada & RHYG & 1913 \\
\hline Chiloé y los chilotes. Estudio de folklore y lingüísticas. Continuación 4 & Cavada & RHYG & 1913 \\
\hline Chiloé y los chilotes. Estudio de folklore y lingüísticas. Continuación 5 & Cavada & RHYG & 1913 \\
\hline Chiloé y los chilotes. Estudio de folklore y lingüísticas. Continuación 6 & Cavada & RHYG & 1914 \\
\hline Estudios de Folklore Chileno & Vicuña & RHYG & 1911 \\
\hline Mitos y supersticiones de la tradición oral chilena. Continuación. & Vicuña & RHYG & 1914 \\
\hline Mitos y supersticiones de la tradición oral chilena. Continuación 2. & Vicuña & RHYG & 1914 \\
\hline Mitos y supersticiones de la tradición oral chilena. Continuación 3. & Vicuña & RHYG & 1914 \\
\hline
\end{tabular}




\begin{tabular}{|c|c|c|c|}
\hline Mitos y supersticiones de la tradición oral chilena. Continuación 4. & Vicuña & RHYG & 1914 \\
\hline Mitos y supersticiones de la tradición oral chilena. Continuación 5. & Vicuña & RHYG & 1915 \\
\hline Mitos y supersticiones de la tradición oral chilena. Continuación 6. & Vicuña & RHYG & 1915 \\
\hline Mitos y supersticiones de la tradición oral chilena. Continuación 7. & Vicuña & RHYG & 1915 \\
\hline $\begin{array}{l}\text { Glosarios etimológico de nombres de personas, plantas, ríos, lugares aborígenes de Chile } \\
\text { y de algunos otros países } 2\end{array}$ & Valenzuela & RHYG & 1914 \\
\hline $\begin{array}{l}\text { Glosarios etimológico de nombres de personas, plantas, ríos, lugares aborígenes de Chile } \\
\text { y de algunos otros países } 3\end{array}$ & Valenzuela & RHYG & 1914 \\
\hline $\begin{array}{l}\text { Glosarios etimológico de nombres de personas, plantas, ríos, lugares aborígenes de Chile } \\
\text { y de algunos otros países }\end{array}$ & Valenzuela & RHYG & 1914 \\
\hline $\begin{array}{l}\text { Glosarios etimológico de nombres de personas, plantas, ríos, lugares aborígenes de Chile } \\
\text { y de algunos otros países } 4\end{array}$ & Valenzuela & RHYG & 1915 \\
\hline $\begin{array}{l}\text { Glosarios etimológico de nombres de personas, plantas, ríos, lugares aborígenes de Chile } \\
\text { y de algunos otros países } 5\end{array}$ & Valenzuela & RHYG & 1915 \\
\hline $\begin{array}{l}\text { Glosarios etimológico de nombres de personas, plantas, ríos, lugares aborígenes de Chile } \\
\text { y de algunos otros países } 6\end{array}$ & Valenzuela & RHYG & 1916 \\
\hline $\begin{array}{l}\text { Glosarios etimológico de nombres de personas, plantas, ríos, lugares aborígenes de Chile } \\
\text { y de algunos otros países } 7\end{array}$ & Valenzuela & RHYG & 1916 \\
\hline $\begin{array}{l}\text { Glosarios etimológico de nombres de personas, plantas, ríos, lugares aborígenes de Chile } \\
\text { y de algunos otros países } 8\end{array}$ & Valenzuela & RHYG & 1916 \\
\hline $\begin{array}{l}\text { Glosarios etimológico de nombres de personas, plantas, ríos, lugares aborígenes de Chile } \\
\text { y de algunos otros países } 9\end{array}$ & Valenzuela & RHYG & 1916 \\
\hline $\begin{array}{l}\text { Glosarios etimológico de nombres de personas, plantas, ríos, lugares aborígenes de Chile } \\
\text { y de algunos otros países } 10\end{array}$ & Valenzuela & RHYG & 1917 \\
\hline $\begin{array}{l}\text { Glosarios etimológico de nombres de personas, plantas, ríos, lugares aborígenes de Chile } \\
\text { y de algunos otros países } 11\end{array}$ & Valenzuela & RHYG & 1917 \\
\hline $\begin{array}{l}\text { Glosarios etimológico de nombres de personas, plantas, ríos, lugares aborígenes de Chile } \\
\text { y de algunos otros países } 12\end{array}$ & Valenzuela & RHYG & 1917 \\
\hline $\begin{array}{l}\text { Glosarios etimológico de nombres de personas, plantas, ríos, lugares aborígenes de Chile } \\
\text { y de algunos otros países } 13\end{array}$ & Valenzuela & RHYG & 1917 \\
\hline Pismaihuile, cuento araucano & Augusta & RMEA & 1922 \\
\hline Descripción de insignias líticas & Reed & RMEA & 1924 \\
\hline
\end{tabular}

